I.

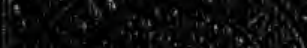

4.

-

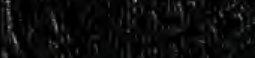

a.

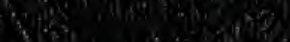

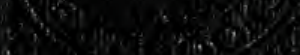

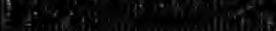




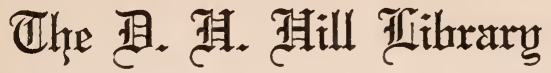

Zurth Caralina State College

$$
\begin{aligned}
& \text { QK47 } \\
& \text { C82 }
\end{aligned}
$$


osciel.

has a mato kilu

This book is due on the date indicated below and is subject to an overdue fine as posted at the circulation desk.

EXCEPTION: Date due will be earlier if this item is RECALLED. 



\section{TWENTIETH CENTURY TEXT-BOOKS \\ EDITED BY}

A. F. NiGhtingale, Ph. D.

SUPERINTENDENT OF HIGH SCHOOLS, CHICAGO 



\section{PLANT RELATIONS}

\section{A FIRST BOOK OF BOTANY}

BY

JOHN M. COUlter, A.M., Ph.D.

HEAD PROFESSOR OF BOTANY

UNIVERSITY OF CHICAGO

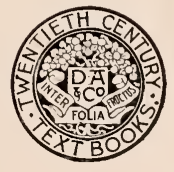


(COPYRIGHT, 1899 ,

BY D. APPLETON AND COMPANY. 


\section{PREFACE.}

THE methods of teaching botany in secondary schools are very diverse, and in so far as they express the experience of successful teachers, they are worthy of careful consideration. As the overwhelming factor in successful teaching is the teacher, methods are of secondary importance, and may well vary. It is the purpose of the present work to contribute another suggestion as to the method of teaching botany in secondary schools. The author does not intend to criticise other methods of teaching, for each teacher has his own best method, but it may be well to state the principles which underlie the preparation of this work.

The botany is divided into two parts, each representing work for half a year. 'The two books are independent, and opinions may differ as to which should precede. The first book, herewith presented, is dominated by Ecology, and also contains certain fundamentals of Physiology that are naturally suggested. The second book will be dominated by Morphology, but plant structure, function, and classification will be dereloped together in an attempt to trace the evolution of the plant kingdom. In the judgment of the author Ecology should precede Morphology, but this order brings to Ecology no knowledge of plant structures and plant groups, which is of course unfortunate. The adrantages which seem to overbalance this disadvantage are as follows:

1. The study of the most evident life-relations of plants gives a proper conception of the place of plants in ]$^{*}$ 
nature, a fitting background for subsequent more detailed studies.

2. Such a riew of the plant kingdom is certainly of the most permanent value to those who can give but a half year to botany, for the large problems of Ecology are constantly presented in subsequent experience, when details of structure would be forgotten.

3. The work in Ecology herein suggested demands little or no use of the compound microscope, an instrument ill adapted to first contacts with nature.

The second book will demand the use of the compound microscope, and those schools which possess such an equipment may prefer to use that part first or exclusively.

In reference to the use of this part something should be said, although such cautions are reiterated in almost every recent publication. A separate pamphlet containing "Suggestions to Teachers" who use this book has been prepared, but a few general statements may be made here. This book is intended to present a connected, readable account of some of the fundamental facts of botany, and may serve to give a certain amount of information. If it performs no other service in the schools, however, its purpose will be defeated. It is entirely too compact for any such use, for great subjects, which should involve a large amount of observation, are often merely suggested. It is intended to serve as a supplement to three far more important factors: (1) the teacher, who must amplify and suggest at every point; (2) the laboratory, which must bring the pupil face to face with plants and their structures; (3) field-work, which must relate the facts observed in the laboratory to their actual place in nature, and must bring new facts to notice which can be observed nowhere else. Taking the results obtained from these three factors, the book seeks to organize them, and to suggest explanations. It seeks to do this in two ways: (1) by means of the text, which is intended to be clear and un- 
technical, but compact; (2) by means of the illustrations, which must be studied as carefully as the text, as they are only second in importance to the actual material. Especially is this true in reference to the landscapes, many of which camnot be made a part of experience.

Thanks are due to various members of the botanical staff of the University, who have been of great service in offering suggestions and in preparing illustrations. In this first book I would especially acknowledge the aid of Professor Charles R. Barnes and Dr. Henry C. Cowles.

The professional botanist who may critically examine this first book knows that Ecology is still a mass of inchoate facts, concerning which we may be said to be making preliminary guesses. It seems to be true, nevertheless, that these facts represent the things best adapted for presentation in elementary work. The anthor has been compelled to depend upon the writings of Warming and of Kerner for this fundamental material. From the work of the latter, and from the recent splendid volume of Schimper, most useful illustrations have been obtained. The number of original illustrations is large, but those obtained elsewhere are properly credited. JoHN M. Coulter.

The University of Chicago, May. 1899.

\section{PREFACE TO THE SECOND EDITION.}

Is this edition the first eleven chapters remain practically as they were, with the exception of such corrections and additions as could be made upon the plates, and a few changes of illustrations. The remaining chapters, however, dealing with plant societies, are essentially recast both in text and illustrations. Especially is this true of the mesophyte and halophyte societies. This has been made necessary by the recent rapid development of the subject, by a larger field experience, and by the availability of more suitable illustrations.

J. M. C.

The University of Chicago, Muy, 1901. 



\section{CON'TENTS.}

CHAPTER

PAGE

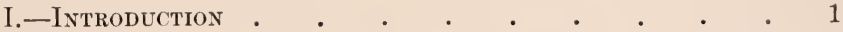

II.-Foliage leaves : The light-Relation a . . 6

III.-Foliage leaves : Function, structure, AND PROTECTION 28

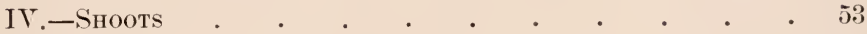

V.-Roots $\quad . \quad$.

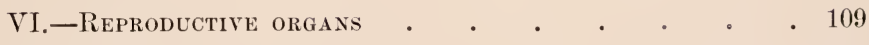

VII.-FLOWERS AND INSECTS . . . . . . . . . . 123

VIII.-AN INDIVIDUAL Plant IN ALL OF its Relations . . 138

IX.-The struggle for existence • . • • • . 142

X. - The nutrition of plants $\quad . \quad$. $\quad . \quad$ • . 149

XI.-Plant societies : Ecological factors - • . 162

XII.-IIYDROPHYTE SOCIETIES . . . . . . . . . 170

XIII.-XEROPHYTE SOCIETIES . . . . . . . . . 193

XIV.—MESOPHYTE SOCIETIES . . . • . . . 233

INDEX . . . . . . . . . . . 259 



\section{BOTANY

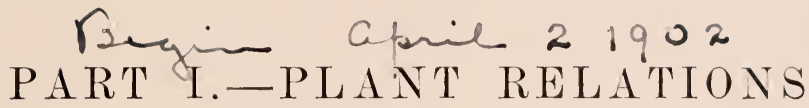

CHAP'TER I.

INTRODUCTION.

1. General relations.-Plants form the natural corering of the earth's surface. So generally is this true that a land surface without plants seems remarkable. Not only do plants eover the land, but they abound in waters as well, both fresh and salt waters. They are wonderfully varied in size, ranging from huge trees to forms so minute that the microseope must be used to discover them. 'They are also exceedingly variable in form, as may be seen by eomparing trees, lilies, ferns, mosses, mushrooms, lichens, and the green thready growths (algce) found in water.

2. Plant societies.-One of the most noticeable facts in reference to plants is that they do not form a monotonous covering for the earth's surface, but that there are forests in one place, thickets in another, meadows in another, swamp growths in another, etc. In this way the general appearance of regetation is exceedingly raried, and each appearance tells of eertain conditions of living. 'These groups of plants living together in similar eonditions, as trees and other plants in a forest, or grasses and other plants in a meadow, are known as plant societies. These societies are as 
numerous as are the conditions of living, and it may be said that each society has its own special regulations, which admit certain plants and exclude others. The study of plant societies, to determine their conditions of living, is one of the chief purposes of botanical field work.

3. Plants as living things.-Before engaging in a study of societies, however, one must discorer in a general way how the individual plant lives, for the plant covering of the earth's surface is a living one, and plants must always be thought of as living and at work. They are as much alive as are animals, and so far as mere living is concerned they live in much the same way. Nor must it be supposed that animals move and plants do not, for while more animals than plants have the power of moving from place to place, some plants have this power, and those that do not can move certain parts. The more we know of living things the more is it evident that life processes are alike in them all, whether plants or animals. In fact, there are some living things about which we are uncertain whether to regard them as plants or animals.

4. The plant body.-Every plant has a body, which may be alike throughout or may be made up of a number of different parts. When the green thready plants (algce), so common in fresh water, are examined, the body looks like a simple thread, without any special parts ; but the body of a lily is made up of such dissimilar parts as root, stem, leaf, and flower (see Figs. \%5, 144, 155, 174). The plant without these special parts is said to be simple the plant with them is called complex. The simple plant lives in the same way and does the same kind of work, so far as living is concerned, as does the complex plant. The difference is that in the case of the simple plant its whole body does every kind of work; while in the complex plant different kinds of work are done by different regions of the body, and these regions come to look unlike when different shapes are better suited to different work, as in the 
case of a leaf and a root, two regions of the body doing different kinds of work.

5. Plant organs.-These regions of the plant body thus set apart for special purposes are called organs. The simplest of plants, therefore, do not have distinct organs, while the complex plants may have several kinds of organs. All plants are not either very simple or very complex, but beginning with the simplest plants one may pass to others not quite so simple, then to others more eomplex, and so on gradually until the most complex forms are reached. This process of becoming more and more eomplex is known as differentiation, which simply means the setting apart of different regions of the body to do different kinds of work. The advantage of this to the plant becomes plain by using the common illustration of the difference between a tribe of savages and a civilized eommunity. The sarages all do the same things, and each savage does everything. In the civilized community some of the members are farmers, others bakers, others tailors, others butchers, ete. 'This is what is known as "division of labor," and one great adrantage it has is that every kind of work is better done. Differentiation of organs in a plant means to the plant just what division of labor means to the community; it results in more work, and better work, and new kincis of work. The very simple plant resembles the savage tribe, the complex plant resembles the civilized community. It must be understood, however, that in the case of plants the differentiation referred to is one of organs and not of individuals.

6. Plant functions. - Whether plants have many organs, or few organs, or no organs, it should be remembered that they are all at work, and are all doing the same essential things. Although many different kinds of work are being carried on by plants. they may all be put under two heads, nutrition and reproduction. Every plant, whether simple or complex, must eare for two things: (1) its own support (nutrition), and ( 2 ) the production of other plants like 
itself (reproduction). 'To the great work of nutrition many kinds of work contribute, and the same is true of reproduction. Nutrition and reproduction, however, are the two primary kinds of work, and it is interesting to note that the first adrance in the differentiation of a simple plant body is to separate the nutritive and reproductive regions. In the comples plants there are nutritive organs and reproductive organs : by which is meant that there are distinct organs which specially contribute to the work of nutrition, and others which are specially concerned with the work of reproduction. The different kinds of work are conveniently spoken of as functions, each organ having one or more functions.

\%. Life-relations.-In its nutritive and reproductive work the plant is very dependent upon its surroundings. It must receive material from the outside and get rid of waste material; and it must leave its offspring in as favorable conditions for living as possible. As a consequence, every organ holds a definite relation to something outside of itself, known as its life-relation. For example, green leaves are definitely related to light, many roots are related to soil, certain plants are related to abundant water, some plants are related to other plants or animals (living as parasites), etc. A plant with several organs, therefore, may hold a great variety of life-relations, and it is quite a complex problem for such a plant to adjust all of its parts properly to their necessary relations. The study of the life-relations of plants is a division of Botany known as Ecology, and presents to us many of the most important problems of plant life.

It must not be supposed that any plant or organ holds a perfectly simple life-relation, for it is affected by a great variety of things. A root, for instance, is affected by light, gravity, moisture, soil material, contact, etc. Every organ, therefore, must adjust itself to a very complex set of life-relations, and a plant with several organs has so many 
delicate adjustments to care for that it is really impossible, as yet, for us to explain why all of its parts are placed just as they are. In the beginning of the study of plants, only some of the most prominent functions and life-relations can be considered. In order to do this, it seems better to begin with single organs, and afterwards these can be put together in the construction of the whole plant. 


\section{CHAPTER II.}

\section{FOLIAGE LEAVES: THE LIGHT-RELATION.}

8. Definition.-A foliage leaf is the ordinary green leaf, and is a very important organ in comnection with the work of nutrition. It must not be thought that the work done by such a leaf cannot be done by green plants which have no leares, as the algæ, for example. A leaf is simply an organ set apart to do such work better. In studying the work of a leaf, therefore, we have certain kinds of work set apart more distinctly than if they were confused with other kinds. For this reason the leaf is selected as an introduction to some of the important work carried on by plants, but it must not be forgotten that a plant does not need leaves to do this work ; they simply enable it to work more effectively.

9. Position.-It is easily observed that foliage leaves grow only upon stems, and that the stems which bear them always expose them to light; that is, such leaves are aerial rather than subterranean (see Figs. 1, 75, 1\%4). Many stems grow underground, and such stems either bear no foliage leaves, or are so placed that the foliage leaves are sent above the surface, as in most ferns and many plants of the early spring (see Figs. 45, 46, 144).

10. Color-Another fact to be observed is that foliage leaves have a characteristic green color, a color so universal that it has come to be associated with plants, and especially with leaves. It is also evident that this green color holds some necessary relation to light, for the leaves of plants grown in the dark, as potatoes sprouting in a cellar, 
do not develop this color. Even when leaves have developed the green color they lose it if deprived of light, as is shown by the process of blanching celery, and by the effect on the color of grass if a board has lain upon it for some time. It seems plain, therefore, that the green color found in working foliage leaves depends upon light for its existence.

We conclude that at least one of the essential life-relations of a foliage leaf is what may be called the light-relation. This seems to explain satisfactorily why such leaves are not developed in a subterranean position, as are many stems and most roots, and why plants which produce them do not grow in the dark, as in caverns. The same green, and hence the same light-relation, is observed in other parts of the plant as well, and in plants without leares, the only difference being that leaves display it most conspicuously. Another indication that the green color is connected with light may be obtained from the fact that it is found only in the surface region of plants. If one cuts across a living twig or into a cactus body, the green color will be seen only in the outer part of the section. The conclusion is that the leaf is a special organ for the light-relation. Plants sometimes grow in such situations that it would be unsafe for them to display leaves, or at least large leaves. In such a case the work of the leaves can be thrown upon the stem. A notable illustration of this is the cactus plant, which produces no foliage leaves, but whose stem displays the leaf color.

11. An expanded organ.-Another general fact in reference to the foliage leaf is that in most cases it is an expanded organ. This means that it has a great amount of surface exposed in comparison with its mass. As this form is of such common oecurrence it is safe to conclude that it is in some way related to the work of the leaf, and that whaterer work the leaf does demands an exposure of surface rather than thickness of body. It is but another step to say that 
the amount of work an active leaf can do will depend in part upon the amount of surface it exposes.

THE LIGHT-RELATION.

12. The general relation.-The ordinary position of the foliage leaf is more or less horizontal. 'This enables it to receive the direct rays of light upon its upper surface. In

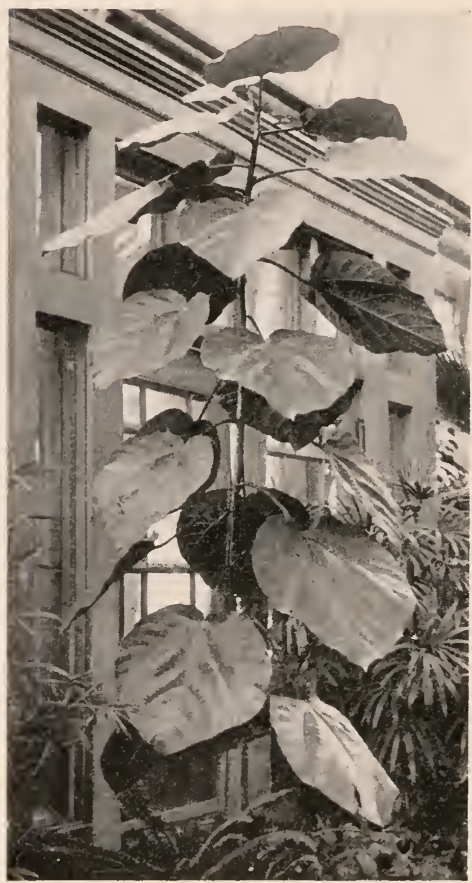

Fig. 1. The leaves of this plant (Ficus) are in general horizontal, but it will be seen that the lower ones are directed downward, and that the leaves become more horizontal as the stem is ascended. It will also be seen that the leaves are so broad that there are few vertical rows. this way more rays of light strike the leaf surface than if it stood obliquely or on edge. It is often said that leaf blades are so directed that the flat surface is at right angles to the incident rays of light. While this may be true of horizontal leaves in a general way, the observation of almost any plant will show that it is a very general statement, to which there are numerous exceptions (see Fig. 1). Leaves must be arranged to receive as much light as possible to help in their work, but too much light will destroy the green substance (chloro$p h(y)$ l), which is essential to the work. 'The adjustment to light, therefore, is a delicate one, for there must be just enough 
and not too much. The danger from too much light is not the same in the case of all leaves, even on the same plant, for some are more shaded than others. Leares also have a way of protecting themselves from too intense light by their structure, rather than by a change in their position. It is evident, therefore, that the exact position which any particular leaf holds in relation to light depends upon many circumstances, and cannot be corered by a general rule, except that it seeks to get all the light it can without danger.

13. Fixed position.-Leaves differ very much in the power of adjusting their position to the direction of the light.
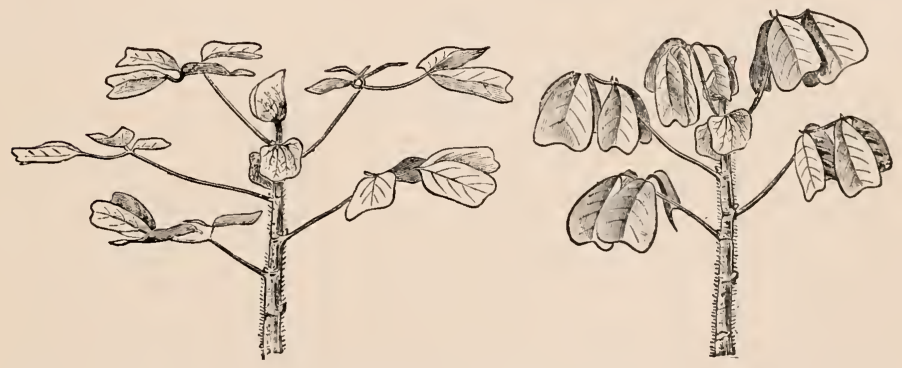

FIg. 2. The day and night positions of the leaves of a member (Amicia) of the pea family.-After Strasburger.

Most leaves when fully grown are in a fixed position and camnot change it, however unfarorable it may prove to be, except as they are blown abont. Such leaves are said to have fixed light positions. 'This position is determined by the light conditions that prevailed while the leaf was growing and able to adjust itself. If these conditions continue, the resulting fixed position represents the best one that can be secured under the circumstances. The leaf may not receive the rays of light directly throughout the whole period of daylight, but its fixed position is such that it probably receives more light than it would in any other position that it could secure. 
14. Motile leaves.-There are leaves, however, which have no fixed light position, but are so constructed that they can shift their position as the direction of the light changes. Such leares are not in the same position in the

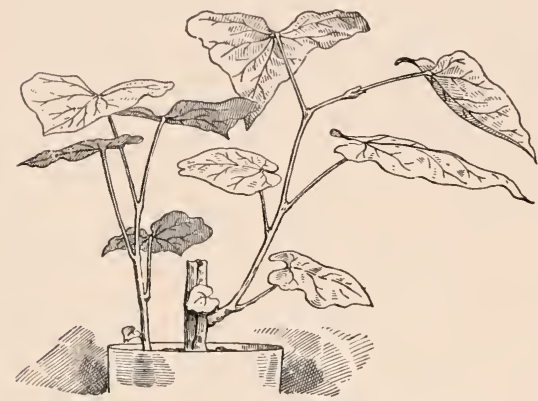

FIg. $3 a$. The day position of the leaves of redbud (Cercis).-After Arthur. afternoon as in the forenoon, and their night position may be very different from either (see Figs. '), 3a, $3 b, 4)$. Some of the common house plants show this power. In the case of the common Oxalis the night position of the leaves is remarkably different

from the position in light. If such a plant is exposed to the light in a window and the positions of the leaves noted, and then turned half way around, so as to bring the other side to the light, the leaves may be observed to adjust themselves gradually to the changed light-relations.

15. Compass plants. $-\mathrm{A}$

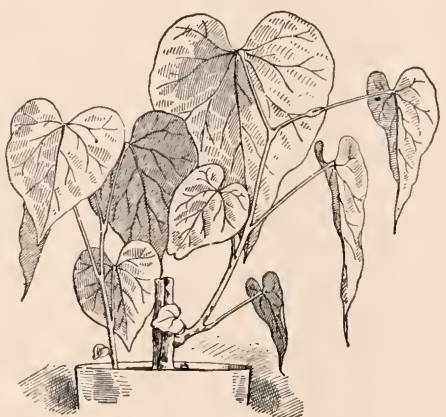

Fig. 3b. The night position of the leaves of redbud (Cercis).-After Anthur. striking illustration of a special light position is found in the so-called "compass plants." 'The best known of these plants is the rosin-weed of the prairie region. Growing in situations exposed to intense light, the leaves are turned edgewise, the flat faces being turned away from the intense rays of midday, and directed towards the rays of less intensity ; that is, those of 


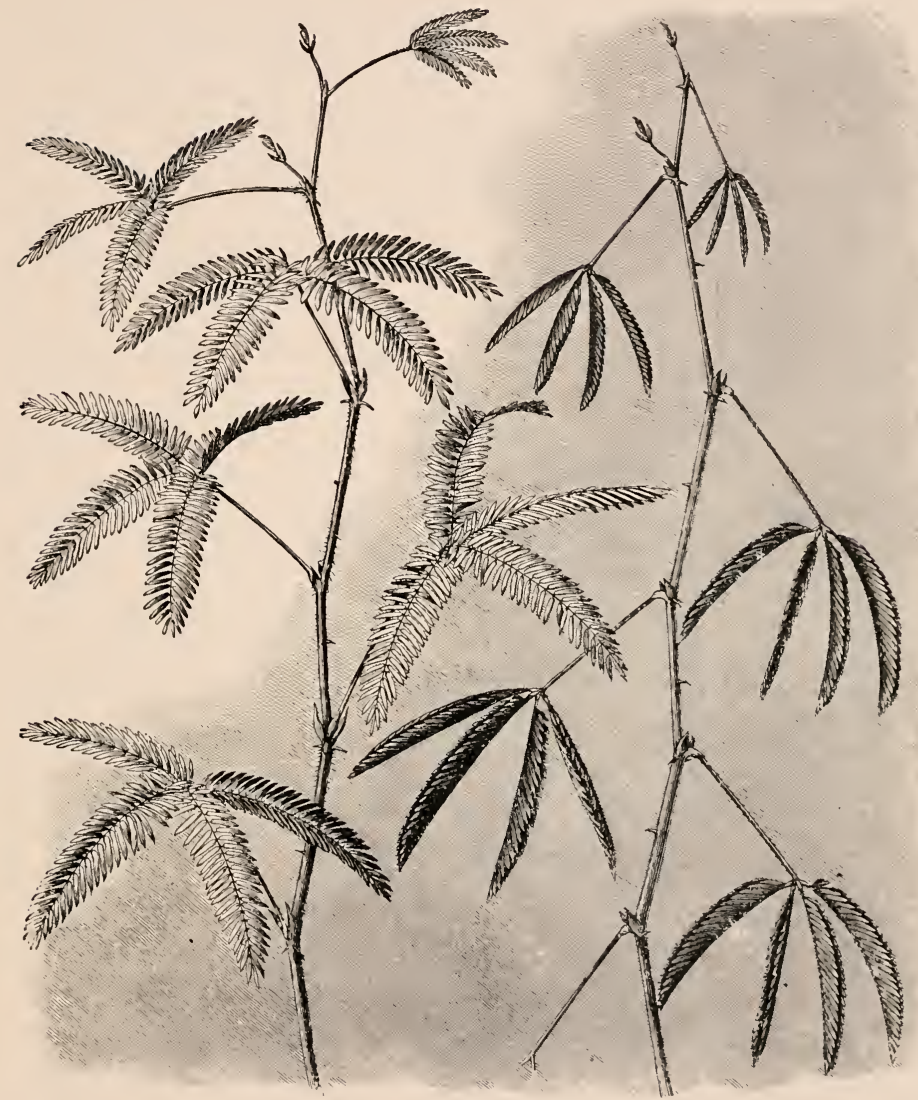

Fig. 4. Two sensitive plants, showing the motile leaves. The plant to the left has its leaves and numerous leaflets expanded; the one to the right shows the leaflets folded together and the leaves drooping.-After KERNER.

the morning and evening (see Fig. 1\%0). As a result, the apex of the leaf points in a general north or south direction. It is a significant fact that when the plant grows in shaded places the leaves do not assume any such position. It seems evident, therefore, that the position has something to do with avoiding the danger of too intense light. It 


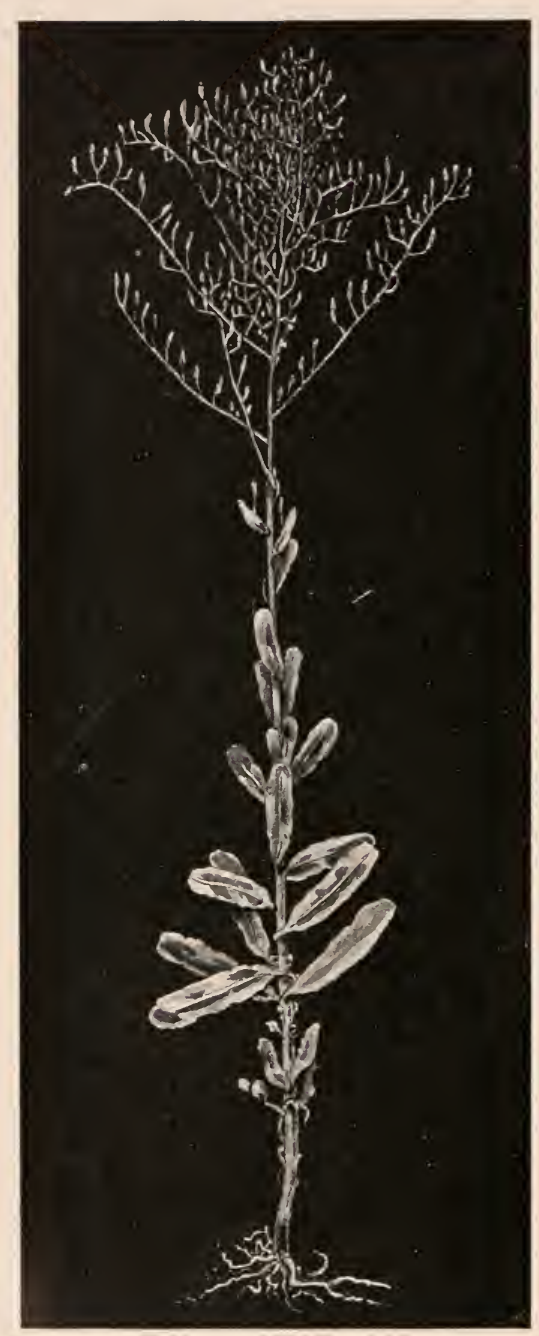

FIG, 5. The common prickly lettuce (Lactuca Scariola), showing the leaves standing edgewise, and in a general north and south plane. -After Artuur and MacDougal. must not be supposed that there is any accuracy in the north or south direction, as the edgewise position seems to be the signifieant one. In the rosin-weed probably the north and south direction is the prevailing one; but in the prickly lettuce, a very common weed of waste grounds, and one of the most striking of the compass plants, the elgewise position is frequently assumed without any special reference to the north or south direction of the apex (see Fig. 5).

\section{Heliotropism.-} The property of leaves and of other organs of responding to light is known as heliotropism, and it is one of the most important of those external influences to which plant organs respond (see Figs. 6, 43).

It should be understood clearly that this is but a slight glimpse 


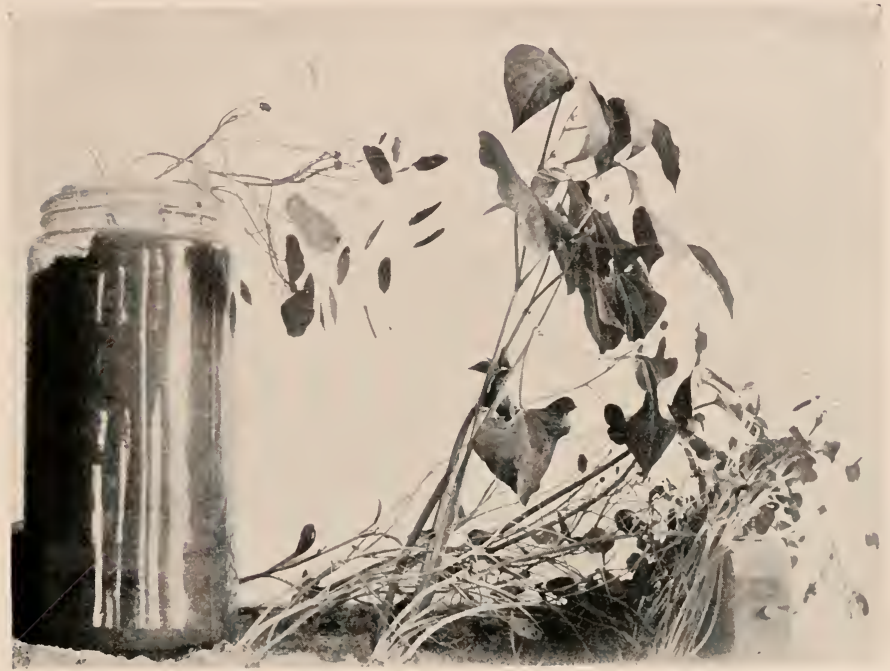

FIG. 6. These plants are growing near a window. It will be noticed that the stems bend strongly towards the light, and that the leaves face the light.

of the most obvious relations of foliage leares to light, and that the important part which heliotropism plays, not only in connection with foliage leaves, but also in connection with other plant organs, is one of the most important and extensive subjects of plant physiology.

\section{RELATION OF LEAVES TO ONE ANOTIIER.}

\section{A. On erect stems.}

In view of what has been said, it would seem that the position of foliage leaves on the stem, and their relation to one another, must be determined to some extent by the necessity of a farorable light-relation. It is apparent that the conditions of the problem are not the same for an erect as for a horizontal stem.

1\%. Relation of breadth to number of vertical rows.Upon an erect stem it is observed that the leaves are usu- 
ally arranged in a definite number of vertical rows. It is to the adrantage of the plant for these leaves to shade one another as little as possible. 'Therefore, the narrower the leaves, the more numerous may be the rertical rows (see Figs. $\%, 8)$ : and

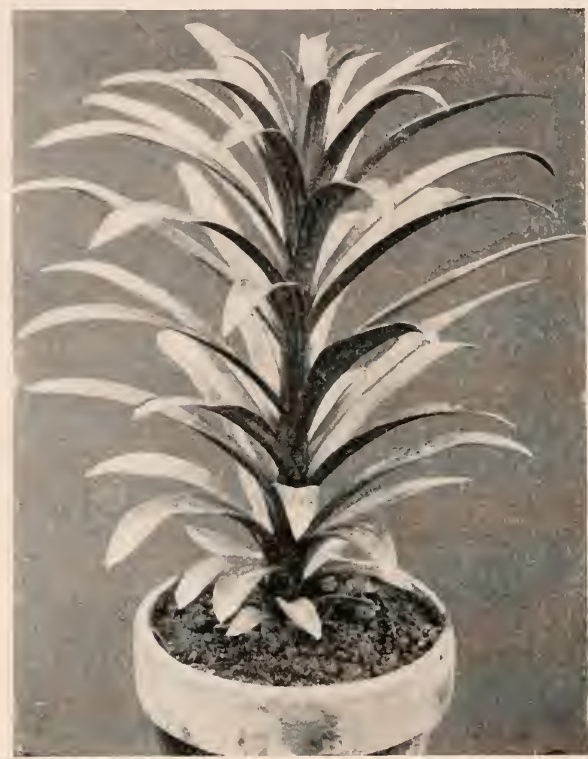

FIG. 7. An Easter lily, showing narrow leaves and numerous vertical rows.

the broader the leaves the fewer the vertical rows (see Fig. 1). A relation exists, therefore, between the breadth of leaves and the number of rertical rows, and the meaning of this becomes plain when the light-relation is considered.

18. Relation of length to the distance between leaves of the same row.-The leaves in a vertical row may be close together or far apart. If they should be close together and at the same time long. it is evident that they will shade each other considerably, as the light camnot well strike in between them and reach the surface of the lower leaf. 'Therefore, the closer together the leaves of a vertical row, the shorter are the leaves; and the farther apart the leaves of a row, the longer may they be. Short leaves permit the light to strike between them even if they are close together on the stem; and long leaves permit the same thing only when they are far apart on the stem. A 


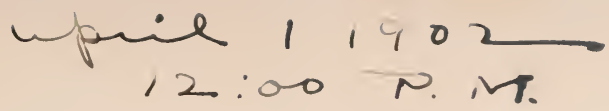

FOLIAGE LEAVES : THE LIGHT-RELATION.

relation is to be observed, therefore, between the length of leaves and their distance apart in the same vertical row.

The same kind of relation ean be observed in reference to the brealth of leaves, for if leaves are not only short but narrow they can stand very close together. It is thus seen that the length and breadth of leaves, the number of vertical rows on the stem, and the distance between the leaves

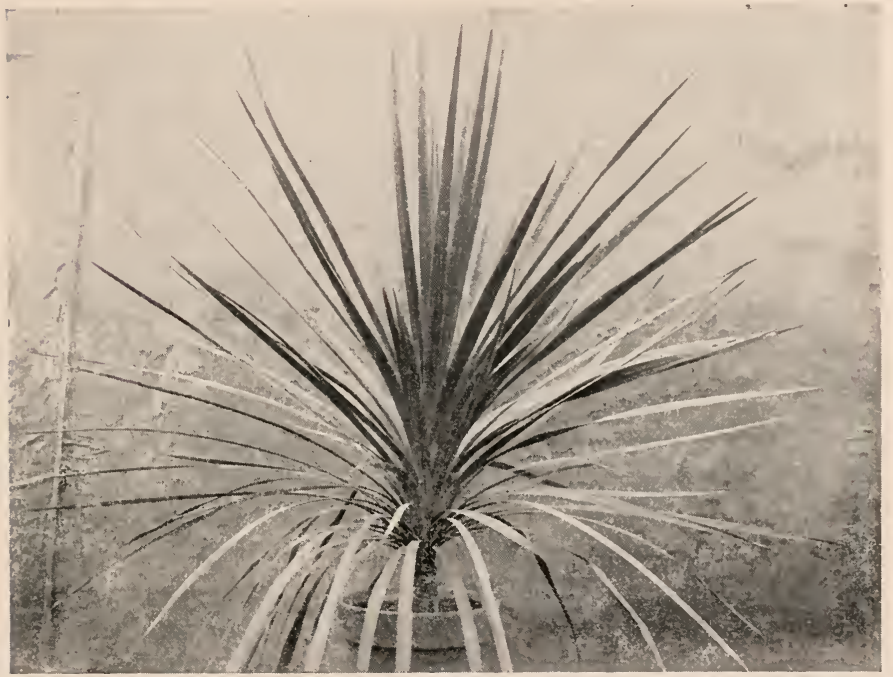

FIG. 8. A dragon-tree, showing narrow leaves extending in all directions, and numerous vertical rows.

of any row, all have to do with the light-relation and are answers to the problem of shading.

19. Elongation of the lower petioles.-There is still another common arrangement by which an effective lightrelation is secured by leares which are broad and placed close together on the stem. In such a case the stalks (petioles) of the lower leaves become longer than those above and thus thrust their blades beyond the shadow (see Fig. 9). It may be noticed that it is very common to 
find the lowest leaves of a plant the largest and with the longest petioles, even when the leaves are not very close together on the stem.

It must not be supposed that by any of these derices shading is absolutely aroided. This is often impossible and sometimes undesirable. It simply means that by these

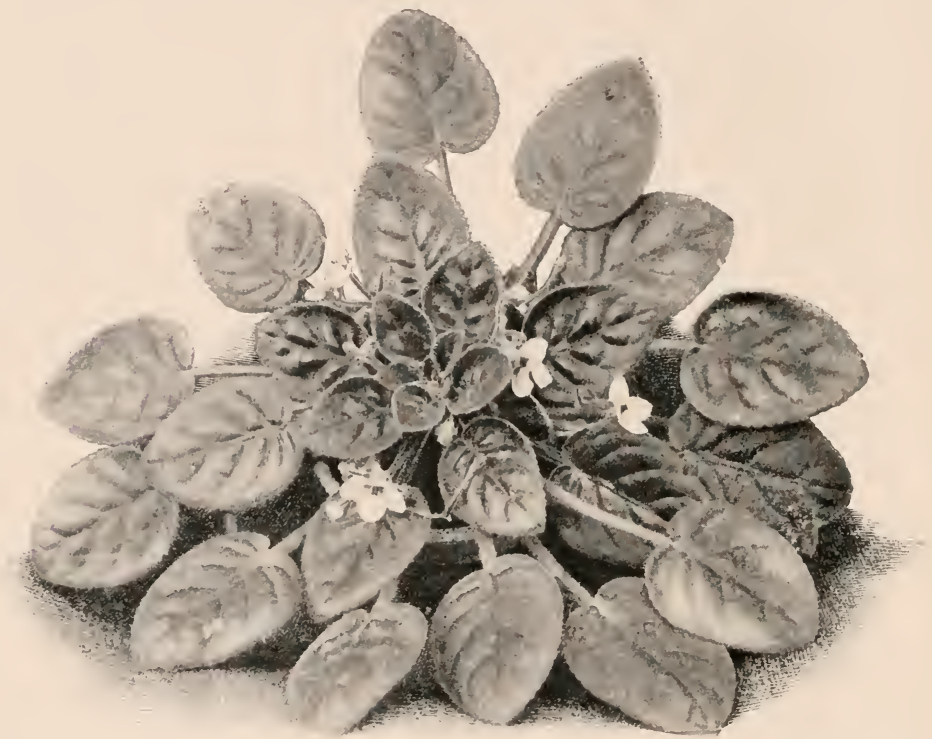

Fig. 9. A plant (Saintpaulia) with the lower petioles elongated, thrusting the blades beyond the shadow of the upper leaves. A loose rosette.

arrangements the most favorable light-relation is sought by avoiding too great shading.

20. Direction of leaves.-Not only is the position on the stem to be observed, but the direction of leaves may result in a favorable relation to light. It is a very common thing to find a plant with a eluster of comparatively large leaves at or near the base, where they are in no danger of shading other leaves, and with the stem leaves gradually becoming 
smaller and less horizontal toward the apex of the stem (see Figs. 10, 13). 'The common shepherd's purse and the mullein may be taken. as illustrations. By this arrangement all the leaves are very completely exposed to the light.

\section{The rosette habit.-} The habit of producing a cluster or rosette of leaves at the base of the stem is called the rosette habit. Often this rosette of leaves at the base, frequently lying flat on the ground or on the rocks, includes the only foliage leaves the plant produces. It is evident that a rosette, in which the leaves must orerlap one another more or less, is not a very favorable light arrangement, and therefore it must be that something is being provided for besides the light-relation (see Figs. 11, 12, 13). What this is will appear later, but even in

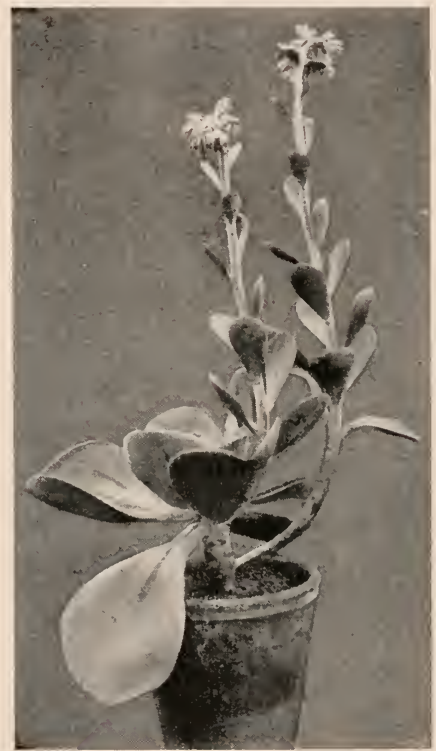

FIG. 10. A plant (Echeveria) with fleshy leaves, showing large horizontal ones at base, and others becoming smaller and more directed upward as the stem is ascended. this comparatively unfavorable light arrangement, there is evident adjustment to secure the most light possible under the circumstances. 'The lowest leares of the rosette are the longest, and the upper (or inner) ones beeome gradually shorter, so that all the leaves have at least a part of the surface exposed to light. The overlapped base of such leaves is not expanded as much as the exposed apex, and hence they are mostly narrowed at the base and broal at the apex. This narrowing at the base is sometimes 
carried so far that most of the part which is covered is but a stem (petiole) for the upper part (blade) which is exposed.

In many plants which do not form close rosettes a gen-

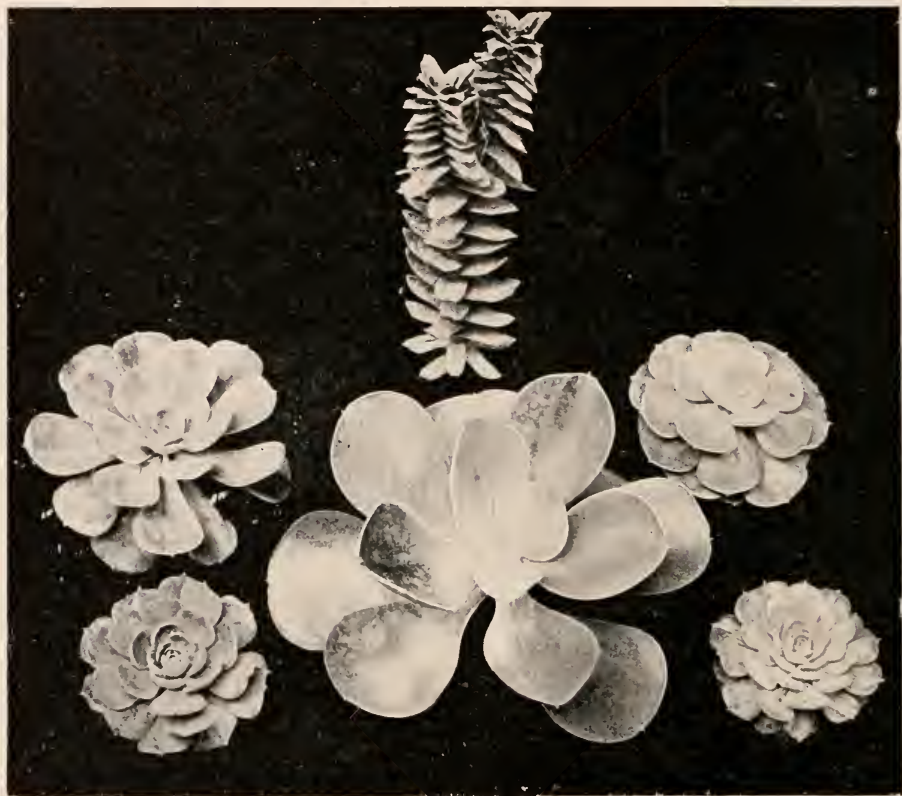

Fig. 11. A group of live-for-evers, illustrating the rosette habit and the light-relation. In the rosettes it will be observed how the leaves are fitted together and dininish in size inwards, so that excessive shading is avoided. The individual leaves also become narrower where they overlap, and are broadest where they are exposed to light. In the background is a plant showing leaves in very definite vertical rows.

eral rosette arrangement of the leaves may be observed by looking down upon them from above (see Fig. 9), as in some of the early buttercups which are so low that the large leaves would seriously shade one another, except that the lower leaves have longer petioles than the upper, and so reach beyond the shadow. 

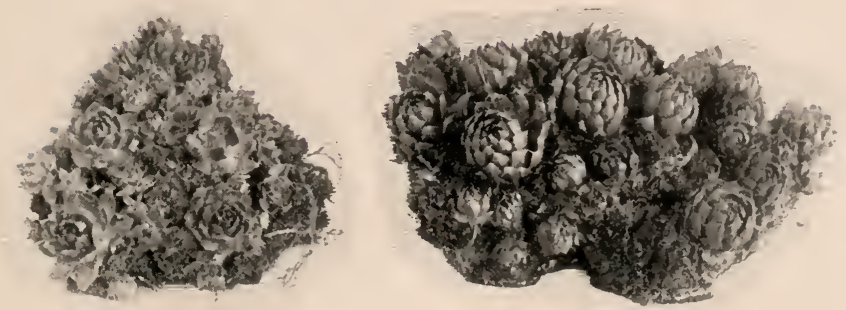

Fig. 12. Two clumps of rosettes of the house leck (Sempervirum), the one to the right showing the compact winter condition, the one to the left with rosettes more open after being kept indoors for several days.

22. Branched leaves.-Another notable feature of foliage leaves, which has something to lo with the light-relation, is that on some plants the blade does not consist of one piece, but is lobed or eren broken up into separate pieces. When the divisions are distinct they are called leaflets, and every gradation in leaves can be found, from distinct leaflets to lobed leaves, toothed leaves, and finally those whose margins are not indented at all (entire). This difference in leaves probably has more important reasons than the lightrelation, but its significance may be observed in this comnection. In those plants whose leaves are undivided, the leaves generally either diminish in size toward the top of the stem, or the lower ones develop longer petioles. In this case the general outline of the

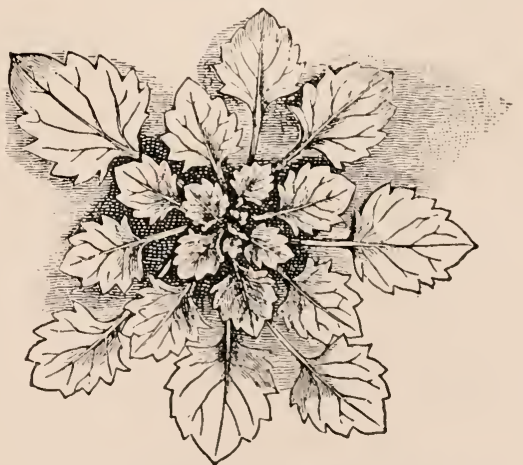

FIg. 13. The leaves of a bellflower (Campanula), showing the rosette arrangement. The lower petioles are successively longer, earrying their blades beyond the shadow of the blades above. -After Ker.xer. 


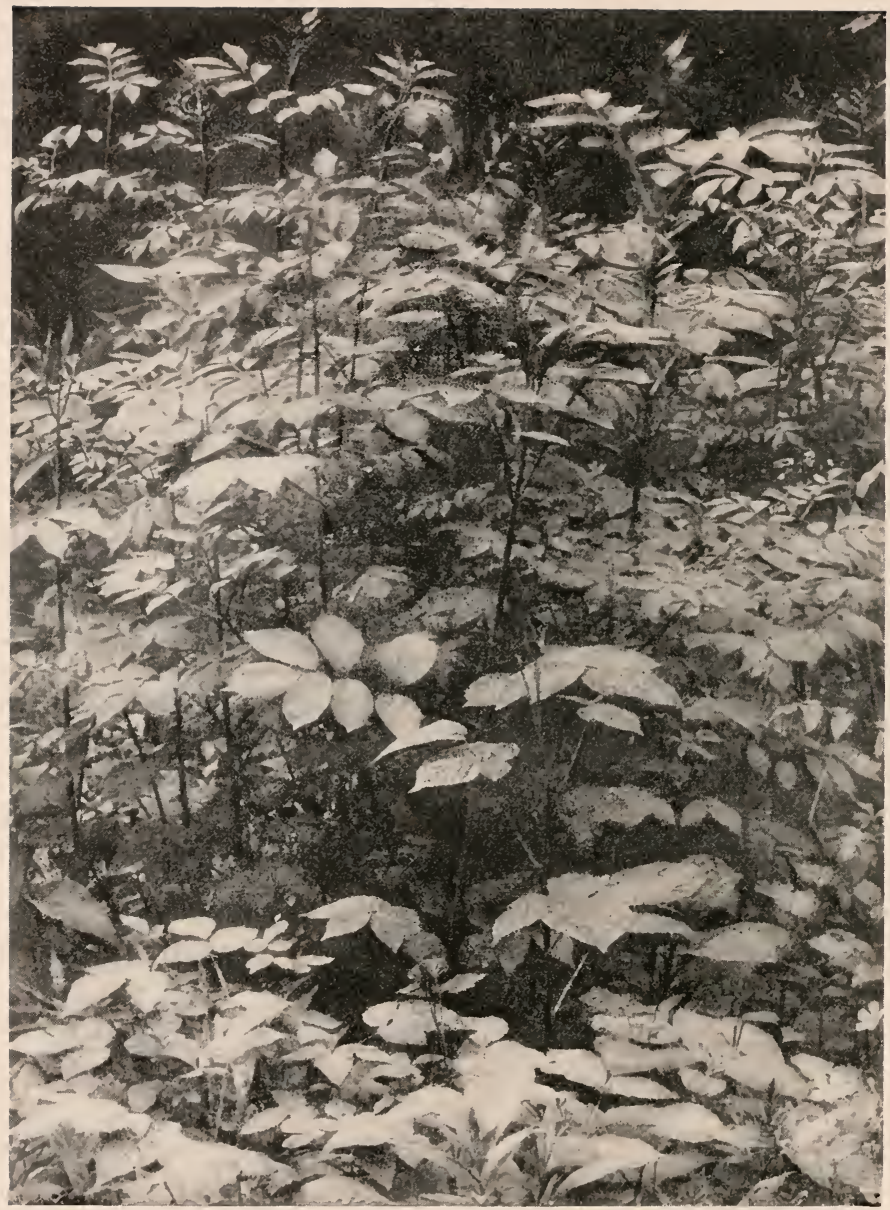

F'IG. 14. A group of leaves, showing how branched leaves overtop each other without dangerous shading. It will be seen that the larger blades or less-branched leaves are towards the bottom of the group. 
plant is conical, a form very common in herbs with entire or nearly entire leaves. In plants whose leaf blades are broken up into leaflets (compound or branched leaves), however, no such diminution in size toward the top of the stem is necessary (see Fig. 17), though it may frequently

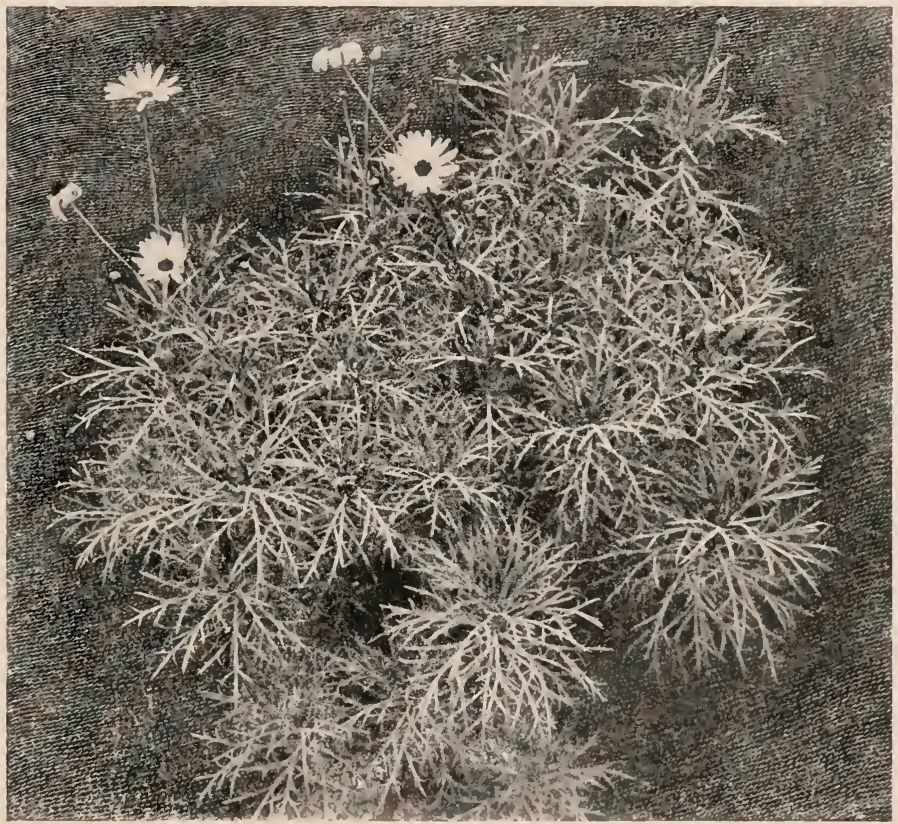

FIG. 15. A plant showing much-branched leaves, which occur in great profusion without cutting off the light from one another.

occur. When a broad blade is broken up into leaflets the danger of shading is very much less, as the light can strike through between the upper leaflets and reach the leaflets below. On the lower leaves there will be splotehes of light and shadow, but they will shift throughout the day, so that probably a large part of the leaf will receive light at some time during the day (see Fig. 11). The 
general outline of such a plant, therefore, is usually not conical, as in the other case, but cylindrical (see Figs. 4, $15,16,22,45,83,96,155,162,174$ for branched leaves).

Many other factors enter into the light-relation of foliage leaves upon erect stems, but those given may suggest.

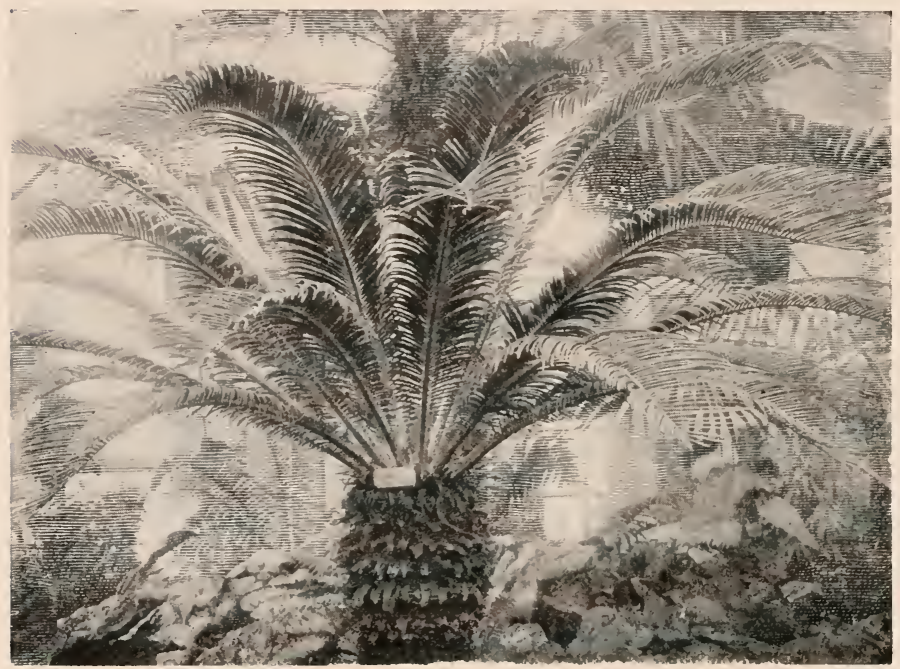

Frg. 16. A cycad, showing much-branched leaves and palm-like habit.

observation in this direction, and serve to show that the arrangement of leaves in reference to light depends upon many things, and is by no means a fixed and indifferent thing. The study of any growing plant in reference to this one relation presents a multitude of problems to those who know how to observe.

\section{B. On horizontal stems.}

23. Examples of horizontal stems, that is, stems exposed on one side to the direct light, will be found in the case of many branches of trees, stems prostrate on the ground, and 
stems against a support, as the ivies. It is only necessary to notice how the leaves are adjusted to light on an erect stem, and then to bend the stem into a horizontal position or against a support, to realize how unfavorable the same arrangement would be, and how many new adjustments must be made. 'The leaf blades must all be brought to the light side of the stem, so far as possible, and those that belong to the lower side of the stem must be fitted into the spaces left by the leaves which belong to the upper side. This may be brought about by the twisting of the stem, the twisting of the petioles, the bending of the blade on the petiole, the lengthening of petioles, or in some other way. Every horizontal stem has its own special problems of leaf adjustment which may be observed (see Figs. 18, $50)$.

Sometimes there is not space enough for the full development of every blade. and smaller ones are fitted

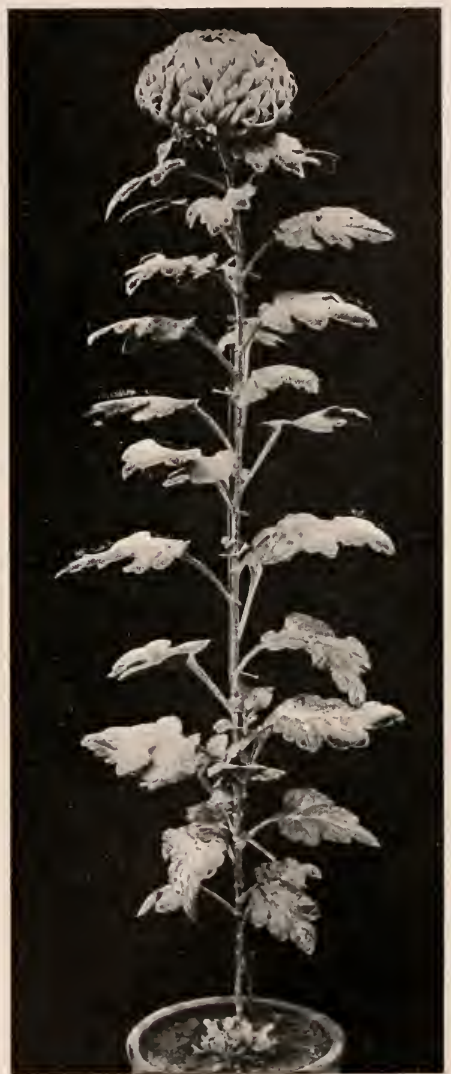

FIG. 17. A chrysanthemum, showing lobed leaves, the rising of the petioles to adjust the blades to light, and the general cylindrical habit. into the spaces left by the larger ones (see Fig. 21). This sometimes results in what are called unequally paired leares, where opposite leaves develop one large blade and one small 
one. Perhaps the most complete fitting together of leaves is found in certain ivies, where a regular layer of angular interlocking leaves is formed, the leaves fitting together like

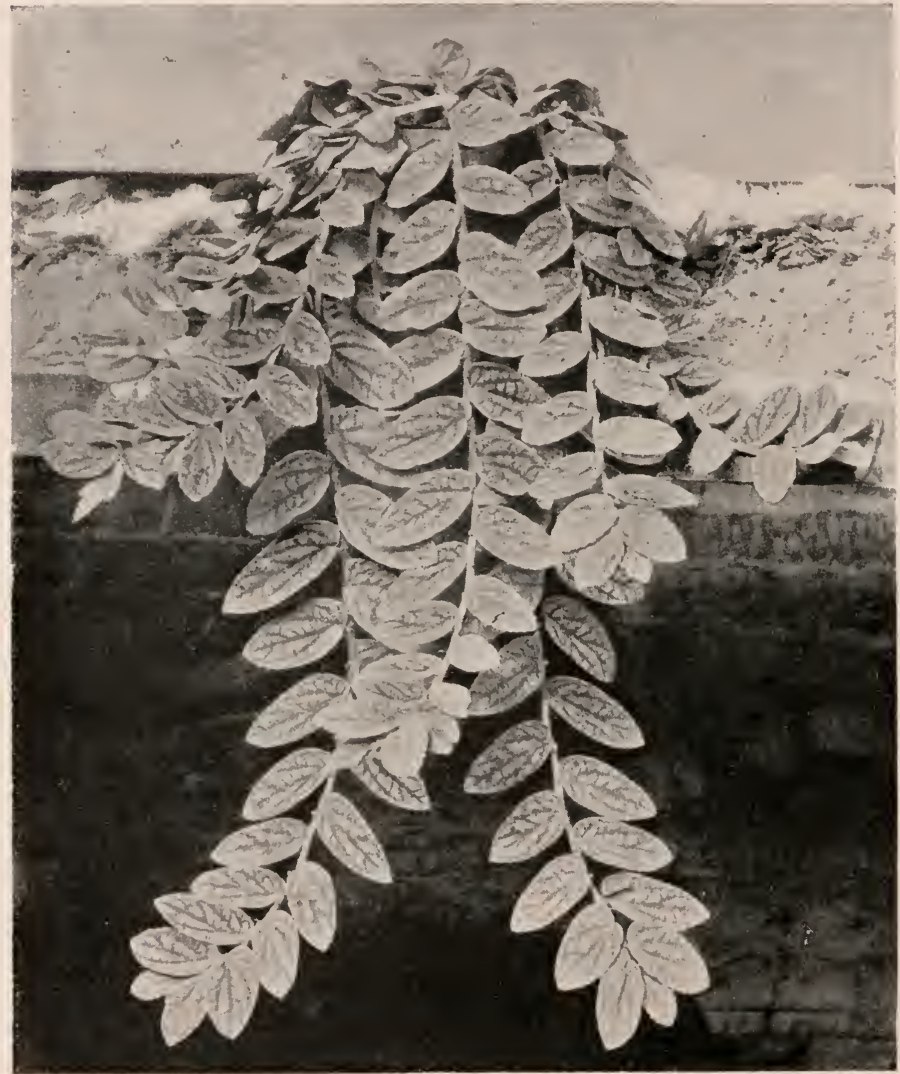

FIG. 18. A plant (Pellionia) with drooping stems, showing how the leaves are all brought to the lighted side and fitted together.

the pieces of a mosaic. In fact such an arrangement is known as the mosaic arrangement, and involves such an amount of twisting, displacement, elongation of petioles, 


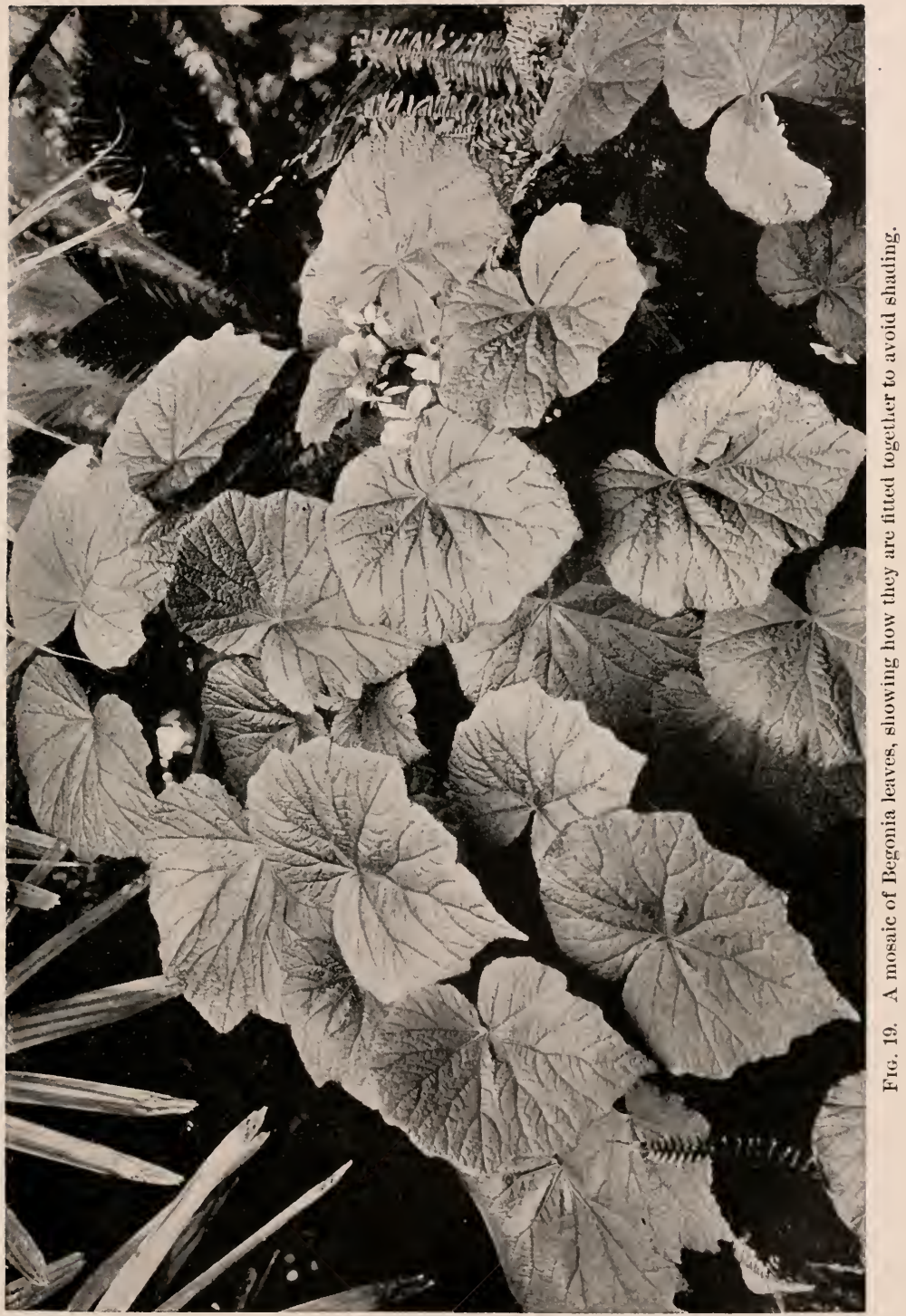




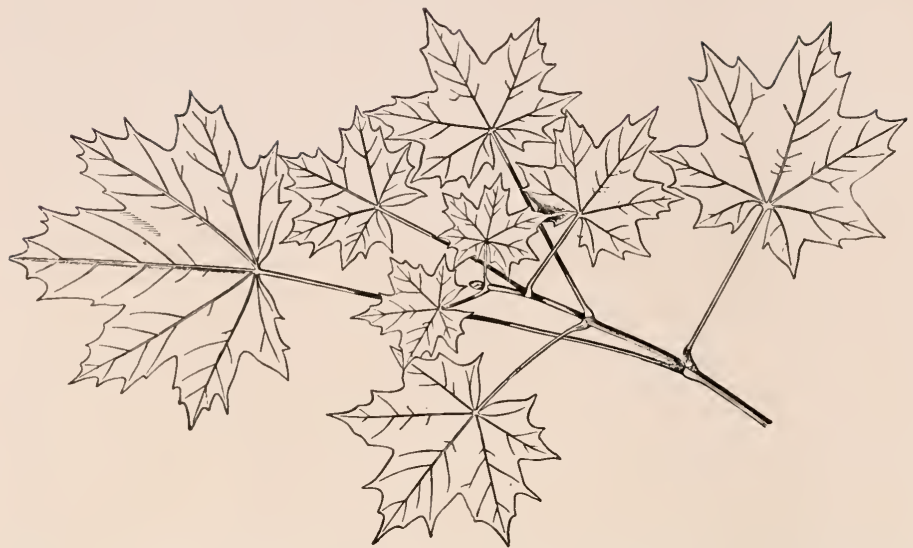

Fig. 20. A spray of maple, showing the adjustment of the leaves in size and position of blades and length of petioles to secure exposure to light on a horizontal stem.After Kenner.

etc., as to give ample evidence of the effort put forth by plants to secure a favorable light-relation for their foliage

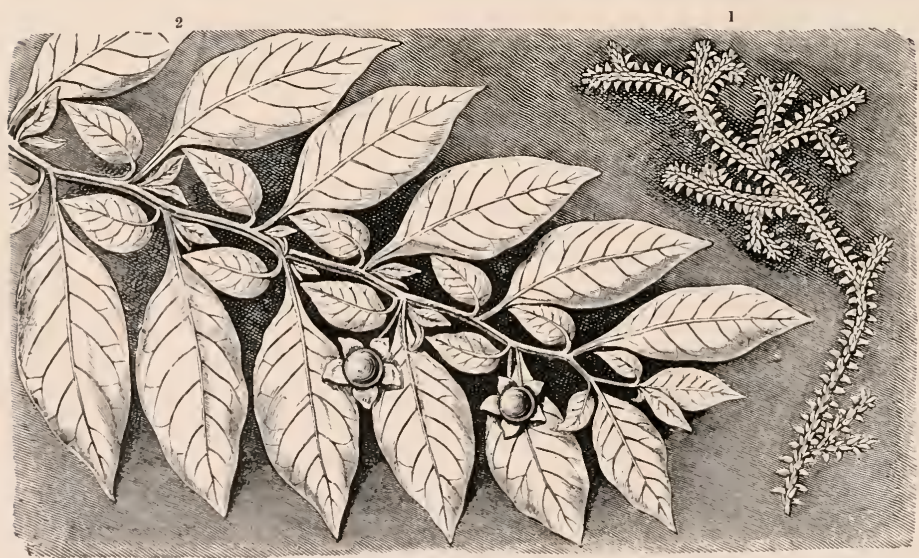

FIG. 21. Two plants showing adjustment of leaves on a horizontal stem. The plant to the left is nightshade, in which small blades are fitted into spaces left by the large ones. The plant to the right is Selaginella, in which small leaves are distributed along the sides of the stem, and others are displayed along the upper surface.-After KErner. 
leaves (see Figs. 19, 22). In the case of ordinary shade trees every direction of branch may be found, and the resulting adjustment of leaves noted (see Fig. 20).

Looking up into a tree in full foliage, it will be noticed that the horizontal branches are comparatively bare be-

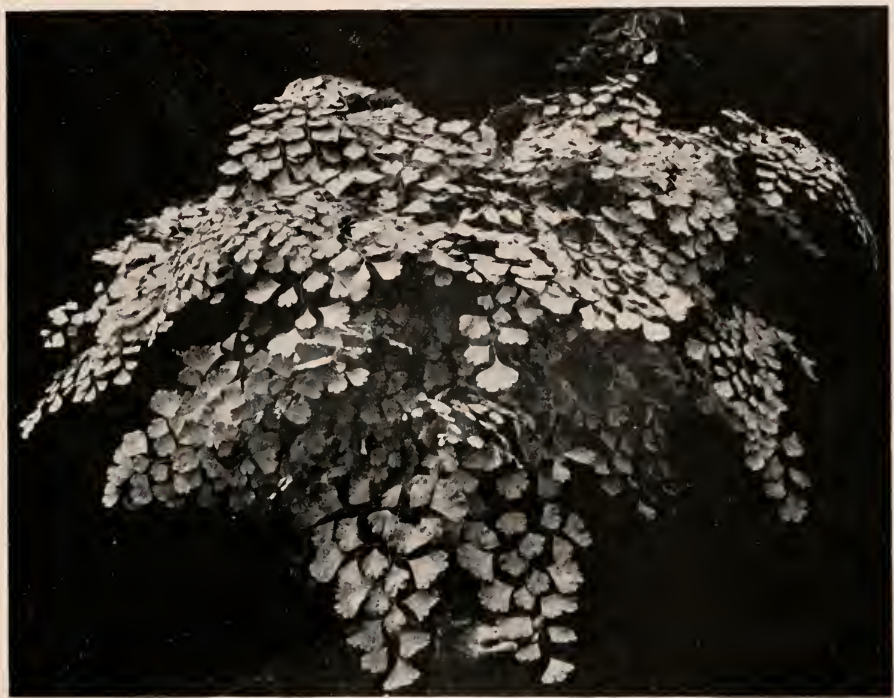

Fig. 22. A mosaic of fern (Adiantum) leaflets.

neath, while the leaf blades have been carried to the upper side and have assumed a mosaic arrangement.

Sprays of maidenhair fern (see Fig. 92) show a remarkable amount of adjustment of the leaflets to the light side. Another group of fern-plants, known as club-mosses, has horizontal stems clothed with numerous very small leaves. These leaves may be seen taking adrantage of all the space on the lighted side (see Fig. ə1).

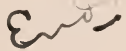




\section{CHAP'TER IIT.}

FOLIAGE LEAVES: FUNCTION, STRUCTURE, AND PROTECTION.

\section{A. Functions of foliage leaves.}

24. Functions in general.-We have observed that foliage leaves are light-related organs, and that this relation is an important one is evident from the various kinds of adjustment used to secure it. We infer, therefore, that for some important function of these leaves light is necessary. It would be hasty to suppose that light is necessary for every kind of work done by a foliage leaf, for some forms of work might be carried on by the leaf that light neither helps nor hinders. Foliage leaves are not confined to one function, but are eoncerned in a variety of processes, all of which have to do with the great work of nutrition. Among the variety of functions which belong to foliage leares some of the most important may be selected for mention. It will be possible to do little more than indicate these functions until the plant with all its organs is considered, but some evidence can be obtained that various processes are taking place in the foliage leaf.

25. Photosynthesis.-The most important function of the foliage leaf may be detected by a simple experiment. If an actively growing water plant be submerged in water in a glass vessel, and exposed to the light, bubbles may be seen coming from the leaf surfaces and rising through the water (see Fig. 23). The water is merely a device by which the bubbles of gas may be seen. If the plant is very active the 
bubbles are numerous. That this activity holds a definite relation to light may be proved by gradually removing the vessel containing the plant from the light. As the light diminishes the bubbles diminish in number, and when a

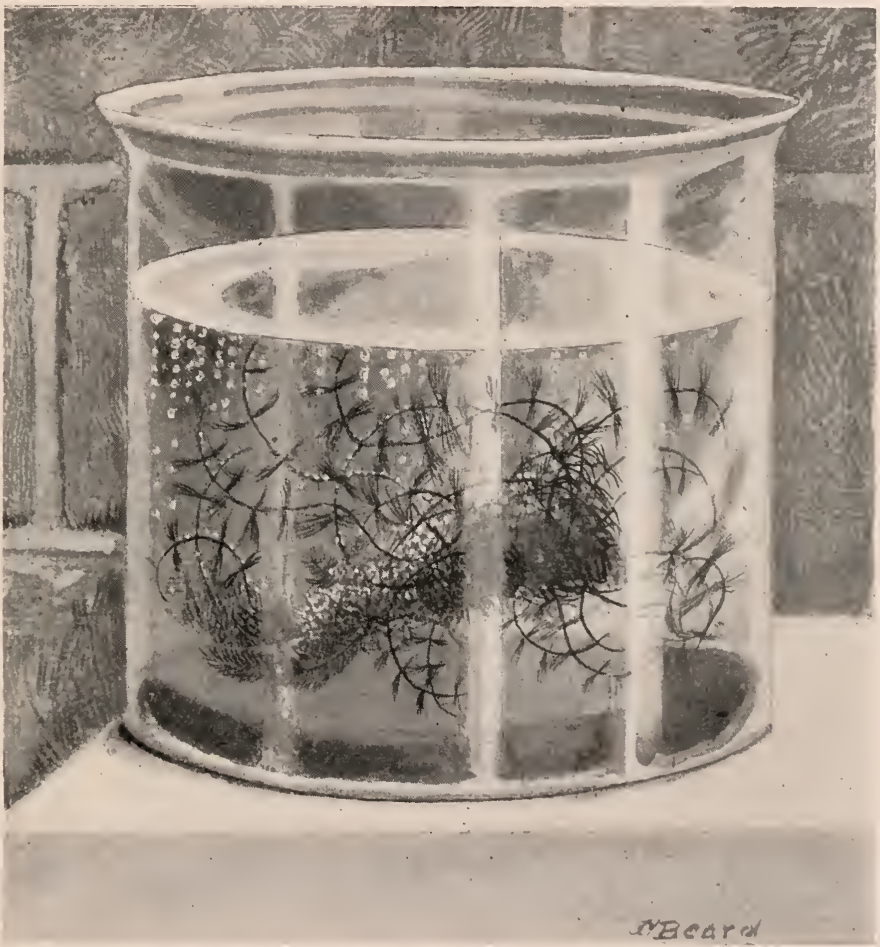

FIG. 23. An experiment to illustrate the giving off of oxygen in the process of photo. synthesis.

certain amount of darkness has been reached the bubbles will cease entirely. If now the ressel he brought back gradually into the light, the bubbles will reappear, more and more numerous as the light increases. 'That this gas being given off is oxygen may be proved by collecting the 
bubbles in a test tube, as in an ordinary chemical experiment for collecting gas over water, and testing it in the usual way.

Some very important things are learned by this experiment. It is evident that some process is going on within the leaves which needs light and which results in giving off oxygen. It is further evident that as oxygen is eliminated, the process indieated is dealing with substanees which contain more oxygen than is needed. The amount of oxygen given off may be taken as the measure of the work. The more oxygen, the more work; and, as we have observed, the more light, the more oxygen; and no light, no oxygen. Therefore, light must be essential to the work of which the elimination of oxygen is an external indication. That this process, whatever it may be, is so essentially related to light, suggests the idea that it is the special process which demands that the leaf shall be a light-related organ. If so, it is a dominating kind of work, as it chiefly determines the life-relations of foliage leaves.

The process thus indicated is known as photosynthesis, and the name suggests that it has to do with the arrangement of material with the help of light. It is really a process of food manufacture, by which raw materials are made into plant food. This process is an exeeedingly important one, for upon it depend the lives of all plants and animals. The foliage leaves may be considered, therefore, as special orguns of photosynthesis. They are special organs, not exelusive organs, for any green tissue, whether on stem or fruit or any part of the plant body, may do the same work. It is at once apparent, also, that during the night the process of photosynthesis is not going on, and therefore during the night oxygen is not being given off.

Another part of this process is not so easily observed, but is so closely related to the elimination of oxygen that it must be mentioned. Carbon dioxide occurs in the air to which the foliage leaves are exposed. It is given off from 
our lungs in breathing, and also comes off from burning wood or coal. It is a common waste product, being a combination of carbon and oxygen so intimate that the two elements are separated from one another with great difficulty. During the process of photosynthesis it has been discovered that carbon dioxide is being absorbed from the air by the leaves. As this gas is absorbed chiefly by green parts and in the light, in just the conditions in which oxygen is being given off, it is natural to connect the two, and to infer thist the process of photosynthesis involves not only the green color and the light, but also the absorption of carbon dioxide and the elimination of oxygen.

When we observe that carbon dioxide is a combination of carbon and oxygen, it seems reasonable to suppose that the carbon and oxygen are separated from one another in the plant, and that the carbon is retained and the oxygen given back to the air. The process of photosynthesis may be partially defined, therefore, as the breaking up of carbon dioxide by the green parts of the plants in the presence of light, the retention of the carbon, and the elimination of the oxygen. The carbon retained is combined into real plant food, in a way to be described later. We may consider photosynthesis as the most important function of the foliage leaf, of which the absorption of carbon dioxide and the evolution of oxygen are external indications; and that light and chlorophyll are in some way essentially comneeted with it.

26. Transpiration.-One of the easiest things to observe in connection with a working leaf is the fact that it gives off moisture. A simple experiment may demonstrate this. If a glass vessel (bell jar) be inverted over a small active plant the moisture is seen to condense on the glass, and even to trickle down the sides. A still more convenient way to demonstrate this is to select a single vigorous leaf with a good petiole; pass the petiole through a perforated cardboard resting upon a tumbler containing water, and invert 
a second tumbler over the blade of the leaf, which projects above the eardboard (see Fig. 2t). It will be observed that moisture given off from the surface of the working leaf is condensed on the inner surface of the inverted tumbler. 'The cardboard is to shut off evaporation from the water in the lower tumbler.

When the amount of water given off by a single leaf is noted, some vague idea may be formed as to the amount of moisture given off by a great mass of vegetation, such as a meadow or a forest. It is evident that green plants at work are contributing a very large amount of moisture to the air in the form of water vapor, moisture which has been absorbed by some region of the plant. The foliage leaf, therefore, may be regarded as an organ of transpiration, not that the leaves alone are engaged in transpiration, for many parts of the plant do the same thing, but because the foliage leaves are the chief seat of transpiration.

In ease the leaves are submerged, as is true of many plants, it is evident that transpiration is practically checked, for the leaves are already bathed with water, and under such eireumstances water vapor is not given off. It is evident that under such circumstances leaf work must be carried on withont transpiration. In some eases, as in eertain grasses, fuehsias, etc., drops of water are extruded at the apex of the leaf, or at the tips of the teeth. 'This process is ealled guttation, and by means of it a good deal of water passes from the leaf. It is specially used by shade plants, which live in eonditions which do not favor transpiration.

27. Respiration.-Another kind of work also may be detected in the foliage leaf, but not so easily deseribed. In fact it escaped the attention of botanists long after they had diseovered photosynthesis and transpiration. It is work that goes on so long as the leaf is alive, never ceasing day or night. The external indication of it is the absorption 


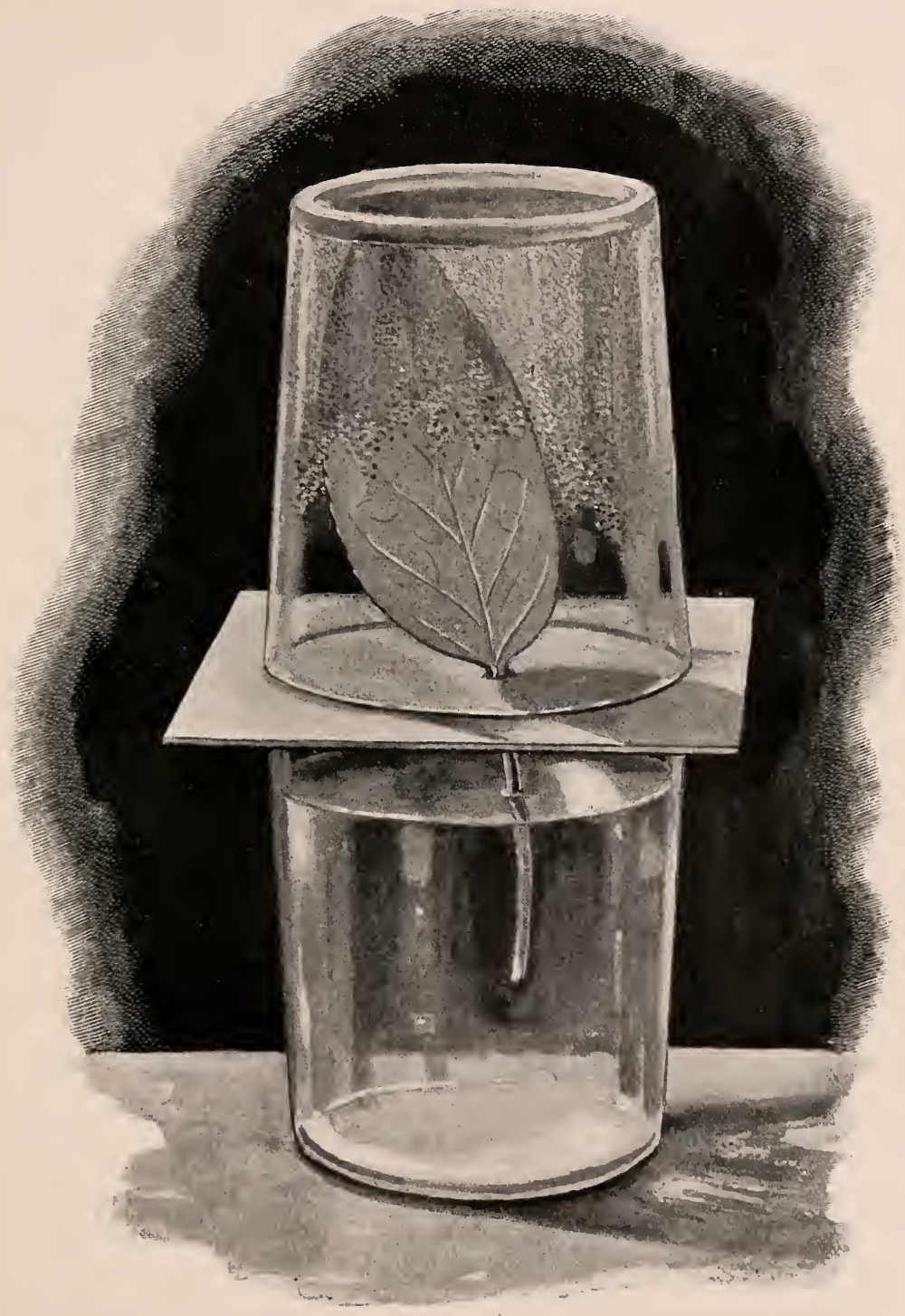

FIG. 24. Experiment illustrating transpirntion. 
of oxygen and the giving out of carbon dioxide. It will be noted at once that this is exactly the reverse of what takes place in photosynthesis. During the day, therefore, carbon clioxide and oxygen are both being absorbed and evolved. It will also be noted that the taking in of oxygen and the giving ont of carbon dioxide is just the sort of exchange which takes place in our own respiration. In fact this process is also called respiration in plants. It does not depend upon light, for it goes on in the dark. It does not depend apon chlorophyll, for it goes on in plants and parts of plants which are not green. It is not peculiar to leaves, but goes on in every living part of the plant. A process which goes on without interruption in all living plants and animals must be very closely related to their living. We conclude, therefore, that while photosynthesis is peculiar to green plants, and only takes place in them when light is present, respiration is necessary to all plants in all conditions, and that when it eeases life must soon eease. The fact is, respiration supplies the energy which enables the living substance to work.

Once it was thought that plants differ from animals in the fact that plants absorb carbon dioxide and give off oxygen, while animals absorb oxygen and give off carbon dioxide. It is seen now that there is no such difference, but that respiration (absorption of oxygen and evolution of carbon dioxide) is common to both plants and animals. The difference is that green plants have the added work of photosynthesis.

We must also think of the foliage leaf, therefore, as a respiring organ, because very much of such work is done by it, but it must be remembered that respiration is going on in every living part of the plant.

This by no means completes the list of functions that might be made out for foliage leaves, but it serves to indicate both their peculiar work (photosynthesis) and the fact that they are doing other kinds of work as well. 
FOLIAGE LEAVES: FUNCTION, STRUCTURE, ETC.

B. Structure of foliage leaves.

28. Gross structure.-It is evident that the essential part of a foliage leaf is its expanded portion or blade. Often the leaf is all blade (see Figs. \%,

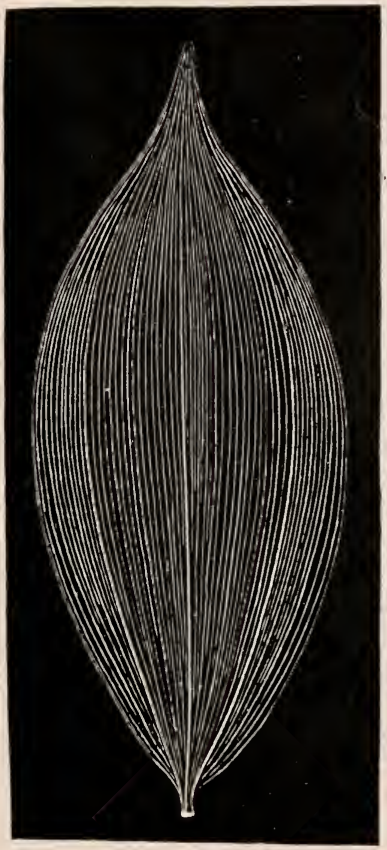
$8,18)$; frequently there is a longer or shorter leaf-stalk (petiole) which helps to put

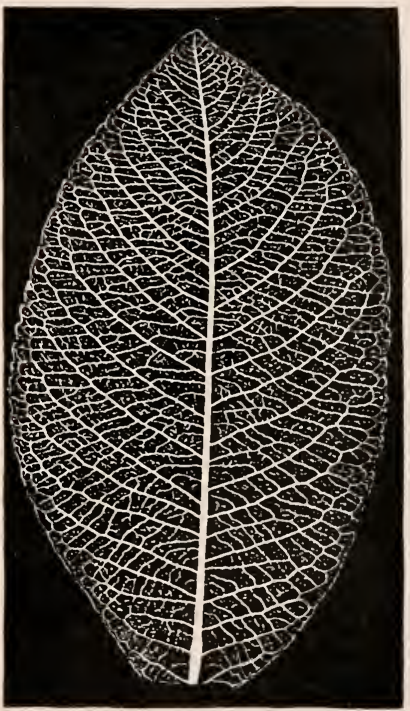

Fig. 25. Two types of leaf venation. 'The tigure to the left is a leaf of Solomon's seal (Polygonatum), and shows the principal veins parallel, the very minnte cross veinlets being invisible to the naked eye, being a monocotyl type. The figure to the right is a leaf of a willow, and shows netted veins, the main central vein (midrib) sending out a series of parallel branches, which are connected with one another by a network of veinlets, being a dicotyl type.-After Ettringsuausen.

the blade into better light-relation (see Figs. 1, 9, 1\%, 20, $26)$; and sometimes there are little leaf-like appendages (stipules) on the petiole where it joins the stem, whose funetion is not always clear. Upon examining the blade it is seen to consist of a green substance through which a 
fi amework of veins is variously arranged. The large veins which enter the blade send off smaller branches, and these send off still smaller ones, until the smallest veinlets are

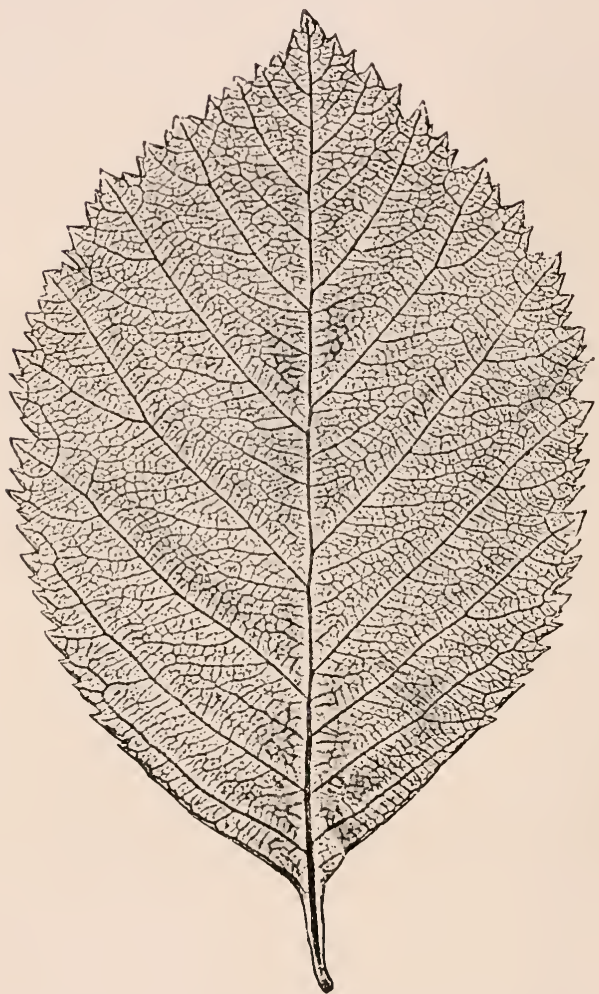

FIg. 26. A leaf of hawthorn, showing a short petiole, and a broad toothed blade with a conspicuous network of veins. Note the relation between the veins and the teeth.-After Strasburger. invisible, and the framework is a close network of branching reins. This is plainly shown bya "skeleton" leaf, one which has been so treated that all the green substance has disappeared, and only the network of veins remains. It will be noticed that in some leaves the reins and reinlets are very prominent, in other's only the main veins are prominent, while in some it is hard to detect any veins (see Figs. 25, 26).

29. Significance of leaf veins, - It is elear that the framework of veins is doing at least two things for the blade: (1) it mechanically supports the spread out green substance; and (2) it conducts material to and from the green substance. So complete is the network of veins that this 
FOLIAGE LEAVES: FUNCTION, STRUCTURE, ETC. 37

support and conduction are very perfect (see Fig. $2 \%$ ). It is also clear that the green substance thus supported and supplied with material is the important part of the leaf, the part that demands the light-relation. Study the various plans of the vein systems in Figs. 3, 9, 13, 18, 19, 20, 21, $25,26,51,70,76,82,83,92,161$.

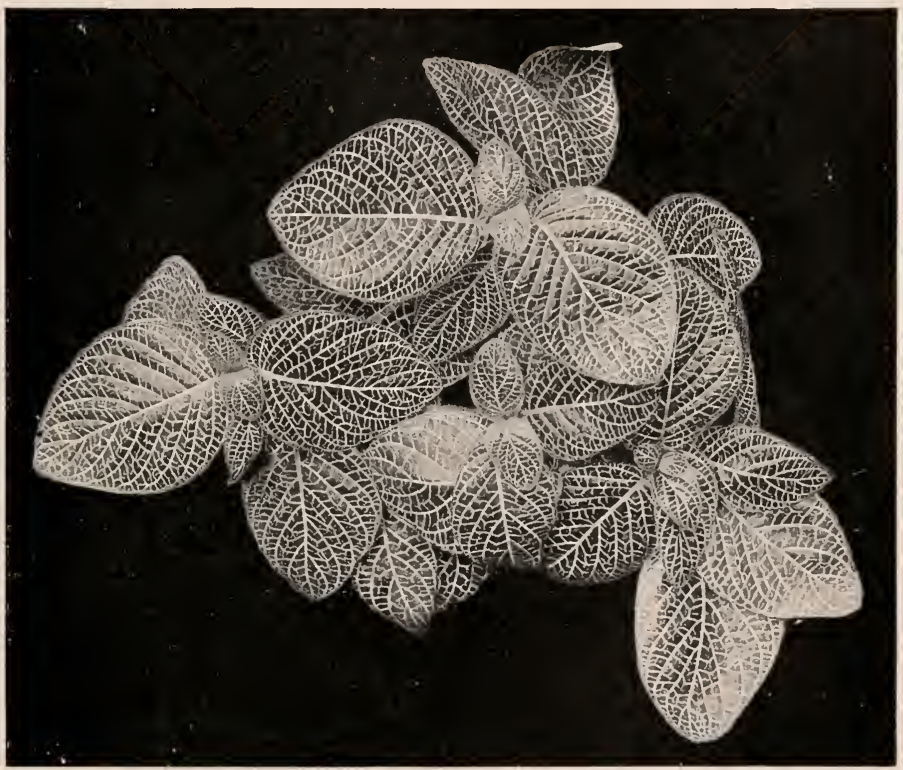

Fig. 27. A plant (Fittonia) whose leaves show a network of veins, and also an adjustment to one another to form a mosaic.

30. Epidermis.-If a thiek leaf be taken, such as that of a hyacinth, it will be found possible to peel off from its surface a delicate transparent skin (epidermis). This epidermis completely corers the leaf, and generally shows no green color. It is a protective covering, but at the same time it must not completely shut off the green substance beneath from the ontside. It is found, therefore, that three important parts of an ordinary foliage leaf are : (1) 
a network of veins; (2) a green substance (mesophyll) in the meshes of the network ; and (3) over all an epidermis.

31. Stomata.-If a compound microscope is used, some very important additional facts may be discovered. The

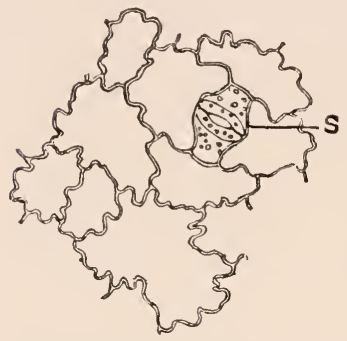

Fig. 28. Cells of the epidermis of Maranta, showing the interlocking walls, and a stoma $(s)$ with its two guardcells. thin, transparent epidermis is found to be made up of a layer of cells which fit closely together, sometimes dovetailing with each other. Curious openings in the epidermis will also be discovered, sometimes in very great numbers. Guarding each opening are two crescent-shaped cells, known as guard-cells, and between them a slit-like opening leads through the epidermis. The whole apparatus is known as a stoma (plural stomata), which really means "mouth," of which the guard-cells might be called the lips (see Figs. 28, 29 ). Sometimes stomata are found only on the under side of the leaf, sometimes only on the upper side, and sometimes on both sides.

The important fact about stomata is that the guard-cells can change their shape, and so regulate the size of the opening. It is not certain just why the guard-cells change their shape and just what stomata do for leaves. They are often called "breathing pores," but the name is very inappropriate. Stomata are not peculiar to the epidermis of foliage leaves, for they are found in the epidermis of any green part, as stems, young fruit, etc. It is evident, therefore, that they hold an important relation to green tissue which is covered by epidermis. Also, if we examine

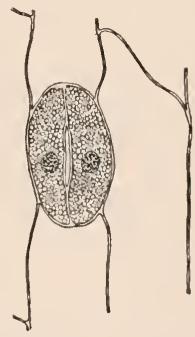

Fig. 29. A single stoma from the epidermis of a lily leaf, showing the two guard-cells full of chlorophyll, and the small slit-like opening between. 
foliage leaves and other green parts of plants which live submerged in water, we find that the epidermis contains no stomata. Therefore, stomata hold a definite relation to green parts covered by epidermis only when this epidermis is exposed to the air.

It wonld seem that the stomata supply open passageways for material from the green tissue through the epidermis to the air, or from the air to the green tissue, or both. It will be remembered, however, that quite a number of substances are taken into the leaf and given out from it, so that it is hard to determine whether the stomata are speeially for any one of these morements. For instance, the leaf gives out moisture in transpiration, oxygen in photosynthesis, and carbon dioxide in respiration ; while it takes in carbon dioxide in photosynthesis, and oxygen in respiration. It is thought stomata specially favor transpiration, and, if so, "breathing pores" is not a happy phrase, for they certainly assist in the other exchanges.

32. Mesophyll. - If a cross-section be made of an ordinary foliage leaf, such as that of a lily, the three leaf regions ean be seen in their proper relation to each other. Bounding the section above and below is the layer of transparent epidermal cells, pierced here and there by stomata, marked by their peculiar guarl-cells. Between the epidermal layers is the green tissne, known as the mesophyll, made up of cells which contain numerons small green bodies which give color to the whole leaf, and are known as chlorophyll bodies or chloroplasts.

The mesophyll cells are nsmally arranged differently in the upper and lower regions of the leaf. In the upper region the cells are elongated and stand npright, presenting their narrow ends to the upper leaf surface, forming the palisade tissue. In the lower region the cells are irregular, and so loosely arranged as to leave passageways for air between, forming the spongy tissue. The air spaces among the cells communicate with one another, so that a system of 
air chambers extends throughont the spongy mesophyll. It is into this system of air chambers that the stomata open, and so they are put into direct communication with the mesophyll or working cells. 'The peculiar arrangement of the upper mesophyll. to form the palisade tissue, has to do with the fact that that surface of the leaf is exposed to the direct rays of light. 'This light, so necessary to the mesophyll, is also dangerous for at least two reasons. If

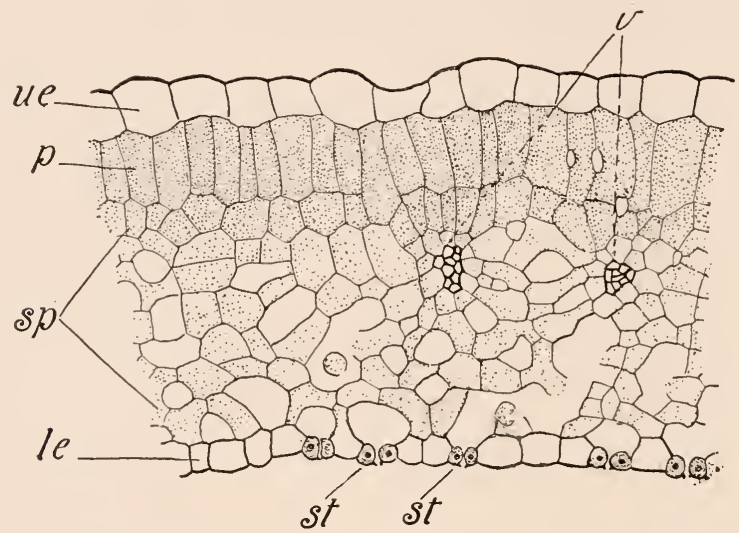

Fig. 30. A section through the leaf of lily, showing upper epidermis (ue), lower epidermis (le) with its stomata $(s t)$, mesophyll (dotted cells) composed of the palisade region $(p)$ and the spongy region $(s p)$ with air spaces among the cells, and two veins $(v)$ eut across.

the light is too intense it may destroy the chlorophyll, and the heat may dry out the cells. By presenting only narrow ends to this direct light the cells are less exposed to intense light and heat. Study Fig. 30.

33. Veins. - In the cross-section of the leaf there will also be seen here and there, embedded in the mesophyll, the cut ends of the veinlets, made up partly of thickwalled cells, which hold the leaf in shape and conduct material to and from the mesophyll (see Fig. 30). 
FOLIAGE LEAVES: FUNCTION, STRUCTURE, ETC. 41

\section{Leuf protection.}

34. Need of protection.-Such an important organ as the leaf, with its delicate active cells well displayed, is exposed to numerous dangers. Chief among these dangers are intense light, drought, and cold. All leaves are not exposed to these dangers. For example, plants which grow in the shade are not in danger from intense light; many

o.s.

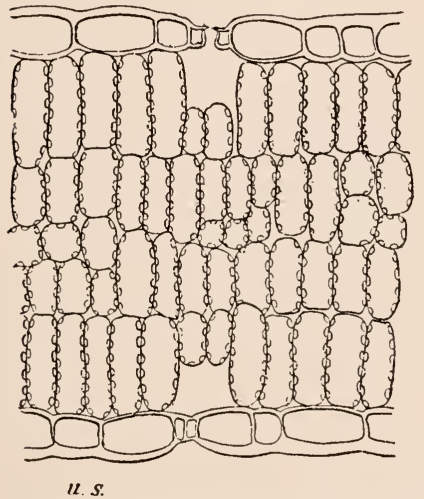

water plants are not in danger from drought ; and plants of the tropical lowlands are in no

FIg. 31. Sections through leaves of the same plant, showing the effect of exposure to light upon the structure of the mesophyll. In both cases $o s$ indicates upper surface, and $u s$ under surface. In the section at the left the growing leaf was exposed to direct and intense sunlight, and, as a consequence, all of the mesophyll cells have assumed the protected or palisade position. In the section at the right the leaf was grown in the shade, and none of the mesophyll cells have organized in palisacle fashion.-After StaHL.

danger from eold. The danger from all these somrces is beeause of the large surface with no great thickness of body, and the protection against all of them is practically the same. Most of the forms of protection can be reduced to two general plans: (1) the development of protective structures between the endangered mesophyll and the air ; (2) the diminution of the exposed surface.

35. Protective structures. - The palisade arrangement of mesophyll may be regarded as an adaptation for protection, 
but it usually occurs, and does not necessarily imply extreme conditions of any kind. However, if the eells of the palisade tissue are unusually narrow and elongated, or

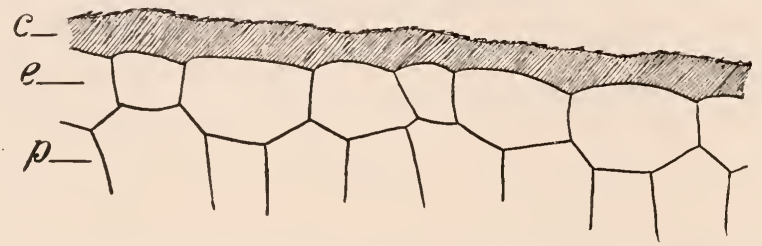

FIG. 32. Section through a portion of the leaf of the yew (Taxus), showing cuticle $(c)$, epidermis $(e)$, and the upper portion of the palisade cells $(p)$.

form two or three layers, we might infer the probability of exposure to intense light or drought. 'The accompanying illustration (Fig. 31) shows in a striking way the effect of light intensity upon the structure of the mesophyll, by contrasting leaves of the same plant exposed to the extreme conditions of light and shade.

The most usual structural adaptations, howerer, are connected with the epidermis. The outer walls of the epidermal cells may become thickened, sometimes excessively

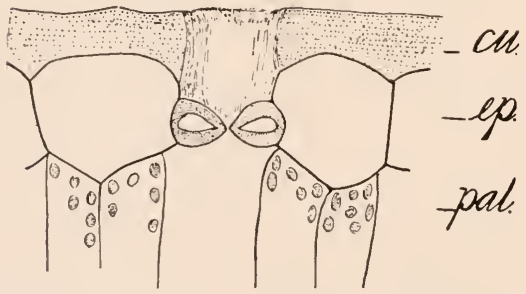

Fig. 33. Section through a portion of the leaf of carnation, showing the heary cuticle (cu) formed by the outer walls of the epidermal cells $(e p)$. Through the cuticle a passageway leads to the stoma, whose two guard-cells are seen lying between the two epidermal cells shown in the figure. Below the epidermal cells some of the palisade cells ( $p a l)$ are shown containing chloroplasts, and below the stoma is seen the air chamber into which it opens. so; the other epidermal walls may also become more or less thickened; or even what seems to be more than one epidermal layer is found protecting the mesophyll. If the outer walls of the epidermal cells continue to thicken, the outer region of the thick wall loses its structure and forms the cuticle, which is one of the 


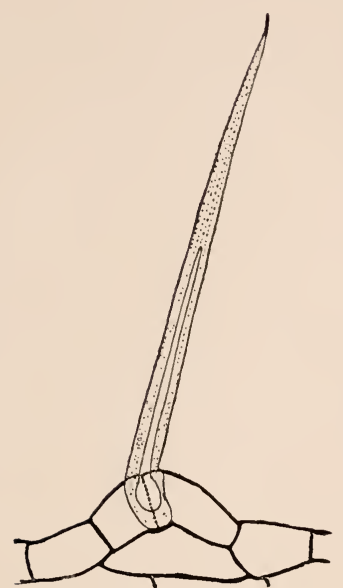

Fig. 34. A hair from the leaf of Potentilla. It is seen to grow out from the epidermis.

best protective substances (see Fig. 3?). Sometimes this cuticle becomes so thick that the passageways through it leading down to the stomata become regular canals (see Fig. 33).

Another very common protective structure upon leares is to be found in the great variety of hairs developed by the epidermis. These may form but a slightly downy covering, or the leaf may be covered by a woolly or felt-like mass so that the epidermis is entirely concealed. The common mullein is a good illustration of a feltcovered leaf (see Fig. 36). In cold or dry regions the hairy covering of leaves is very noticeable, often giving them a brilliant silky white or bronze look (see Figs. 34, 35). Sometimes, instead of a hair-like covering, the epidermis develops scales of various patterns, often overlapping, and forming an excellent protection (see Fig. 3\%). In all these cases it should be remembered that these hairs and scales may serve other purposes also, as well as that of protection.

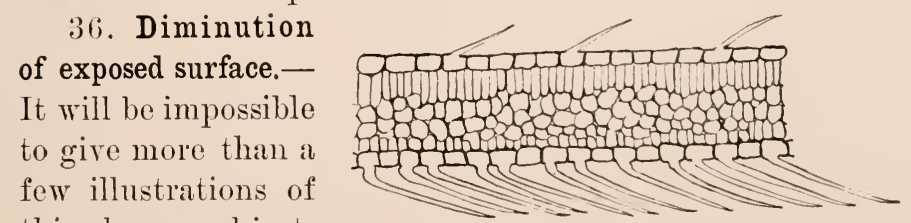
this large subject. In very dry regions it has always been noticed that the leaves are small and

Fig. 35. A section through the leaf of bush clover (Lespedeza), showing upper and lower epidermis, palisade cells, and eclls of the spongy region. The lower epidermis produces numerous hairs which bend sharply and lie along the leaf surface (appressed), forming a close covering. 


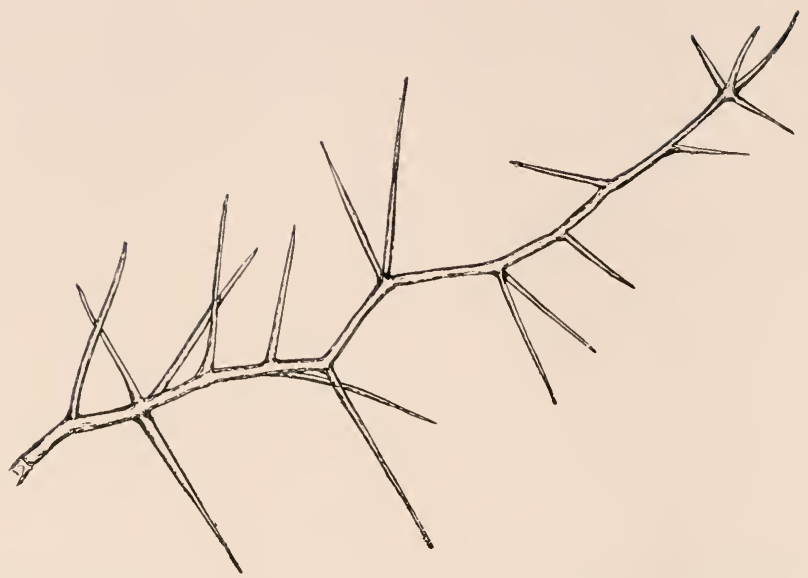

FIG. 36. A branching hair from the leaf of common mullein. The whole plant has a felt-like covering composed of such hairs.

comparatively thick, although they may be very numerous (see Figs. 4, 17\%). In this way each leaf exposes a small

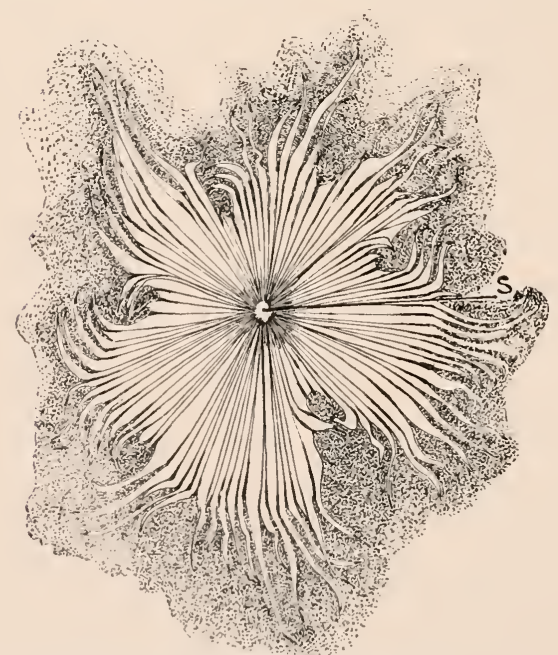

FIg. 37. A scale from the leaf of Shepherdia. These scales overlap and form a complete covering. surface to the drying air and intense sunlight. In our southwestern dry regions the cactus a bounds, plants which have reduced their leaves so much that they are no longer used for chlorophyll work, and are not usually recognized as leaves. In their stead the globular or cylindrical or flattened stems are green and do leaf work (Figs. 

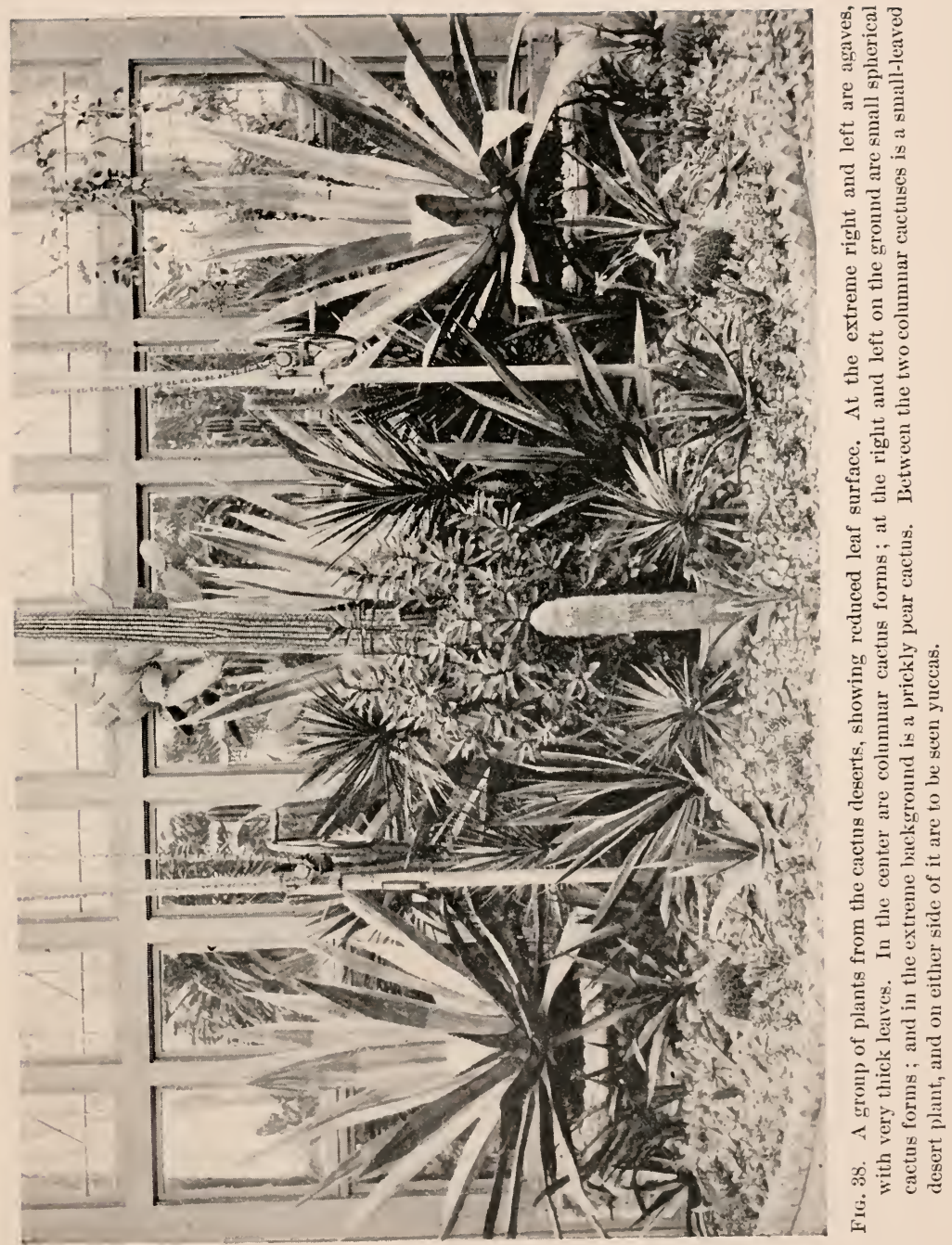


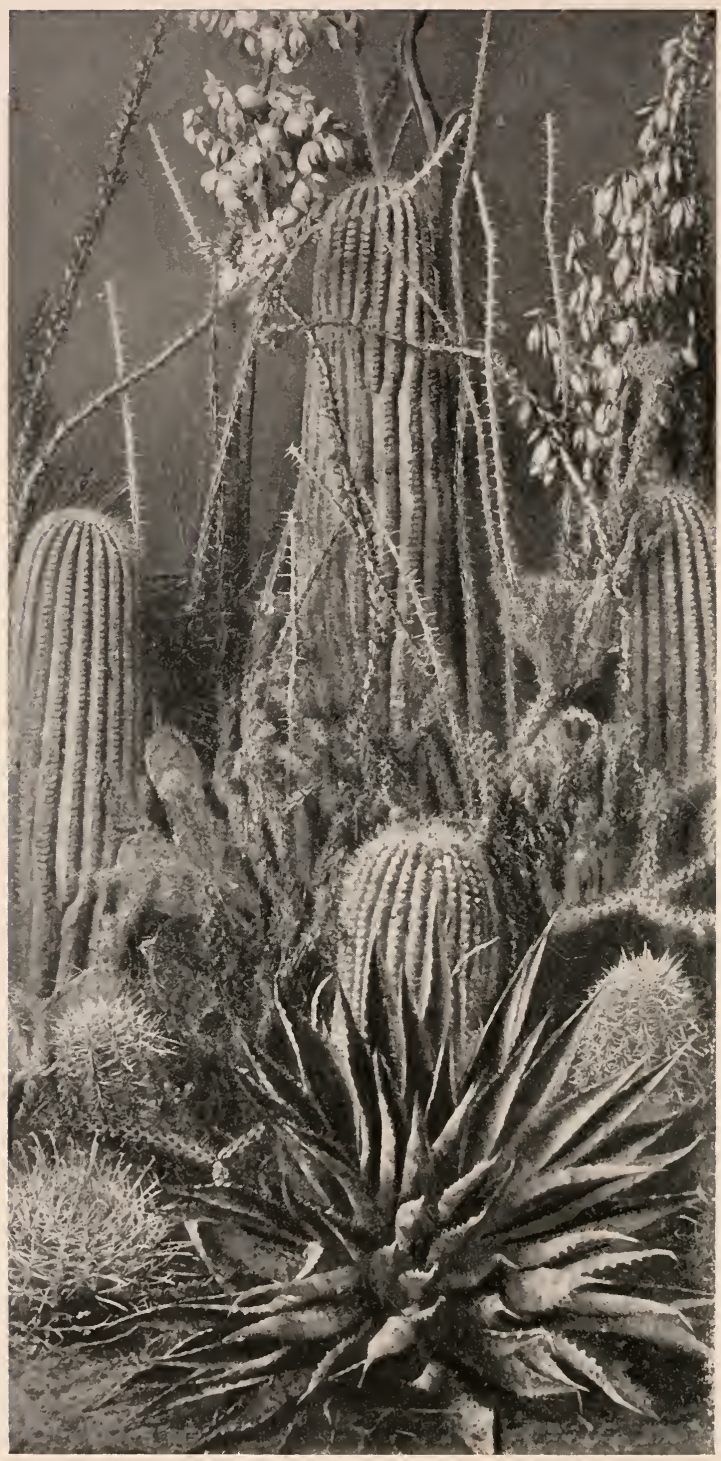

Fig. 39. A group of cactus forms (slender cylindrical, columnar, and globular), all of them spiny and without leaves; an agave in front ; clusters of yucca flowers in the background. 
$38,39,40,190,191,192,193)$. In the same regions the agaves and yuccas retain their leaves, but they become so thick that they serve as water reservoirs (see Figs. 38, 39,

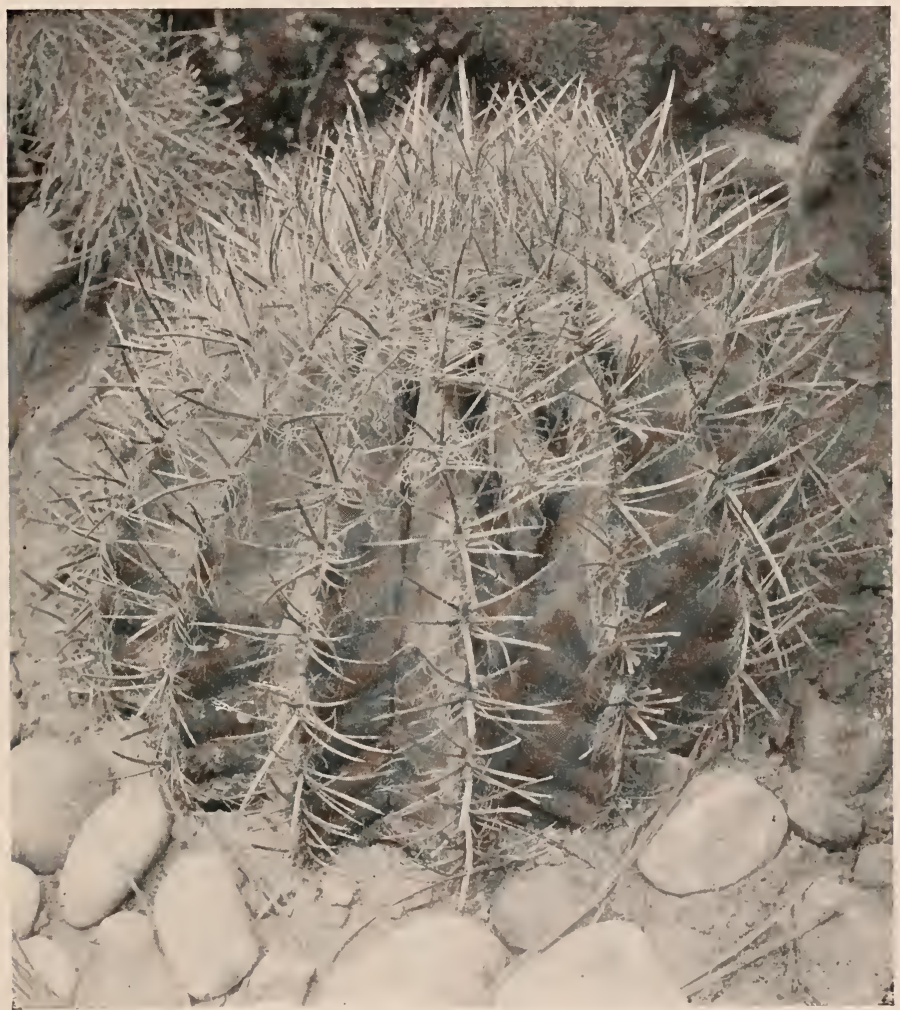

Fig. 40. A globular cactus, showing the ribbed stem, the strong spines, and the entire absenee of leaves.

194). In all these cases this rednced surface is supplemented by palisade tissue, very thick epidermal walls, and an abundant cuticle.

3\%. Rosette arrangement.- The rosette arrangement of leaves is a very common method of protection used by 
small plants growing in exposed situations, as bare rocks and sandy ground. 'The cluster of leaves, flat upon the ground, or nearly so, and more or less overlapping, is very effectively arranged for resisting intense light or drought or cold (see Figs. 11, 12, 48).

38. Protective positions. - In other cases, a position is assumed by the leaves which directs their flat surfaces so that they are not exposed to the most intense rays of light. 'The so-called "com-
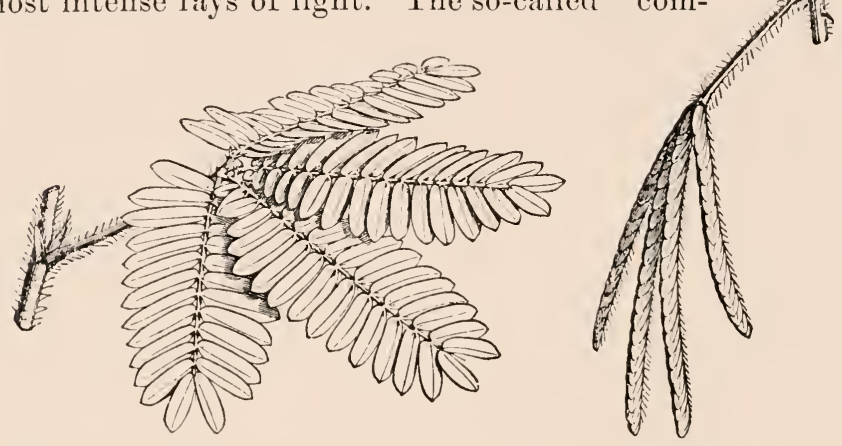

FIG. 41. A leaf of a sensitive plant in two conditions. In the figure to the left the leaf is fully expanded, with its four main divisions and numerous leaflets well spread. In the figure to the right is shown the same leaf after it has been "shocked" by a sudden touch, or by sudden heat, or in some other way. The leaflets have been thrown together forward and upward; the four main divisions have been moved together; and the main leaf-stalk has been directed sharply downward. The whole change has very much reduced the surface of exposure.After Duchartre.

pass plants," already mentioned, are illustrations of this, the leaves standing elgewise and receiving on their surface the less intense rays of light (see Figs. 5, 1\%0). In the dry regions of Australia the leaves on many of the forest trees and shrubs have this characteristic edgewise position, known as the profile position, giving to the foliage a very curious appearance.

Some leaves have the power of shifting their position according to their needs, directing their flat surfaces toward the light, or more or less inclining them, according 


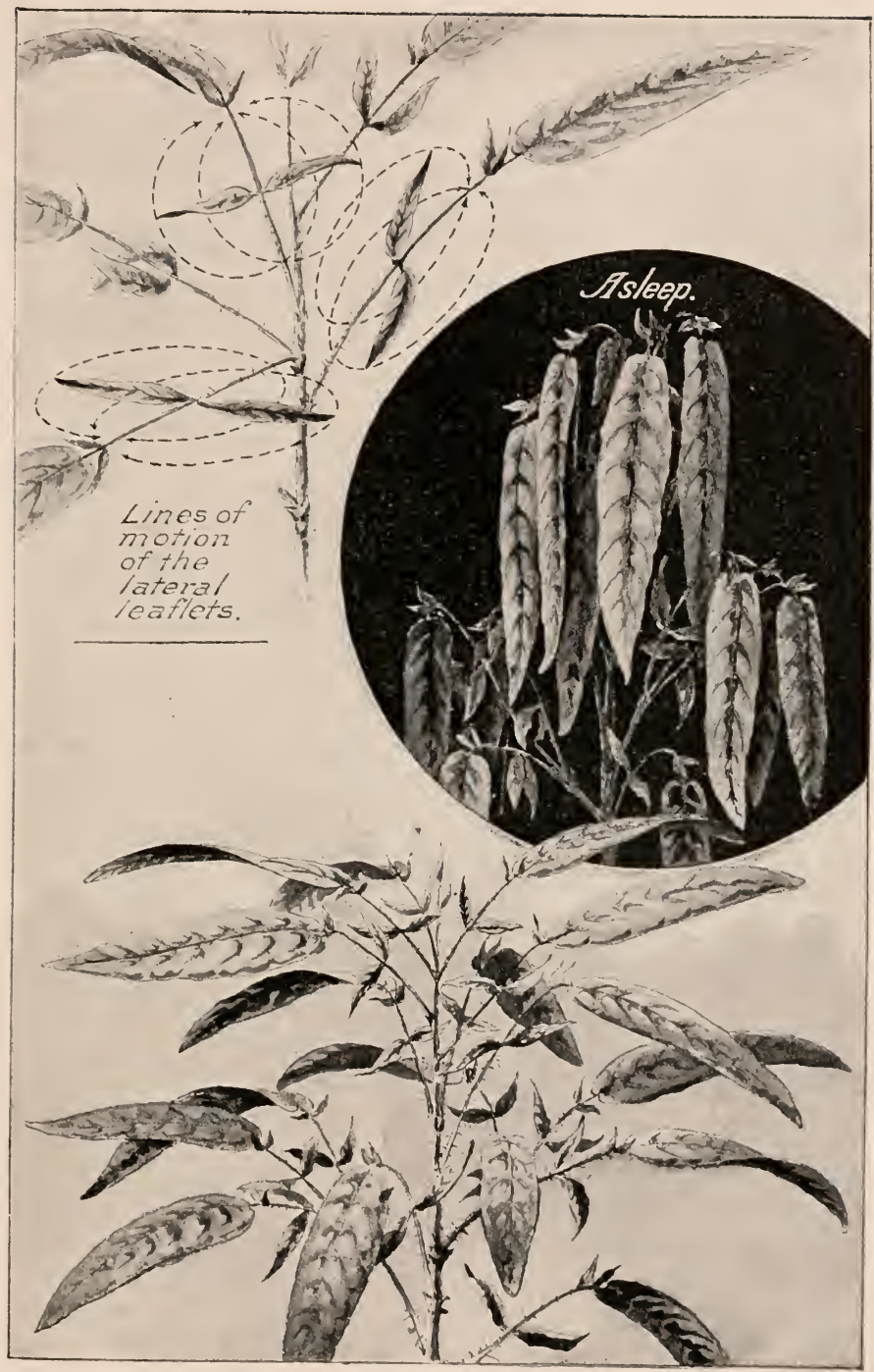

Fig. 42. The telegraph plant (Desmodium gyrans). Each leaf is made up of three leaflets, a large terminal one, and a pair of small lateral ones. In the lowest figure the large leaflets are spread out in their day position ; in the central figure they are turned sharply downward in their night position. The name of the plant refers to the peculiar and constant motion of the pair of lateral leaflets, each one of which describes a curve with a jerking motion, like the sccond-hand of a watch, as indicated in the uppermost figure. 
to the danger. Perhaps the most completely adapted leaves of this kind are those of the "sensitive plants," whose leares respond to various external influences by changing their positions. The common sensitive plant abounds in dry regions, and may be taken as a type of such plants (see irigs. 4, 41, 171). The leaves are divided into very numerous small leaflets, sometimes very small, which stretch in pairs along the leaf branches. When drought approaches, some of the pairs of leaflets fold to-
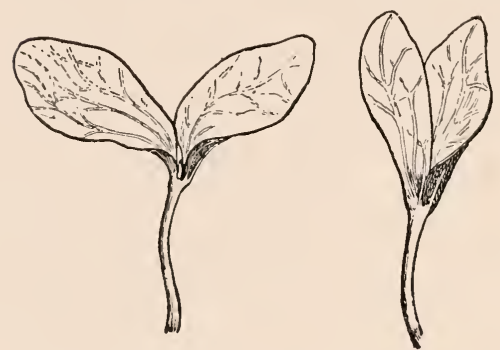

Fig. 43. Cotyledons of squash seedling, showing positions in light (left figure) and in darkness (right figure).-After AtKinsox. gether, slightly redueing the surface exposure. As the drought continues, more leaflets fold together, then still others, until finally all the leaflets may be folded together, and the leaves themselves may bend against the stem. It is like a sailing ressel gradually taking in sail as a storm approaches, until finally nothing is exposed, and the ressel weathers the storm by presenting only bare poles. Sensitive plants can thus regulate the exposed surface very exactly to the need.

Such motile leaves not only behave in this mammer at the coming of drought, but the positions of the leaflets are shifted throughont the day in reference to light, and at night a very characteristic position is assumed (see Figs. :2, $3,42)$, once called a "sleeping position." The danger from night exposure comes from the radiation of heat which oceur's, which may chill the leaves to the danger point. The night position of the leaflets of Oxalis has been referred to already (see \$14). Similar changes in the direction of the leaf planes at the coming of night may be observed in most of the Leguminose, eren the common 
white elover displaying it. It can be observed that the expanded seed leaves (cotyledons) of many young germinating plants shift their positions at night (see Fig. 43), often assuming a rertical position which brings them in contact with one another, and also covers the stem bud (plumule).

Certain leaves with well-dereloped protective struetures are able to endure the winter, as in the case of the so-ealled evergreens. In the case of juniper, however, the winter and summer positions of the leaves are quite different (see Fig. 44). In the winter the leaves lie close against the stem and overlap one another; while with the coming of warmer conditions they become widely spreading.

39. Protection against rain.-It is also necessary for leaves to aroid becoming wet by rain. If the water is allowed to soak in there is clanger of filling the stomata and interfering with the air exchanges. Hence it will be noticed that most leares are able to shed water, partly by their positions, partly by their structure. In many plants the leaves are so ar-

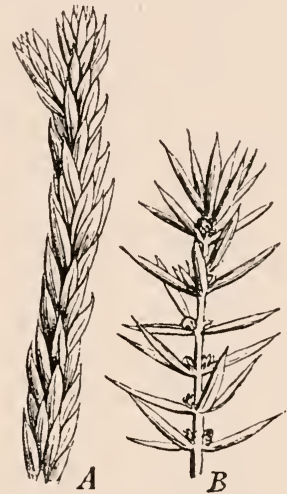

Fig. 44. Two twigs of juniper, showing the effect of heat and cold upon the positions of the leaves. The ordinary protected winter position of the leaves is slown by $A$; while in $B$, in response to warmer concitions, the leaves have spread apart and have become freely exposed.-After Wakmixg. ranged that the water rums off towards the stem and so reaches the main root system : in other plants the rain is shed outwards, as from the eaves of a house.

Some of the structures which prevent the rain from soaking in are a smooth epidermis, a cuticle layer, waxy secretions, felt-like coverings, ete. Interesting experiments may be performed with different leares to test their power of shedding water. If a gentle spray of water is allowed to play upon different plants, it will be observed 
that the water glances off at once from the surfaces of some leares, runs off more slowly from other's, and may be more or less retained by others.

In this same comnection it should be noticed that in most horizontal leaves the two surfaces differ more or less in appearance, the upper usually being smoother than the lower, and the stomata occurring in larger numbers, sometimes exclusively, upon the under surface. While these differences doubtless have a more important meaning than protection against wetting, they are also suggestive in this connection.

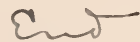




\section{CHAP'TER IV.}

\section{SHOOTS.}

40. General characters. - The term shoot is used to include both stem and leaves. Among the lower plants, such as the alga and toadstools, there is no distinet stem and leaf. In such plants the working body is spoken of as the thallus, which does the work done by both stem and leaf in the higher plants. These two kinds of work are separated in the higher plants, and the shoot is differentiated into stem and leaves.

41. Life-relation.-In seeking to discover the essential life-relation of the stem, it is evident that it is not necessarily a light-relation, as in the case of the foliage leaf, for many stems are subterranean. Also, in general, the stem is not an expanded organ, as is the ordinary foliage leaf. This indicates that whatever may be its essential life-relation it has little to do with exposure of surface. It becomes plain that the stem is the great leaf-bearing organ, and that its life-relation is a leaf-relation. Often stems branch, and this increases their power of producing leares.

In classifying stems, therefore, it seems natural to use the kind of leaves they bear. From this standpoint there are three prominent kinds of stems : (1) those bearing foliage leares; (2) those bearing scaly leaves; and (3) those bearing floral leares. There are some peculiar forms of stems which do not bear leaves of any kind, but they need not be included in this general riew. 


\section{A. Stems bearing foliage leaves.}

42. General character.- $\Lambda$ s the purpose of this stem is to display foliage leares. and as it has been discovered that the essential life-relation of foliage leaves is the light-relation, it follows that a stem of this type must be able to relate its leares to light. It is, therefore, commonly aerial, and that it may properly display the leaves it is generally elongated, with its joints (nodes) bearing the leares well separated (see Figs. 1, 4, 18, 20).

The foliage-bearing stem is generally the most conspicuous part of the plant and gives style to the whole body. One's impression of the forms of most plants is obtained from the foliage-bearing stems. Such stems have great range in size and length of life, from minute size and very short life to huge trees which may enclure for centuries. Branching is also quite a feature of foliage-hearing stems ; and when it occurs it is evident that the power of displaying foliage is correspondingly increased. Certain prominent types of foliage-bearing stems may be considered.

43. The subterranean type.-It may seem strange to include any subterranean stem with those that bear foliage, as such a stem seems to be away from any light-relation. Ordinarily subterranean stems send foliage-bearing branches above the surface, and such stems are not to be classed as foliage-bearing stems. But often the only stem possessed by the plant is subterranean, and no branches are sent to the surface. In such cases only foliage leaves appear above ground, and they come directly from the subterranean stem. The ordinary ferns furnish a conspicuous illustration of this habit, all that is seen of them above ground being the characteristic leaves, the commonly called "stem" being only the petiole of the leaf (see Figs. 45, 46, 144). Many seed plants can also be found which show the same habit, especially those which flower early in the spring. This cannot be regarded as a very favorable type of stem for 


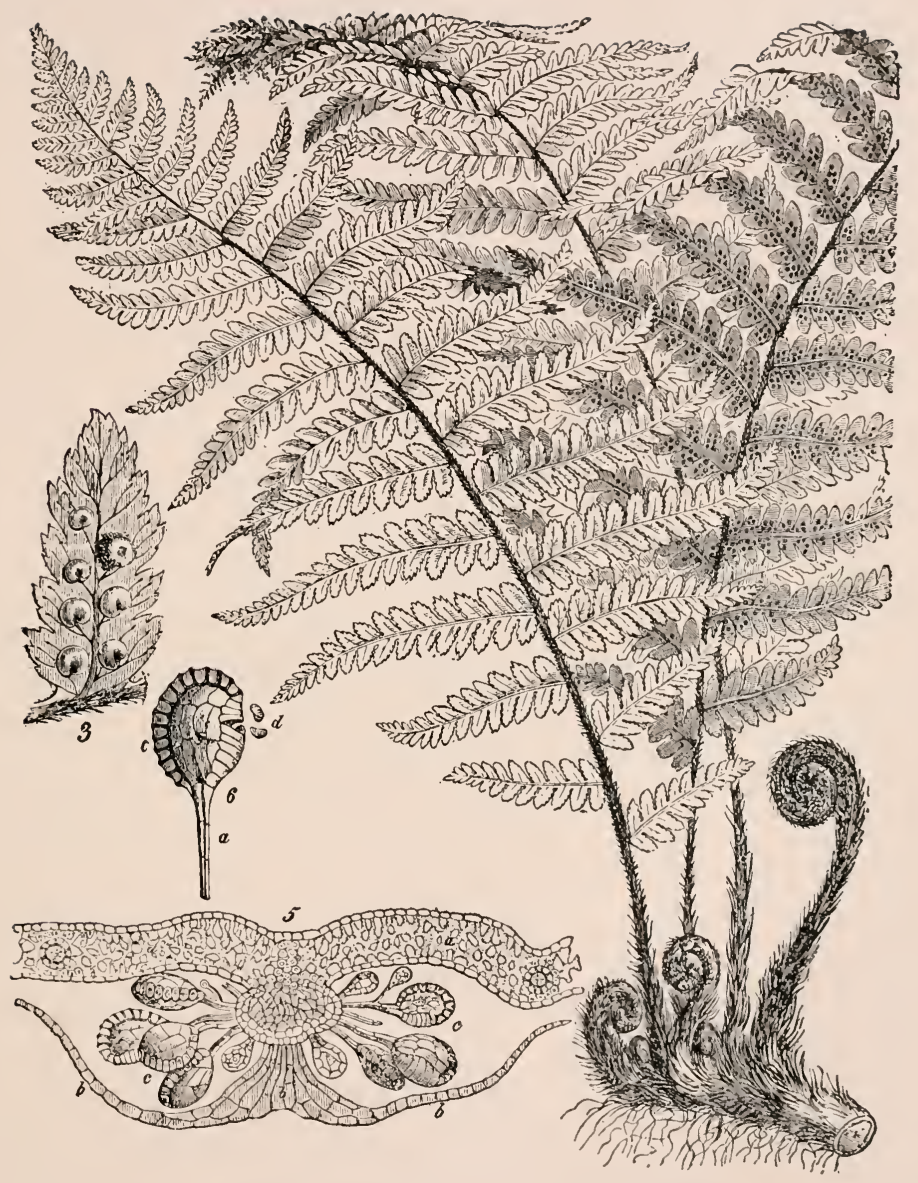

Fig. 45. A fern (Aspidium), showing three large branching leaves coming from a horizontal subterranean stem (rootstock); growing leaves are also shown, which are gradually unrolling. The stem, young leaves, and petioles of the large leaves are thickly covered with protecting hairs. The stem gives rise to numerous small roots from its lower surface. The figure marked 3 represents the under surface of a portion of the leaf, showing seven groups of spore cases; at 5 is represented a section through one of these groups, showing how the spore cases are attached and protected by a flap) ; while at 6 is represented a single spore case opening and discharging its spores, the heavy spring-like ring extending along the back and over the top.-After Wossidio. 
leaf display, and as a rule such stems do not produce many foliage leaves, but the leaves are apt to be large.

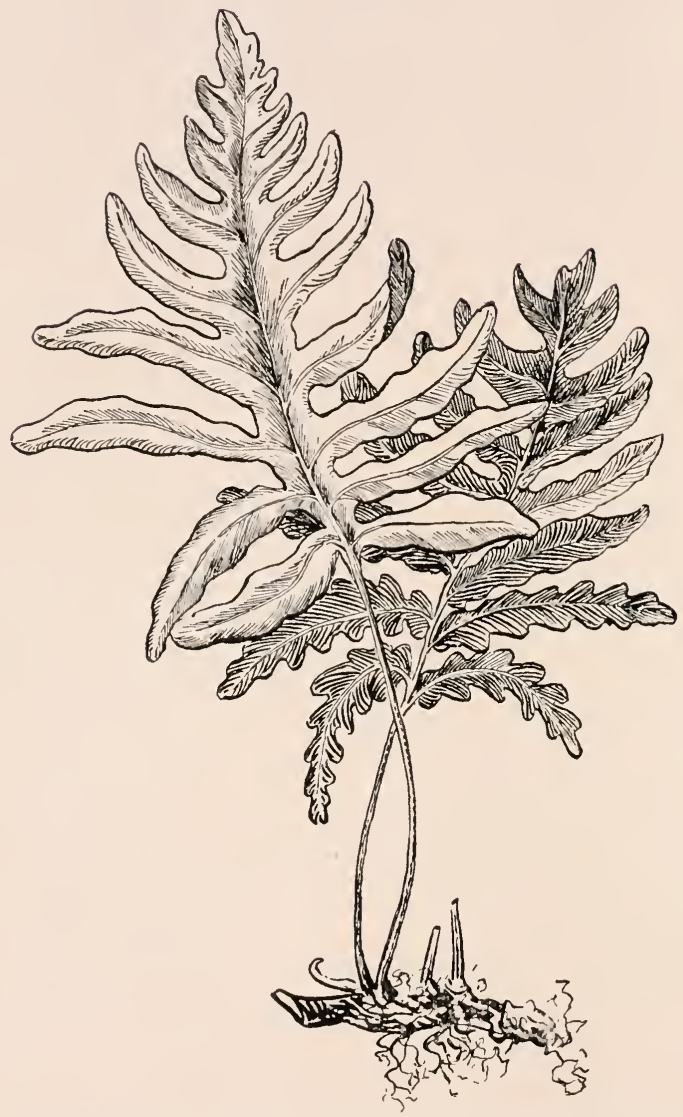

FIG. 46. A common fern, showing the underground stem (rootstock), which sends the few large foliage leaves above the surface.-After Atinsson.

The subterranean position is a good one, however, for purposes of protection against cold or drought, and when the foliage leaves are killed new ones can be put out by 
the protected stem. This position is also taken advantage of for comparatively safe food storage, and such stems are apt to become more or less thickened and distorted by this food deposit.

44. The procumbent type.-In this ease the main body of the stem lies more or less prostrate, although the advancing tip is usually erect. Such stems may spread in all

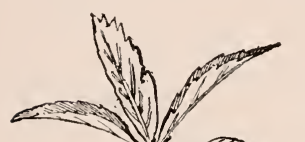
directions, and become interworen into a mat or carpet. They are found especially on sterile and exposed soil,

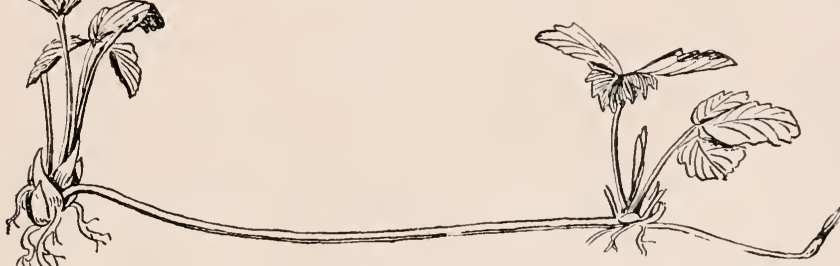

Fig. 4\%. A strawberry plant, showing a runner which has developed a new plant, which in turn has sent out another runner.-After Seubert.

and there may be an important relation between this fact and their habit, as there may not be sufficient building material for erect stems, and the erect position might result in too much exposure to light, or heat, or wind, ete. Whatever may be the cause of the procumbent habit, it has its adrantages. As compared with the ereet stem, there is economy of building material, for the rigid structures to enable it to stand upright are not necessary. On the other hand, such a stem loses in its power to display leaves. Instead of being free to put out its leaves in every direction, one side is against the ground, and the space for leaves is diminished at least one-half. All the leaves it bears are necessarily directed towards the free side (see Fig. 18).

We may be sure, however, that any disadrantage coming from this unfarorable position for leaf display is orerbalanced by advantages in other respects. The position is 


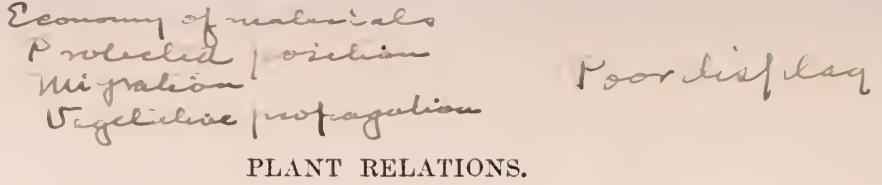

certainly one of protection, and it has a further advantage in the way of migration and regetative propagation. As the stem advances over the ground, roots strike out of the nodes into the soil. In this way fresh anchorage and new soil supplies are secured; the old parts of the stem may

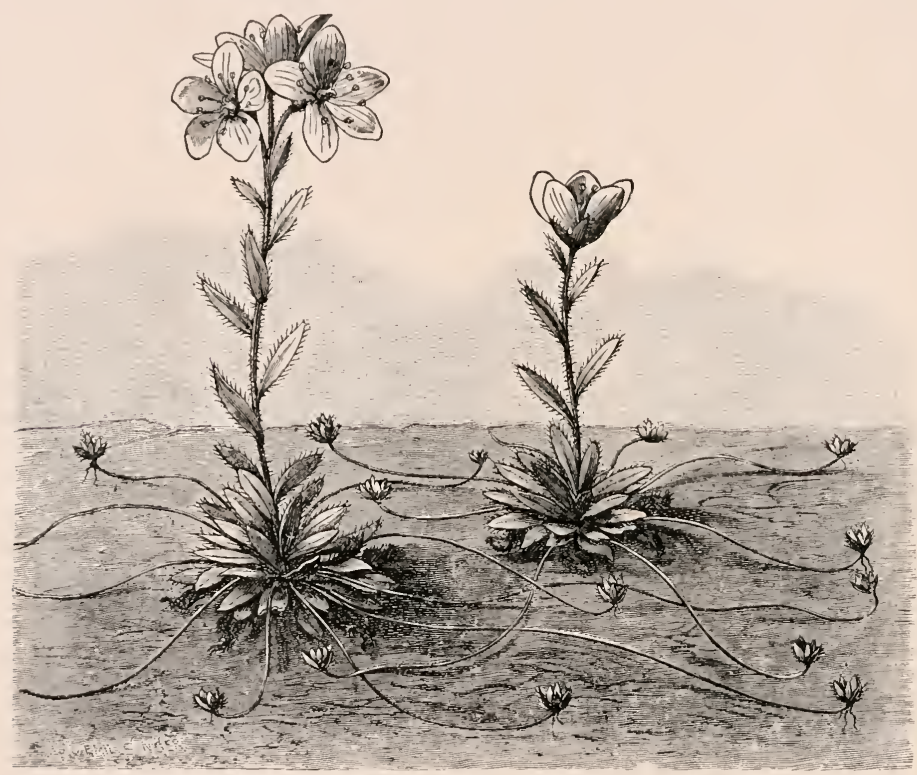

Fig. 48. Two plants of a saxifrage, showing rosette habit, and also the numerous runners sent out from the base, which strike root at tip and produce new plants. -After líerner.

dic, but the newer portions have their soil comnection and continue to live. So effective is this habit for this kind of propagation that plants with erect stems often make use of it, sending out from near the base special prostrate branches, which advance over the ground and form new plants. A very familiar illustration is furnished by the strawberry plant, which sends out peeuliar naked "rumners" to strike root and form new plants, which then become 


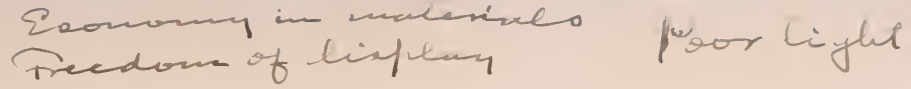

SHOOTS.

independent plants by the dying of the runners (see Figs. $47,48)$.

45. The floating type.-In this case the stems are sustained by water. Numerous illustrations can be found in small inland lakes and slow-moving streams (see Fig. 49 ). Beneath the water these stems often seem quite erect, but

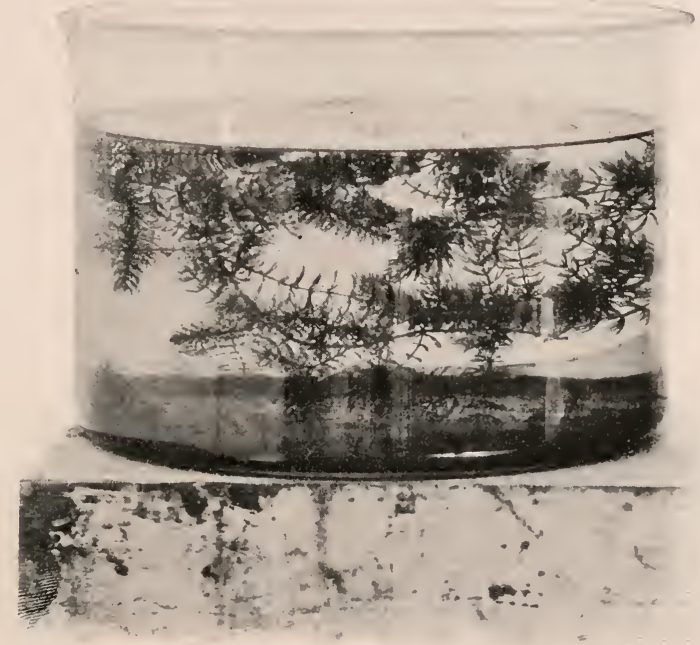

Fig. 49. A submerged plant (Ceratophyllum) with floating stems, showing the stem joints bearing finely divided leaves.

when taken ont they collapse, lacking the buoyant power of the water. Growing free and more or less upright in the water, they seem to have all the freedom of erect stems in displatying foliage leaves, and at the same time they are not ealled upon to build rigid structures. Eeonomy of building material and entire freedom to display foliage would seem to be a happy combination for plants. It must be noticed, however, that another very important condition is introduced. 'To reach the leaf surfaces the light must pass through the water, and this diminishes its intensity so 
greatly that the working power of the leaves is reduced. It no rery great depth of water a limit is reached, beyond which the light is no longer able to be of service to the leaves in their work. Hence it is that water plants are

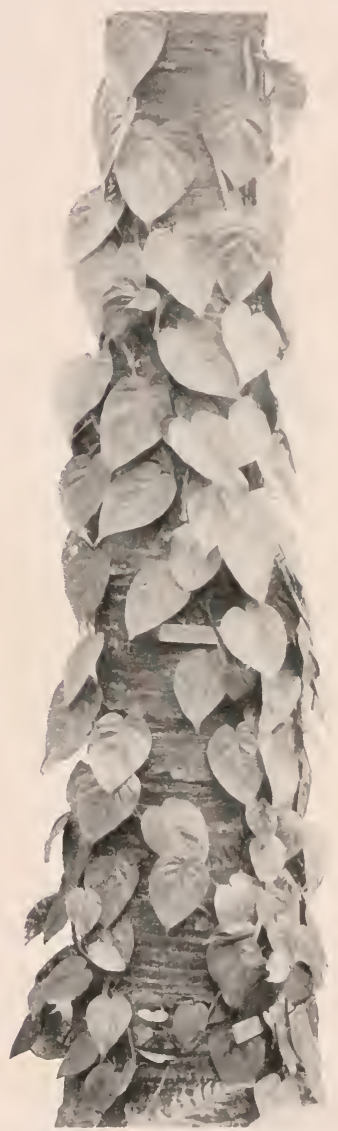

Fis. 50. A 1 ine or liana climbing the trunk of a tree. The leaves are all adjusted to face the ligl:t and to avoid shading one allother as far as possible. restricted to the surface of the water, or to shoal places; and in such places regetation is rery abundant. Water is so serious an impediment to light that very many plants bring their working leaves to the surface and float them, as seen in water lilies, thus obtaining light of undiminished intensity.

46. The climbing type-Climbing stems are dereloped especially in the tropics, where the regetation is so dense and overshadowing that many stems hare learned to climb upon the bodies of other plants, and so spread their leares in better light (see Figs. 50, 55, 98, 212). (ireat woody rines fairly interlace the regetation of tropical forests, and are known as "lianas," or "lianes." The same habit is noticeable, also, in our temperate regetation, but it is by no means so extensively displayed as in the tropies. There are a good many forms of climbing stems. Remembering that the habit refers to one stem depending upon another for mechanical support, we may include many hedge plants in the 
list of climbers. In this case the stems are too weak to stand alone, but by interlacing with one another they may keep an upright position. 'There are stems, also, which climb by twining about their support, as the hop vine and

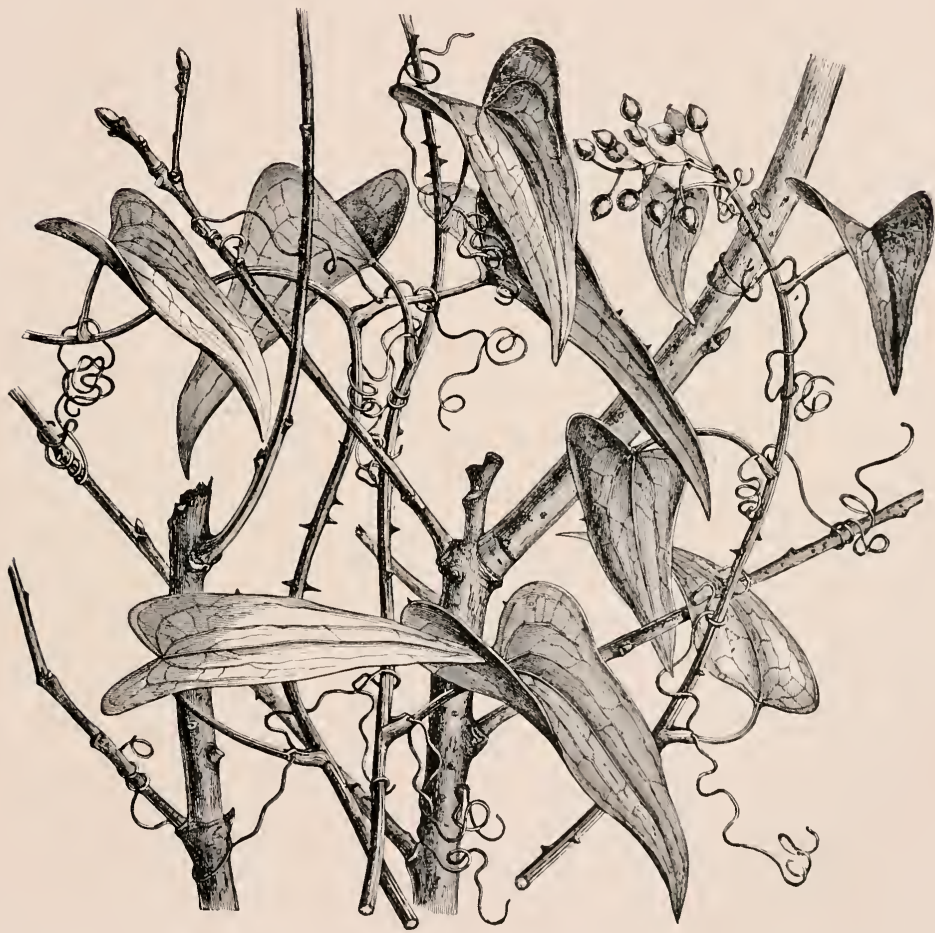

Fig. 51. A cluster of smilax, showing the tendrils which enable it to climb, and also the prickles.-After KerNer.

morning glory ; others which put out tenchils to grasp the support (see Figs. 51, 5:), as the graperine and star cucumber; and still others which climb by sending ont suckers to act as holdfasts, as the woodbine (sce Figs. 53, 54). In all these cases there is an attempt to reach towards 
the light without dereloping such structures in the stem as would enable it to stand upright.

4\%. The erect type-This type seems altogether the best adapted for the proper display of foliage leaves. Leaves

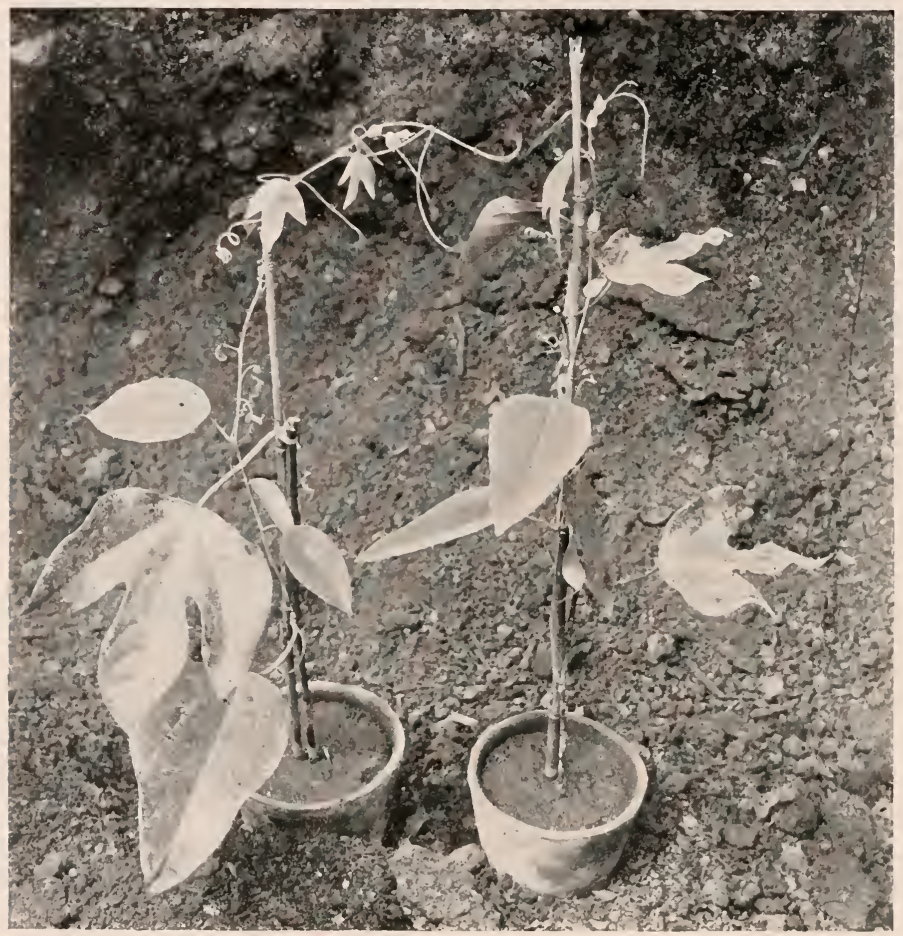

Fıg. 52. Passion-flower vines elimbing supports by means of tendrils, which may be seen more or less extended or coiled. The two types of leaves upon a single stem may also be noted.

can be sent ont in all directions and carried upward towards the light; but it is at the expense of developing an elaborate mechanical system to enable the stem to retain this position. There is an interesting relation between these erect bodies and zones of temperature. At high alti- 


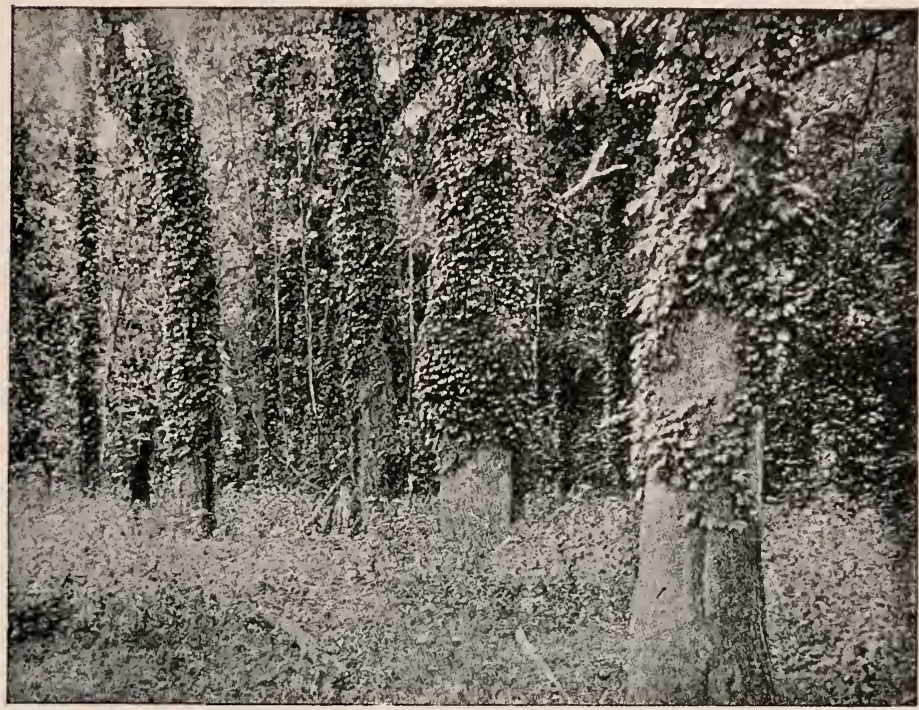

Fig. 53. Woodbine (Ampelopsis) in a deciduous forest. The tree trunks are almost covered by the dense masses of woodbine, whose leaves are adjusted so as to form compact mosaics. A lower stratum of vegetation is visible, composed of shrubs and tall herbs, showing that the forest is somewhat open.-After Scurmer.

tudes or latitudes the subterranean and prostrate types of foliage-bearing stems are most common: and as one passes to lower altitudes or latitudes the erect stems become more numerons and more lofty. Among stems of the ereet type the tree is the most impressive, and it has dereloped into a great variety of forms or "habits." Any one recognizes the great difference in the habits of the pine and the elm (see Figs. 56, $5 \%, 58,59)$, and many of our

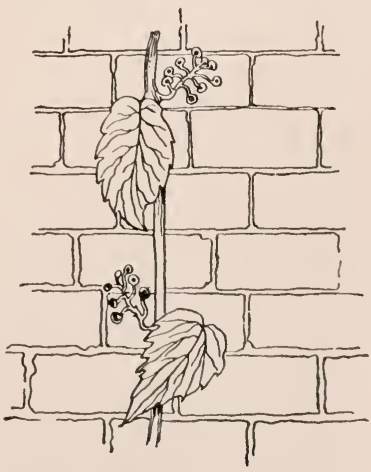

Fic. 54. A portion of a woodbine (Ampelopsis). The stem tendrils have attached themselves to a smooth wall by means of disk-like suckers.-After Strasiurgek. 


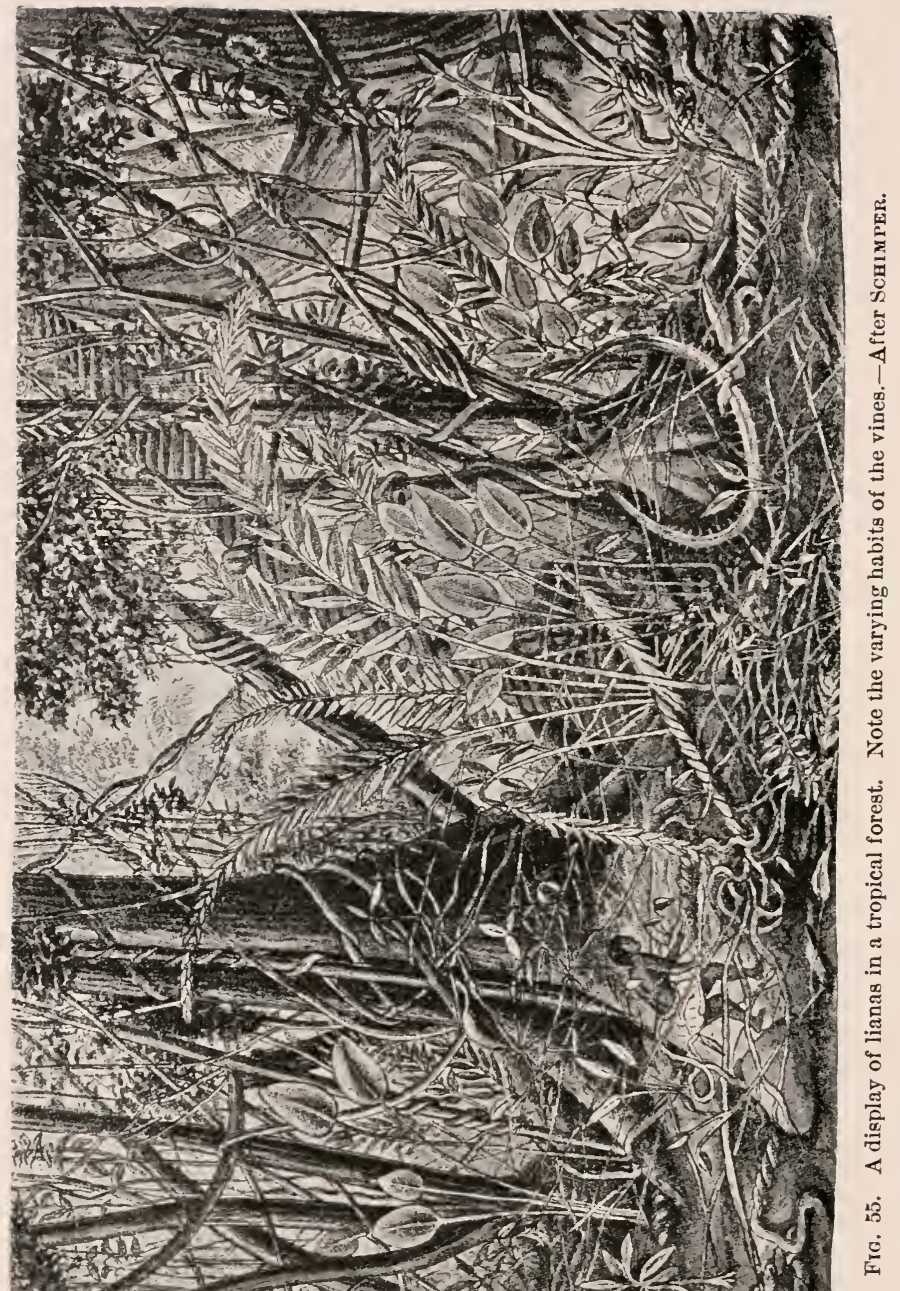




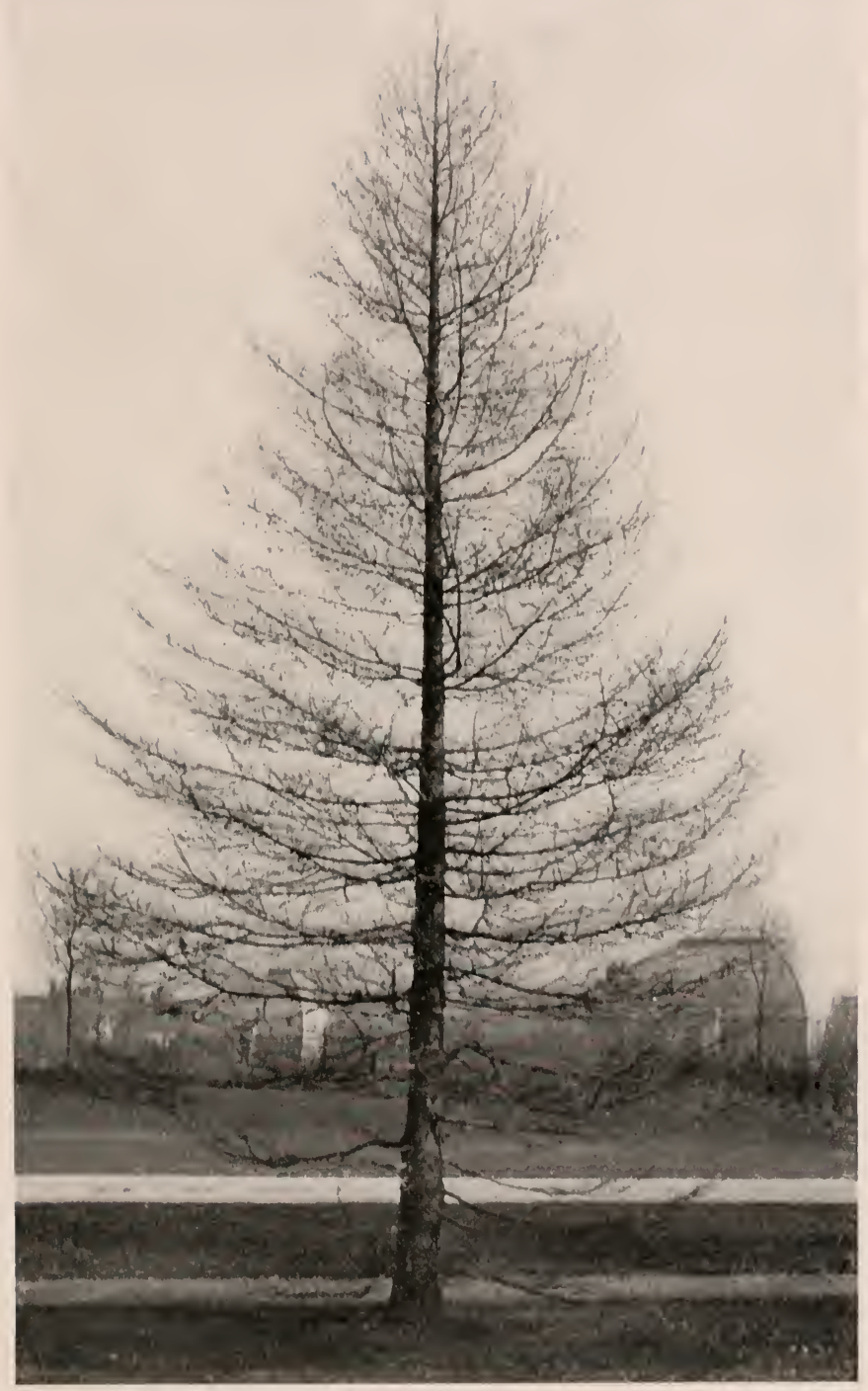

Fra. 56. A tree of the pine type (larch), showing the continuous central shaft and the horizontal branches, which tend to become more upright towards the top of the tree. The general outline is distinctly conical. The larch is peculiar among such trees in periodically shedding its leaves. 


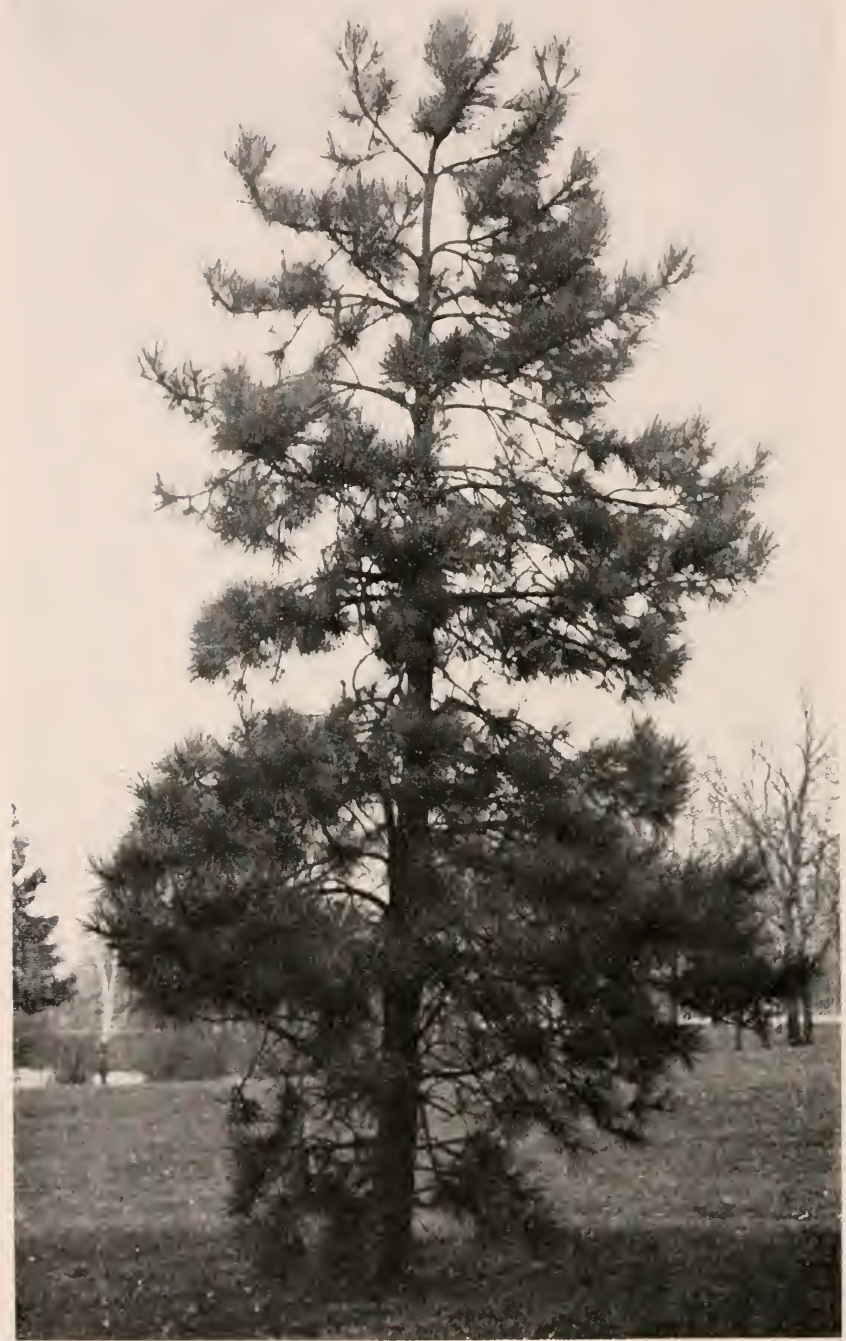

FIG. 5\%. A pine tree, showing the central shaft and also the bunching of the needle leaves toward the tips of the branches where there is the best exposure to light. 
common trees may be known, even at a distance, by their characteristic habits (see Figs. 60, 61, 62). The difliculty of the mechanical problems solved by these huge bodies is very great. 'They maintain form and position and endure tremendous pressure and strain.

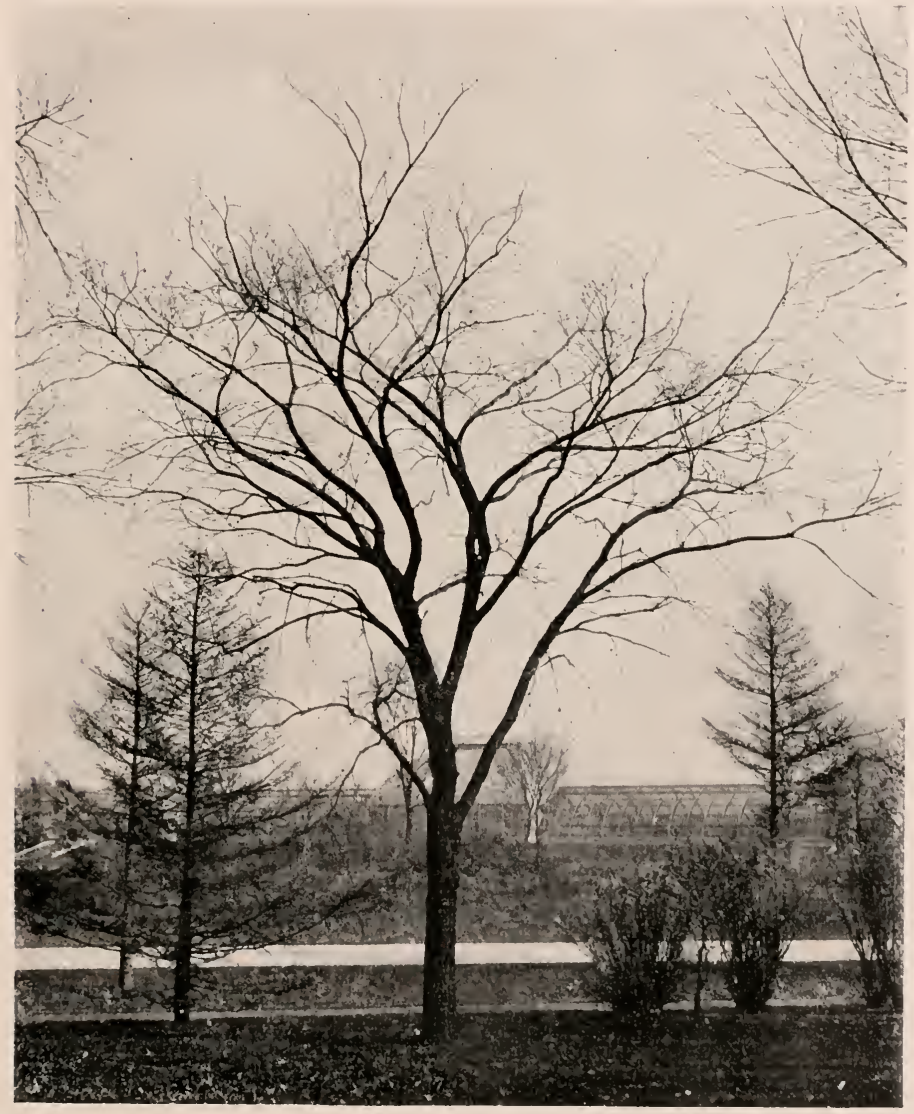

Fig. 58. An elm in its winter condition, showing the absence of a continuous central shaft, the main stem soon breaking up into branches, and giving a spreading top. On each side in the background are trees of the pine type, showing the central shaft and conical ontline, 
48. Relation to light.-As stems bearing foliage leares hold a special relation to light, it is necessary to speak of the influence of light upon their direction, the response to

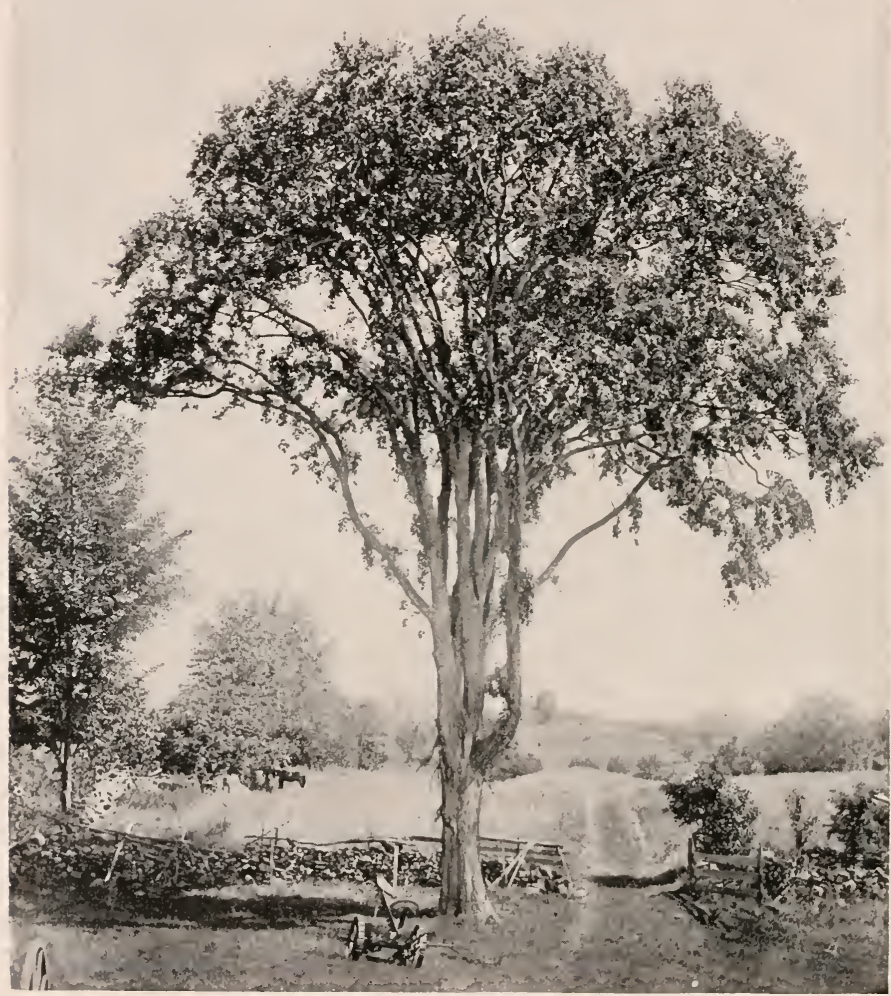

Fig. 59. An elm in foliage, showing the breaking up of the trunk into branches and the spreading top.

which is known as heliotropism, already referred to under foliage leaves. In the case of an erect stem the tendency is to grow towards the source of light (see Figs. 1, 64). 
This has the general result of placing the leaf blades at right angles to the rays of light, and in this respeet the heliotropism of the stem aids in securing a farorable leaf position (see Figs. (i3), 63a). Prostrate stems are differently affected by the light, howerer, being directed transversely to the rays of light. The same is true of many foliage

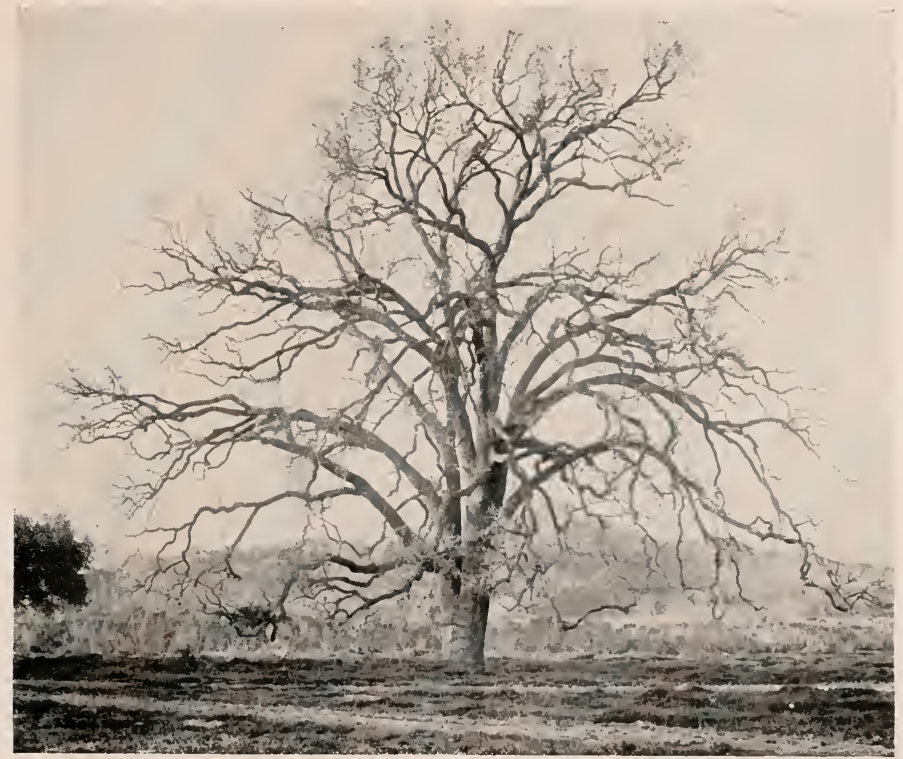

FIG. 60. An oak in its winter condition, showing the wide branching. The various directions of the branches have been determined by the light-relations.

branches, as maly be seen by observing almost any tree in which the lower branches are in the general transverse position. These branches generally tend to turn upwards when they are beyond the region of shading. Subterranean stems are also mostly horizontal, but they are out of the influence of light, and under the influence of gravity, the response to which is known as geotropism, which guides them into the transverse position. The climbing stem, like the erect one, 


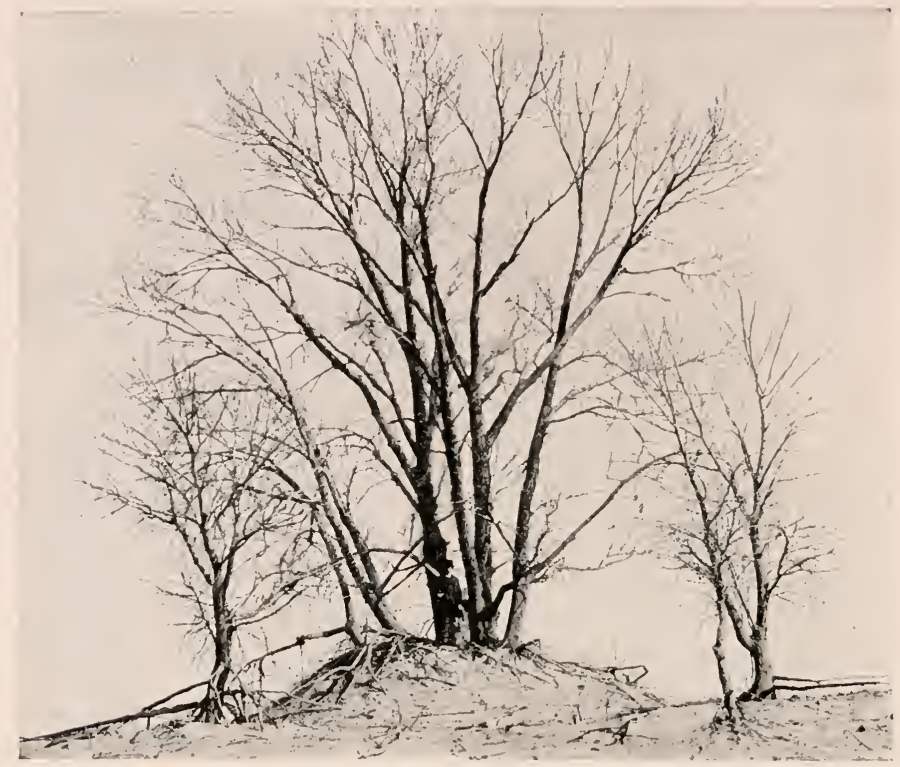

Fig. 61. Cottonwoods, in winter condition, on a sand dune, showing the branching habit, and the tendency to grow in groups.

grows towards the light, while floating stems may be either erect or transverse.

\section{B. Stems bearing scule leaves.}

49. General character. $-\Lambda$ scale leaf is one which does not serve as foliage, as it does not develop the necessary chlorophyll. 'This means that it does not need such an exposure of surface, and hence scale leaves are usually much smaller, and certainly are more inconspienous than foliage leaves. $\quad \Lambda$ good illustration of scale leaves is furnished by the ordinary scaly buds of trees, in which the covering of overlapping scaly leaves is very conspicuous (see Fig. 65). As there is no development of chlorophyll in such leaves, 
they do not need to be exposed to the light. Stems bearing only scale leaves, therefore, hold no necessary light-relation, and may be subterranean as well as aerial. For the same

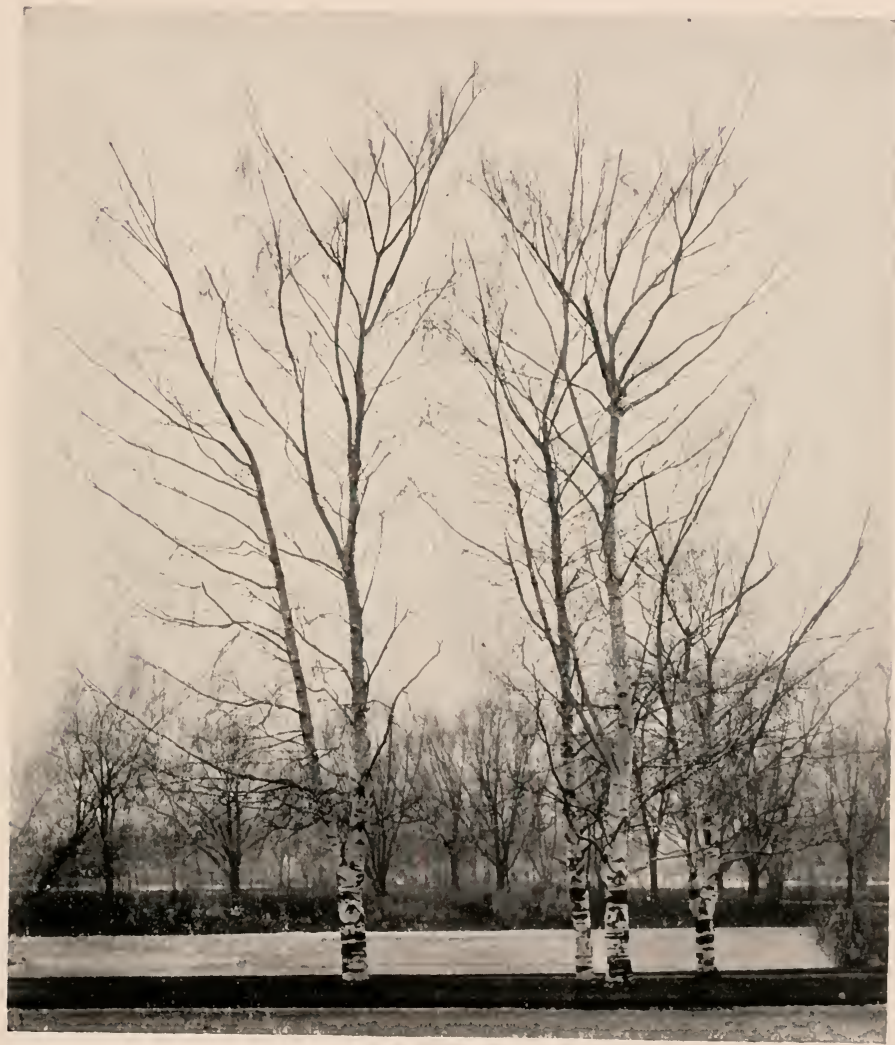

Frg. 62. A group of weeping birches, showing the branching habit and the peculiar hanging branchlets. The trunks also show the habit of birch bark in peeling off in bands around the stem.

reason scale leaves do not need to be separated from one another, but may overlap, as in the buds referred to. Sometimes scale leaves occur so intermixed with foliage 


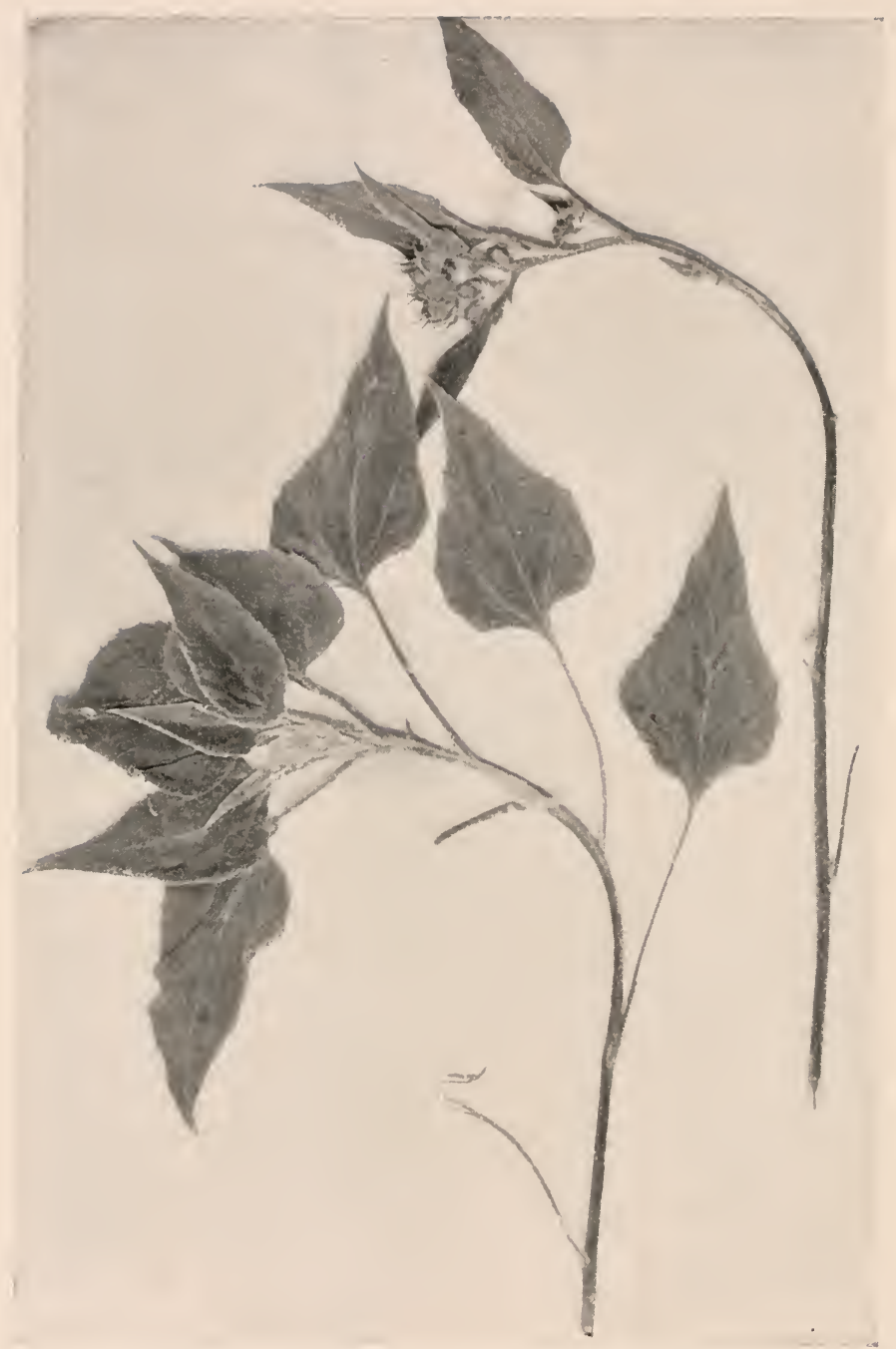

Fig. 63. Suntlowers with the upper part of the stem sharply bent towards the light. giving the leaves better exposure.-After ScHAFFNER. 
leaves that no peculiar stem type is developed. In the pines scale leaves are found abundantly on the stems which are developed for foliage purposes. In fact, the main stem axes of pines bear only scale leaves, while short spur-like branches bear the characteristic needles, or foliage leaves, but the form of the stem is controlled by the needs of the foliage. Some very distinct types of seale-bearing stems may be noted.

\section{0 . The bud type.}

-In this case the nodes bearing the leaves remain close together, not separating, as is necessary in ordinary foliage-bearing stems, and the leaves overlap. In a stem of this character the later joints may become separated and bear foli-

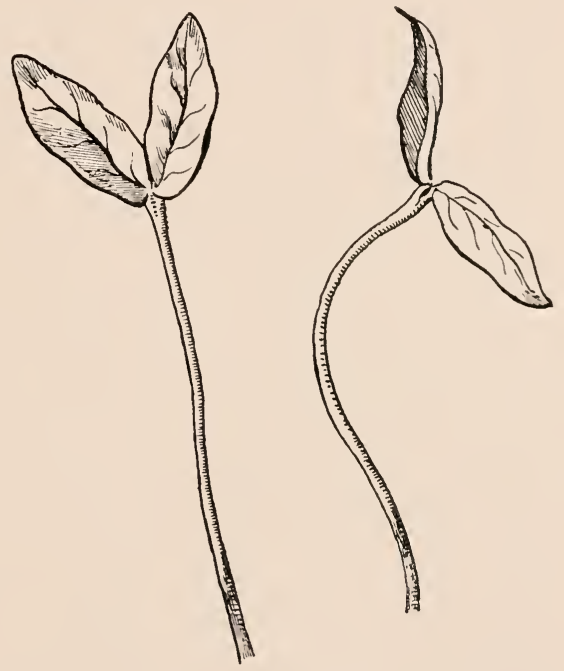

FIG. $63 a$. Cotyledons of cistor-oil bean ; the seedling to the left showing the ordinary position of the cotyledons, the one to the right showing the curvature of the stem in response to light from one side.-After Atrinson.

age leares, so that

one finds scale leaves below and foliage leaves above on the same stem axis. 'This is always true in the case of branch buds, in which the scale leaves serve the purpose of protection, and are aerial, not because they need a light-relation, but because they are protecting young foliage leaves which do.

Sometimes the scale leaves of this bud type of stem do not serve so much for protection as for food storage, and become fleshy. Ordinary bulbs, such as those of lilies, ete., 


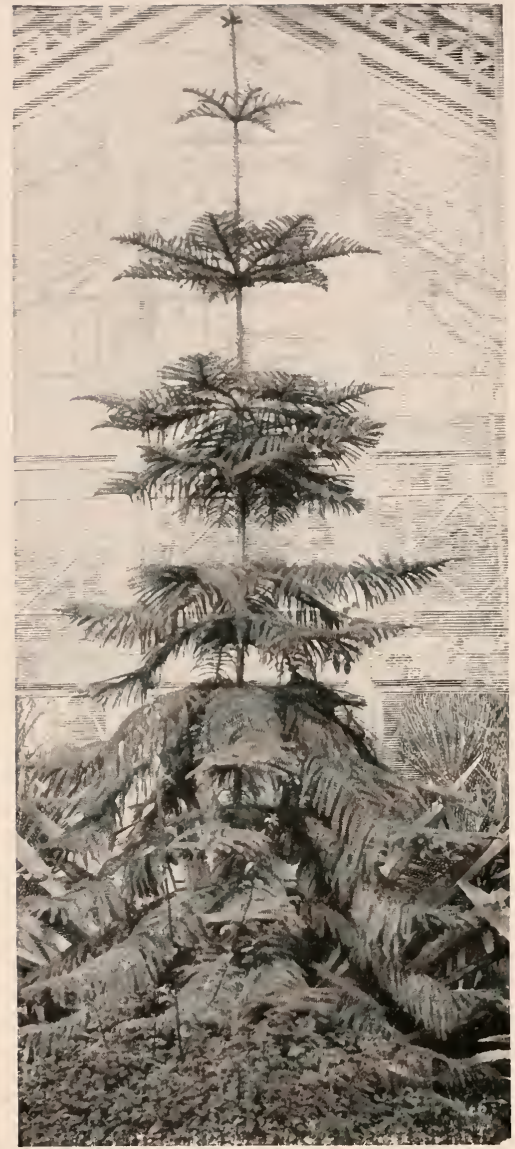

Fig. 64. An araucarian pine, showing the central shaft, and the regular clusters of branches spreading in every direction aud bearing numerous small leaves. The lowermost branches extend downwards and are the largest, while those above become more horizontal and smaller. These differences in the size and direction of the branches secure the largest light exposure. are of this character; and as the main purpose is food storage the most favorable position is a subterranean one (see Fig. 66). Sometimes such scale leaves become very broad and not merely overlap but enwrap one another, as in the case of the onion.

51. The tuber type. - The ordinary potato may be taken as an illnstration (see Fig. 6\%). The minute scale leaves, to be found at the "eyes" of the potato, do not overlap, which means that the stem joints are farther apart than in the bud type. The whole form of the stem results from its use as a place of food storage, and hence such stems are generally subterranean. Food storage, subterranean position, and reduced scale leaves are facts which seem to follow each other naturally. 
52. The rootstock type.-This is probably the most common form of subterranean stem. It is elongated, as are foliage stems, and hence the scale leaves are well separated. It is prominently used for food storage, and is also admirably adapted for subterranean migration (see Fig. 68). It can do for the plant, in the way of migration, what prostrate foliagebearing stems do, and is in a more protected position. Advancing beneath the ground, it sends up a succession of branches to the surface. It is a very efficient method for the "spreading" of plants, and is extensively used by grasses in covering areas and forming turf. 'The persistent continuance of the worst weeds is often due to this habit (see Figs. 69, \%0). It

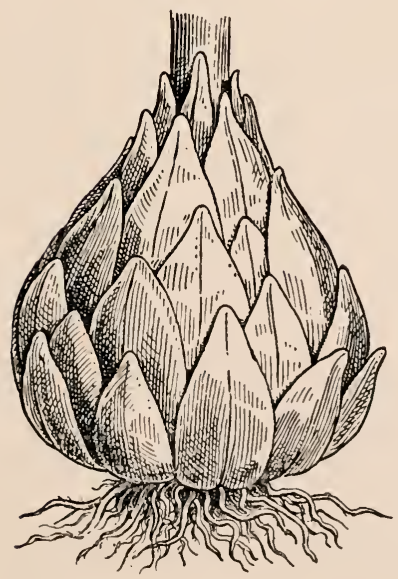

Fig. 66. A bulb, made up of overlapping scales, which are fleshy on account of food storage. - After GraY. is impossible to remore all of the inclefinitely branching rootstocks from the soil, and any fragments that remain are able to send up fresh crops of aerial branches.

\section{Alternation of rest and} activity.-In all of the three stem types just mentioned, it is important to note that they are associated with a remarkable alternation between rest and vigorous activity. From the branch buds the new leaves 


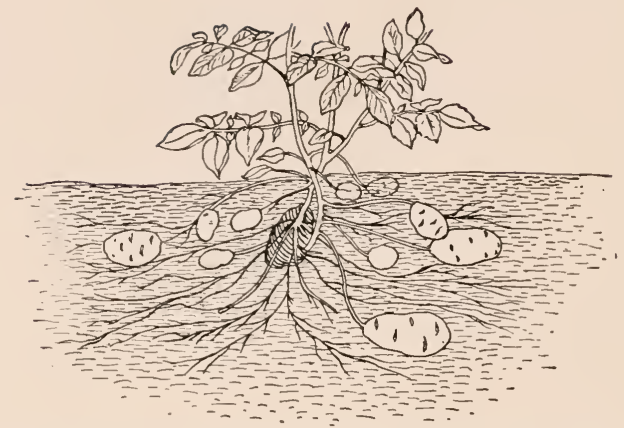

Fig. 6\%. A potato plant, showing the subterranean tubers.After Strasburger.

emerge with great rapidity, and trees become covered with new foliage in a few days. From the sub. terranean stems the aerial parts come up so speedily that the surface of the ground seems to be covered suddenly with young regetation. 'This sudden ehange from comparative rest to great activity has been well spoken of as the "awakening" of regetation.

\section{Stems bearing floral leaves.}

54. The flower.-The so-called "flowers" which certain plants produce represent another type of shoot, being stems with peculiar leaves. So attractive are flowers that they have been very much studied; and this fact has led many people to believe that flowers are the only parts of plants worth studying. Aside from the fact that a great many plants do not produce flowers, even in those that do the flowers are connected with only one of the plant processes, that of reproduction. Every one knows that flowers are exceedingly variable, and names

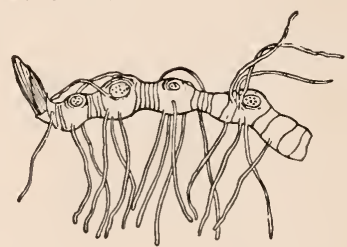

FIG. 68. The rootstock of Solomon's seal; from the under side roots are developed; and on the npper side are seen the scars which mark the positions of the successive aerial branches which bear the leaves. The advancing tip is protected by scales (forming a bud), and the positions of previous buds are indicated by groups of ring-like scars which mark the attachment of former scales. Advancing in front and dying behind such a rootstock may give rise to an indefinite succession of aerial plants.-After GraY. 
have been given to every kind of variation, so that their study is often not much more than learning the definitions of names. However, if we seek to discover the life-relations of flowers we find that they may be stated very simply.

5๊. Life-relations.-The flower is to produce seed. It must not only put itself into proper relation to do this, but

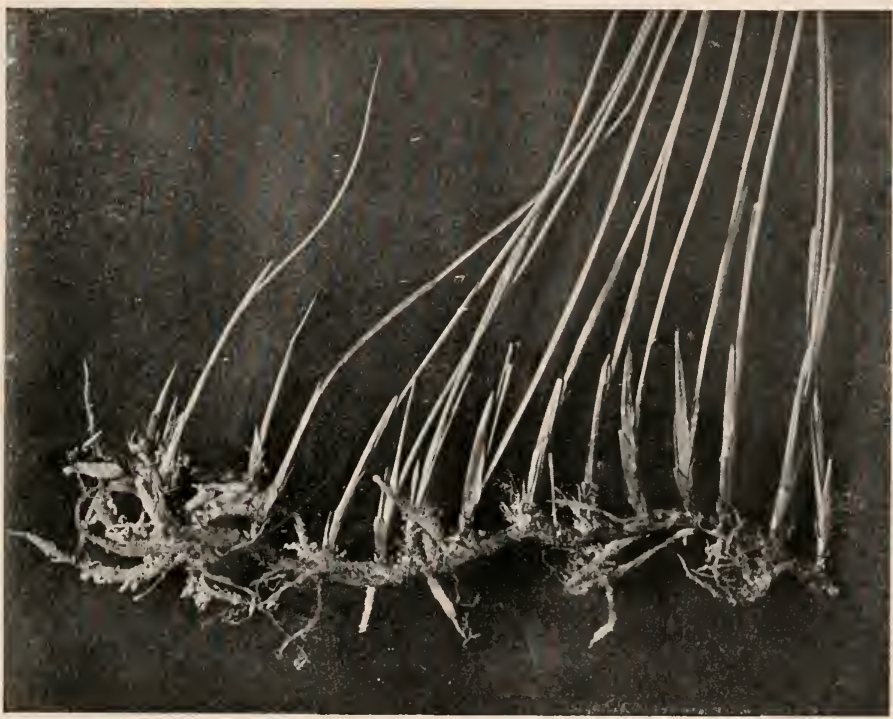

Fig. 69. The rootstock of a rush (.Juncus), showing how it advances beneath the ground and sends above the surface a succession of branehes. The breaking up of such a rootstock only results in so many separate individuals.-After Cow Les.

there must also be some arrangement for putting the seeds into proper conditions for developing new plants. In the production of seed it is necessary for the flower to secure a transfer of certain yellowish. powdery bodies which it produces, known as pollen or pollen-grains, to the organ in which the seeds are produced, known at the pistil. This transfer is called pollination. One of the important things, therefore, in comnection with the flower, is for it to put 


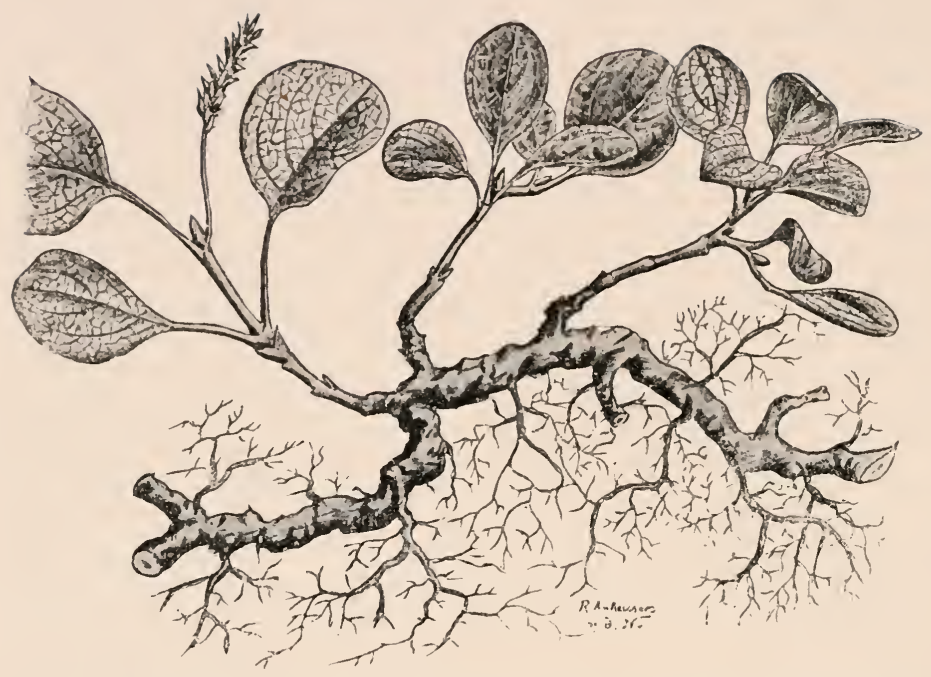

Fig. 70. An alpine willow, showing a strong rootstock developing aerial branches and roots, and capable of long life and extensive migration.-After ScHMPER.

itself into such relations that it may secure pollination.

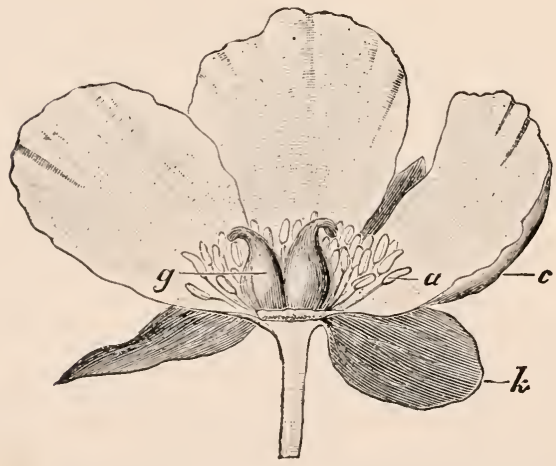

FIf. 71. A flower of peony, showing the four sets of floral organs: $k$, the scpals, together called the calyx ; $c$, the petals, together called the corolla ; $a$, the numerous stamens; $g$, the two carpels, which contain the ovules. - After STrasBurger.
Besides pollination, which is necessary to the production of seeds. there must be an arrangement for seed distribution. It is always well for seeds to be scattered. so as to be separated from one another and from the parent plant. The two great external problems in connection with the flower, therefore, are polli- 
nation and seed-distribution. It is necessary to call attention to certain peculiar features of this type of stem.

56. Structures. - The joints of the stem do not spread apart, so that the peculiar leaves are kept close together, usually forming a rosette-like cluster (see Fig. 71). These leaves are of four kinds: the lowest (outermost) ones (individually sepals, collectively calyx) mostly resemble small foliage leaves; the next higher (inner) set (individually petals, collectively corolla) are usually the most conspicuous, delicate in texture and brightly colored; the third set (stamens) produces the pollen; the highest (innermost) set (carpels) form the pistil and produce the ovules, which are to become seeds. These four sets may not all be present in the same flower; the members of the same set may be more or less blended with one another, forming tubes, urns, etc. (see Figs. $\%, \% 3, \% 4$ ) ; or the different members may be modified in the greatest variety of ways.

Another peenliarity of this type of stem is that when the

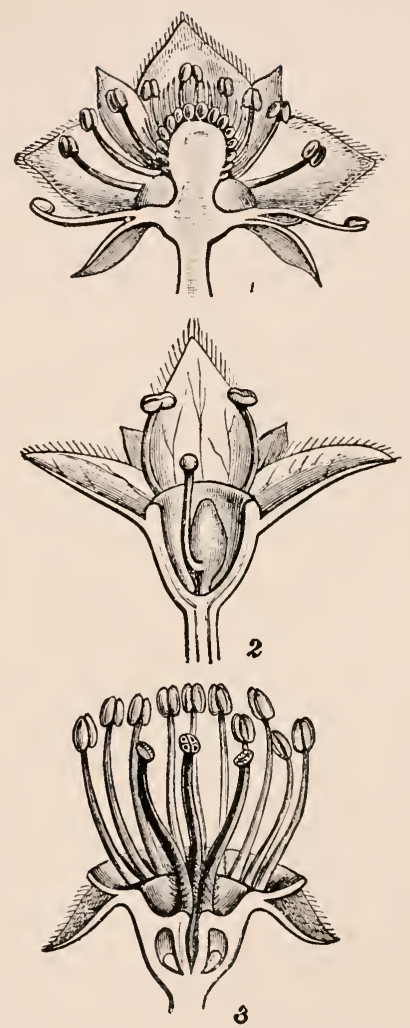

Fig. 72. A group of flowers of the rose family. The one at the top (Potentilla) shows three broad sepals, much smaller petals alternating with them, a gromp of stamens, and a large receptacle bearing numerons small carpels. The central one (Alchemilla) shows the tips of two small sepals, three larger petals mited below, stamens arising from the rim of the nrn, and a single peeuliar pistil. The lowest flower (the common apple) shows the sepals, petals, stamens, and three styles, all arising from the ovary part of the pistil.-After Focke. 

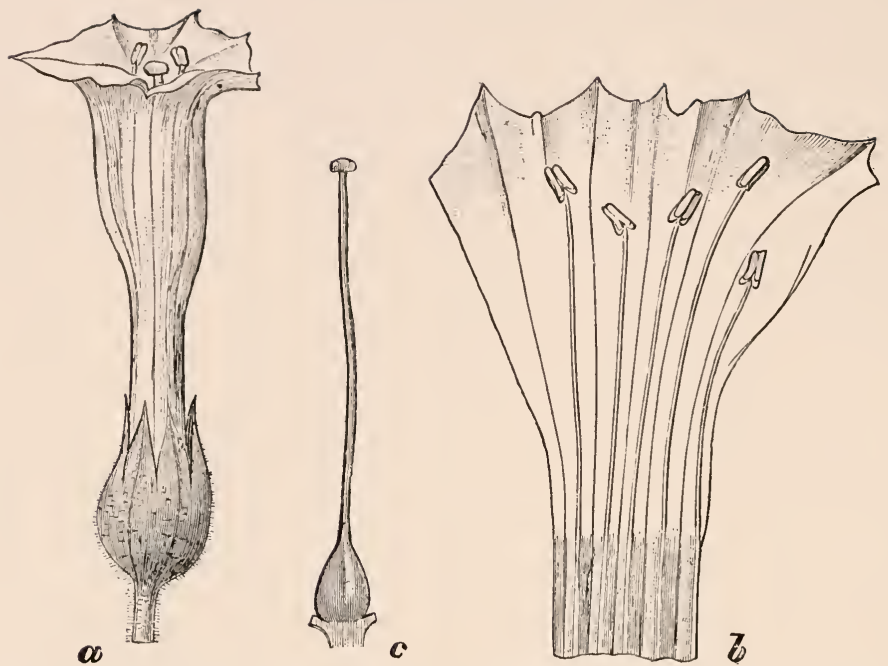

F1G. 73. A flower of the tobacco plant: $a$, a complete flower, showing the calyx with its sepals blended below, the funnelform corolla made up of united petals, and the stamens just showing at the mouth of the corolla tube : $b$, a corolla tube split open and showing the five stamens attached to it near the base; $c$, a pistil made up of two blended carpels, the bulbons base (containing the ovules) being the ovary, the long stalk-like portion the style, and the knob at the top the stigma.-After strasburger.

last set of floral leaves (carpels) appear, the growth of the stem in length is checked and the cluster of floral leaves
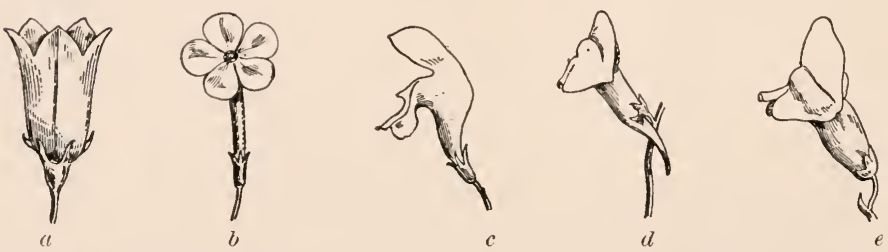

Fig. it. A group of flower forms : $a$, a flower of harebell, showing a bell-shaped corolla composed of five petals; $b$, a flower of phlox, showing a tubular corolla with its five petals distinct above and sharply spreading: $c$, a flower of dead-nettle, showing an irregular corolla with its five petals forming two lips above the fumnelform base ; $d$, a flower of toad-flax, showing a two-lipped corolla, and also a spur formed by the base of the corolla; $e$, a flower of the snapdragon, showing the two lips of the corolla closed.-After GraY. 
appears to be upon the end of the stem axis. It is usual, also, for the short stem bearing the floral leaves to broaden

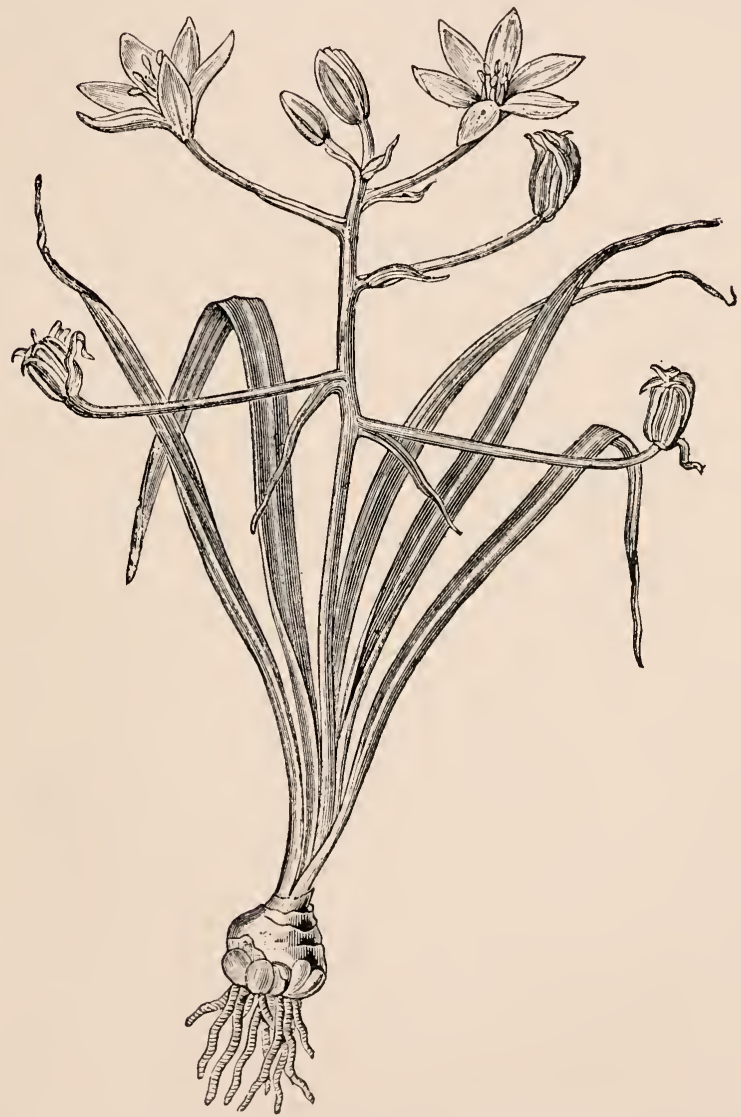

Fig. 75. The Star-of-Bethlehem (Ornithogalum), showing the loose clnster of flowers at the end of the stem. The leaves and stem arise from a bulb, which produces a cluster of roots below.-After STRAsBuRgEn.

at the apex and form what is called a receptacle, upon which the close set floral leares stand.

Although many floral stems are produced singly, it is 
very common for them to branch, so that the flowers appear in clusters, sometimes loose and spray-like, sometimes compact (see Figs. $\% 5$, $\%$, $\%$ ). For example, the common

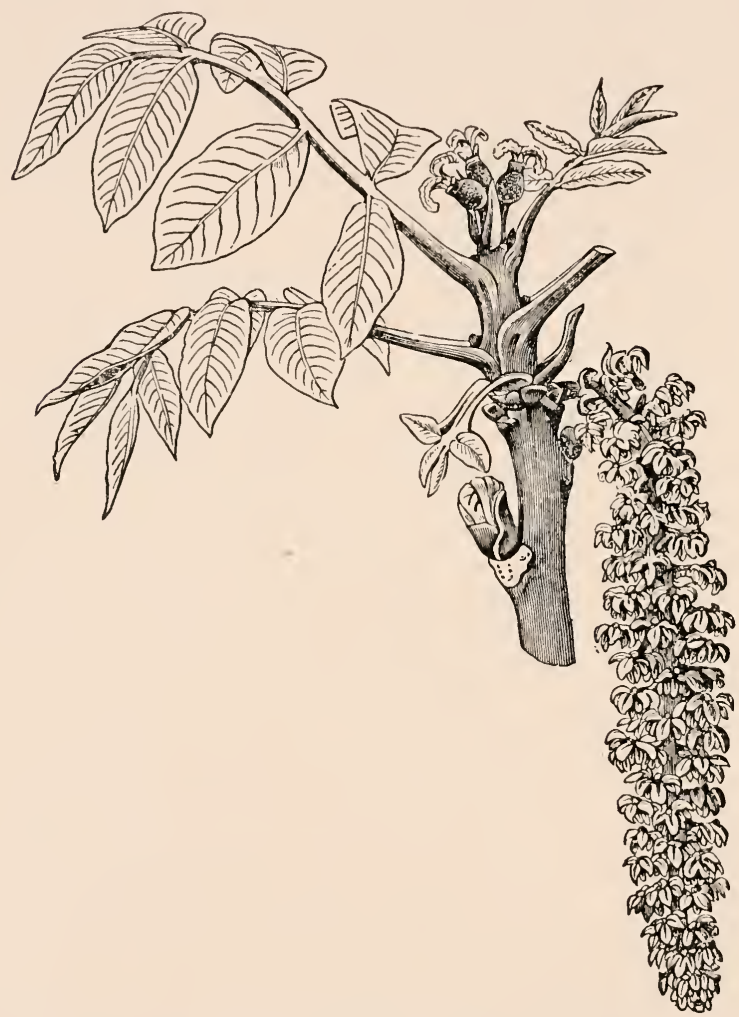

Fig. 76. A flower cluster from a walnut tree.-After Strasburger.

dandelion "flower" is really a compact head of flowers. All of this branching has in view better arrangements for pollination or for seed-distribution, or for both.

The subject of pollination and seed-distribution will be considered under the head of reproduction. 
STRUCTURE AND FUNCTION OF THE STEM.

5\%. Stem structure.-The aerial foliage stem is the most favorable for studying stem structure, as it is not distorted by its position or by being a depository for food. If an active twig of an ordinary woody plant be cut across, it will

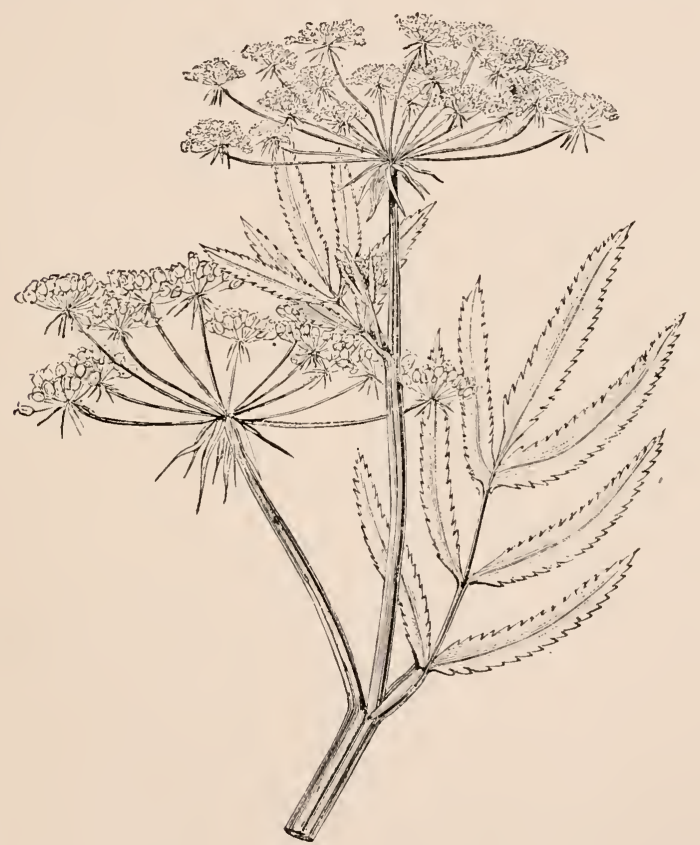

Fig. $\%$. Flower clusters of an umbellifer (Sium).-After Strasburger.

be seen that it is made up of four general regions (see Fig. 78): (1) an outer protecting layer, which may be stripped off as a thin skin, the epidermis; (2) within the epidermis a zone, generally green, the cortex; (3) an inner zone of wood or vessels, known as the vascular reqion; (4) a central pith.

58. Dicotyledons and Conifers.-Sometimes the vessels 


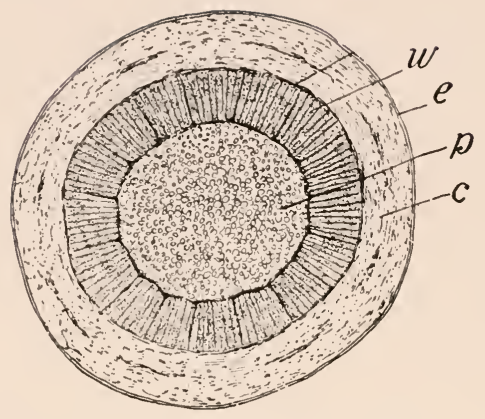

FIG. 78. Section across a young twig of box elder, showing the four stem regions: $e$, epidernis, represented by the heavy bounding line ; $c$, cortex ; $w$, vascular cylinder ; $p$, pith.

are arranged in a hollow eylinder, just insicle of the cortex, leaving what is ealled pith in the center (see Fig. \%s). Sometimes the pith disappears in older stems or parts of stems and leaves the stem hollow. When the vessels are arranged in this way and the stem lives more than a year, it can increase in cliameter by adding new ressels ontside of the old. In the ease of trees these additions appear in cross-section like a series of concentric rings, and as there is usually but one growth period during the year, they are often called anmual rings (see Fig. 79), and the age of a tree is often estimated by counting them. 'This method of ascertaining the age of a tree is not absolutely certain, as there may be more than one growth period in some years. In the case of trees and shrubs the epidermis is replaced on the older parts by layers of cork, which sometimes becomes very thick and makes up the onter part of what is commonly called bark.

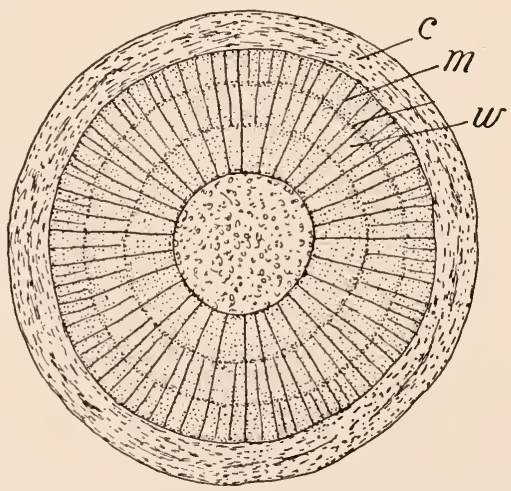

Fig. 79. Section across a twig of box elder three years old, showing three annual rings, or growth rings, in the vascular cylinder. The radiating lines $(m)$ which cross the vascular region $(w)$ represent the pith rays, the principal ones extending from the pith to the cortex $(c)$. 
Stems which increase in diameter mostly belong to the great groups called Dicotyledons and Conifers. 'To the former belong most of our common trees, such as maple, oak, beech, hickory, etc. (see Figs. 58, 59, 60, 61), as well as the great majority of common herbs; to the latter belong the pines, hemlocks, etc. (see Figs. 56, 57, 198 to 201). This annual increase in diameter enables the tree to put out an increased number of branches and hence foliage leaves each year, so that its capacity for leaf work becomes greater year after year. A reason for this is that the stem is conducting important food supplies to the leaves, and if it increases in diameter it can conduct more supplies each year and give work to more leaves.

59. Monocotyledons.-In other stems, however, the ressels are arranged differently in the central region. Instead of forming a hollow cylinder enclosing a pith, they are scattered through the central region, as may be seen in the crosssection of a corn-stalk (see Fig.

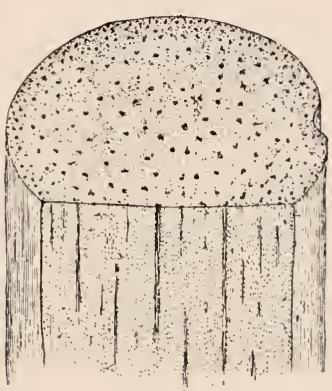

FIG. 80. A corn-stalk, showing cross-section and longitudinal section. The dots represent the scattered bundles of vessels, which in the longitudinal section are seen to be long fiber-like strands. s0). Such stems belong mostly to a great group of plants known as Monocotyledons, to which belong palms, grasses, lilies, etc. For the most part such stems do not increase in diameter, hence there is no branching and no increased foliage from year to year. A palm well illustrates this habit, with its columnar, unbranching trunk, and its crown of foliage leaves, which are about the same in number from year to year (see Figs. 81, 82).

60. Ferns. - The same is true of the stems of most fernplants, as the vessels of the central region are so arranged that there can be no diameter increase, though the ar- 


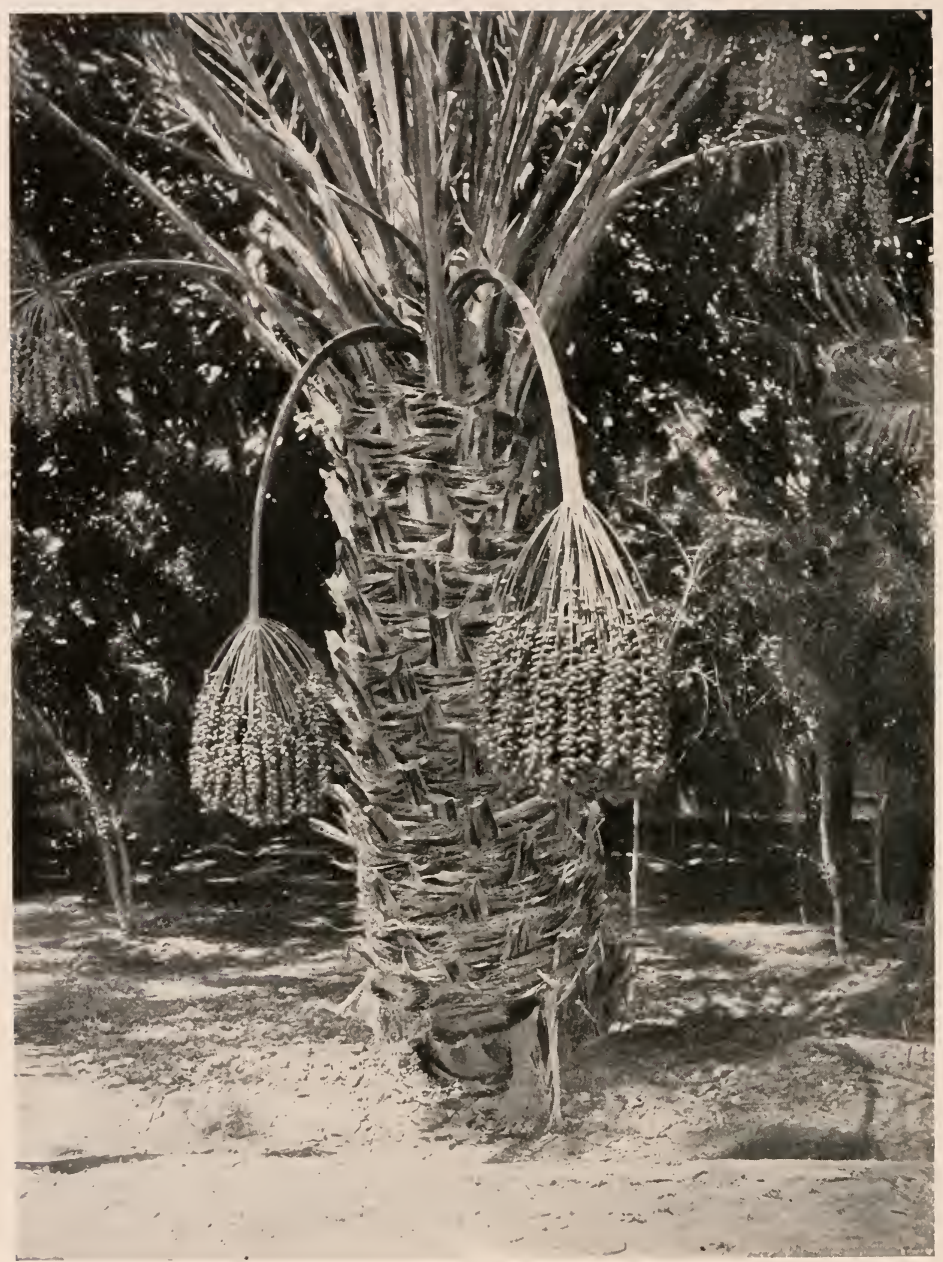

FIG. 81. A date palm, showing the unbranched columnar trunk covered with old leaf bases, and with a cluster of huge active leaves at the top, only the lowest portions of which are shown. Two of the very heavy fruit clusters are also shown. 
rangement is very different from that found in Monocotyledons. It will be noticed how similar in general appearance is the habit of the tree fern and that of the palm (see Fig. 83).

61. Lower plants. - In the case of moss-plants, and such algie and fungi as develop stems, the stems are very much

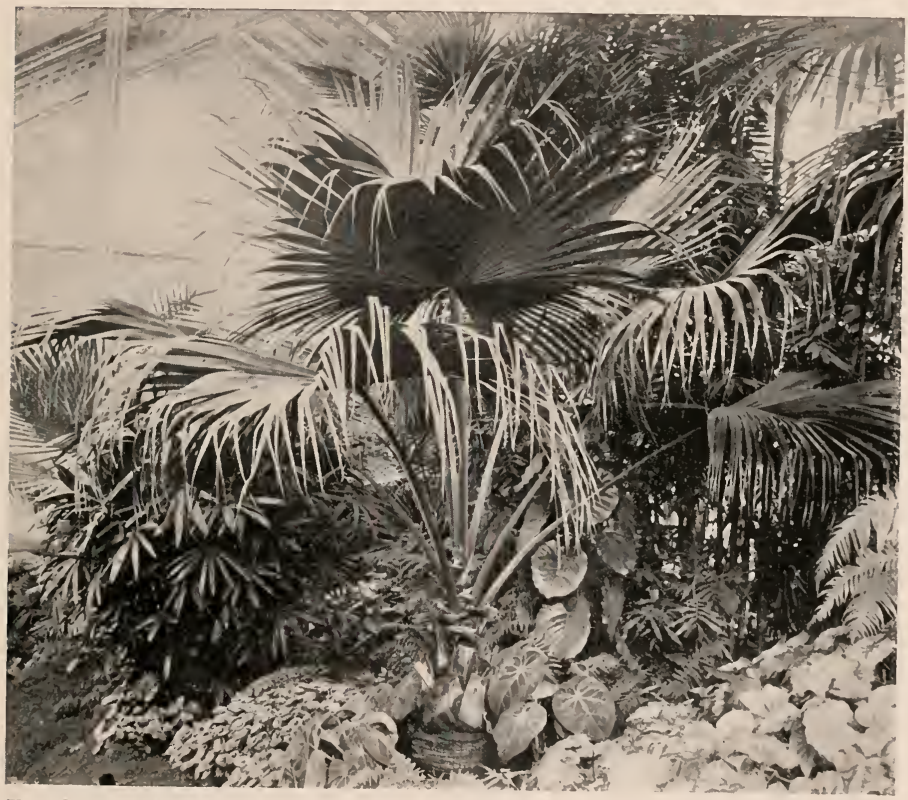

FIG. 82. A palm of the palmetto type (fan palm), with low stem and a crown of large leaves.

simpler in construction, but they serve the same general purpose.

62. Conduction by the stem.- Aside from the work of prodncing leaves and furnishing mechanical support, the stem is a great conducting region of the plant. 'This subject will be considered in Chapter X., under the general head of "The Nutrition of Plants," 


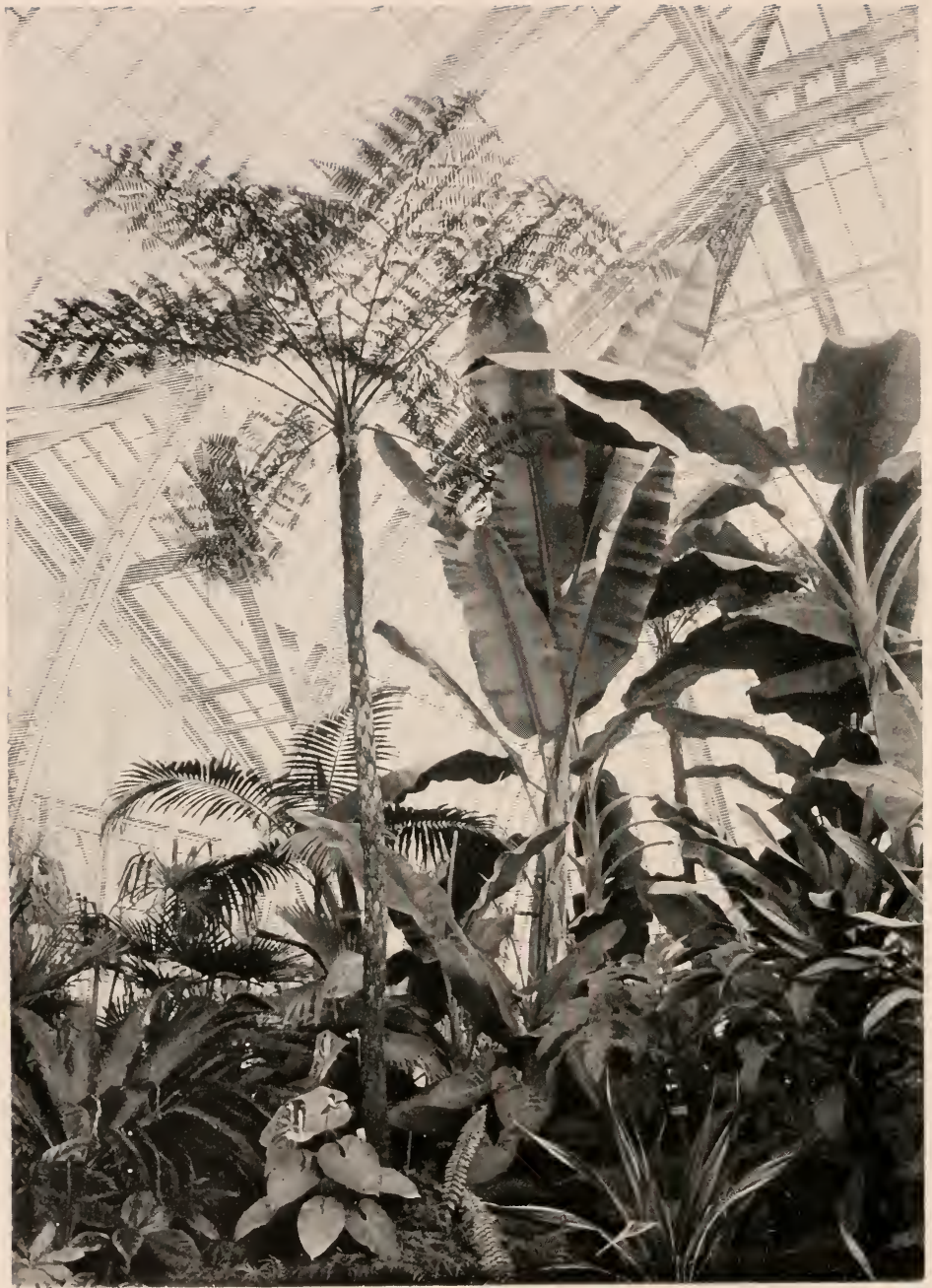

FIG. 83. A group of tropical plants. To the left of the center is a tree fern, with its slender columnar stem and crown of large leaves. The large-leaved plants to the right are bananas (monocotyledons). 


\section{CHAPTER V.}

ROOTS.

63. General character.-The root is a third prominent plant organ, and it presents even a greater variety of relations than leaf or stem. In whatever relation it is found it is either an absorbent organ or a holdfast, and very often both. For such work no light-relation is necessary, as in the ease of foliage leaves ; and there is no leaf-relation, as in the case of stems. Roots related to the soil may be taken as an illustration.

It is evident that a soil root anchors the plant in the soil, and also absorbs water from the soil. If absorption is considered, it is further evident that the amount of it will depend in some measure upon the amount of surface which the roots expose to the soil. We have already noticed that the foliage leaf has the same problem of exposure, and it solves it by becoming an expanded organ. The question may be fairly asked, therefore, why are not roots expanded organs? The receiving of rays of light, and the absorbing of water are very different in their demands. In the former case a flat surface is demanded, in the latter tubular processes. The increase of surface in the root, therefore, is obtained not by expanding the organ, but by multiplying it. Besides, to obtain the soil water the roots must burrow in every direction, and must send out their delicate threadlike branches to come in contact with as much soil as possible. Furthermore, in soil roots absorption is not the only thing to consider, for the roots act as holdfasts and must grapple the soil. This is certainly done far more effectively 
by numerous thread-like processes spreading in every direction than by flat. expanded processes.

It should also be noted that as soil roots are subterranean they are used often for the storage of food. as in the case of many subterranean stems. Certain prominent root types may be noted as follows:

64. Soil roots. - These roots push into the ground with
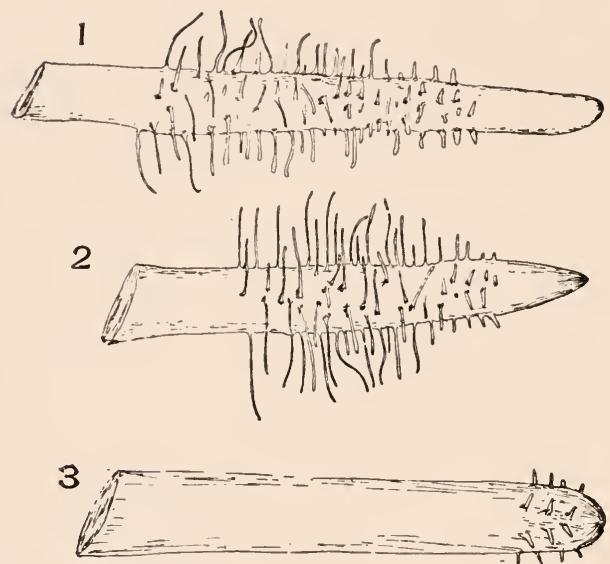

Fig. 84. Root tips of corn, showing root hairs, their position in reference to the growing tip, and the effect of the surrounding medium upon their development : 1 , in soil ; 2 , in air ; 3 , in water. great energy. and their absorbing surfaces are entirely corered. Only the youngest parts of a root system absorb actively, the older parts transporting the absorbed material to the stem, and helping to grip the soil. The soil root is the most common root type, being used by the great majority of seed plants and fern plants, and among the moss plants the very simple root-like processes are mostly soil-related. 'To such roots the water of the soil presents itself either as free water-that is, water that can be drained away-or as films of water adhering to each soil particle, often called water of adhesion. 'To come in contact with this water, not only does the root system usually branch profusely in every direction, but the youngest branches develop abundant absorbing hairs, or root hairs (see Fig. 84), which crowd in among the soil particles and 
absorb moisture from them. By these root hairs the ab-

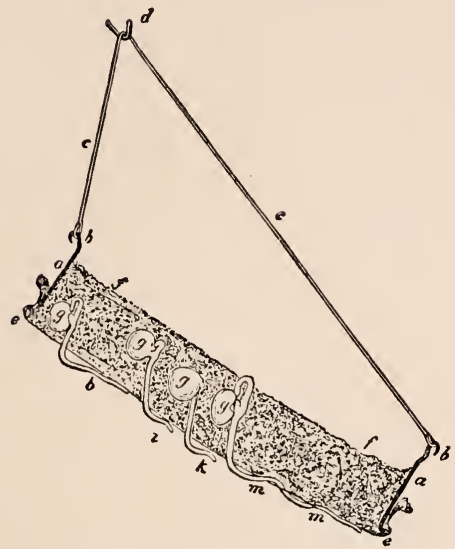

Fici. 85. Apparatus to show the influence of water (hydrotropism) npon the direction of roots. The ends $(\alpha)$ of the box have hooks for hanging, while the box proper is a cylinder or trongh of wire netting and is filled with damp sawdust. In the sawdust are planted peas $(g)$, whose roots $(h, i, k, m)$ first descend until they emerge from the damp sawdnst, bnt soon turu back toward it.-After SACHs. sorbing surface, and hence the amount of absorption, is greatly increased. Individual root hairs do not last very long, but new ones are constantly appearing just behind the advancing root tips, and the old ones are as constantly disappearing.

(1) Geotropism and hydrotropism.-Many outside influences affect roots in the direction of their growth, and as soil roots are especially favorable for observing these influences, two prominent ones may be mentioned. The influence of gravity, or the earth influence, is very strong in directing the soil root.

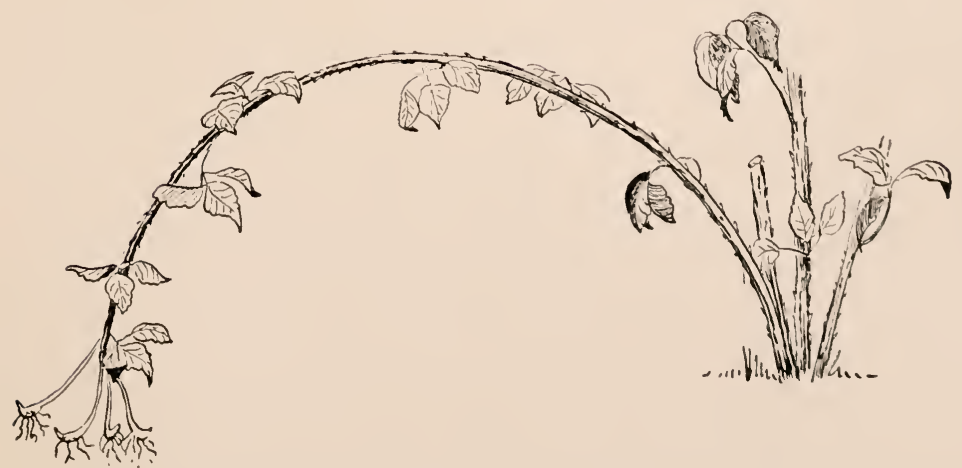

Fig. 86. A raspberry plant, whose stem has been bent down to the soil and has "struck root."-After BEAL. 
As is well known, when a seed germinates the tip that is to develop the root turns towards the earth, even if it has come from the seed in some other direction. 'This response to gravity by the plant is known as geotropism. Another directing influence is moisture, the response to which is

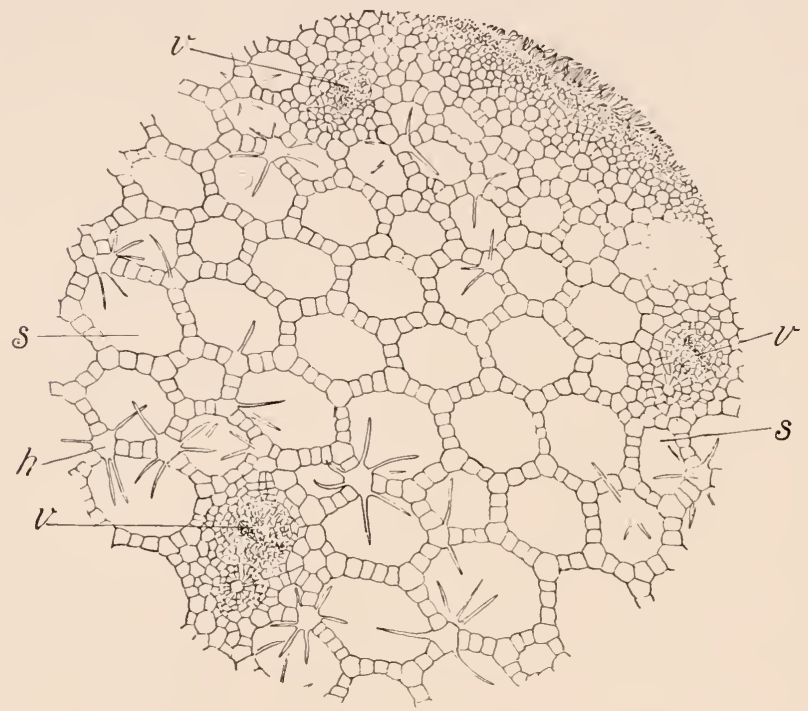

Fig. 8i. A section throngh the leaf stalk of a yellow pond lily (Niphar). showing the numerous conspicuons air passages $(s)$ by means of which the parts nnder water are aerated; $h$, internal hairs projecting into the air passages; $v$, the mnch reduced and comparatively few vascular buudles.

known as hydrotropism. By means of this the root is directed towards the most favorable water supply in the soil. Ordinarily, geotropism and hydrotropism direct the root in the same general way, and so roinforce each other; but the following experiment may be arranged, which will separate these two influences. Bore several small holes in the bottom of a box (such as a cigar box), suspended as indicated in Figure 85, and cover the bottom with blotting paper. Pass the root tips of several germinated seeds 
through the holes, so that the seeds rest on the paper, and the root tips hang through the holes. If the paper is kept moist germination will continue, but geotropism will direct the root tips downwards, and hydrotropism (the moist paper) will direct them upwards. In this way they will pursue a devious course, now directed by one influence and now by the other.

If a root system be examined it will be found that when there is a main axis (tap root) it is directed steadily downwards, while the branches are directed differently. This indicates that all parts of a root system are not alike in their response to these influences. Several other influences are also concerned in directing soil roots, and the path of any root branch is a result of all of them. How variable they are may be seen by the numerous directions in which the branches

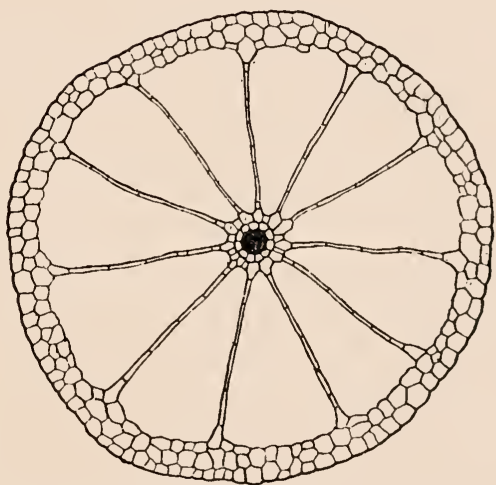

Fig. 88. A section through the stem of a waterwort (Elutime), showing the remarkably large and regularly arranged air passages for root aeration. The single rednced vascular bundle is central and connected with the small cortex by thin plates of cells which radiate like the spokes of a wheel.-After Scinenck.

travel, and the whole root system preserves the record of these numerous paths.

(:) The pull on the stem.-Another root property may be noted in connection with the soil root, namely the pull on the stem. When a strawberry rumner strikes root at tip (see Fig. $4 \%$ ). the roots, after they obtain anchorage in the soil, pull the tip a little beneath the surface, as if they had gripped the soil and then slightly contracted. 'The same thing may be observed in the process known as 
"layering," by which a stem, as a bramble, is bent down and covered with soil. The covered joints strike root, and the pulling follows (see Fig. 86). A very plain illustration of this pulling by roots can be obtained from many tuberous plants. 'Tubers, bulbs, rootstocks, etc., are underground structures which have been observed to bury themselves deeper and deeper in the soil. This is effected by the young

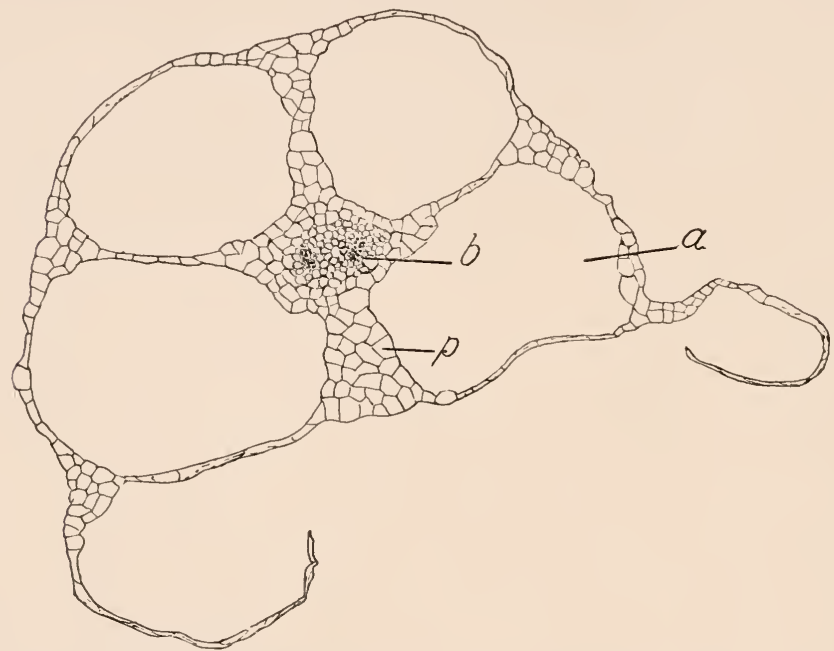

Fig. 89. Section through the leaf of a quillwort (Isoftes), showing the four large air chambers $(a)$, the central vascular region $(b)$, and the very poorly developed cortex.

roots which they continue to put forth. These roots grip the soil, then contract, and the tuber is pulled a little deeper. The compact tuber known as the Indian turnip ("Jack-inthe-pulpit") has been found to bury itself very deeply and rapidly, and this may be observed by transplanting a young and vigorous tuber into a pot of loose soil.

(3) Soil dangers.-In this connection certain soil dangers and the response of the roots should be noted. The soil may become poor in water or poor in certain essential materials, and this results in an extension of the root sys- 
tem, as if seeking for water and the essential materials. Sometimes the root system becomes remarkably extensive, visiting a large amount of soil in order to proeure the necessary supplies. Sometimes the soil is poor in heat, and root aetivity is interfered with. In such cases it is very common to find the leaves massed against the soil, thus slightly ehecking the loss of heat.

Most soil roots also need free air, and when water covers the soil the supply is cut off. In many cases there is some way by which a supply of free air may be brought down into the roots from the parts above water ; sometimes by large air passages in leaves and stems (see Figs. 8\%, 88, 89, 90) ; sometimes by developing special root structures which rise above the water level, as prominently shown by the cypress in the development of knees. These knees are outgrowths from roots beneath the water of the eypress

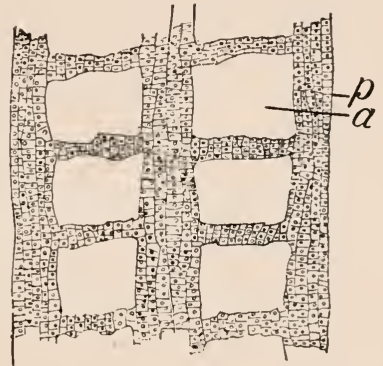

FIG, 90. Longitudinal section through a young quillwort leaf, showing that the four air chambers shown in Fig. 89 are not contimuous passages, but that there are four vertical rows of prominent chambers. The plates of cells separating the chambers in a vertical row very soon become dead and full of air. In addition to the work of aeration these air ehambers are very serviceable in enabling the leaves to float when they break off and carry the comparatively heary spore cases. swamp, and rise above the water level, thus reaching the air and aerating the root system (see Fig. 91). It has been shown that if the water rises so high as to flood the knees for any length of time the trees will die, but it does not follow that this is the ehief reason for their development.

65. Water roots. $-A$ very different type of root is developed if it is exposed to free water, without any soil relation. If a stem is floating, clusters of whitish thread-like roots usually put ont from it and dangle in the water. If the water level sinks so as to bring the tips of these roots to the mucky 


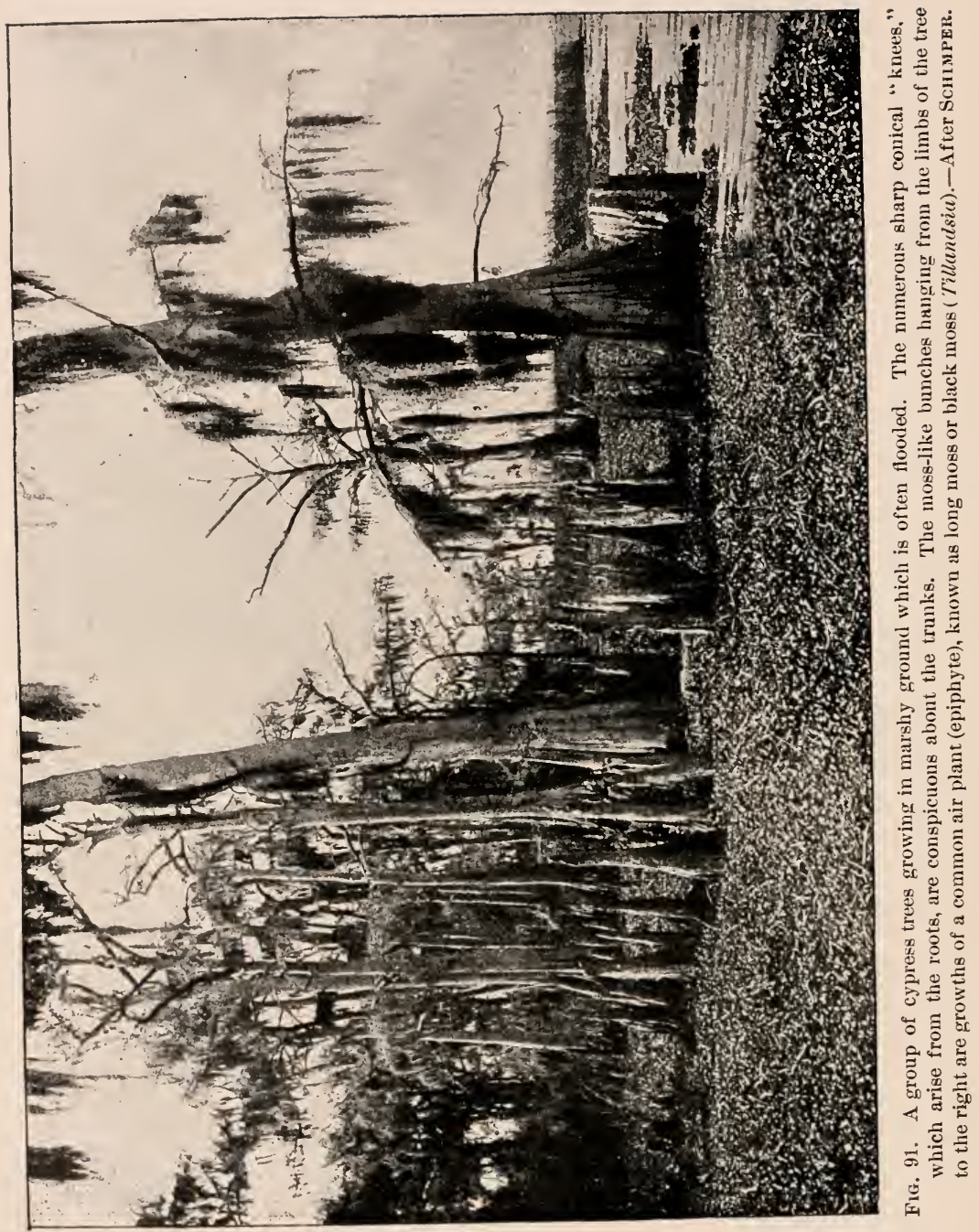




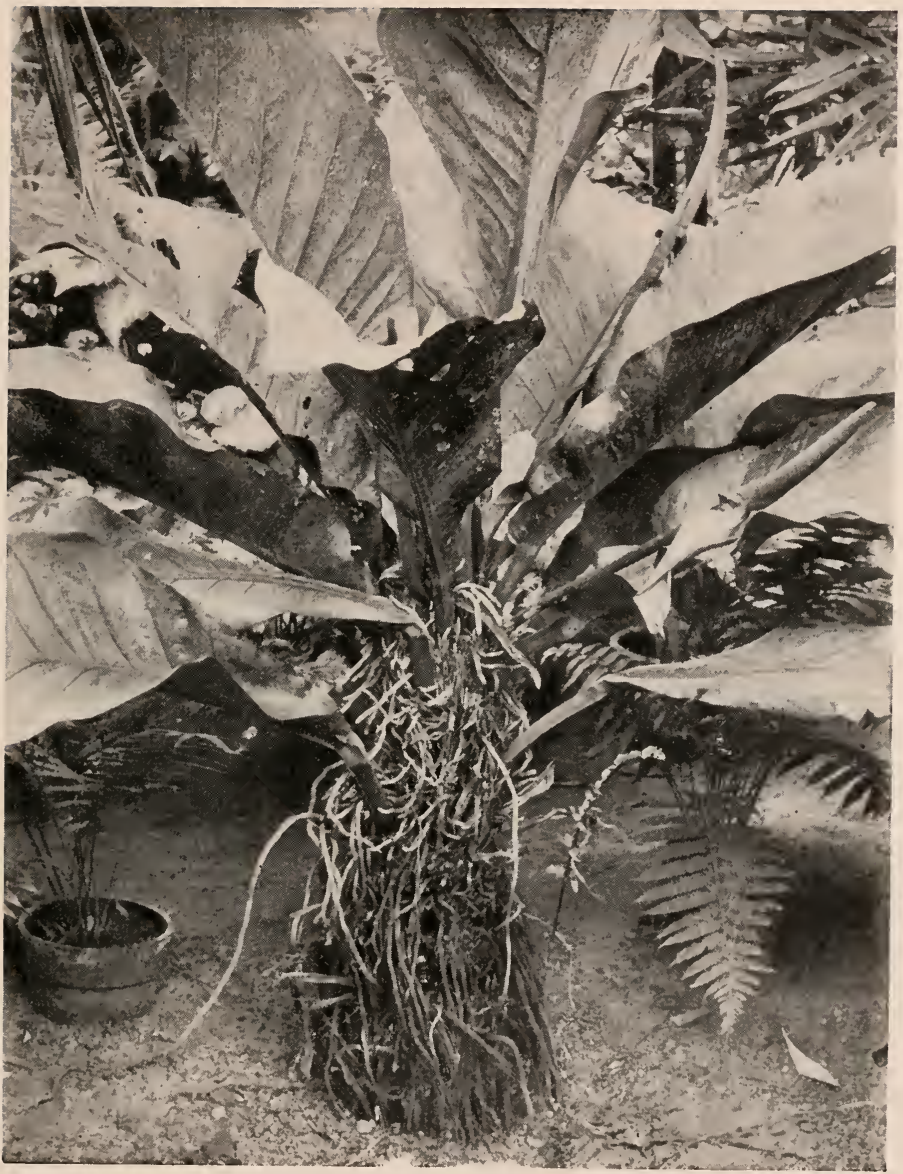

Frg. 92. A tropical aroid (Anthurium), showing its large leaves, and bunches of aerial roots.

soil they usually do not penetrate or enter into any soil relation. Such pure water roots may be found dangling from the under surface of the common duck weeds, which often cover the surface of stagnant water with their minute. green, disk-like bodies. 
Plants which ordinarily develop soil roots, if brought into proper water relations, may develop water roots. For instance, willows or other stream bank plants may be so close to the water that some of the root system enters it. In such cases the numerous clustered roots show their water

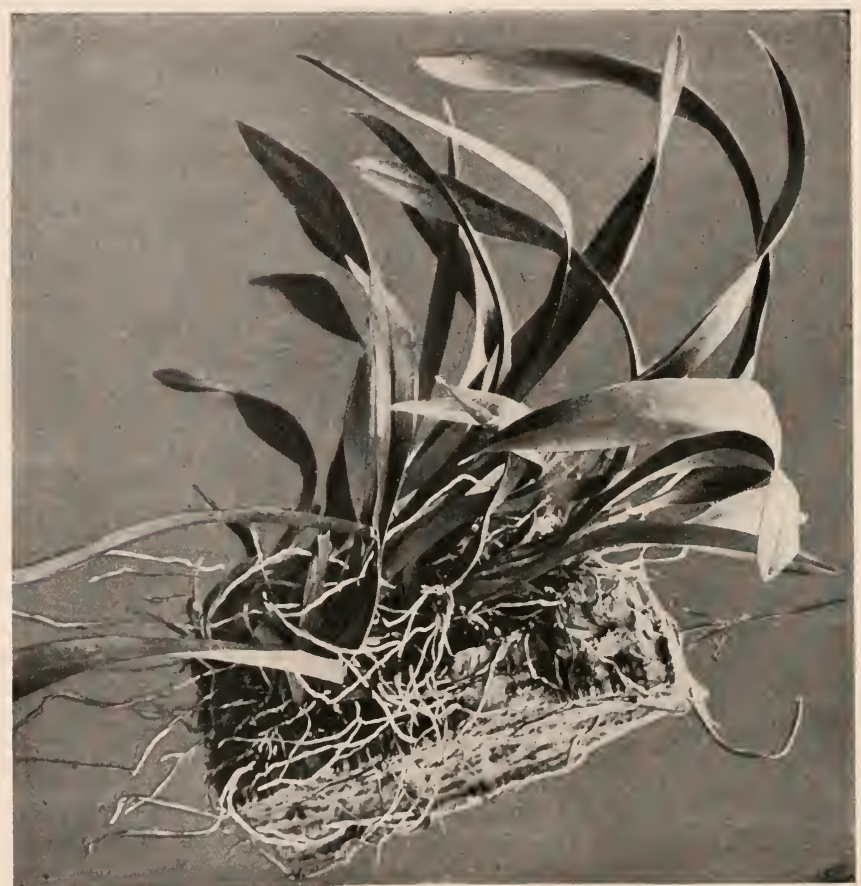

Fig. 93. An orchid, showing aerial roots.

character. Sometimes root systems developing in the soil may enter tile drains, when water roots will develop in such clusters as to choke the drain. 'The same bunching of water roots may be noticed when a hyacinth bulb is grown in a vessel of water.

66. Air roots. - In certain parts of the tropics the air is so moist that it is possible for some plants to obtain suffi- 
cient moisture from this source, without any soil-relation or water-relation. Among these plants the orehids are most notable, and they may be observed in almost any greenhouse. Clinging to the trunks of trees, usually imitated in the greenhouse by nests of sticks, they send out long roots which dangle in the moist air (see Figs. 93, 94). It is necessary to have some special absorbing and condensing arrangement, and in the orehids this is usually provided by the development of a sponge-like tissue about the root known as the velamen, which greedily absorbs the moisture of the air. Examine also Figs. 92, 95, 96, 9\%.

6\%. Clinging roots. - These roots are developed to fasten the plant body to some support, and do no work of absorption (see Fig. 98). Very common illustrations may be obtained from the ivies, the trumpet creeper, etc. These roots eling to varions supports, stone walls, tree trunks, ete.,

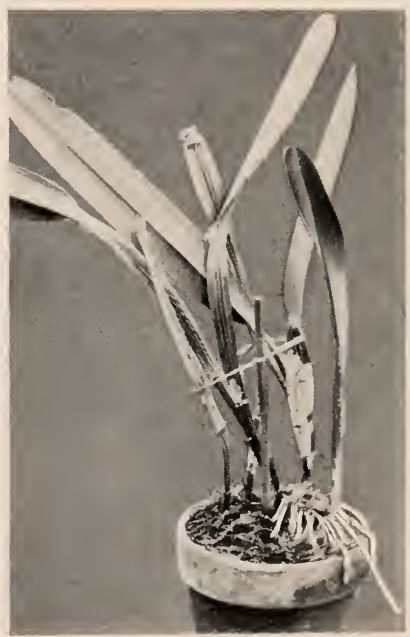

Fig. 94. An orchid, showing aerial roots and thick leaves. by sending minute tendril-

like branches into the erevices. The sea-weeds (alga) develop grasping struetures extensively, a large majority of them being anchored to rocks or to some rigid support beneath the water, and their bodies floating free. 'The root-like processes by which this anchorage is secured are very prominent in many of the common marine sea-weeds (see Fig. 15\%).

68. Prop roots.-Some roots are developed to prop stems or wide-spreading branches. In swampy ground, or in tropical forests, it is very common to find the base of 


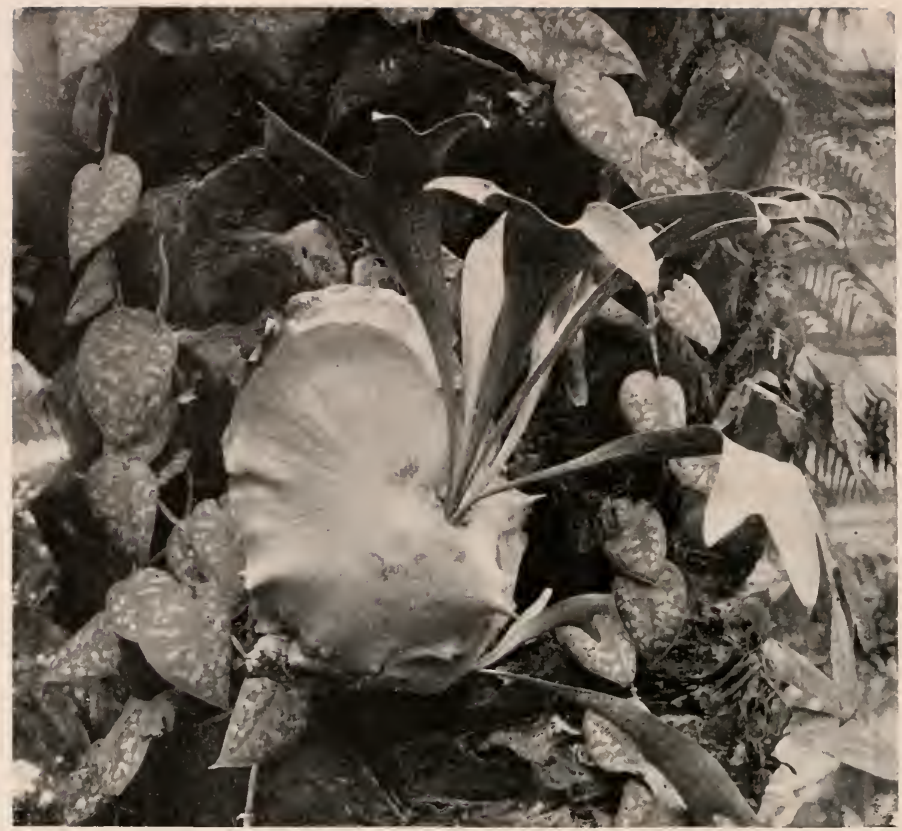

F1G. 95. A staghorn fern (Platycerium), an aerial plant of the tropics. About it is a vine, which shows the leaves adjusted to the lighted side.

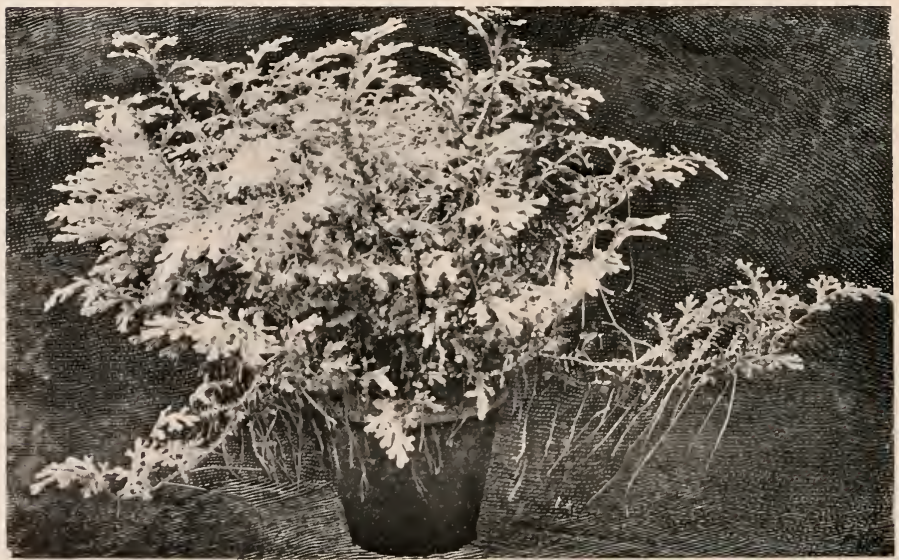

Fig, 96. Selaginella, showing dangling rhizophores and finely divided leaves. 


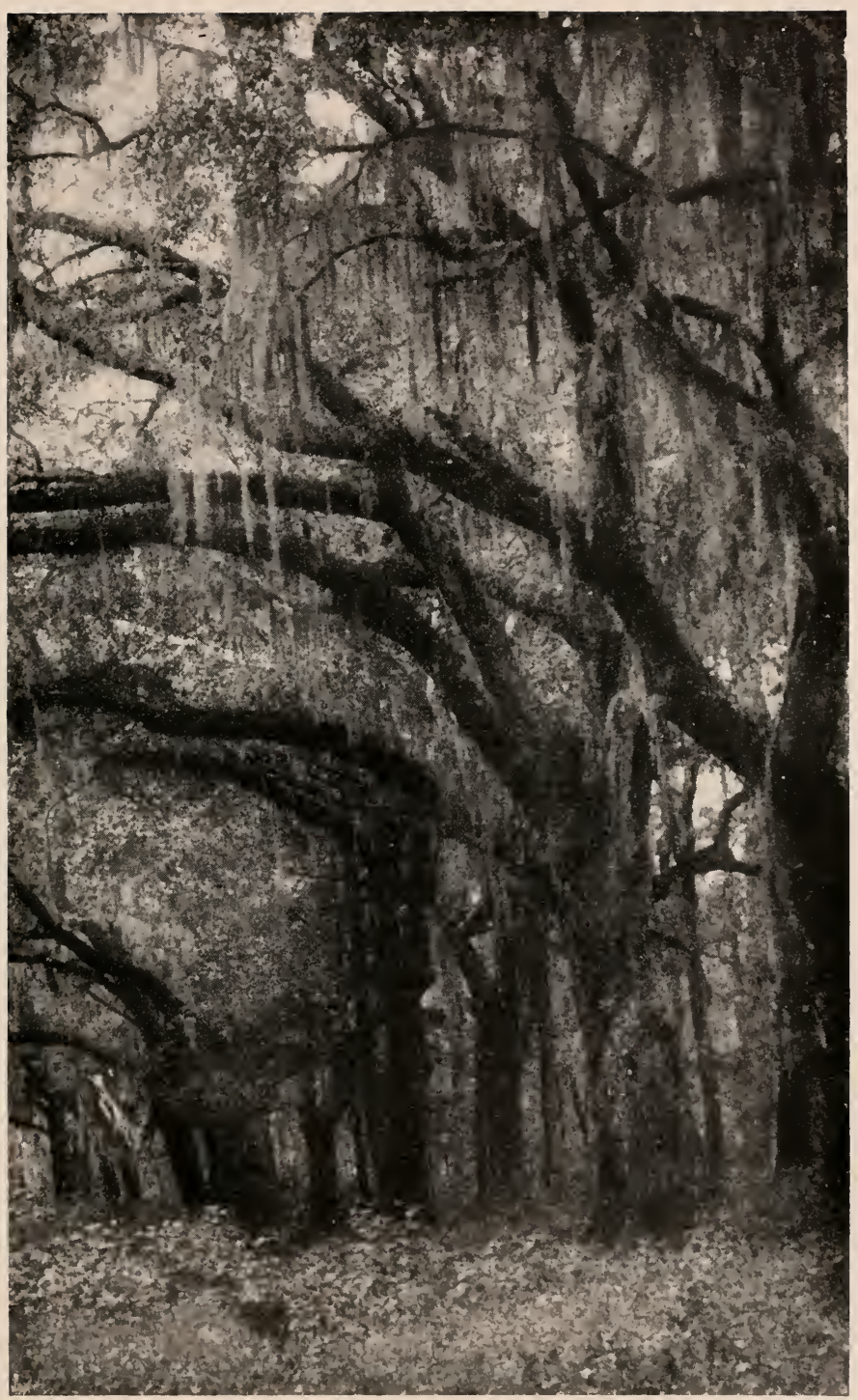

Fig. 97. Live oaks, in the Gulf States, upon which are growing masses of long moss or black moss (Tillandsia), a common aerial plant. 


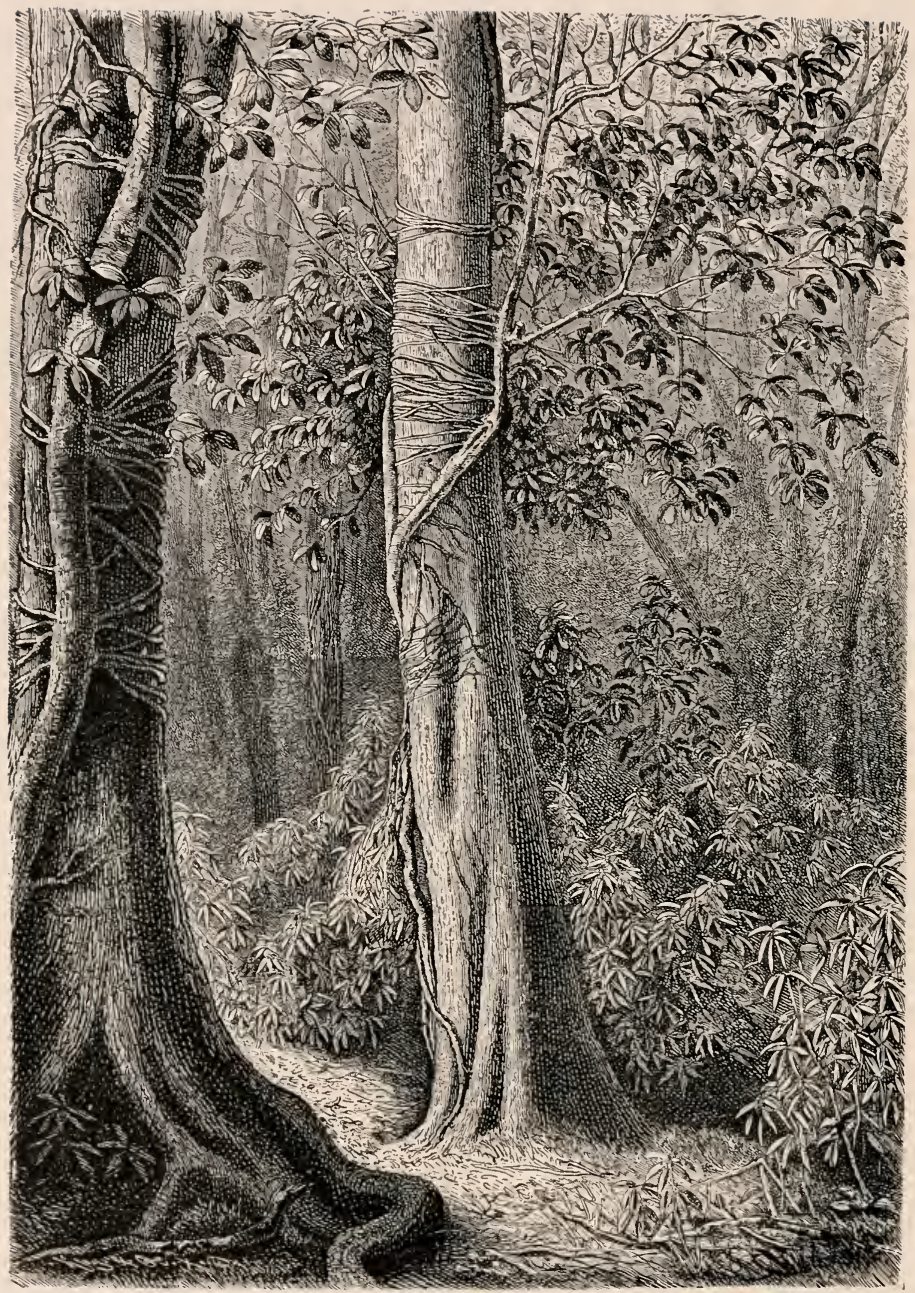

FIG. 98. A tropical forest, showing the cord-like holdfasts developed by an epiphyte, which pass around the tree trunks like tightly bound ropes.-Ifter KERNER. 
tree trunks buttressed by such roots which extend out over and beneath the surface, and divide the area about the tree into a series of irregular chambers (see Fig. 100). Some-

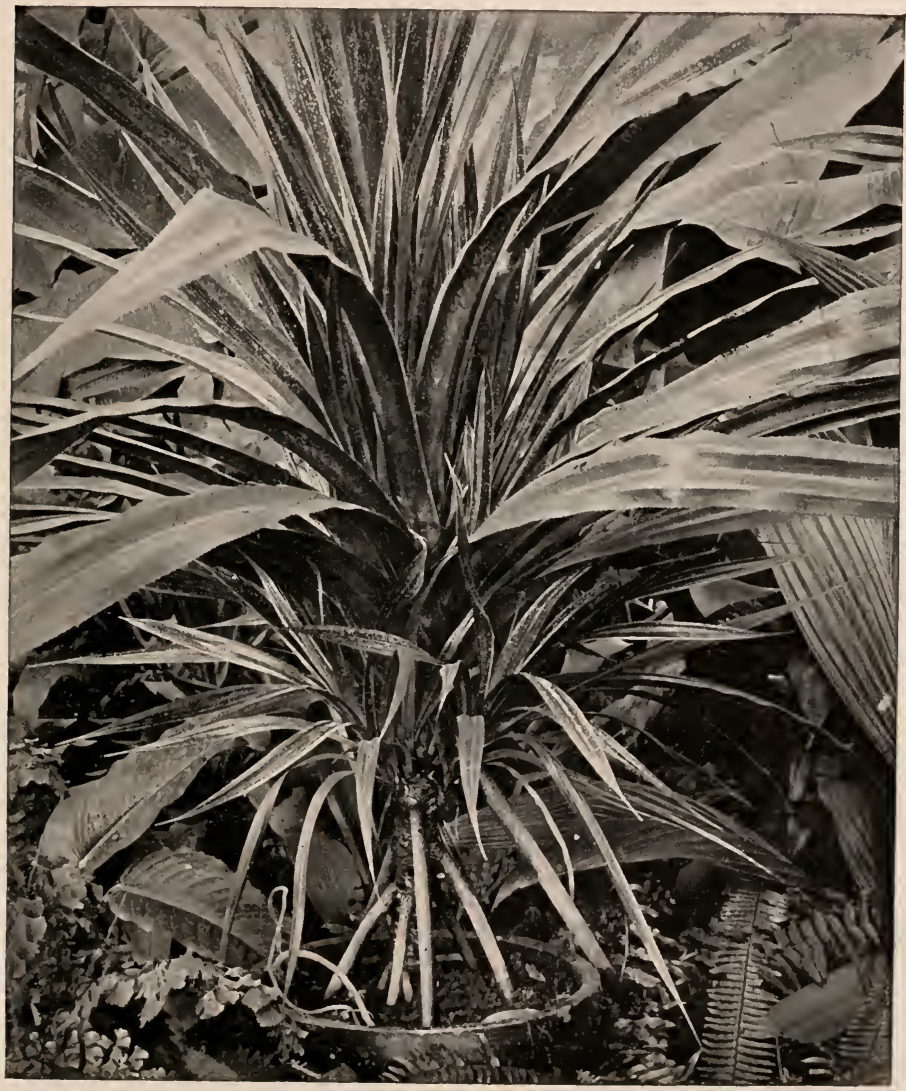

Fig. 99. A screw-pine (Pandanus), from the Indian Ocean regiou, showing the prominent prop roots put out near the base.

times a stem, either inclined or with a poorly developed primary root system, puts out prop roots which support it, as in the screw-pine (see Fig. 99). A notable case is 


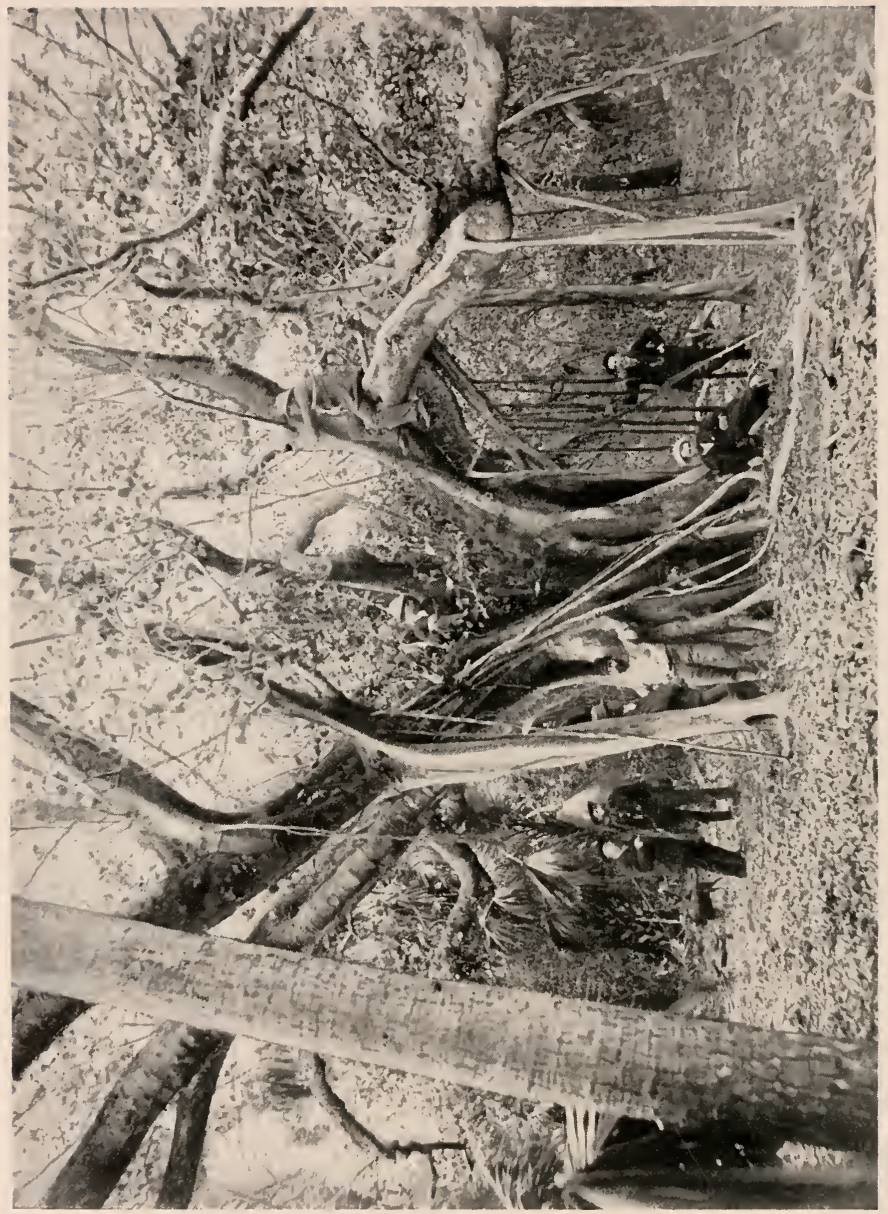




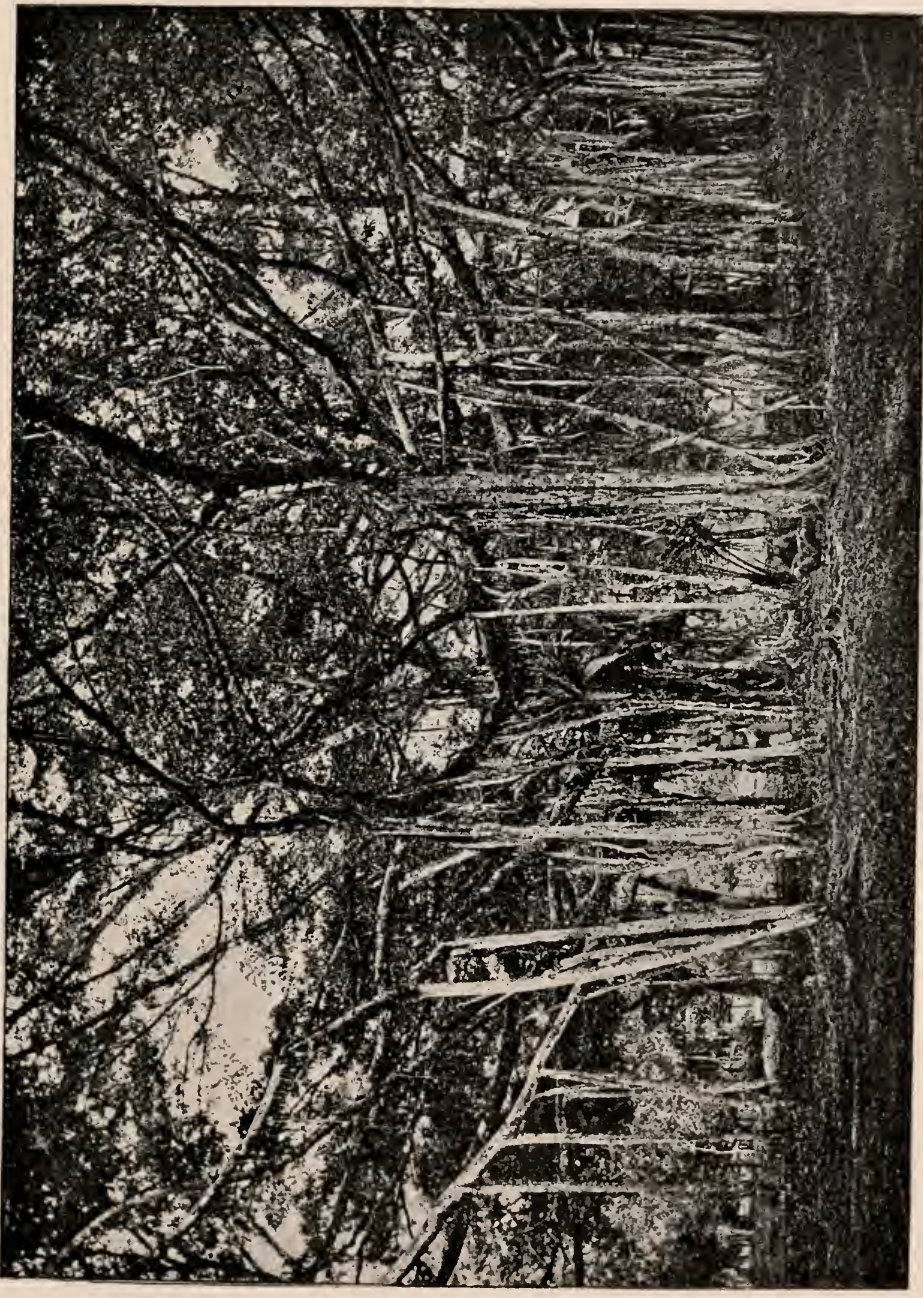

ह 
that of the banyan tree, whose wide-spreading branches are supported by prop roots, which are sometimes very numerous (see Fig. 101). The immense banyans usually

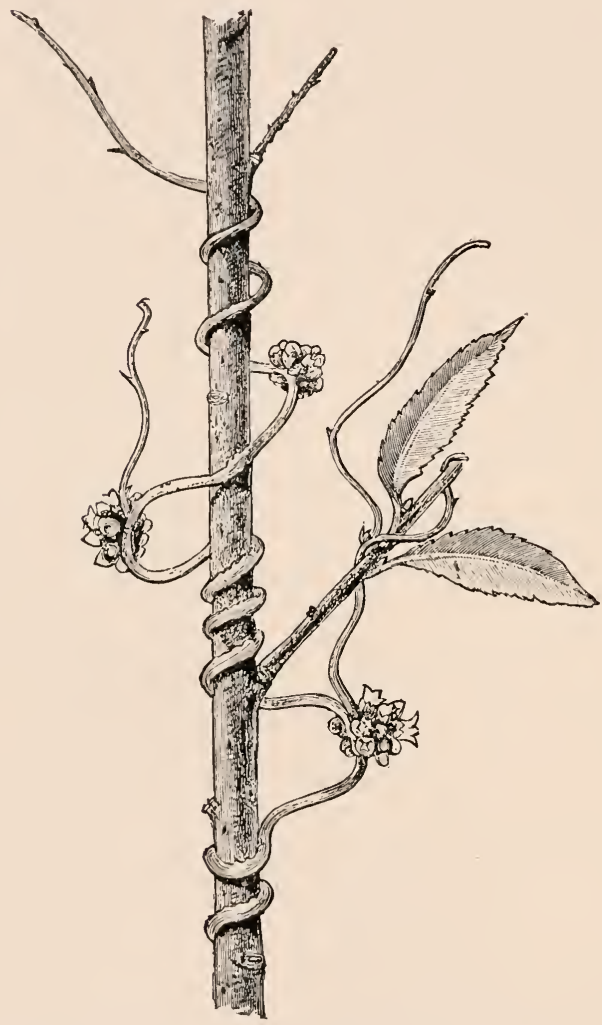

Fig. 102. A dodder plant parasitic on a willow twig. The leafless dodder twines abont the willow, and sends ont sucking processes which penetrate and absorb.-After STRAsBURGer. illustrated are especially cultivated as sacred trees, the prop roots being assisted in penetrating the soil. There is record of such a tree in Ceylon with 350 large and 3,000 small prop roots, able to cover a village of 100 liuts.

\section{Parasites.} -Besides the roots mentioned abore, certain plants develop root-like processes which relate them toliosts. A host is a living plant or animal upon which some other plant or animal is living as a parasite. The parasite gets its supplies from the host, and must be related to it properly. If the parasite grows upon the surface of its host, it must penetrate the body to obtain 
food supplies. 'Therefore, processes are developed which penetrate and absorb. The mistletoe and dodder are seedplants which have this habit, and both have such processes (see Figs. 102, 103). This habit is much more extensively developed, however, in a low group of plants known as the fungi. Many of these parasitic fungi live upon plants and animals,

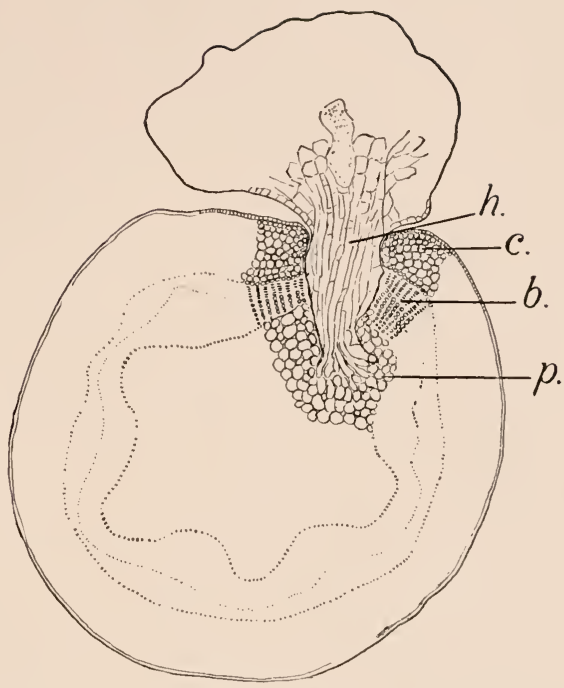

FIG. 103. A section showing the living connection between dodder and a golden rod upon which it is growing. The penetrating and absorbing organ $(h)$ has passed through the cortex $(c)$, the vascular zone $(b)$, and is disorganizing the pith $(l))$.

common illustrations being the mildews of lilac leaves and many other plants, the rust of wheat, the smut of corn, etc.

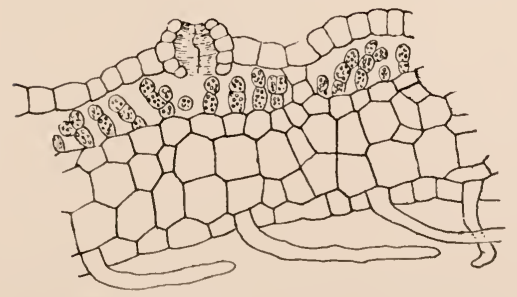

Fig. 104. Section through the thallus of a liverwort (Marchantia), showing the hair-like processes (rhizoids) which come from the under surface and act as roots in gripping and absorbing. In the epidermis of the upper surface a chimney-like opening is seen, leading into a chamber containing cells with chloroplasts.

\section{$\%$. Root structure.} -In the lowest groups of plants (alga, fungi, and moss-plants) true roots are not formed, but very simple structures, generally hairlike (see Fig. 10t). In fern-plants and seedplants, howerer, the root is a complex structure, so different from the root-like pro- 
cesses of the lower groups that it is regarded as the only true root. It is quite uniform in structure, consisting of a tough and fibrous central axis surrounded by a region of more spongy structure. The tough axis is mostly made

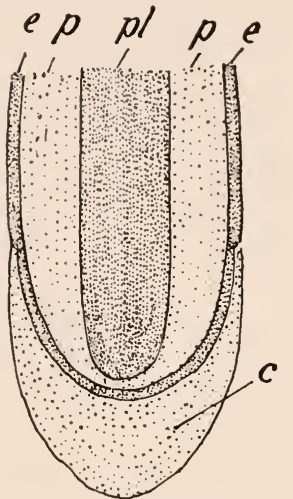

Fig. 105. A longitudinal section through the root tip of shepherd's purse, showing the central vascular axis $(p)$, surrounded by the cortex (p), outside of the cortex the epidermis $(e)$ which disappears in the older parts of the root, and the prominent root-cap $(c)$.

up of ressels, so called because they conduct material, and is called the rascular axis. The outer more spongy region is the cortex, which covers the vascular axis like a thick skin (see Fig. 105).

One of the peculiarities of the root, in which it differs from the stem, is that the branches come from the vaseular axis and burrow through the cortex, so that when the latter is peeled off the branches are left attached to the axis, and the cortex shows the holes through which they passed. It is evident that when such a root is absorbing, the absorbed material (water with various materials in solution) is received into the cortex, through which it must pass to the vascular axis to be condneted to the stem.

Another peculiarity of the root is that it elongates only by growth at the tip, while the stem usually continues to elongate some distance behind its growing tip. In the soil this delicate growing tip is protected by a little cap of cells, known as the root-cap (see Fig. 105).

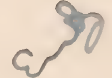




\section{CHAP'TER VI.}

\section{REPRODUCTIVE ORGANS.}

IT will be remembered that nutrition and reproduction are the two great functions of plants. In diseussing foliage leaves, stems, and roots, they were used as illustrations of nutritive organs, so far as their external relations are concerned. We shall now briefly study the reproductive organs from the same point of view, not describing the processes of reproduction, but some of the external relations.

;1. Vegetative multiplication.-Among the very lowest plants no special organs of reproduction are dereloped, but most plants have them. There is a kind of reproduction by which a portion of the parent body is set apart to produce a new plant, as when a strawberry rumner produces a new strawberry plant, or when a willow twig or a grape

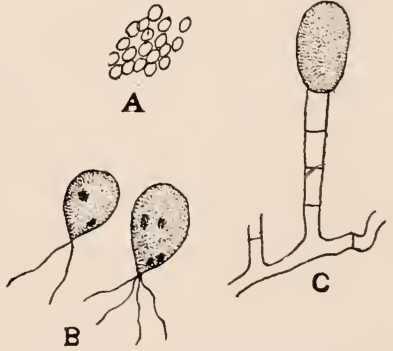

Fig. 106. A group of spores: $A$. spores from a common mold (a fungus), which are so minute and light that they are carried about by the air ; $B$, two spores from a common alga (Ulothrix), which can swim by means of the hair-like processes; $C$. the conspicuous dotted cell is a spore developed by a common mildew (a fungus), which is carried about by currents of air. cutting is planted and produces new plants, or when a potato tuber (a subterranean stem) produces new potato plants, or when pieces of Begonia leaves are used to start new Begonias. This is known as vegetutive multiplication, a kind of reproduction which does not use special reproductive organs. 
72. Spore reproduction.-Besides regetative multiplication most plants develop special reproductive bodies, known as spores, and this kind of reproduction is known as spore reproduction. These spores are very simple bodies, but have the power of producing new individuals. There are two great groups of spores, differing from each other not at all in their powers, but in the method of their production by the parent plant. One kind of spore is

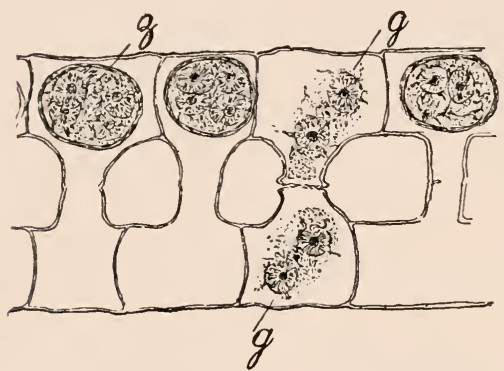

Fig. 10\%. Fragments of a common alga (Spirogyra). Portions of two threads are shown, which have been joined together by the growing of connecting tubes. In the upper thread four cells are shown, three of which contain eggs $(z)$, while the cell marked $g$, and its mate of the other thread each contain a gamete, the lower one of which will pass through the tube, blend with the upper one, and form another egg.

produced by dividing certain organs of the parent; in the other case two special bodies of the parent blend together to form the spore. Although they are both spores, for convenience we may call the first kind spores (see Figs. 106, 109), and the second kind eggs (see Fig. 10\%).* The two special bodies which blend together to form an egg are called gametes (see Figs. 107, 108, 109). These terms are necessary to any discussion of the external relations. Most plants develop both spores and eggs, but they are not always equally conspicuons. Among the algæ, both spores and eggs are prominent; among certain fungi the same is true, but many fungi are not known to produce eggs; among moss-plants the spores are prominent and abundant, but the egg is concealed and not generally noticed. What has been said

* It is recognized that this spore is really a fertilized egg, but in the absence of any accurate simple word, the term egg is used for conrenience, 
of the moss-plants is still more true of the fern-plants; while among the seed-plants certain spores (pollen grains) are conspicuous (see Fig. 110), but the eggs can be observed only by special manipulation in the laboratory. Seeds are neither spores nor eggs, but peculiar reproductive bodies which the hidden egg has helped to produce.

73. Germination. - Spores and eggs are expected to germinate; that is, to begin the development of a new plant. This germination needs certain external conditions, prominent among which are definite amounts of heat, moisture, and oxygen, and sometimes light. Conditions of germination may be observed most easily in connection with seeds. It must be understood, however. that what is called the germination of seeds is something

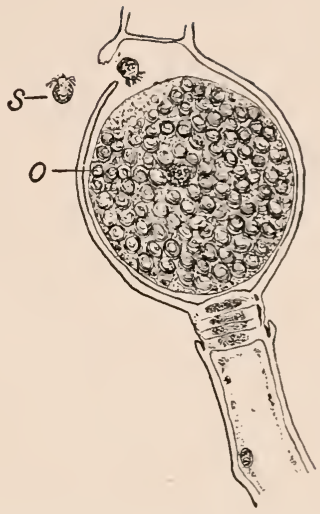

Fig. 108. A portion of the body of a common alga (Edogonium), s how ing gametes of very unequal size and activity; a very large one $(o)$ is lying in a globular cell, and a very small one is entering the cell, another similar one $(s)$ being just ontside. The two small gametes have hair-like processes and can swim freely. The small and large gam. etes unite and form an egg.

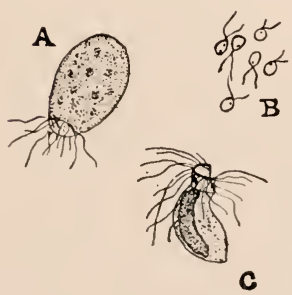

Fıc. 109. A group of swimming cells : $A$, a spore of (Edogonium (an alga); $B$, spores of Ulollurix (an alga): $C$, a gamete of Equisefum (horse-tail or scouring rush).

very different from the germination of spores and eggs. In the latter cases, germination inchides the very beginnings of the young plant. In the case of a seed, germination begun by an egg has been checked, and seed germination is its renewal. In other words, an egg has germinated and produced a young plant called the "embryo," and the germination of the seed simply consists in the continued growth and the escape of this embryo. 


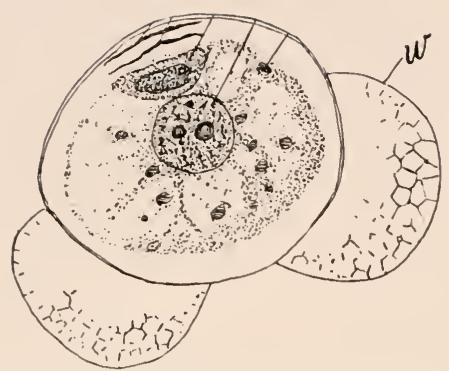

Fig. 110. A pollen grain (spore) from the pine, which develops wings $(w)$ to assist in its transportation by currents of air.

It is evident that for the germination of seeds light is not an essential condition, for they may germinate in the light or in the dark; but the need of heat, moisture, and oxygen is very apparent. The amount of heat required for germination varies widely with different seeds, some germinating at much lower temperatures than others. Every

kind of seed, or spore, or egg has a special temperature range, below which and above which it cannot germinate. The two limits of the range may be called the lowest and highest points, but between the two there is a best point of temperature for germination. The same general fact is true in reference to the moisture supply.

\section{Dispersal of reproductive bodies.}

-Among the most striking external relations, however, are those connected with the dispersal of spores, gametes, and seeds. Spores and seeds must be carried away from the parent plant, and separated from each other, out of the reach of rivalry for nutritive naterial; and gametes must come together and blend to form the eggs. Conspicuous among the means of transfer are the following.

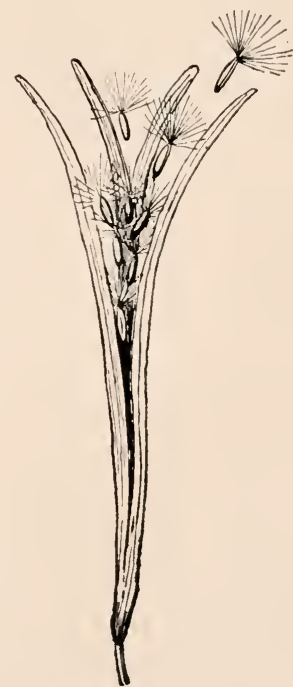

Fig. 111. A pod of fireweed (Epilobium) opening and exposing its plumed seeds which are transported by the wind.-After BEAL. 
75. Dispersal by locomotion.-The common method of locomotion is by means of movable hairs (cilia) developed upon the reproductive body, which propel it through the water (see Fig. 109). Swimming spores are very common among the alga, and at least one of the gametes in algæ, moss-plants, and fern-plants has the power of swimming by means of eilia.

\section{Dispersal by} water. It is very common for reproductive bodies to be transported by currents of water. The spores of many water plants of all groups, not constructed for locomotion, are thus floated about. This method of transfer is also very common among seeds. Many seeds are buoyant, or become so after soaking in water, and may be carried to great distances by

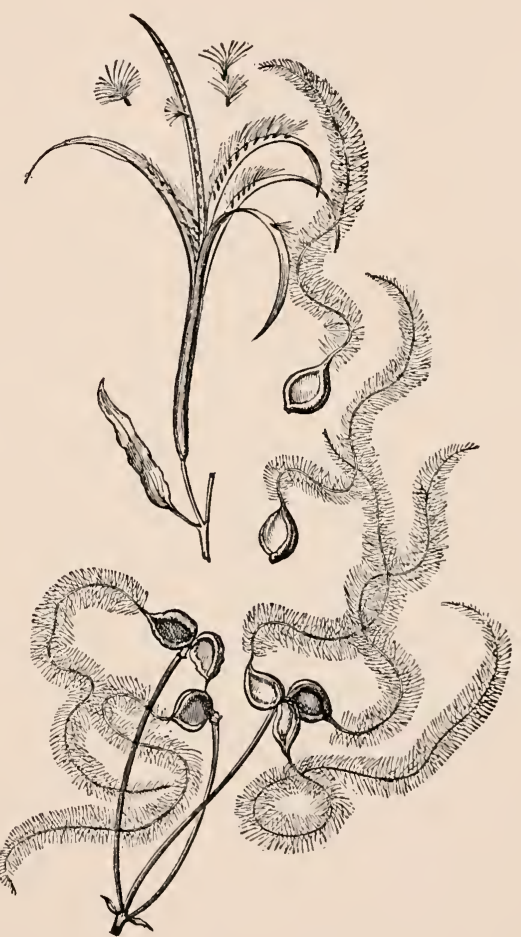

Fig. 112. The upper figure to the left is an opening pod of fireweed discharging its plumed seels. The lower fignre represents the seed-like fruits of Clematis with their long tail-like plumes.After línneis.

currents. For this reason the plants growing upon the banks or flood-plains of streams may have come from a wide area. Many seeds ean even endure prolonged soaking in sea-water, and then germinate. Darwin estimated 


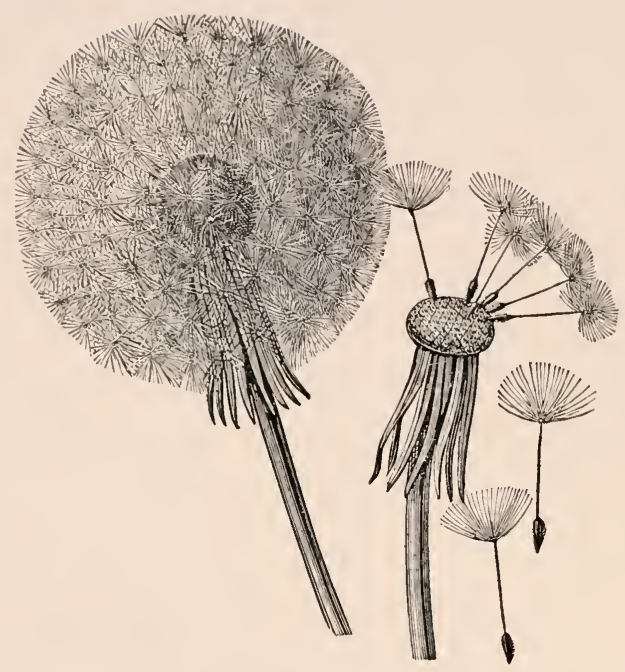

Fig. 113. A ripe dandelion head, showing the mass of plumes, a few seed-like fruits with their plumes still attached to the receptacle, and two fallen off.-After KERNER. that at least fourteen per cent. of the seeds of any country can retain their vitality in sea-water for twenty eight days. At the ordinary rate of movement of ocean currents, this length of time would permit such seeds to be transported over a thousand miles, thus making possible a very great range in distribution.

\%\%. Dispersal of spores by air.-This is one of the most common methods of transporting spores and seeds. In most cases spores are sufficiently small and light to be transported by the gentlest movements of air. Among the fungi this is a very common method of spore dispersal (see Fig. 106), and it is extensively used in scattering the spores of moss-plants, fern-plants (see Fig. 45), and seed-plants. Among seed-plants this is one method of pollination, the

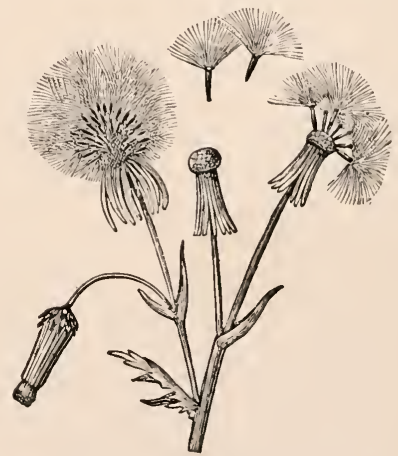

FIg. 114. Seed-like fruits of Senecio with plumes for dispersal by air.After lierner. 


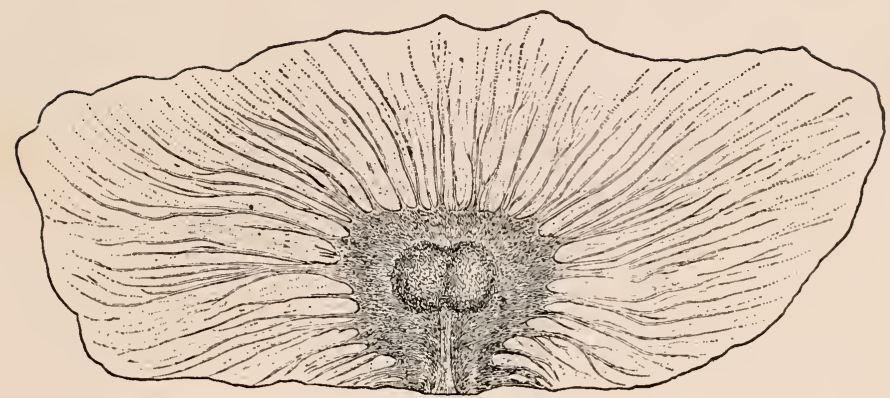

Fic. 115. A winged seed of Bignonia.-After Strasburger.

spores called pollen grains being scattered by the wind, and occasionally falling upon the right spot for germination. With such an agent of transfer the pollen must be very light and powdery, and also very abundant, for it must come down al-

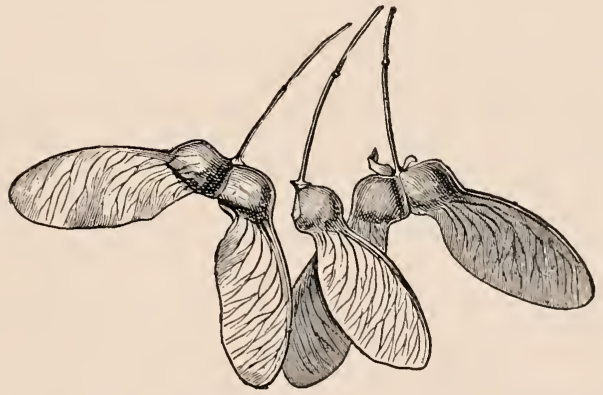

Fig. 116. Winged fruit of maple.-After KerNer. most like rain to be certain of reaching the right places.

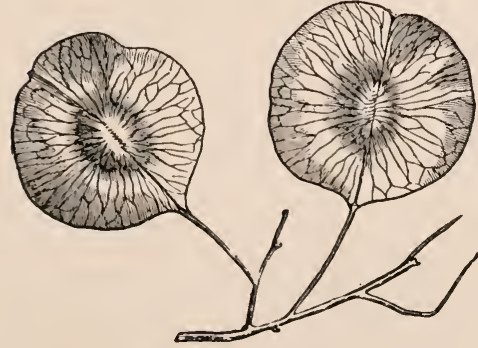

Fig. 11\%. Winged fruit of Ptelea.-After KERNER. Among the grmnosperms (pines, hemlocks, etc.) this is the exclusive method of pollination, and when a pine forest is shedding pollen the air is full of the spores, which may be carried to a great distance before being deposited. Occasional 


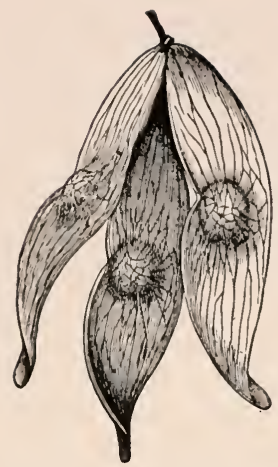

FIG. 118. Winged fruit of Ailanthus.-After KERNER.

common forest trees (oak. hickory, chestnut, etc.).

78. Dispersal of seeds by air._. Seeds are very rarely light enough to be carried by currents of air without some special adaptation. Wings and plumes of very many and often very beautiful patterns are exceedingly common in connection with seeds or seedlike fruits (see Figs. $115,116,11 \%, 118$, 119). Wings are developed by the fruit of maples and of ash, and by the seeds reports of "showers of sulphur" have arisen from an especially heary fall of pollen that has been carried far from some gymnosperm forest. In the case of pines and their near relatives, the pollen spores are assisted in their dispersal through the air by developing a pair of broad wings from the outer coat of the spore (see Fig. 110). 'This same method of pollination-that is, carrying the pollen spores by currents of air-is also used by many monocotyledons, such as grasses; and by many dicotyledons, such as our most

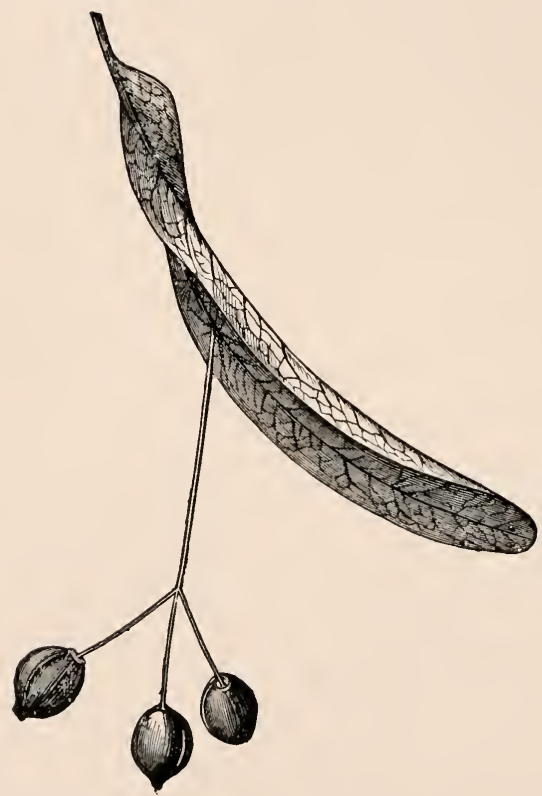

FIG. 119. Frnit of basswood (Tilia), showing the peculiar wing formed by a leaf.-After KERNER. 


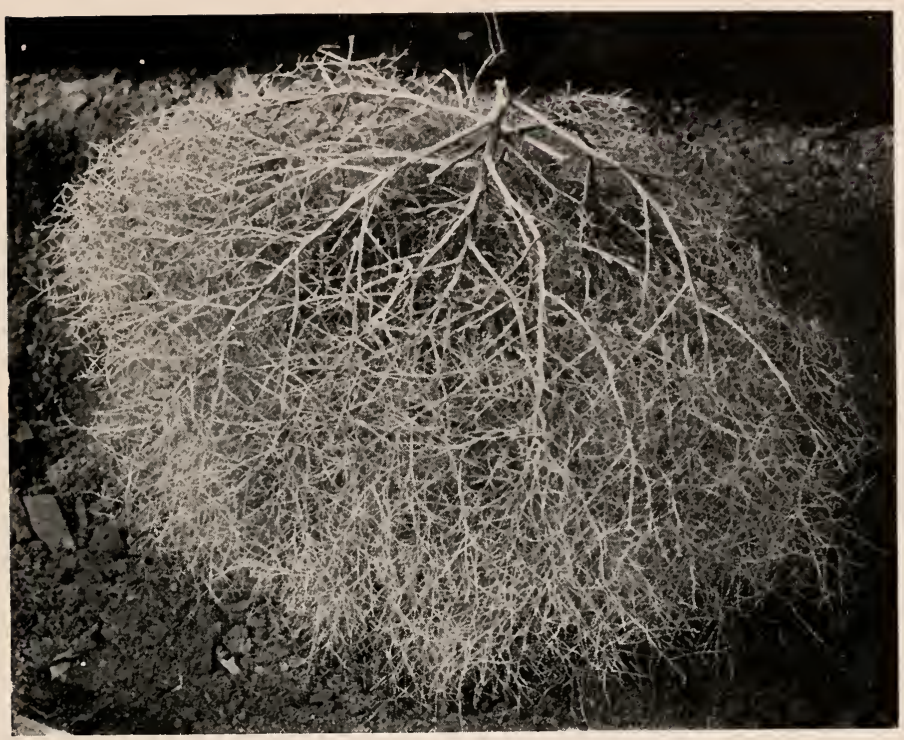

Fig. 120. A common tumbleweed (Cycloloma).

of pine and catalpa. Plumes and tufts of hairs are leveloped by the seed-like fruits of dandelion, thistle. and very many of their relatives, and by the seeds of the milkweed (see Figs. 111, 112, 113, 114). On plains, or level stretches. where winds are strong. a curious habit of seed dispersal has been developed by certain plants known as "tumbleweeds" or “ field rollers." 'These plants are profusely branching annuals with a small root system in a

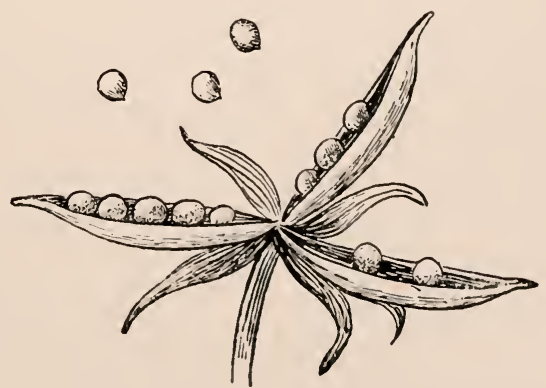

Fig. 121. The 3-valved fruit of violet discharging its seeds.-After BEAL. 


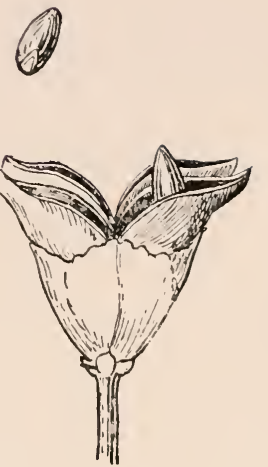

FIg. 12.). A fruit of witch hazel discharging its seeds.-After BEAL.

light or sandy soil (see Fig. 120). When the work of the season is over, and the absorbing rootlets have shriveled, the plant is easily blown from its anchorage by a gust of wind, and is trundled along the surface like a light wicker ball, the ripe seed ressels dropping their seeds by the way. In case of an obstruction, such as a fence, great masses of these tumbleweeds may often be seen lodged against the windwarl side.

\%9. Discharge of spores.-In many plants the distribution of spores and seeds is not provided for by any of the methods just mentioned, but the ressels containing them are so constructed that they are discharged with more or less violence and are somewhat scattered.

Many spore cases, especially those of the lower plants, burst irregularly, and with sufficient violence to throw out spores. In the liverworts peculiar cells, called elaters or "jumpers," are formed among the spores, and when the wall of the spore case is ruptured the claters are liberated. and by their active motion assist in discharging the spores.

In most of the true mosses the spore case opens by pushing off a lid at the apex, which exposes a delicate fringe of teeth covering the mouth of the urn-like case. These teeth bend in and ont of the open spore case as they become moist or

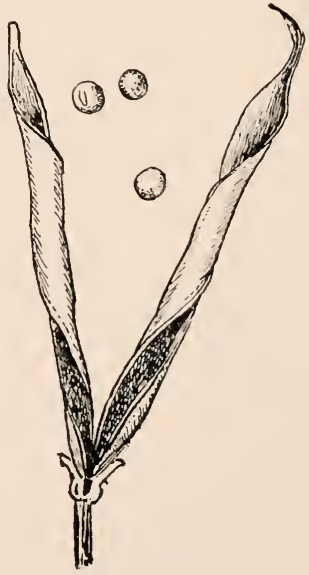

FIG, 123. A pod of wild bean bursting, the two valves violently twisting and discharging the seeds.-After BEAL. 
dry, and are of considerable service in the discharge of spores.

In the common ferns a heavy spring-like ring of cells encircles the delicate-walled spore case. When the wall becomes dry and comparatively brittle the spring straightens with considerable force, the delicate wall is suddenly torn and the spores are discharged (see Fig. 45).

Even in the case of the pollenspores of seed-plants, a special layer of the wall of the pollen-sac usually develops as a spring-like layer, which assists in opening widely the sac

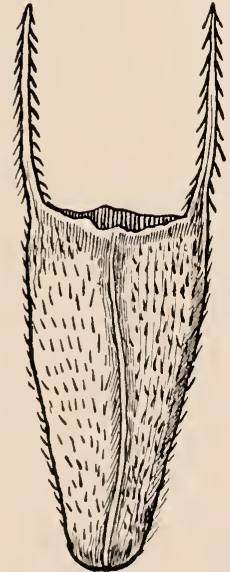

Fig. 1:5. A fruit of beggar ticks, slowing the two barbed appendagres which lay hold of animals. -After Beal. when the wall begins to yield along the line of breaking.

\section{Discharge of}

seeds. - While seeds are generally carried away from the parent plant by the agency of water currents or air currents, as already noted, or by animals, in some instances there is a mechanical discharge provided for in the structure of the seedcase. In such plants as the witch hazel and violet, the walls of the seed-ressel press upon the contained seeds, so that when rupture occurs the seeds are pinched out, as a moist apple-seed is discharged by being pressed between the thumb and finger (see Figs. 121, 12:). In the touchme-not a strain is developed in the wall of the seed-ressel, so that at rupture it 
suddenly curls up and throws the seeds (see Fig. 123). The squirting cucumber is so named because it becomes very much distended with water, which is finally forcibly ejected along with the mass of seed. An "artillery plant" common

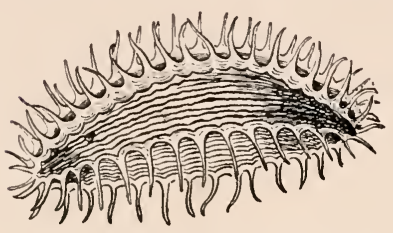

FIG. 1:6. The fruit of carrot, showing the grappling appendages.-After BEAL. in eultivation discharges its seeds with considerable violence; while the detonations resulting from the explosions of the seed-vessels of Hura crepitans, the "monkey's dinner bell," are often remarked by travelers in tropical forests.

81. Dispersal of seeds by animals.-Only a few illustrations ean be given of this very large subjeet. Water birds are great carriers of seeds which are contained in the mud elinging to their feet and legs. 'This mud from the borders of ponds is usually completely filled with seeds and spores of various plants. One has no conception of the number until they are actually computed. The following extract from Darwin's Oriain of Species illustrates this point :

"I took, in February, three tablespoonfuls of mud from three different points beneath water,

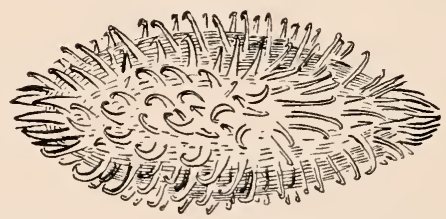

Fig. 12\%. The fruit of cocklebur, showing the grappling appendages.-After BEAL. on the edge of a little pond. This mud when dried weighed only $6 \frac{8}{4}$ ounces; I kept it covered up in my study for six months, pulling up and counting each plant as it grew ; the plants were of many kinds, and were altogether $53 \pi$ in number; and yet the viscid mud was all contained in a breakfast cup!"

Water birds are generally high and strong fliers, and the seeds and spores may thus be transported to the margins of distant ponds or lakes, and so very widely dispersed.

In many cases seeds or fruits develop grappling append- 
ages of rarious kinds, which lay hold of animals brushing past, and so the seeds are dispersed. Common illustrations are Spanish needles, beggar ticks, stick seeds. burdock, etc. Study Figs. 124, 125, 126, 12\%, 128, 129, 130.

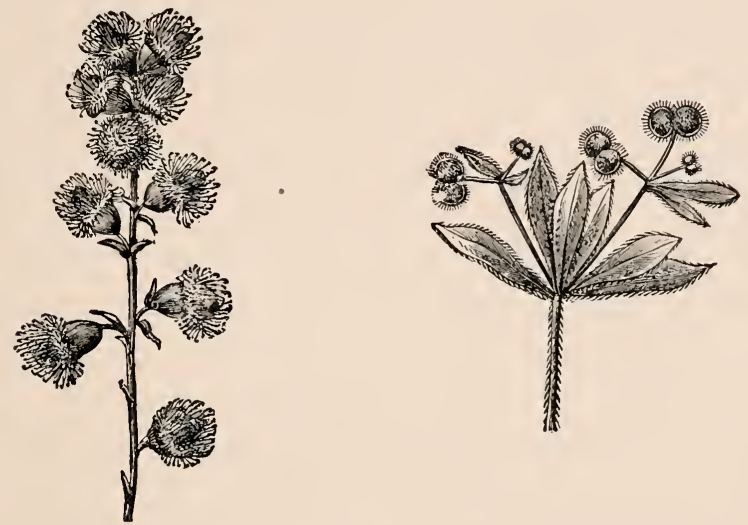

Fr6. 128. Fruits with grappling appendages. That to the left is agrimony; that to the right is Galium.-After KenNer.

In still other cases the fruit becomes pulpy, and attractive as food to certain birds or mammals. Many of the seeds (such as those of grapes) may be able to resist the attacks of the digestive fluids and escape from the alimentary tract in a condition to germinate. As if to attract the attention of fruit-eating animals, fleshy fruits usually become brightly colored when ripe, so that they are plainly seen in contrast with the foliage.

82. Dispersal of pollen spores by insects.The transfer of pollen, the name applied to certain spores of seed-
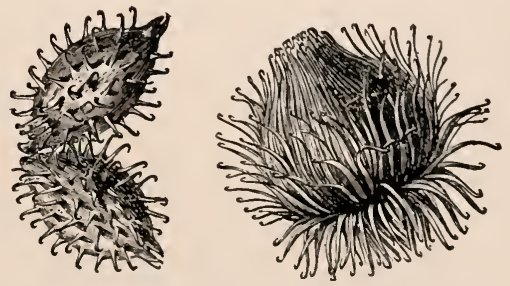

FIG. 129. Fruits with grappling appendages. The figure to the left is cocklebur; that to the right is burdock.-After KERNER. 


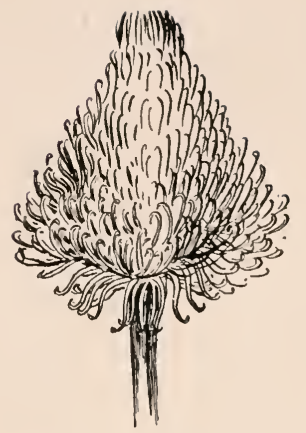

FIG. 130. A head of fruits of burdock, showing the grappling appendages.After BEAL.

plants, is known as pollination, and the two chief agents of this transfer are eurrents of air and insects. In \$ry the transfer by currents of air was noted, such plants being known as anemophitous plants. Such plants seldom produce what are generally recognized as true flowers. All those seed-plants which produce more or less showy flowers, however, are in some way related to the visits of insects to bring about pollination, and are known as entomophilous plants. 'This relation between insects and flowers is so important and so extensive that it will be treated in a separate chapter. 


\section{CHAPTER VII.}

\section{FLOWERS AND INSECTS.}

83. Insects as agents of pollination.-The use of insects as agents of pollen transfer is very extensive, and is the prevailing method of pollination among monocotyledons and dicotyledons. All ordinary flowers, as usually recognized, are related in some way to pollination by insects, but it must not be supposed that they are always successful ir. securing it. This mutually helpful relation between flowers and insects is a very wonderful one, and in some cases it has become so intimate that they camnot exist without each other. Flowers have been modified in every way to be adapted to insect visits, and insects have been variously adapted to flowers.

84. Self-pollination and cross-pollination.-The advantage of this relation to the flower is to secure pollination. The pollen may be transferred to the carpel of its own flower, or to the carpel of some other flower. 'The former is known as self-pollination, the latter as cross-pollination. In the case of cross-pollination the two flowers concerned may be upon the same plant, or upon different plants, which may be quite distant from one another. It would seem that cross-pollination is the preferred method, as flowers are so commonly arranged to secure it.

85. Advantage to insects. - The adrantage of this relation to the insect is to secure food. 'This the flower provides either in the form of nectar or pollen; and insects risiting flowers may be divided roughly into the two groups of nectar-feeding insects, represented by butterflies and moths, 
and pollen-feeding insects, represented by the numerous bees and wasps. When pollen is provided as food, the amount of it is far in excess of the needs of pollination. The presence of these supplies of food is made known to the insect by the display of color in connection with the flowers, by odor, or by form. It should be said that the attraction of insects by color has been doubted recently, as certain experiments have suggested that some of the common flower-visiting insects are color-blind, but remarkably keen-scented. However this may be for some insects, it seems to be sufficiently established that many insects recognize their feeding ground by the display of color.

86. Suitable and unsuitable insects.-It is evident that all insects desiring nectar or pollen for food are not suitable for the work of pollination. For instance, the ordinary ants are fond of such food, but as they walk from plant to plant the pollen dusted upon them is in great danger of being brushed off and lost. 'The most farorable insect is the flying one, that can pass from flower to flower through the air. It will be seen, therefore, that the flower must not only secure the visits of suitable insects, but must guard against the depredations of unsuitable ones.

8\%. Danger of self-pollination.-There is still another problem which insect-pollinating flowers must solve. If cross-pollination is more adrantageous to the plant than self-pollination, the latter should be prevented so far as possible. As the stamens and carpels are usually close together in the same flower, the danger of self-pollination is constantly present in many flowers. In those plants which have stamen-producing flowers upon one plant and carpelproducing flowers upon another, there is no such danger.

88. Problems of pollination.-In most insect-pollinating flowers, therefore, there are three problems: (1) to prevent self-pollination, ( 2$)$ to secure the risits of suitable insects, and (3) to ward off the visits of unsuitable insects. It must not be supposed that flowers are uniformly suceessful 
in solving these problems. They often fail, but succeed often enough to make the effort worth while.

89. Preventing self-pollination.-It is evident that this danger arises only in those flowers in which the stamens and carpels are associated, but their separation in different flowers may be considered as one method of prevent-
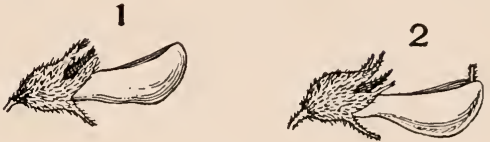
ing self-pollination. In order to mnderstand the various arrangements to be considered, it is necessary to explain that the carpel does not receive the pollen indifferently over its whole surface. There is one definite region organized, known as the stigma, upon which the pollen must be deposited if it is to do its work. Usually this is at the most projecting point of the carpel, very often at the end of a stalklike prolongation from the ovary (the bulbous part of the carpel), known as the style;

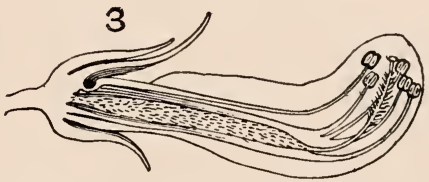

FIG. 131. Parts of the flower of rose acacia (Robinia hispida). In 1 the keel is shown projecting from the hairy calyx, the other more showy parts of the corolla having been removed. Within the keel are the stamens and the carpel, as seen in 3 . The keel forms the natural landing place of a visiting bee, whose weight depresses the keel and causes the tip of the style to protrude, as shown in 2. This style tip bears pollen upon it, canght among the hairs, seen in 3 , and as it strikes the body of the bee some pollen is brushed off. If the bee has previonsly visited another flower and received some pollen, it will be seen that the stigma, at the very tip of the style, striking the body first, will very probably receive some of it. The nectar pit is shown in 3, at the base of the uppermost stamen.-After Grax.

sometimes it may run down one side of the style. When the stigma is ready to receive pollen it has upon it a sweetish, sticky fluid, which holds and feeds the pollen. In this condition the stigma is said to be mature: and the pollen is mature when it is shedding, that is, ready to fall 
out of the pollen-sacs or to be remored from them. The devices used by flowers containing both stamens and earpels to prevent self-pollination are very numerous, but most of them may be included under the three following heads :

(1) Position.-In these cases the

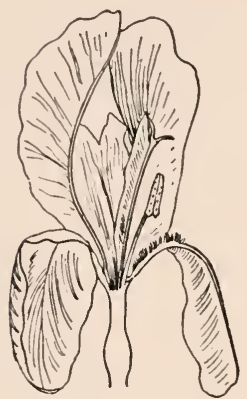

Fig. 132. A portion of the flower of an iris, or llag. The single stamen shown is standing between the petal to the right and the petal-like style to the left. Near the top of this style the stigmatic shelf is seen extending to the right, which nust receive the pollen upon its upper surface. The nectar pit is at the junction of the petal and stamen. While obtaining the nectar the insect brushes the pollen-bearing part of the stamen. and pollen is lodged upon its body. In visiting the next flower and entering the stamen chamber the stigmatic shelf is apt to be brushed.-After GraY. pollen and stigma are ready at the same time, but their position in reference to each other, or in reference to some conformation of the flower, makes it unlikely that the pollen will fall upon the stigma. The stigma may be placed above or beyond the pollen sacs, or the two may be separated by some mechanieal obstruction, resulting in much of the irregularity of flowers.

In the flowers of the rose acacia and its relatives, the sereral stamens and the single carpel are in a cluster, enclosed in the keel of the flower. The stigma is at the summit of the style, and projects somewhat beyond the pollen-sacs shedding pollen. Also there is often a rosette of hairs. or bristles, just beneath the stigma, which acts as a barrier to the pollen (see Fig. 131).

In the iris, or common flag, each stamen is in a sort of pocket between the petal and the petal-like style, while the stigmatic surface is on the top of a flap, or shelf, which the style sends out as a roof to the poeket. With such an arrangement, it would seem impossible for the pollen to reach the stigma unaided (see Fig. 132).

In the orehids, remarkable for their strange and beautiful flowers, there are 
usually two pollen-sacs, and stretched between them is the stigmatic surface. In this case, however, the pollen grains are not dry and powdery, but cling together in a mass, and cannot escape from the sac without being pulled out (see Fig. 133). The same sort of pollen is developed by the milkweeds.

(2) Consecutive maturity.--In these cases the pollen and
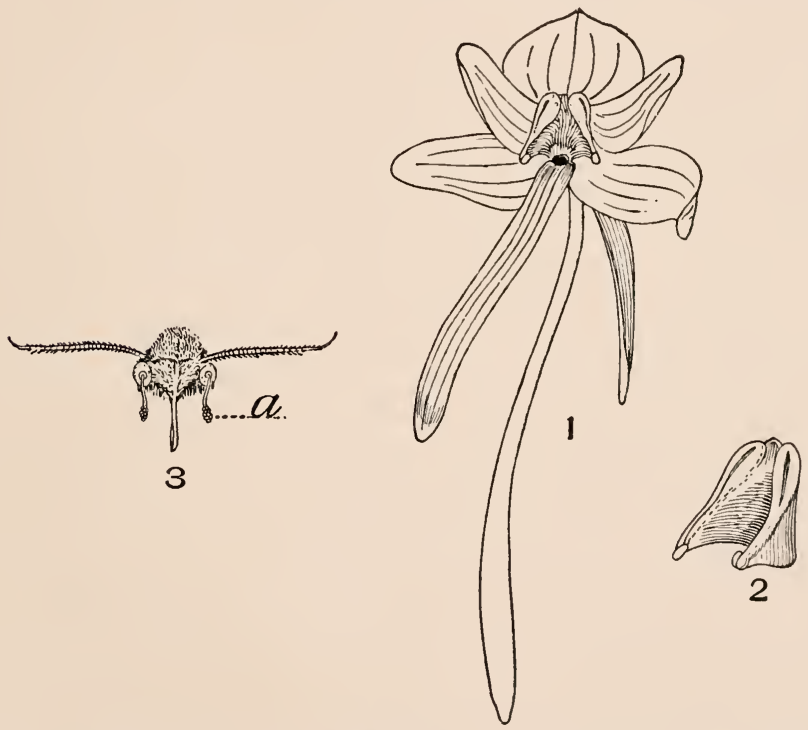

Fig. 133. A flower of an orchid (Habenaria). At 1 the complete flower is shown, with three sepals behind, and three petals in front, the lowest one of which has developed a long strap-shaped portion, and a still longer spur portion, the opening to which is seen at the base of the strap. At the bottom of this long spur is the nectar, which is reached by the long proboscis of a moth. The two pollen sacs of the single stamen are seen in the centre of the flower, diverging downwards, and between them stretches the stigma surface. The relation between pollen sacs and stigma surface is more clearly shown in 2 . Within each pollen salc is a mass of sticky pollen, ending below in a sticky disk, which may be seen in 1 and 2 . When the moth thrusts his proboscis into the nectar tube, his head is against the stigmatic surface and also against the disks. When lie removes his head the disks stick fast and the pollen masses are dragged ont. In 3 a pollen mass $(a)$ is shown sticking to each eye of a moth. Upon visiting another flower these pollen masses are thrust against the stigmatic surface and pollination is effected.-After Grar. 
stigma of the same flower are not mature at the same time. It is evident that this is a very effective method of preventing self-pollination. When the pollen is being shed the stigma is not ready to receive, or when the stigma is ready to receive the pollen is not ready to be shed. In some cases the pollen is ready first, in other cases the stigma, the former condition being called protandry, the latter protogyny. This is a very common method of preventing
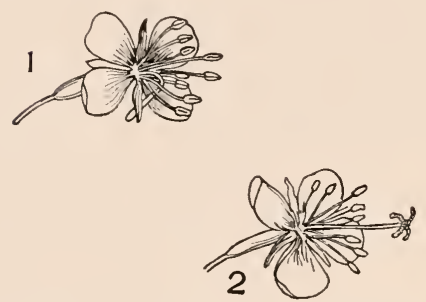

FIG. 134. Flowers of fireweed (Epilobium), showing protandry. In 1 the stamens are thrust forward, and the style is sharply turned downward and backward. In 2 the style is thrnst forward, with its stigmatic branches spread. An insect in passing from 1 to 2 will almost certainly transfer pollen from the stamens of 1 to the stigmas of 2.-After GraY. self-pollination, and is commonly not associated with irregularity.

The ordinary figwort may be taken as an example of protogyny. When the flowers first open, the style, bearing the stigma at its tip, is found protruding from the urn-like flower, while the four stamens are curved down into the tube, and not ready to shed their pollen. At some later time the style bearing the stigma wilts, and the stamens straighten up and protrude from the tube. In this way, first the receptive stigma, and afterwards the shedding pollen-sacs. occupy the same position.

Protandry is even more common, and many illustrations can be obtained. For example, the showy flowers of the common fireweed, or great willow herb, when first opened display their eight shedding stamens prominently, the style being sharply curved downward and backward, carrying the four stigma lobes well out of the way. Later, the stamens bend away, and the style straightens up and exposes its stigma lobes, now receptive (see Fig. 13t).

(3) Difference in pollen.-In these cases there are at 
least two forms of flowers, which differ from one another in the relative lengths of their stamens and styles. In the accompanying illustrations of Houstonia (see Fig. 135) it is to be noticed that in one flower the stamens are short and included in the tube, and the style is long and projecting, with the four stigmas exposed well above the tube. In the other flower the relative lengths are exactly reversed, the style being short and included in the tube, and the stamens long and projecting. It appears that the pollen from the short stamens is most effective upon the stigmas of the short styles, and that the pollen from the long stamens is most effective upon the stig-
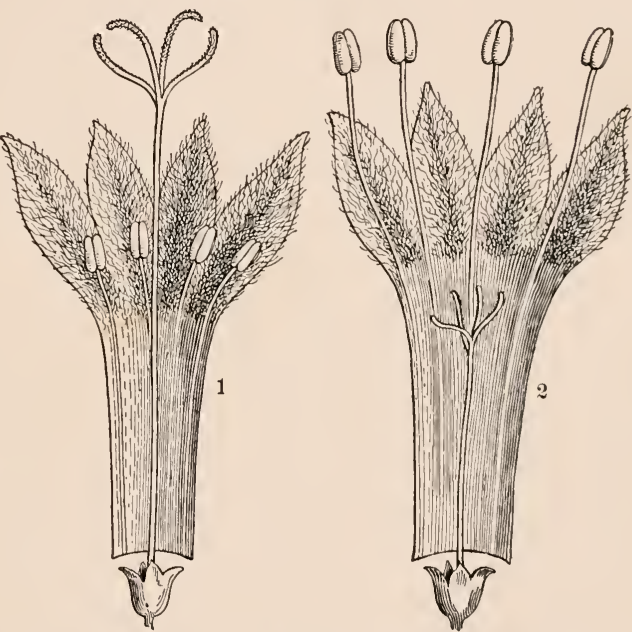

Fiti. 135. Flowers of Houstonia, showing two forms of flowers. In 1 there are short stamens and a long style; in 2 long stamens and short style. An insect risiting 1 will receive a band of pollen about the front part of its boly; upon visiting 2 this band will rub against the stigmas, and a fresh pollen band will be received upon the hinder part of the body, which, upon visiting another flower like No. 1, will brush against the stigmas.After Grax.

mas of the long styles; and as short stamens and long styles, or long stamens and short styles, are associated in the same flower, the pollen must be transferred to some other flower to find its appropriate stigma. This means that there is a difference between the pollen of the short stamens and that of the long ones.

In some cases there are three forms of flowers, as in one 
of the common loosestrifes. Each flower has stamens of two lengths, which, with the style, makes possible three combinations. One flower has short stamens, middle-length stamens, and long style ; another has short stamens, middlelength style, and long stamens; the third has short style, middle-length stamens, and long stamens. In these cases also the stigmas are intended to receive pollen from stamens
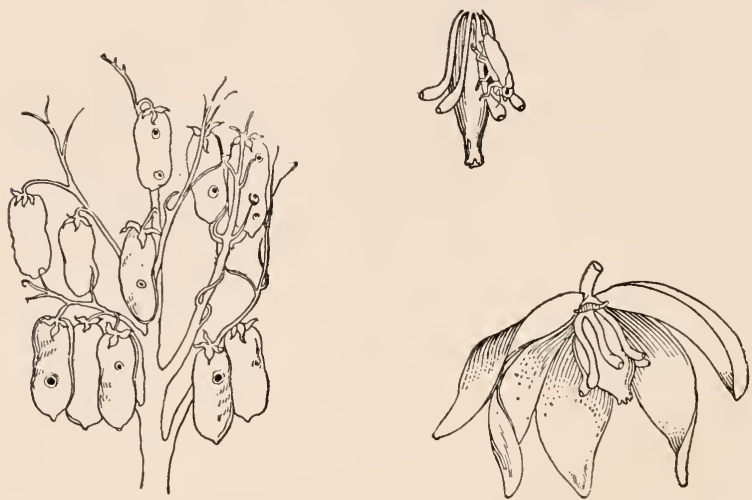

Fig. 136. Yucca and Pronuba. In the lower figure to the right an opened flower shows the peudent ovary with the stigma region at its apex. The upper figure to the right shows the position of Promuba when collecting pollen. The figure to the left represents a cluster of eapsules of Yucca, which shows the perforations made by the larva of Pronuba in escaping.-After Rilex and Trelease.

of their own length, and a transfer of pollen from flower to flower is necessary.

90. Self-pollination.-In considering these three general methods of preventing self-pollination, it must not be supposed that self-pollination is never provided for. It is provided for more extensively than was once supposed. It is found that many plants, such as violets, in addition to the usual showy, insect-pollinated flowers, produce flowers that are not at all showy, in fact do not open, and are often not prominently placed. The fact that these flowers are often closed has suggested for them the name cleistogamous 
flowers. In these flowers self-pollination is a necessity, and is found to be very effective in producing seed.

91. Yucca and Pronuba.-There can be no doubt, also, that there is a great deal of self-pollination effected in flowers adapted for pollination by insects, and that the insects themselves are often responsible for it. But in the remarkable case of $Y$ ucca and Pronuba there is a definite arrangement for self-pollination by means of an inseet (see Fig. 136). Yueea is a plant of the southwestern arid regions of North America, and Pronuba is a moth. The plant and the moth are very dependent wpon each other. 'The bellshaped flowers of Yucea hang in great terminal elusters, with six hanging stamens, and a central ovary ribbed lengthwise, and with a fummel-shaped opening at its apex, which is the stigma. The numerous ovules occur in lines beneath the furrows. During the day the small female Pronuba rests quietly within the flower, but at dusk becomes very active. She travels down the stamens, and resting on the open pollen-sac scoops out the somewhat sticky pollen with her front legs. Holding the little mass of pollen she runs to the ovary, stands astride one of the furrows, and piereing through the wall with her ovipositor, deposits an egg in an orule. After depositing sereral eggs she rums to the apex of the ovary and begins to erowd the mass of pollen she has collected into the funnel-like stigma. These actions are repeated several times, until many eggs are deposited and repeated pollination has been effected. As a result of all this the flower is pollinated, and seeds are formed which develop abundant nourishment for the moth larva, which beeome mature and bore their way out through the wall of the capsule (Fig. 136).

92. Securing cross-pollination.-In very many ways flowers are adapted to the visits of suitable insects. In obtaining neetar or pollen as food, the risiting insect receives pollen on some part of its boly which will be likely to come in contact with the stigma of the next flower visited. 


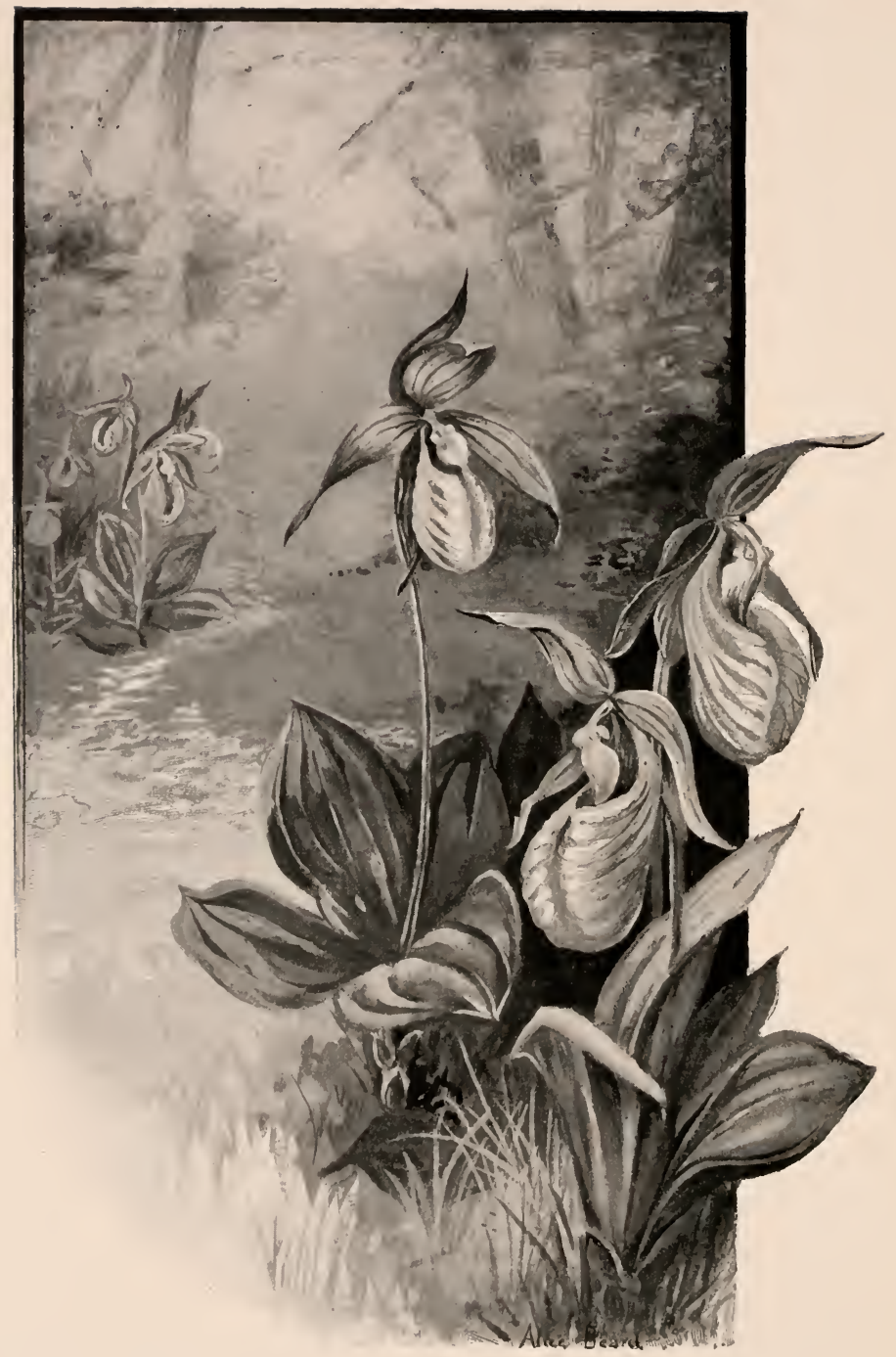

Fig. 137. A clump of lady-slippers (Cypripedium), showing the habit of the plant and the general structure of the flower.-After GiBson. 
Illustrations of this process may be taken from the flowers alrearly deseribed in connection with the prevention of self-pollination.

In the flowers of the pea family, such as the rose acacia (see Fig. 131), it will be noticed that the stamens and pistil are concealed within the keel, which forms the natural landing place for the bees which are used in pollination. This keel is so inserted that the weight of the insect depresses it, and the tip of the style comes in contact with its body. Not only does the stigma strike the body, but by the glaneing blow the surface of the style is rubbed against the insect, and on this style, below the stigma, the pollen has been deposited and is rubbed off against the inseet. At the next flower visited the stigma is likely to strike the pol-

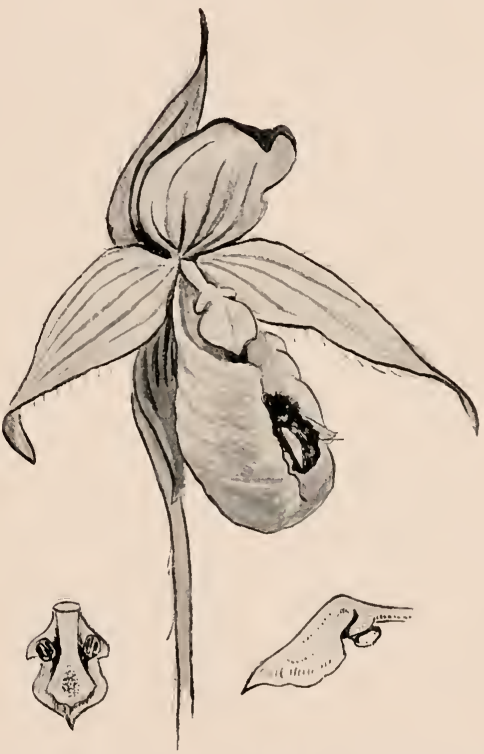

Fig. 138. Flower of cypripedium, showing the flap overhanging the opening of the pouch, into which a bee is crowding its way. The small figure to the right shows a side view of the flap; that to the left a view beneath the flap, showing the two dark anthers, and between them, further down (forward), the stigma surface.-After GiBson. len obtained from the previous flower, and the style will deposit a new supply of pollen.

In the flower of the common flag (see Fig. 132) the nectar is deposited in a pit at the bottom of the chamber formed by each style and petal. In this chamber the stamen is found, and more or less roofing it over is the flap, or shelf, 
upon the upper surface of which the stigma is developed. $\Lambda$ s the insect crowds its way into this narrowing chamber, its body is dusted by the pollen, and as it visits the next flower and thrusts aside the stigmatic shelf, it is apt to deposit upon it some of the pollen previonsly received.

The story of pollination in connection with the orchids is still more complicated (see Fig. 133). Taking an ordinary orchid for illustration, the details are as follows. Each of the two pollen masses terminates in a sticky disk or button; between them extends the concave stigma surface, at the bottom of which is the opening into the long

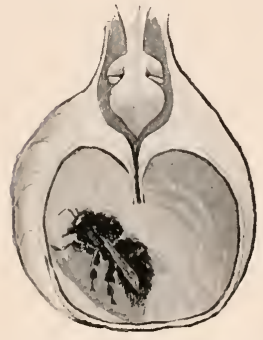

FIG.139. A bee imprisoned in the ponch (partly cut away) of Cypripedium. -After Gibson. tube-like spur in which the nectar is found. Such a flower is adapted to the large moths, with long probosces which can reach the bottom of the tube. As the moth thrusts its proboscis into the tube, its head touches the sticky button on each side, so that when it flies away these buttons stick to its head, sometimes directly to its eyes, and the pollen masses are torn out. These masses are then carried to the next flower and are thrust against the stigma in the attempt to get the nectar.

In the lady-slipper (Cypripedium), another orehid, the flowers have a conspicuous pouch (see Fig. 13\%), in which the nectar is secreted. A peculiar structure, like a flap, overhangs the opening of the pouch, beneath which are the two anthers, and between them the stigmatic surface (see Fig. 138). Into the pouch a bee crowds its way and becomes imprisoned (see Fig. 139). The nectar which the bee obtains is in the bottom of the pouch (see Fig. 140). When escaping, the bee moves towards the opening overhung by the flap and rubs first against the stigmatic surface (see Fig. 141), and then against the anthers, receiving pollen on its back (see Fig. 142). A visit to another flower 
will result in rubbing some of the pollen upon the stigma, and in receiving more pollen for another flower.

In cases of protandry, as the common figwort, flowers in the two conditions will be visited by the pollinating insect, and as the shedding stamens and receptive stigmas occupy the same relative position, the pollen from one flower

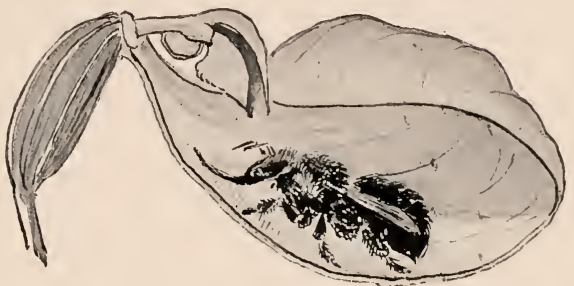

FIG. 140. A bee obtaining nectar in the pouch of Cypripedium.-After Gibson. will be carried to the stigma of another. It is evident that exactly the same methods prevail in the case of protogyny, as the fireweed (see Fig. 134).

The Houstonia (see Fig. 135), in which there are stamens and styles of different lengths, is visited by insects

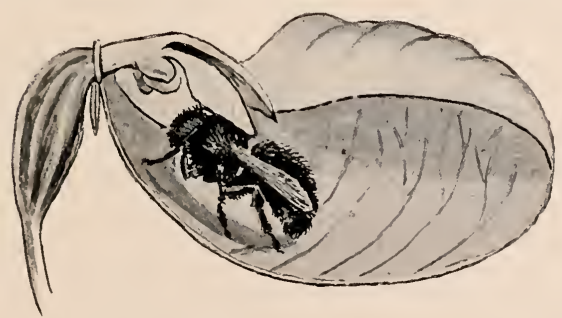

Fig. 141. A bee escaping from the ponch of Cypripedium, and coming in contact with the stigma. Advancing a little further the bee will come in contact with the anthers and receive pollen,-After Gibson. whose bodies fill the tube and protrude above it. In visiting flowers of both kinds, one region of the body receives pollen from the short stamens, and another region from the long stamens. In this way the insect will carry about two bands of pollen, which come in contact with the corresponding stigmas. When there are three forms of flowers, as mentioned in the case of one of the loosestrifes, the insect receives three pollen bands, one for each of the three sets of stigmas.

93. Warding off unsuitable insects.-Prominent among 
the unsuitable insects, which Kerner calls " mubidden guests," are ants, and adaptations for reducing their visits to a minimum may be taken as illustrations.

(1) Hairs. - $\perp$ common device for turning back ants, and other creeping insects, is a barrier of hair on the stem, or in the flower cluster, or in the flower.

(2) Giundular secretions.-In some cases a sticky secretion is exuded from the surface of plants, which

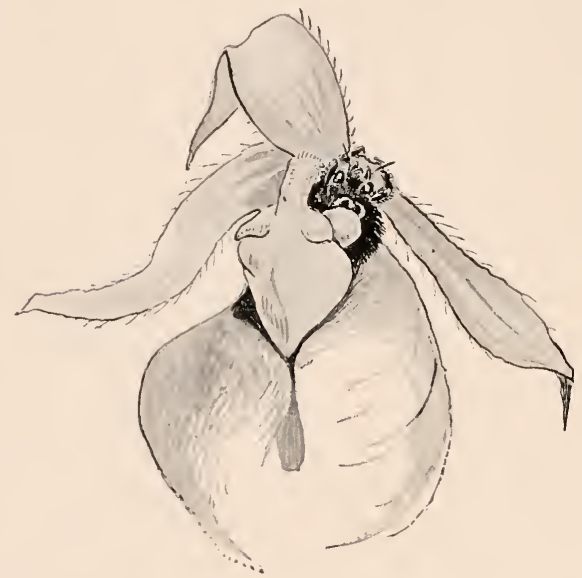

FIG. 142. A bee eseaping from the pouch of Cypripedium, and rubbing against an anther.-After Gibson. effectively stops the smaller creeping insects. In certain species of catch-fly a sticky ling girdles each joint of the stem.

(3) Isolation.The leaves of certain plants form water reservoirs about the stem. To ascend such a stem, therefore, a creeping insect must cross a series of such reservoirs. Teasel furnishes a common illustration, the opposite leaves being united at the base and forming a series of cups. More extensive water reservoirs are found in Bilbergia, sometimes called " traveler's tree," whose great flower clusters are protected by large reservoirs formed by the rosettes of leaves, which creeping insects camnot cross.

(4) Latex.-This is a milky secretion found in some plants, as in milkweeds. Caoutchone is a latex secretion of certain tropical trees. When latex is exposed to the air it stiffens immediately, becoming sticky and finally 
hard. In the flower clusters of many latex-secreting plants the epidermis of the stem is very smooth and delicate, and easily pierced by the claws of ants and other creeping insects who seek to maintain footing on the smooth surface. Wherever the epidermis is pierced the latex gushes out, and by its stiffening and hardening glues the insect fast.

(5) Protective forms. - In some cases the structure of the flower prevents the access of small creeping insects to the pollen or to the nectar. In the common snapdragon the two lips are firmly closed (see Fig. 74), and they can be forced apart only by some heary insect, as the bumble-bee, alighting upon the projecting lower lip, all lighter insects being excluded. In many species of Pentstemon, one of the stamens does not develop pollen sacs, but lies like a bar across the mouth of the pit in which the nectar is seereted. Through the crevices left by this bar the thin proboscis of a moth or butterfly can pass, but not the whole body of a creeping insect. Very numerous adaptations of this kind may be observed in different flowers.

(6) Protective closure.-Certain flowers are elosed at certain hours of the day, when there is the chief danger from ereeping insects. For instance, the evening primroses open at dusk, after the deposit of dew, when ants are not abroad; and at the same time they secure the risits of moths, which are night-fliers.

Numerous other adaptations to hinder the visits of unsuitable insects may be observed, but those given will serve as illustrations. 


\section{CHAP'TER VIII.}

\section{AN INDIVIDUAL PLANT IN ALL OF ITS RELATIONS.}

For the purpose of summarizing the general life-relations detailed in the preceding chapters, it will be useful to apply them in the case of a single plant. Taking a common seed-plant as an illustration, and following its history from the germination of the seed, certain general facts become evident in its relations to the external world.

94. Germination of the seed.-The most obrious needs of the seed for germination are certain amounts of moisture and heat. In order to secure these to the best advantage, the seed is usually rery definitely related to the soil, either upon it and covered by moisture and heat-retaining debris, or embedded in it. Along with the demand for heat and moisture is one for air (supplying oxygen), which is essential to life. The relation which germinating seeds need, therefore, is one which not only secures moisture'and heat adrantageously, but permits a free circulation of air.

95. Direction of the root.-The first part of the young plantlet to emerge from the seed is the tip of the axis which is to develop the root system. It at once appears to be very sensitive to the earth influence (geotropism) and to moisture influence (hydrotropism), for whaterer the direction of emergence from the seed, a curvature is developed which directs the tip towards and finally into the soil (see Fig. 143). When the soil is penetrated the primary root may continue to grow vigorously downward, showing a strong geotropic tendency, and forming what is known as the tap-root, from which lateral roots arise, which are 
much more influenced in direction by other external causes, especialiy the presence of moisture. As a rule, the soil is not perfectly uniform, and contact with different substances induces curvatures, and as a result of these and other causes, the root system may become very intricate, which is extremely favorable for absorbing and gripping.

96. Direction of the stem. -As soon as the stem tip is extricated from the seed, it exhibits sensitiveness to the light influence (heliotropism). being guided in a general way towards the light (see Fig. 143a). Direction towards the light, the source of the influence, is spoken of as positive heliotropism, as distinguished from direetion away from the light, called negative heliotropism. If the main axis continues to develop, it continues to show this positive heliotropism strongly, but the branches may show
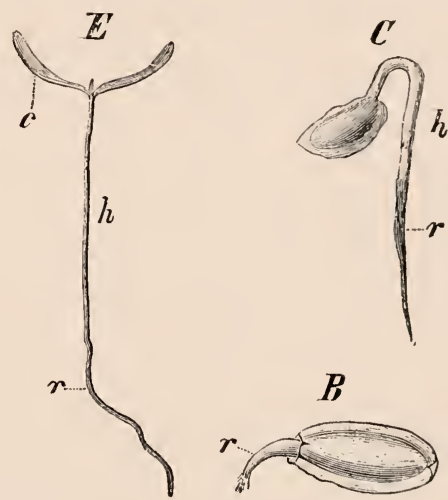

Fig. 143. Germination of the seed of arbor-vite $($ Thuja). $B$ shows the emergence of the axis ( $r$ ) which is to develop the root, and its turning towards the soil. $C$ shows a later stage, in which the root $(r)$ has been somewhat developed, and the stem of the embryo $(h)$ is developing a curve preparatory to pulling out the sced leaves (cotyledons). E shows the young plantlet entirely free from the seed, with its root $(r)$ extending into the soil, its stem (h) erect, and its first leaves $(c)$ horizontally spread.-After STRAsBURGER. every variation from positive to transverse heliotropism; that is, a direction transverse to the direction of the rays of light. In some plants certain stems, as stolons, runners, etc., show strong transverse heliotropism, while other stems, as rootstocks, ete., show a strong transverse geotropism.

9\%. Direction of foliage leaves.-The general direction of foliage leaves on an erect stem is transversely heliotropic; 
if necessary, the parts of the leaf or the stem itself twisting to allow the blade to assume this position. The danger of the leaves shading one another is reduced to a minimum by the elongation of internodes, the spiral arrangement, shortening and changing direction upwards, or lobing.

This outlines the general nutritive relations, the roots

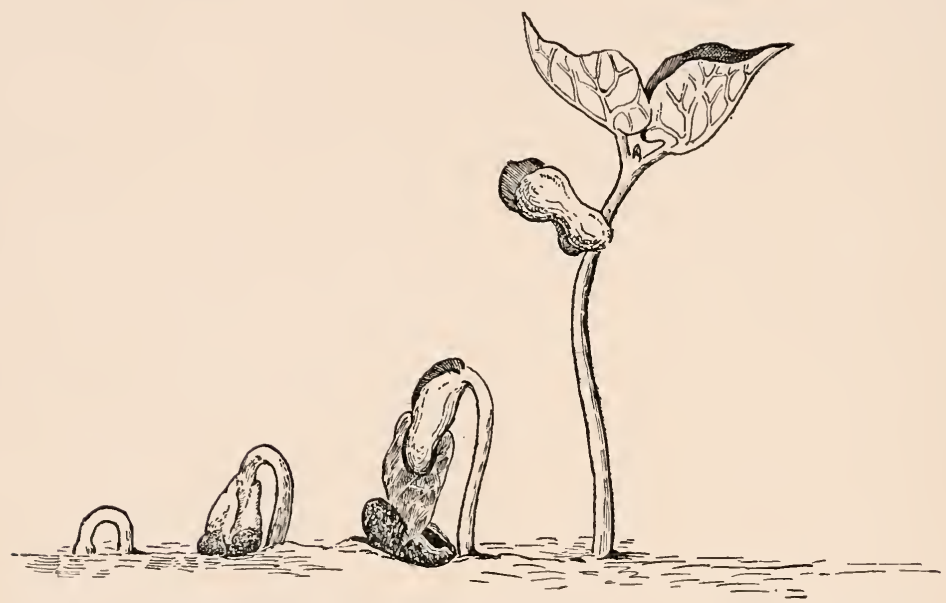

FIg. 143 $\iota$. Germination of the garden bean, showing the arch of the seedling stem above ground, its pull on the seed to extricate the cotyledons and plumnle, and the final straightening of the stem and expansion of the young leaves.-After Atrinson.

and leaves being favorably placed for absorption, and the latter also favorably placed for photosynthesis.

98. Placing of flowers.-The purposes of the flower seem to be served best by exposed positions, and consequently flowers mostly appear at the extremities of stems and branches, a position evidently favorable to pollination and seed dispersal. The flower's thus exposed are very commonly massed, or, if not, the single flower is apt to be large and conspicuous. The various devices for protecting neetar and pollen against too great moisture, and the more 
delicate structures against chill; for securing the visits of suitable insects, and warding off unsuitable insects; and for dispersing the seeds, need not be repeated.

99. Branch buds. - If the plant under examination be a tree or shrub, branch buds will be observed to be developed during the growing season (see Fig. 65). This device for protecting growing tips through a season of dangerous cold is very familiar to those living in the temperate regions. The internodes do not elongate, hence the leaves overlap; they develop little or no chlorophyll, and become scales. The protection afforded by these overlapping scales is often increased by the development of hairs. or by the secretion of mucilage or gum. 


\section{CHAPTER IX.}

\section{THE STRUGGLE FOR EXISTENCE.}

100. Definition.-The phrase "struggle for existence" has come to mean, so far as plants are concerned, that it is usually impossible for them to secure ideal relations, and that they must encounter unfarorable conditions. The proper light and heat relations may be difficult to obtain, and also the proper relations to food material. It often happens, also, that conditions once fairly favorable may become unfarorable. Also, multitudes of plants are trying to take possession of the same conditions. All this leads to the so-called "struggle," and rastly more plants fail than succeed. Before considering the organization of plant societies, it will be helpful to consider some of the possible changes in conditions, and the effect on plants.

101. Decrease of water.-This is probably the most common factor to fluctuate in the enviromment of a plant. Along the borders of streams and ponds. and in swampy places, the variation in the water is very noticeable, but the same thing is true of soils in general. However, the change chiefly referred to is that which is permanent, and which compels plants not merely to tide orer a drought, but to face a permanent decrease in the water supply.

Around the margins of ponds are very commonly seen fringes of such plants as bulrushes, cat-tail flags, reedgrasses, etc., standing in shoal water. As these plants grow close together, silt from the land is entangled by them, and presently it accumulates to such an extent that there is no more standing water, and the water supply for the 
bulrushes and their associates has permanently decreased below the farorable amount. In this way certain lake margins gradually encroach upon the water, and in so doing the water supply is permanently diminished for many plants. By the same process, smaller lakelets are gradually being converted into bogs, and the bogs in turn into drier ground, and these unfarorable changes in water supply are a menace to many plants.

The operations of man, also, have been very effective in diminishing the water supply for plants. Drainage, which is so extensively practiced, while it may make the watersupply more favorable for the plants which man desires, certainly makes it very unfavorable for many other plants. The clearing of forests has a similar result. The forest soil is receptive and retentive in reference to water, and is somewhat like a great sponge, steadily supplying the streams which drain it. The removal of the forest destroys much of this power. The water is not held and gradually doled ont, but rushes off in a flood; hence, the streams which drain the cleared area are alternately flooded and dried up. This results in a much less total supply of water arailable for the use of plants.

10\%. Decrease of light.-It is very common to observe tall, rank regetation shading lower forms, and seriously interfering with the light supply. If the rank regetation is rather temporary, the low plants may learn to precede or follow it, and so avoid the shading : but if the orer-shading vegetation is a forest growth, shading becomes permanent. In the case of deciduous trees, which drop their leaves at the close of the growing season and put ont a fresh crop in the spring, there is an interval in the early spring, before the leares are fully developed, during which low plants may secure a good exposure to light (see Fig. 144). In such places one finds an abundance of "spring flowers," but later in the season the low plants become very searce. This effective over-shading is not common to all forests, for 


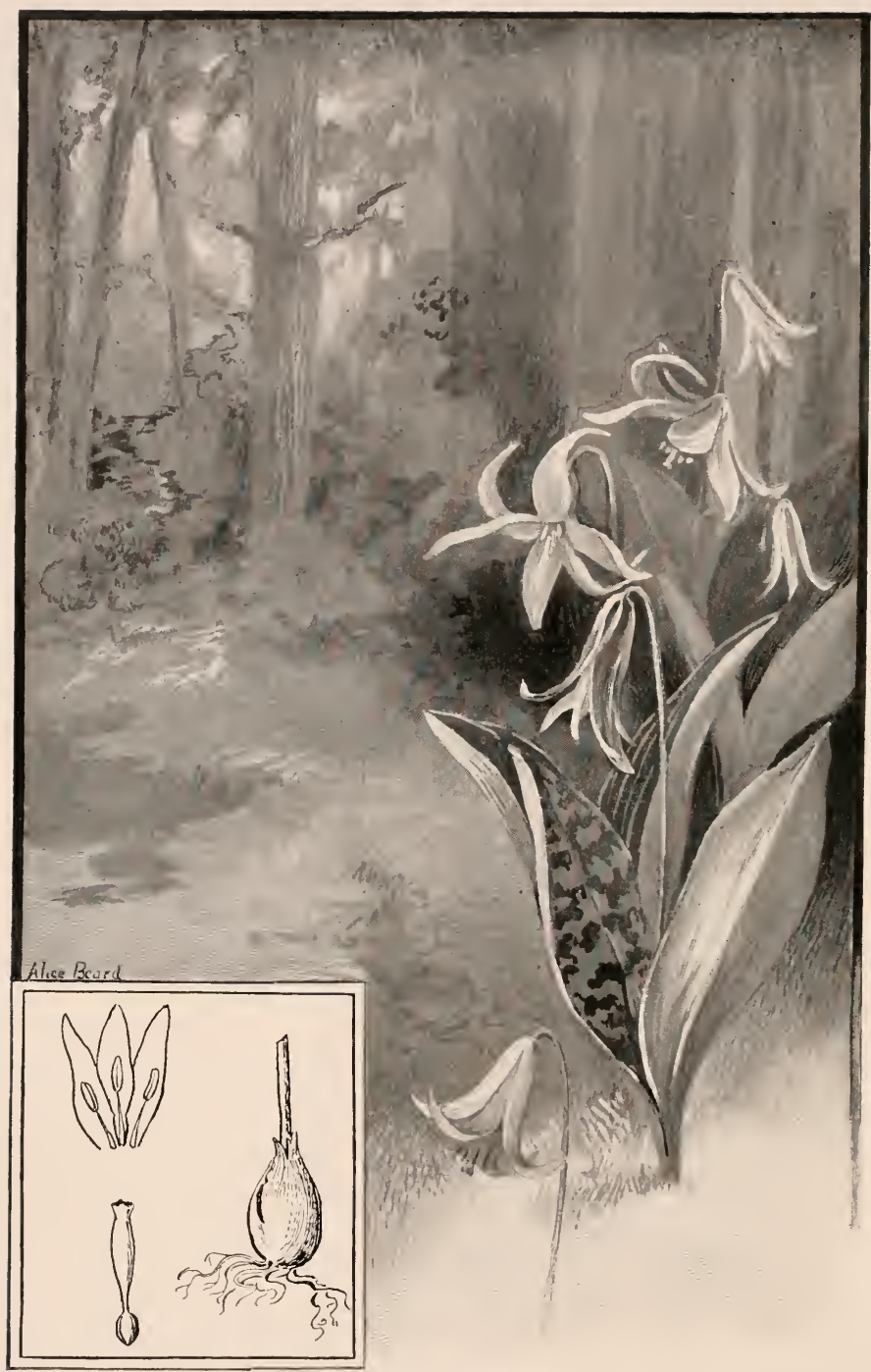

FIG. 144. A common spring plant (dog-tooth violet) which grows in deciduons forests. The large mottled leaves and the conspicuons flowers are sent rapidly above the surface from the subterranean bulb (see cut in the left lower corner), where are also seen dissected out some petals and stamens and the pistil. 
there are "light forests," such as the oak forest, which permit much low regetation, as well as the shade forests, such as beech forests, which permit very little.

In the forest regions of the tropics, however, the shading is permanent, since there is no annual fall of leares. In such conditions the climbing habit has been extensively cultivated.

103. Change in temperature.-In regions outside of the tropics the annual change of temperature is a very important factor in the life of plants, and they have provided for it in one way or another. In tracing the history of plants, howerer, back into what are called " geological times." we discover that there have been relatively permanent changes in temperature. Now and then glacial conditions prevailed, during which regions before temperate or even tropical were subjected to arctic conditions. It is very evident that such permanent changes of temperature must hare had an immense influence upon plant life.

104. Change in soil composition.-One of the most extensive agencies in changing the compositions of soils in certain regions has been the movement of glacicrs of continental extent, which have deposited soil material orer very extensive areas. Areas within reach of occasional floods, also, may have the soil much changed in character by the new deposits. Shifting dunes are billow-like masses of sand, developed and kept in motion by strong prevailing winds, and often encroach upon other areas. Besides these changes in the character of soil by natural agencies, the various operations of man have been influential. Clearing, draining. fertilizing, all change the character of the soil, both in its chemical composition and its physical properties.

105. Devastating animals.-The ravages of animals form an important factor in the life of many plants. For example, grazing animals are wholesale destroyers of vegetation, and may seriously affect the plant life of an area. The various leaf feeders among insocts have frequently done a vast 
amount of damage to plants. Many burrowing animals attack subterranean parts of plants, and interfere seriously with their oceupation of an area.

Various protective adaptations against such attacks have been pointed out, but this subject probably has been much exaggerated. 'The oceurrence of hairs, prickles, thorns, and spiny growths upon many plants may discourage the attacks of animals, but it would be rash to assume that these protections have been developed because of the danger of such attacks. One of the families of plants most completely protected in this way is the great caetus family, chiefly inhabiting the arid regions of southwestern United States and Mexico. In such a region sueculent regetation is at a premium, and it is doubtless true that the armor of thorns and bristles reduces the amount of destruction.

In addition to armor, the acrid or bitter secretions of certain plants or certain parts of plants would have a tendency to ward off the attacks of animals.

106. Plant rivalry.-It is evident that there must be rivalry among plants in oceupying an area, and that those plants which can most nearly utilize identical conditions will be the most intense rivals. For example, a great many young oaks maly start up over an area, and it is evident that the individuals must come into sharp competition with one another, and that but few of them succeed in establishing themselves permanently. This is rivalry between individuals of the same kind ; but some other kind of trees, as the beech, may come into competition with the oak, and another form of rivalry will appear.

As a consequence of plant rivalry, the different plants which finally succeed in taking possession of an area are apt to be dissimilar, and a plant society is usually made up of plants which represent widely different regions of the plant kingdom. It is sometimes said that any well developed plant society is an epitome of the plant kingdom.

A familiar illustration of plant rivalry may be observed 
in the case of what are called "weeds." Every one is familiar with the fact that if cultivated ground is neglected these undesirable plants will invade it vigoronsly and seriously affect the development of plants under cultivation.

10\%. Adaptation. - When the changes mentioned above occur in the environment of plants to such an extent as to make the conditions for living very unfavorable, one of three things is likely to occur, adaptation, migration, or destruction.

The change in conditions may come slowly enough, and certain plants may be able to endure it long enough to adjust themselves to it. Such an adjustment may involve changes in structure, and probably no plants are plastic enough to adjust themselves to extreme and sudden changes which are to be comparatively permanent. 'There are plants, such as the common cress, which may be called amphibious, which can live in the water or out of it without change of structure, but this is endurance rather than adaptation. Many plants, however, can pass slowly into different conditions, such as drier soil, denser shade, etc., and corresponding changes in their structure may be noter. Very often, however, such plants are given no opportunity to adjust themselves to the new conditions, as the area is apt to be invaded by plants already better adapted. While adaptation may be regarded as a real result of ehanged conditions, it would seem to be by no means the common one.

108. Migration.-This is a very common result of changed conditions. Plants migrate as truly as animals, though, of course, their migration is from generation to generation. It is evident, however, that migration cannot be universal, for barriers of rarious kinds may forbid it. In general, these barriers represent unfavorable conditions for living. If a plant area with good soil is surrounded by a sterile area, the latter would form an eflicient barrier to migration from the former. Plants of the lowlands could not cross mountains to eseape from unfavorable conditions. 
To make migration possible, therefore, it is necessary for the conditions to be favorable for the migrating plants in some direction. In the case of bulrushes, cat-tail flags, etc., growing in the shoal water of a lake margin, the building up of soil about them results in unfavorable conditions. As a consequence, they migrate further into the lake. If the lake happens to be a small one, the filling up process may finally obliterate it, and a time will come when such forms as bulrushes and flags will find it impossible to migrate.

In glacial times very many aretic plants migrated southward, especially along the mountain systems, and many alpine plants moved to lower ground. When warmer conditions returned, many plants that had been driven south returned towards the north, and the arctic and alpine plants retreated to the north and up the mountains. The history of plants is full of migrations, compelled by changed conditions and permitted in various directions. It must be remembered, also, that migrations often result in changes of structure.

109. Destruction.-Probably this is by far the most common result of greatly changed conditions. Even if plants adapt themselves to changed conditions, or migrate, their structure may be so changed that they will seem like quite different plants. In this way old forms gradually disappear and new ones take their places. 


\section{CHAPTER $\mathrm{X}$.}

THE NUTKITION OF PLANTS.

110. Physiology.-In the previous chapters plants have been considered in reference to their surroundings. It was observed that various organs of nutrition hold certain life-relations, but it is essential to discorer what these relations mean to the life of the plant. The study of plants from the standpoint of their life-relations has been called Ecology; the study of the life-processes of plants is called Physiology. These two points of view may be illustrated by comparing them to two points of view for the study of man. Man may be studied in reference to his relation to his fellow-men and to the character of the country in which he lives; or his bodily processes may be studied, such as digestion, circulation, respiration, etc. The former corresponds to Ecology, the latter is Physiology.

All of the ecological relations that have been mentioned find their meaning in the physiology of the plant, for liferelations have in view life-processes. The subject of plant physiology is a very complex one, and it would be impossible in an elementary work to present more than a few very general facts. Certain facts in reference to plant movements, an important physiological subject, have been mentioned in connection with life-relations, but it seems necessary to make some special mention of nutrition.

111. Significance of chlorophyll.-Probably the most important fact to observe in reference to the nutrition of plants is that some plants are green or have green parts, while others, such as toadstools, do not show this green 
color. It has been stated that this green color is due to the presence of a coloring matter known as chlorophyll (see \$12). The two groups may be spoken of, therefore, as (1) green plants and (2) plants without chlorophyll. The presence of chlorophyll makes it possible for the plants containing it to manufacture their own food out of such materials as water, soil material, and gases. For this reason, green plants may be entirely independent of all other living things, so far as their food supply is concerned.

Plants without chlorophyll, however, are unable to manufacture food out of such materials, and must obtain it already manufactured in the bodies of other plants or animals. For this reason, they are dependent upon other living things for their food supply, just as are animals. It is erident that plants withont chlorophyll may obtain this food supply either from the living bodies of plants and animals, in which ease they are called parasites, or they may obtain it from the substances derived from the bodies of plants and animals, in which case they are called saprophytes. For example, the rust which attacks the wheat, and is found upon the leares and stems of the living plant, is a parasite; while the mould which often develops on stale bread is a saprophyte. Some plants without chlorophyll can live either as parasites or saprophytes, while others are always one or the other. By far the largest number of parasites and saprophytes belong to the group of low plants called fungi, and when fungi are referred to, it must be understood that it means the greatest group of plants without chlorophyll.

112. Photosynthesis. - The nutritive processes in green plants are the same as in other plants, and in addition there is in green plants the peculiar process known as photosynthesis (see \$25). In plants with foliage leaves, these are the chief organs for this work. It must be remembered, however, that leaves are not necessary for photosynthesis, for plants without leaves, such as alga, perform it. The 
essential thing is green tissue exposed to light, but in this brief account an ordinary leafy plant growing in the soil will be considered.

As the leaves are the active structures in the work of photosynthesis, the raw materials necessary must be brought to them. In a general way, these materials are carbon dioxide and water. 'The gas exists diffused through the atmosphere, and so is in contact with the leaves. It also occurs dissolved in the water of the soil, but the gas used is absorbed from the air by the leaves. The supply of water, on the other hand, in soil-related plants, is obtained from the soil. The root system absorbs this water, which then ascends the stem and is distributed to the leaves.

(1) Ascent of water.-The water does not move upwards through all parts of the stem, but is restricted to a certain definite region. 'This region is easily recognized as the woody part of stems. Sometimes separate strands of wood, looking like fibers, may be seen running lengthwise . through the stem ; sometimes the fibrous strands are packed so close together that they form a compact woody mass, as in shrubs and trees. In the case of most trees new wood is made each year, through which the water moves. Hence the rery common distinction is made between sap-wood, through which the water is moving, and heart-woocl, which the water current has abandoned. Just how the water ascends through these woody fibers, especially in tall trees, is a matter of much discussion, and cannot be regarded as definitely known. In any event, it should be remembered that these woody fibers are not like the open veins and arteries of animal bodies, and no " circulation " is possible. These same wooly strands are seen branching throughout the leaves, forming the so-ealled rein system, and it is evident, therefore, that they form a contimuous route from roots to leaves.

It is easy to demonstrate the aseent of water in the stem, and the path it takes, by a simple experiment. If 
an active stem be cut and plunged into water stained with an aniline color called cosin,* the ascending water will stain its pathway. After some time sections through the stem will show that the water has traveled upwards through it, and the stain will point out the region of the stem used in the morement.

In general, therefore, the carbon dioxide is alssorbed directly from the air by the leaves, and the water is absorbed by the root from the soil, and moves upwards through the stem into the leaves. An interesting fact about these raw materials is that they are very common waste products. They are waste products because in most life-processes they cannot be taken to pieces and used. The fact that they

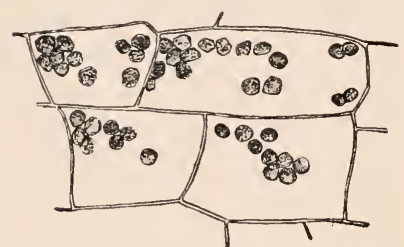

Fig. 145. Some mesophyll cells from the leaf of Fittonia, showing chloroplasts. can be used in photosynthesis shows that it is a very remarkable life process.

(2) Chloroplasts.-Having obtained some knowledge of the raw materials used in photosynthesis, and their sourees, it is necessary to consider the plant machinery arranged for the work. In the working leaf cells it is discovered that the eolor is due to the presence of very small green bodies, known as ehlorophyll bodies or chloroplasts (see Fig. 145). 'These consist of the living substance, known as protoplasm, and the green stain called chlorophyll ; therefore, each ehloroplast is a living body (plastid) stained green. It is in these chloroplasts that the work of photosynthesis is done. In order that they may work it is neeessary for them to obtain a supply of energy from some outside source, and the source used in nature is sunlight. 'The green stain (ehlorophyll) seems to be used in absorbing the necessary energy from sunlight, and the

* The commoner grades of red ink are usually solutions of eosin. 
plastid uses this energy in the work of photosynthesis. It is evident, therefore, that photosynthesis goes on only in the sunlight, and is suspended entirely at night. It is found that any intense light can be used as a substitute for sunlight, and plants have been observed to carry on the work of photosynthesis in the presence of electric light.

(3) Result of photosynthesis. - The result of this work can be stated only in a very general way. Carbon dioxide is composed of two elements, carbon and oxygen, in the proportion one part of carbon to two parts of oxygen. Water is also composed of two elements, hydrogen and oxygen. In photosynthesis the elements composing these substances are separated from one another, and reeombined in a new way. In the process a certain amount of oxygen is liberated, just as much as was in the carbon dioxide, and a new substance is formed, known as a carbohydrate. The oxygen set free escapes from the plant, and may be regarded as waste product in the process of photosynthesis. It will be remembered that the external changes in this process are the absorption of earbon dioxide and the giving off of oxygen (see s:5).

(4) Carbohydrates and proteids. - The carbohydrate formed is an organic substance; that is, a substance made in nature only by life processes. It is the same kind of substance as sugar or starch, and all are known ats carbohydrates ; that is, substances composed of carbon, and of hydrogen and oxygen in the same proportion as in water. The work of photosynthesis, therefore, is to form carbohydrates. The earbohydrates, such as sugar and starch, represent but one type of food material. P'roteids represent another prominent type, substances which contain carbon, hydrogen, and oxygen, as do carbohydrates, but which also contain other elements, notably nitrogen, sulphnr, and phosphorus. The white of an egg may be taken as an example of proteids. They seem to be made from the earbo- 
hydrates, the nitrogen, sulphur, and other necessary additional elements being obtained from soil substances dissolved in the water which is absorbed and conveyed to the leaves.

113. Transpiration.-The water which is absorbed by the roots and passes to the leares is much more abundant than is needed in the process of photosynthesis. It should be remembered that the water is not only used as a raw material for food manufacture, but also acts as a solvent of the soil materials and carries them into the plant. The water in excess of the small amount used in food manufacture is given off from the plant in the form of water vapor, the process being already referred to as transpiration (see $\$ 26$ ).

11t. Digestion.-Carbohydrates and proteids may be regarded as prominent types of plant food which green plants are able to manufacture. These foods are transported through the plant to regions where work is going on, and if there is a greater supply of foor than is needed for the working regions, the excess is stored up in some part of the plant. As a rule, green plants are able to manufacture much more food than they use, and it is upon this excess that other plants and animals live. In the transfer of foods through the plant certain changes are often necessary. For example, starch is insoluble, and hence cannot be carried about in solution. It is necessary to transform it into sugar, which is soluble. These ehanges, made to facilitate the transfer of foods, represent digestion.

115. Assimilation.-When food in some form has reached a working region, it is organized into the living substance of the plant, known as protoplasm, and the protoplasm builds the plant structure. This process of organizing the food into the living substance is known as assimilation.

116. Respiration.-The formation of foods, their digestion and assimilation are all preparatory to the process of respiration, which may be called the use of assimilated food. The whole working power of the plant depends 
"pon respiration, which means the absorption of oxygen by the protoplasm, the breaking down of protoplasm, and the giving off of carbon dioxide and water as wastes. The im-

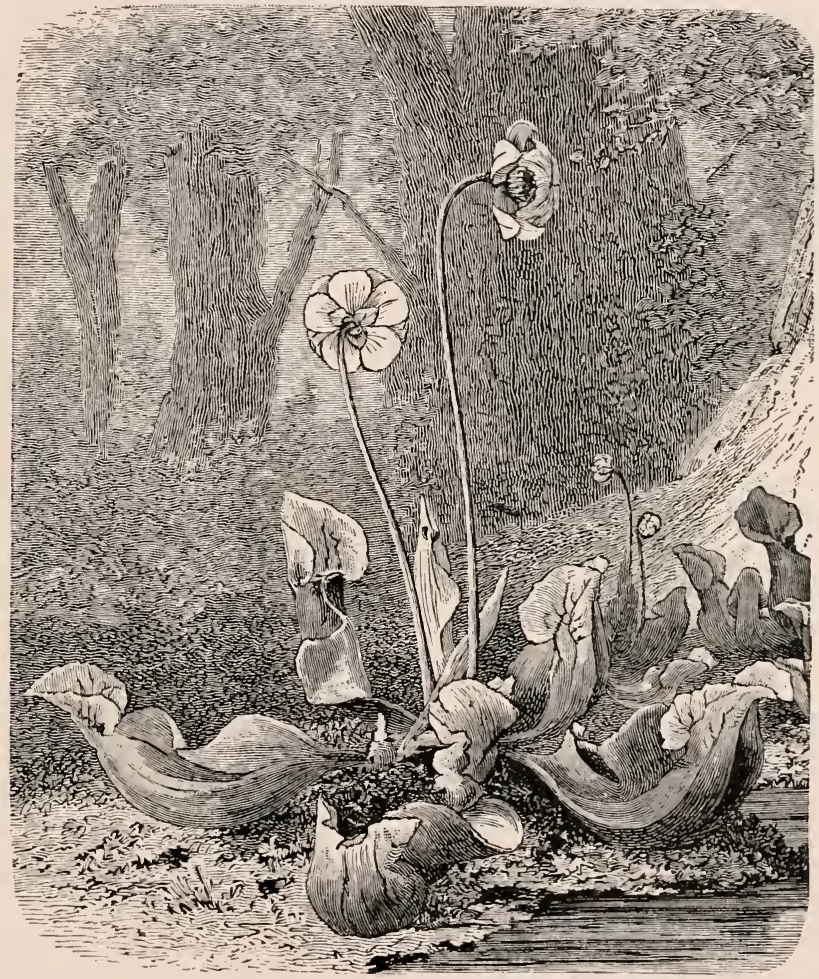

F1G. 146. The common Northern pitcher plant. The hollow leaves, each with a hood and a wing, form a rosette, from the center of which arise the flower stalks.After Kenner.

portance of this process may be realized when it is remembered that there is the same need in our own living, as it is essential for us also to "breathe in "oxygen, and as a result we "breathe out" carbon dioxide and water. This breaking down or "oxidizing" of protoplasm releases the 
power by which the work of the plant is carried on (see $\S 27)$.

11\%. Summary of life-processes.-T'o summarize the nutritive life-processes in green plants, therefore, photosyn-

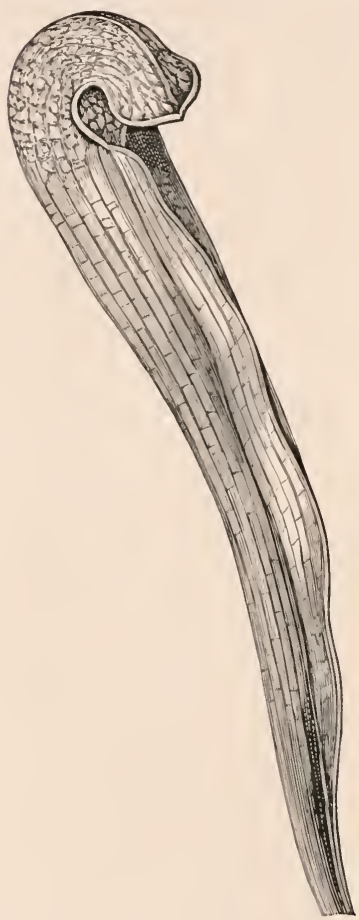

FIG. 14\%. The Sonthern pitcher plant, showing the funnelform and winged pitcher, and the overarching hood with translucent spots.-After línNER. thesis manufactures carbohydrates, the materials used being carbon dioxide and water, the work being done by the chloroplast with the aid of light; the manufacture of proteids uses these carbohydrates, and also substances containing nitrogen, sulphur, etc.; digestion puts the insoluble carbohydrates and the proteids into a soluble form for transfer through the plant; assimilation converts this food material into the living substance of the plant, protoplasm; respiration is the oxidizing of the protoplasm which enables the plant to work, oxygen being absorbed, and carbon dioxide and water rapor being given off in the process.

118. Plants without chlorophyll. - Remembering the life-processes described under green plants, it is erident that plants without chlorophyll camnot do the work of photosynthesis. 'This means that they cannot manufacture carbohydrates, and that they must depend upon other plants or animals for this important food. IIushrooms, puff-balls, moulds, mildews, rusts, dodder, corpse plants, beech drops, etc., may be taken as illustrations of such plants. 
Although plants without chlorophyll cannot manufacture carbohydrates, the other processes, proteid manufacture, digestion, assimilation, and respiration, are carried on. It is true, however, that in obtaining carbohydrates from other plants and animals, proteids are obtained also, so that proteid manufacture is not so prominent as in green plants.

\section{9. "Carnivorous"} plants.-This name has been given to plants which have dereloped the curious habit of capturing insects and using them for food. They are green plants and, therefore, can manufacture carbohydrates. But they live in soil poor in nitrogen compounds, and hence proteid formation is interfered with. The bodies of captured insects supplement the proteid supply, and the plants have come to depend upon them. Many, if not all of these carniyorous plants, secrete a digestive substance which acts upon the

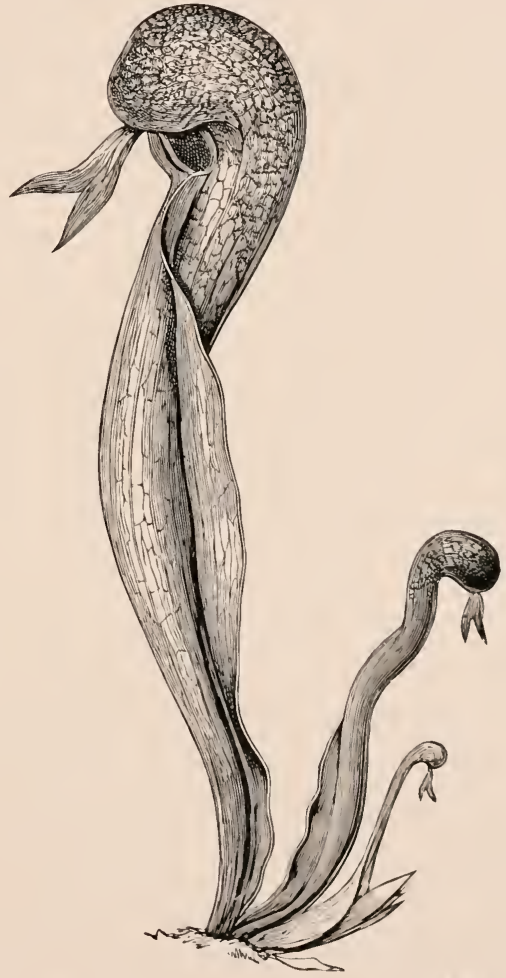

Fic. 148. The Californian pitcher plant (Darling. tonia), showing twisted and winged piteher, the overarehing hood with translucent spots, and the fish-tail appendage to the hood which is attractive to flying insects.-After KiERNER.

bodies of the captured insects very much as the digestive substances of the alimentary canal act upon proteids 
swallowed by animals. Some common illustrations are as follows :

(1) Pitcher plants. - In these plants the leaves form tubes, or urns, of various forms, which contain water, and to which insects are attracted and drowned (see Fig. 146). A pitcher plant common thronghout the Sonthern States may be taken as a type (see Fig. 14\%). The leaves are shaped like slender, hollow cones, and rise in a tuft from

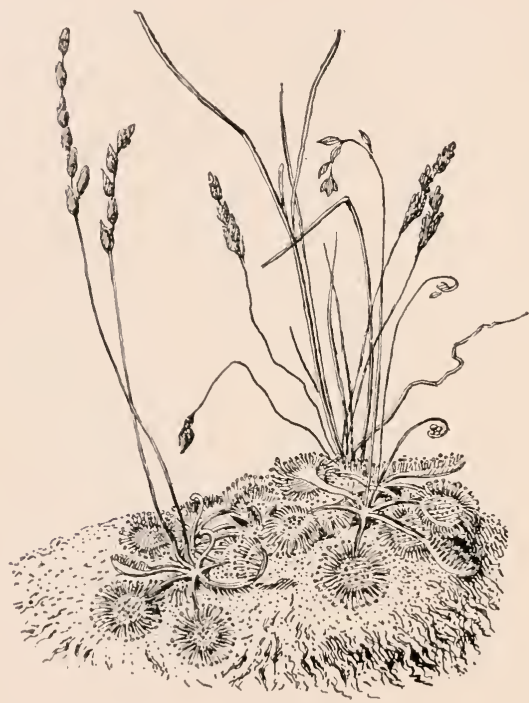

Fri. 149. A sun-dew, showing rosette habit of the insect-catching leaves. the swampy ground. The mouth of this conical urn is overarehed and shaded by a hood, in which are translucent spots, like small windows. Around the mouth of the urn are glands, which secrete a sweet liquid (nectar), and nectar drops form a trail down the outside of the nrn. Inside, just below the rim of the urn, is a glazed zone, so smooth that inseets cannot walk mpon it. Below the glazed zone is another zone, thickly set with stiff. downward-pointing hairs, and below this is the liquid in the bottom of the urn.

If a fly is attracted by the neetar drops mpon this eurious leaf, it naturally follows the trail up to the rim of the urn, where the nectar is abundant. If it attempts to descend within the urn, it slips on the glazed zone, and falls into 
the water, and if it attempts to escape by crawling up the sides of the urn, the thicket of downward-pointing hairs prevents. If it seeks to fly away from the rim, it flies towards the translucent spots in the hood, which look like the way of escape, as the direetion of entrance is in the shadow of the hood. Pounding against the hood, the fly falls into the tube. This Southern pitcher plant is known
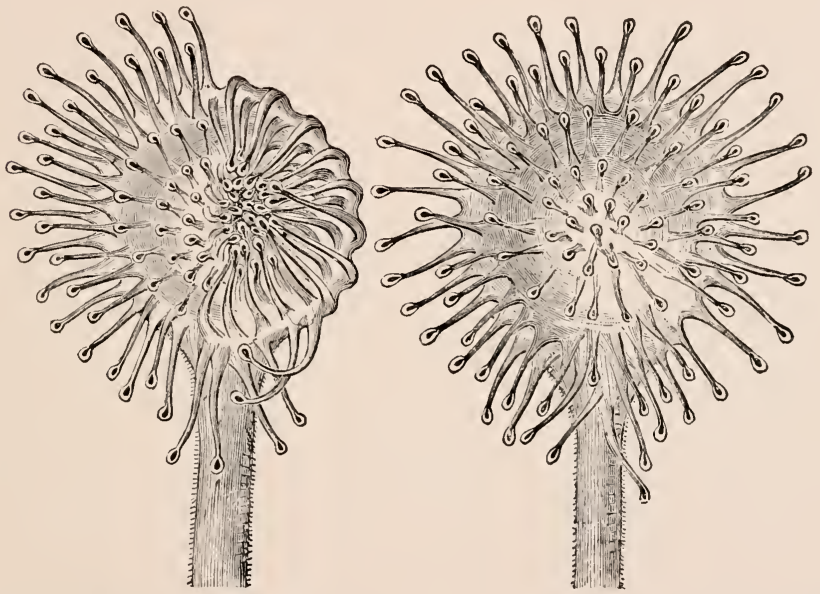

FIg. 150. Two leaves of a sun-dew. The one to the right has its glandular hairs fully expanded; the one to the left shows half of the hairs bending inward, in the position assumed when an insect has been captured.-After KerNer.

as a great fly-catcher, and the urns are often well supplied with the decaying bodies of these inseets.

A much larger Californian piteher plant has still more elaborate contrivances for attracting insects (see Fig. 148).

(2) Drosera.-The droseras are commonly known as "sun-dews," and grow in swampy regions, the leaves forming small rosettes on the ground (see Fig. 149). In one form the leaf blade is round, and the margin is beset by prominent bristle-like hairs, each with a globular gland at its tip (see Fig. 150). Shorter gland-bearing hairs are 
scattered also over the inner surface of the blade. These glands excrete a clear, sticky fluid, which hangs to them in drops like dew-drops. If a small insect becomes entangled

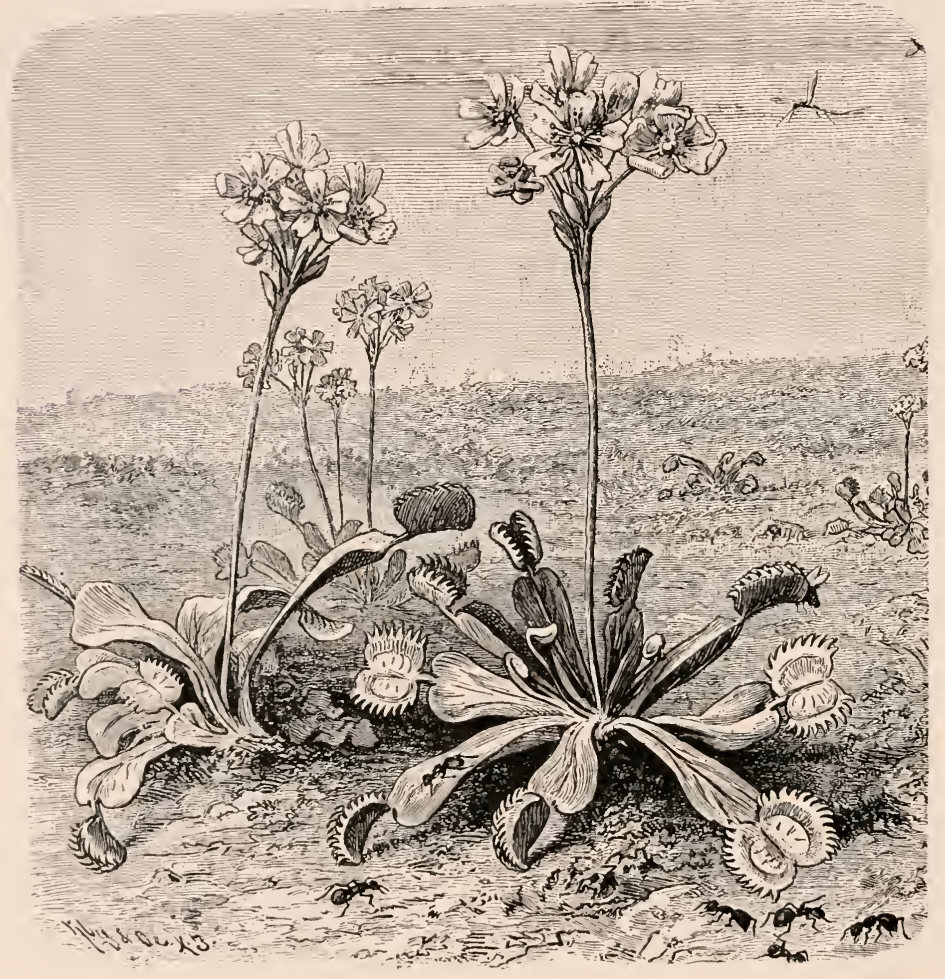

FIG. 151. Plants of Dionce, showing the rosette habit of the leaves with terminal traps, and the ereet flowering stem.-After Kinner.

in the sticky drop, the hair begins to curve inward, and presently presses its victim down upon the surface of the blade. In the ease of larger insects, several of the marginal hairs may join together in holding it, or the whole blade may become more or less rolled inward. 
(3) Dioncea.-This is one of the most famous and remarkable of fly-catehing plants (see Fig. 151). It is found in sandy swamps near Wilmington, North Carolina. The leaf blade is eonstructed like a steel trap, the two halves snapping together, and the marginal bristles interlocking like the teeth of a trap (see Fig. 152). A few sensitive hairs, like feelers, are developed on the leaf surface, and when one of these is touched by a small flying or hovering insect, the trap snaps shut and the insect is caught. Only after digestion does the trap open again.

There are certain green plants, not ealled carnivorous plants, which show the same general habit of supplementing their food supply, and so reducing the necessity of food manufacture. The mistletoe is a green plant, growing upon certain trees, from

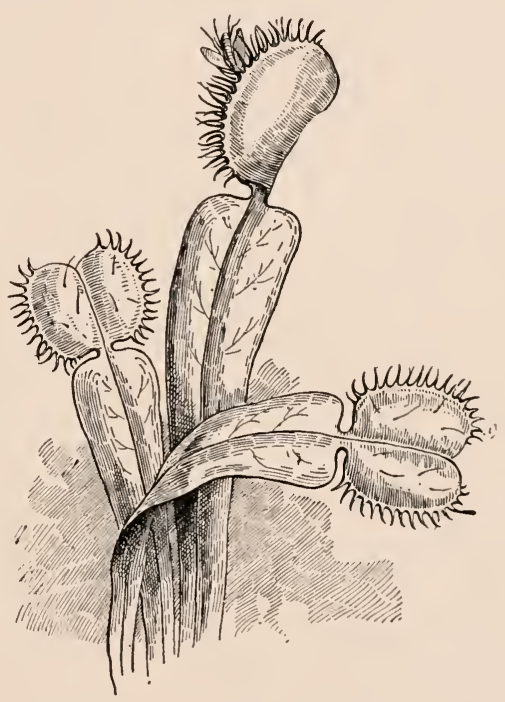

FIG. 152. Three leaves of Dioncea, slowing the details of the trap in the leaves to right and left, and the central trap in the act of capturing an insect.

which it obtains some food, supplementing that which it is able to manufacture.

In rich soil, the organized products of the decaying bodies of plants and animals are often absorbed by ordinary green plants, and so a certain amount of ready-made food is obtained. 


\section{CHAPTER XI.}

\section{PLANT SOCIETIES: ECOLOGICAL FACTORS.}

120. Definition of plant society. - From the previous chapters it has been learned that every complex plant is a combination of organs, and that each organ is related in some special way to its enviromment. It follows, therefore, that the whole plant, made up of organs, holds a very complex relation with its environment. The stem demands certain things, the root other things, and the leaves still others. To satisfy all of these demands, so far as possible, the whole plant is delicately adjusted.

The earth's surface presents very diverse conditions in reference to plant life, and as plants are grouped according to these conditions, this leads to definite associations of plants, those adapted to the same general conditions being apt to live together. Such an association of plants living together in similar conditions is a plant society, the conditions forbidding other plants. It must not be understood that all plants affecting the same conditions will be found living together. For example, a meadow of a certain type will not contain all the kinds of grasses associated with that type. Certain grasses will be found in one meadow, and other grasses will be found in other meadows of the same type.

Very closely related plants generally do not live in the same soeiety, as their rivalry is apt to be intense. Closely related plants are likely to occur, however, in different societies of the same type. A plant society, therefore, may contain a wide representation of the plant kingdom, from plants of low rank to those of high rank. 
Before considering some of the common societies, it is necessary to note some of the conditions which determine plant societies. 'Those things in the environment of the plant which influence the organization of a society are known as ecological factors.

121. Water.-Water is certainly one of the most important conditions in the environment of a plant, and has great influence in determining the organization of societies. If all plants are considered, it will be noted that the amount of water to which they are exposed is exceedingly variable. At one extreme are those plants which are completely submerged; at the other extreme are those plants of arid regions which can obtain very little water; and between these extremes there is every gradation in the amount of available water. Among the most striking adaptations of plants are those for living in the presence of a great amount of water, and those for guarding against its lack.

One of the first things to consider in comnection with any plant society is the amount of water supply. It is not merely a question of its total annual amount, but of its distribution through the year. Is it supplied somewhat uniformly, or is there alternating flood and drought? The nature of the water supply is also important. Are there surface channels or subterranean chamnels, or does the whole supply come in the form of rain and snow which fall upon the area?

Another important fact to consider in connection with the water supply has to do with the structure of the soil. There is what may be called a water level in soils, and it is important to note the depth of this level beneath the surface. In some soils it is very near the surface; in others, such as sandy soils, it may be some distance beneath the surface.

Not only do the amount of water and the depth of the water level help to determine plant societies. but also the substances which the water contains. Two areas may have 
the same amount of water and the same water level, but if the substances dissolved in the water differ in certain particulars, two entirely distinct societies may result.

12. Heat.- The general temperature of an area is important to consider, but it is evident that differences of temperature are not so local as differences in the water supply, and therefore this factor is not so important in the organization of the local associations of plants, ealled societies, as is the water factor. In the distribution of plants over the surface of the earth, however, the heat factor is probably more important than the water factor. 'The range of temperature which the plant kinglom, as a whole, can endure during active work may be stated in a general way as from $0^{\circ}$ to $50^{\circ} \mathrm{C}$. ; that is, from the freezing point of water to $122^{\circ}$ Fahr. 'There are certain plants which can work at higher temperatures, notably certain alga growing in hot springs, but they may be regarded as exceptions. It must be remembered that the range of temperature given is for plants actively at work, and does not include the temperature which many plants are able to endure in a specially protected but very inactive condition. For example, many plants of the temperate regions endure a winter temperature which is frequently lower than the freezing point of water, but it is a question of endurance and not of work.

It must not be supposed that all plants ean work equally well throughout the whole range of temperature given, for they differ widely in this regard. Tropical plants, for instance, accustomed to a certain limited range of high temperature, cannot work continuously at the lower temperatures. For each kind of plant there is what may be called a zero point, below which it is net in the habit of working.

While it is important to note the general temperature of an area throughout the year, it is also necessary to note its distribution. 'Two regions may have presumably the same amount of heat through the year, but if in the one case it is uniformly distributed, and in the other great extremes 
of temperature oceur, the same plants will not be found in both. It is, perhaps, most important to note the temperature during certain eritieal periods in the life of plants, such as the flowering period of seed-plants.

Although the temperature problem may be comparatively uniform over any given area, the effect of it may be noted in the suceession of plants through the growing season. In our temperate regions the spring plants and summer plants and antumn plants differ decidedly from one another. It is evident that the spring plants ean endure greater cold than the summer plants, and the succession of flowers will indicate somewhat these relations of temperature.

It should be remarked, also, that not only is the temperature of the air to be noted, but also that of the soil. These two temperatures may differ by several degrees, and the soil temperature especially affeets root activity, and hence is a very important factor to discover.

At this point it is possible to eall attention to the effect of the combination of ecological factors. For instance, in reference to the occurrence of plants in any society, the water factor and the heat factor camnot be considered each by itself, but must be taken in combination. For example, if in a given area there is a combination of maximum heat and minimum water, the result will be a desert, and only certain specially adapted plants can exist. It is evident that the great heat increases the transpiration, and transpiration when the supply of water is very meager is peculiarly dangerous. Plants which exist in such conditions, therefore, must be specially adapted for controlling transpiration. On the other hand, if in any area the combination is maximum heat and maximum water, the result will be the most luxuriant vegetation on the earth, such as grows in the rainy tropies. It is evident that the possible eombinations of the water and heat factors may be very numerous, and that it is the combination which chiefly affects plant societies. 
123. Soil-The soil factor is not merely important to consider in connection with those plants directly related to the soil, but is a factor for all plants, as it determines the substarices which the water contains. There are two things to be eonsidered in connection with the soil, namely, its chemical composition and its physical properties. Perhaps the physical properties are more important from the standpoint of soil-related plants than the chemical composition, although both the chemical and physical nature of the soil are so bound up together that they need not be considered separately here. 'The physical properties of the soil, which are important to plants, are chiefly those which relate to the water supply. It is always important to determine how receptive a soil is. Does it take in water easily or not? It is also necessary to determine how retentive it is ; it may receive water readily, but it may not retain it.

For convenience in ordinary field work with plants, soils may be divided roughly into six classes: (1) rock, which means solid uncrumbled rock, "pon which certain plants are able to grow; (2) sand, which has small water capacity, that is, it may receive water readily enough, but does not retain it ; (3) lime soil ; (4) clay, which has great water capacity: (5) humus, which is rich in the products of plant and animal decay ; (6) salt soil, in which the water contains various salts, and is generally spoken of as alkaline. These divisions in a rough way indicate both the structure of the soil and its chemical composition. Not only should the kinds of soil on an area be determined, but their depth is an important consideration. It is very common to find one of these soils overlying another one, and this relation between the two will have a very important effect. For instance, if a sand soil is found lying over a clay soil, the result will be that the sand soil will retain far more water than it would alone. If a humus soil in one area overlies a sand soil, and in another area 
overlies a clay soil, the humus will differ very much in the two cases in reference to water.

The soil cover should also be considered. The common soil covers are snow, fallen leaves, and living plants. It will be noticed that all these covers tend to diminish the loss of heat from the soil, as well as the access of heat to the soil. In other words, a good soil cover will very much diminish the extremes of temperature. All this tends to increase the retention of water.

124. Light. - It is known that light is essential for the peculiar work of green plants. Howerer, all green plants eamnot have an equal amount of light. and some have learned to live with a less amount than others. While no sharp line can be drawn between green plants which use intense light, and those which use less intense light, we still recognize in a general way what are called light plants and shade plants. We know that certain plants are chiefly found in situations where they can be exposed freely to light, and that other plants, as a rule. are found in shady situations.

Starting with this idea, we find that plants grow in strata. In a forest society, for example, the tall trees represent the highest stratum; below this there may be a stratum of shrubs, then tall herbs, then low herbs, then forms like mosses and lichens growing close to the ground. In any plant society it is important to note the number of these strata. It may be that the highest stratum shades so densely that many of the other strata are not represented at all. An illustration of this can be obtained from a dense beech forest.

125 . Wind.-It is generally known that wind has a diying effect, and, therefore, it increases the transpiration of plants and tends to imporerish them in water. This factor is especially conspicuous in regions where there are prevailing winds, such as near the sea-coast, around the great lakes, and on the prairies and plains. In all such regions 
the plants have been compelled to adapt themselves to this loss of water; and in some regions the prevailing winds are so eonstant and violent that the force of the wind itself has influenced the appearance of the regetation, giving what is called a characteristic physiognomy to the area.

These five factors have been selected from a much larger number that might be enumerated. but they may be regarded as among the most important ones. It will be noticed that these factors may be combined in all sorts of ways. so that an almost endless series of combinations seems to be possible. This will give some idea as to the possible number of plant societies, for they may be as numerous as are the combinations of these factors.

126 . The great groups of societies.-It is possible to reduce the very numerous societies to three or four great gromps. For convenience, the water factor is chiefly used for this classification. It results in a convenient classification, but one that is probably more or less artıficial. The selection of any one factor from among the many for the purpose of classifieation never results in a very natural classification when the combination of factors determines the group. However, for general purposes, the usual classification on the basis of water supply will be used. On this basis there are three great groups of societies, as follows :

(1) Hydrophytes. - The name means " water plants," and suggests that such societies are at that extreme of the water supply where it is very abundant. Such plants may grow in the water, or in very wet soil, but in any event they are exposed to a large amount of water.

(2) Terophytes. -The name means "drouth plants," and suggests the other extreme of the water supply. 'True xerophytes are exposed to dry soil and dry atmosphere.

(3) Mesophytes.-Between the two extremes of the water supply there is a great middle region of medium water supply, and plants which occupy it are known as meso- 
phytes, the plants of medium conditions. It is evident that mesophytes gradually pass into hydrophytes on the one side, and into xerophytes on the other; but it is also evident that mesophyte societies have the greatest range of water supply, extending from a large amount of water to a very small amount.

It should be understood that these three groups of societies, which are distinguished from one another by the amount of the water supply, are artificial groups rather than natural ones, for they bring together unrelated societies, and often separate those that are closely related. For example, a swampy meadow is put among hydrophyte societies by this classification ; and it may shade into an ordinary meadow, which belongs among the mesophytes. Probably the largest fact which may be used in grouping plant societies is that certain societies are so situated that they seek for the most part to reduce transpiration, and that others are so situated that they seek for the most part to increase transpiration.

However, the factors which determine societies are so numerous that they cannot be presented in an elementary book, and the simpler artificial grouping given above will serve to introduce the societies to observation. 


\section{CHAP'TER YII.}

\section{HYDROPHYTE SOCIETIES.}

$12 \%$ General character.- Hydrophytes are related to abundant water, either throughout their whole structure or in part of their structure. It is a well-known fact that hydrophytes are among the most cosmopolitan of plants, and hydrophyte societies in one part of the world look very much like hydrophyte societies in any other region. It is probable that the abundant water makes the conditions more uniform.

It is ericlent that for those plants, or plant parts, which are submerged, the water affects the heat factor by diminishing the extremes. It also affects the light factor, in so far as the light must pass through the water to reach the chlorophyll-containing parts, as light is diminished in intensity by passing through the water. Before considering a few hydrophyte societies, it is necessary to note the prominent hydrophyte adaptations.

128. Adaptations.-In order that the illustration may be as simple as possible, a complex plant completely cxposed to water is selected, for it is evident that the relations of a swamp plant, with its roots in water and its stem and leaves exposed to air, are complicated. A number of adaptations may be noted in connection with the submerged or floating plant.

(1) Thin-walled epidermis.-In the case of the soil-related plants, the water supply comes mainly from the soil, and the root system is constructed to absorb it. In the case of the water plant under consideration, however, the 
whole plant body is exposed to the water supply, and therefore absorption may take place through the whole surface rather than at any particular region such as the root. In order that this may be done, however, it is necessary for the epidermis to have thin walls, which is usually not the case in epidermis exposed to the air, where a certain amount of protection is needed in the way of thickening.

(2) Roots much reduced or wanting.-It must be evident that if water is being absorbed by the whole free surface of the plant, there is not so much need for a special root region for absorption. 'Therefore, in such water plants the root system nay be much reduced, or may even disappear entirely. It is often retained, however, to act as a holdfast, rather than as an absorbent organ, for most water plants anchor themselves to some sup)port.

(3) Reduction of water-conducting tissues. - In the ordinary soil-related plants, not only is an absorbing root system necessary, but also a conducting system, to carry the water absorbed from the roots to the leares and elsewhere. It has already been noted that this conducting system takes the form of woody strands. It is evident that if water is being absorbed by the whole surface of the plant, the 
work of conduction is not so extensive or definite, and therefore in such water plants the wooly bundles are not so prominently dereloped as in land plants.

(4) Reduction of mechanical tissues.-In the case of ordinary land plants, certain firm tissues are developed so

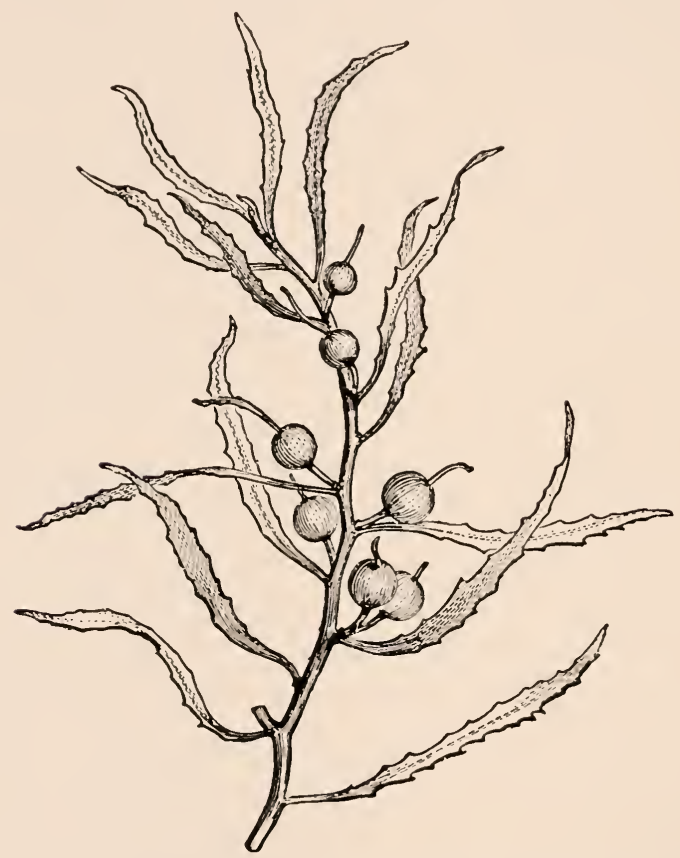

FIG. 154. Gulfweed (Sargassum), showing the thallus differentiated into stem-like and leaf-like portions, and also the bladder-like floats.-After Bennetr and Murrar.

that the plant may maintain its form. These supporting tissues reach their culmination in such forms as trees, where massive bodies are able to stand upright. It is evident that in the water there is no such need for rigid supporting tissues, as the buoyant power of water helps to support the plant. This fact may be illustrated by taking 
out of water submerged plants which seem to be upright, with all their parts properly spread out. When removed they collapse, not being able to support themselves in any way.

(5) Development of air cavities. - The presence of air in the bodies of water plants is necessary for two reasons: (1),

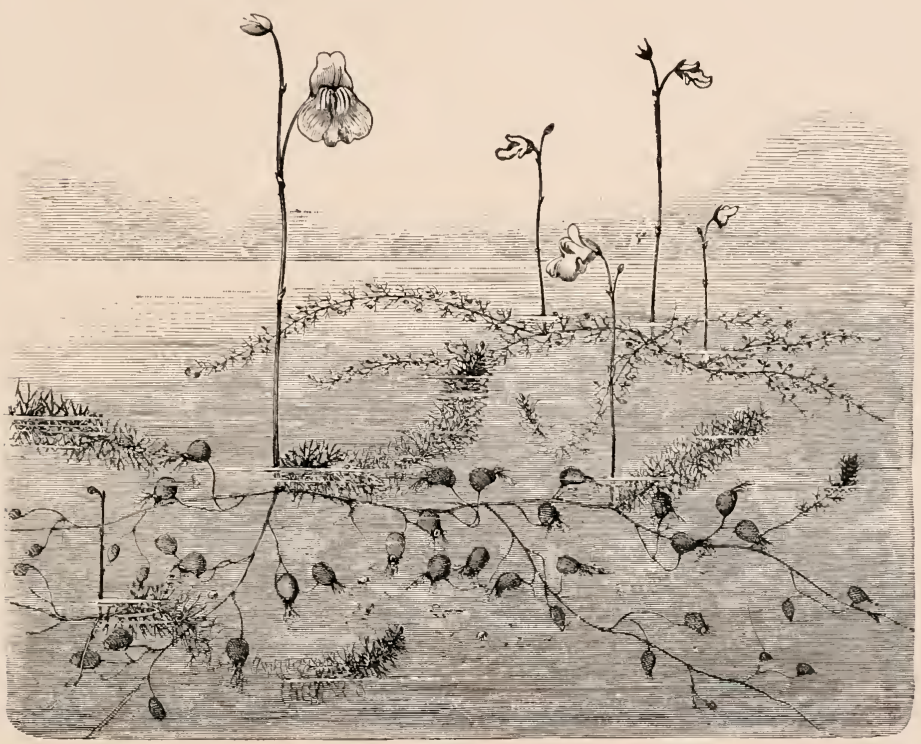

Fig. 155. Bladderwort, showing the numerous bladders which float the plant, the finely divided water leaves, and the erect flowering stems. The bladders are also effective "insect traps," Ctricularia being one of the "carnivorons plants." -After Kenver.

to aerate the plant: $(\stackrel{\sim}{\sim})$, to increase its buoyaney. In most complex water plants there must be some arrangement for the distribution of air containing oxygen. 'This usually takes the form of air chambers and passageways in the body of the plant (see Figs. $8 \%, 88,89,156$ ). Of course such air chambers increase the buyancy of the body. Sometimes, however, a special buoyancy is provided for by the development of regular floats, which are bladder- 
like bodies (see Figs. 153, 15t). These floats are very common among certain of the seaweeds, and are found among higher plants, as the utrieularias or bladderworts, which have received their name from the numerous bladders developed in connection with their bodies (see Fig. 155).

129. The two groups of societies.-The hydrophyte societies may be put into two great divisions. True hydrophytes are those in which the contents and temperature of the water are favorable to plant activity; while rerophytic hydrophytes are those in which the contents and temperature of the water are unfavorable to plant activity, and the structures of the plants are adapted to reduce transpiration, resembling in this feature the structures displayed by the true xerophytes (see $\$ 155$ ).

\section{TRUE HYDROPHYTES.}

A. Free-swimming societies.

130. Definition.-In these societies there is the largest exposure to water, and no relation at all to the nutrient or mechanical support of the soil, the plants being completely supported by the water. They may be either submerged or floating, and they are free to move either by locomotion or by water currents. Two prominent societies are selected as types.

131. The plankton.-This term is used to designate the minute organisms, both plants and animals, which are found in the water. The plankton is composed of individuals invisible to the naked eye, but taken together they represent an enormous organic mass. The plankton societies are especially well represented in the colder oceanie waters, but they are not absent from any waters. Among the most prominent plants in these societies are the diatoms. Diatoms are minute plants of various forms, and all have a wall very full of silica. This makes their bodies 
extremely enduring, and therefore diatoms are often found in great deposits in the rocks, in some cases forming the whole mass of rock. Associated with the diatoms are numerous other plant and animal forms.

132. Pond societies.- The word pond is used to indicate stagnant or slow-moving waters. In such waters freeswimming plants of all groups are associated. Of course the alga are well represented, but even the highest plants are represented by the duekweeds, which are very c o $\mathrm{mmon} \mathrm{m} \mathrm{y}$ seen in the form of small green disks floating on the surface of the water, which they frequently cover with

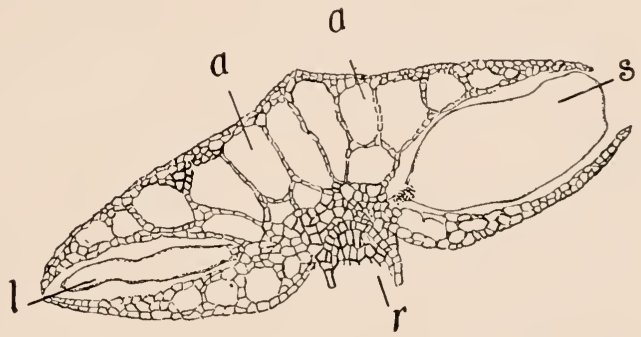

FIG. 156. A section through the body of a duckweed (Lemna), showing the air spaces $(a)$ which make it buoyant, the origin $(r)$ of the simple dangling root, and the pockets $(s$ and $l$ ) from which new plants bud out, and in which flowers are developed. great masses (see Fig. 156). It should be observed that the floating and submerged positions result in a difference in light-relations. The floating forms may be regarded as light forms, being exposed to the greatest amount of light. 'The submerged forms are shade plants, and the shading becomes greater as the depth of the water is greater. It must not be supposed that submerged plants ean live at any depth, for soon a limit is reached, beyond which the light is not intense enough to enable plants to work.

It has been noticed that this complete water habit has affected plants in many ways. For instance, the duckweeds are related to land plants with root, stem, and leaves, but they have lost the distinction between stem and leaf, and the body is merely a flat leaf-like disk floating upon 
the water, with a few roots dangling from the under side, or with no roots at all (see Fig. 156). 'This same duckweed also shows some interesting modifieations in its habits of reproduction. Although related to plants which prodnce flowers and make seed, the duckweeds have almost lost the power of prodncing flowers, and when they do produce them, seeds are very seldom formed. In other words, the ordinary method of reproduction employed by flowering plants has been more or less abandoned. Replacing this method of reproduction is a great power of regetative propagation. From the disk-like body of the plant other disk-like bodies but out, and this budding continues until a large group of disks, more or less commected with each other, may be formed. These plants also form what are known as winter buds-well protected bud-like bodies which sink to the bottom of the pond when the floating plants are lestroyed, and remain protected by the mucky bottom until the waters become warm again in the next growing season.

In examining the pond societies, therefore, attention should be paid to the floating forms and the submerged forms, and also to the varying lepths of the latter. It will also be noted that the leaves of floating forms are comparatively broad, while those of submerged forms are narrow.

\section{Anchored sorieties.}

133. Definition. - These are soeieties fixed to the soil but with submerged or floating leaves. In this case there is still great exposure to water, but there is also a definite soil relation. Two prominent societies are seleeted from this group for illustration.

134. Rock societies. - The term rock is used in this connection in a very general way, meaning simply some firm support beneath the water ; it is just as likely to be a stick 
as a stone. Probably the most prominent group of plants affecting these conditions are algæ, both fresh water and marine. In the fresh waters very many of the alga will be

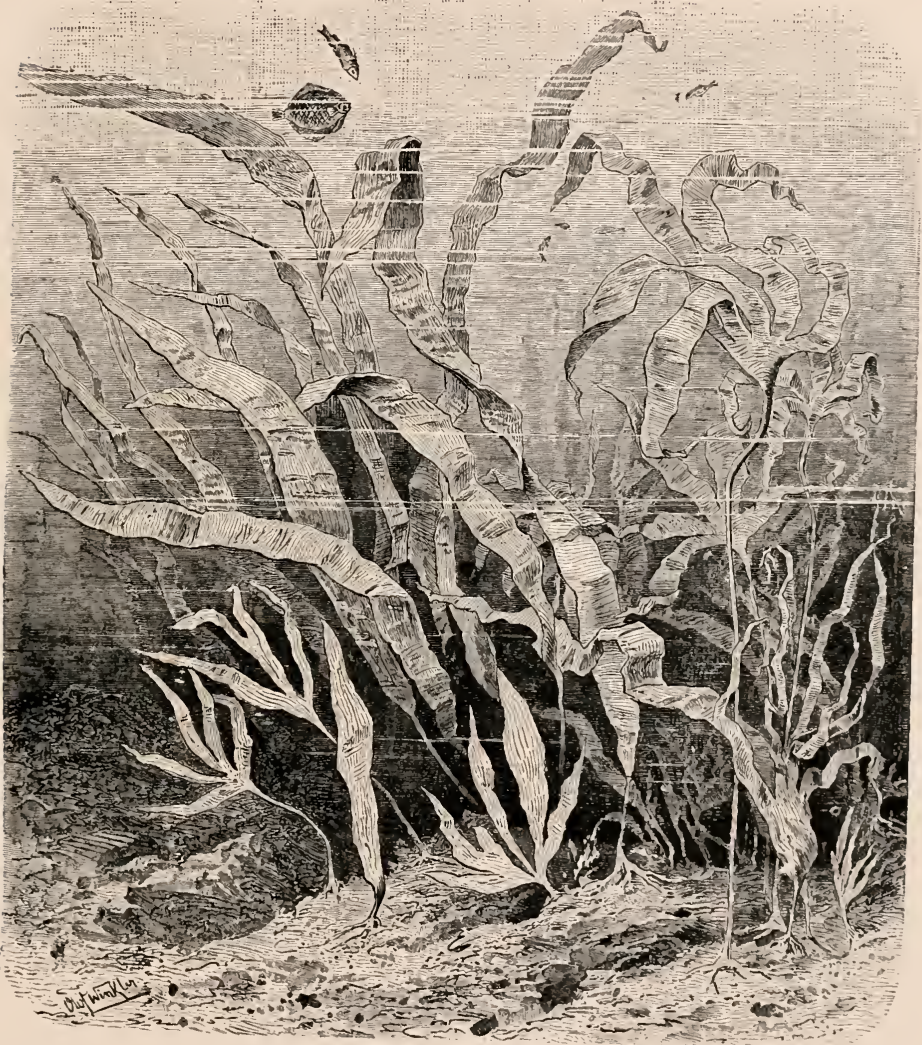

Fig. 15\%. A group of marine seaweeds (Laminarias). Note the various habits of the plant body and the root-like holdfasts.-After KEnNER.

found anchored to some support. The largest display of such forms, however, is found among the marine alga, which abound along all seacoasts (see Fig. 15\%). It will 


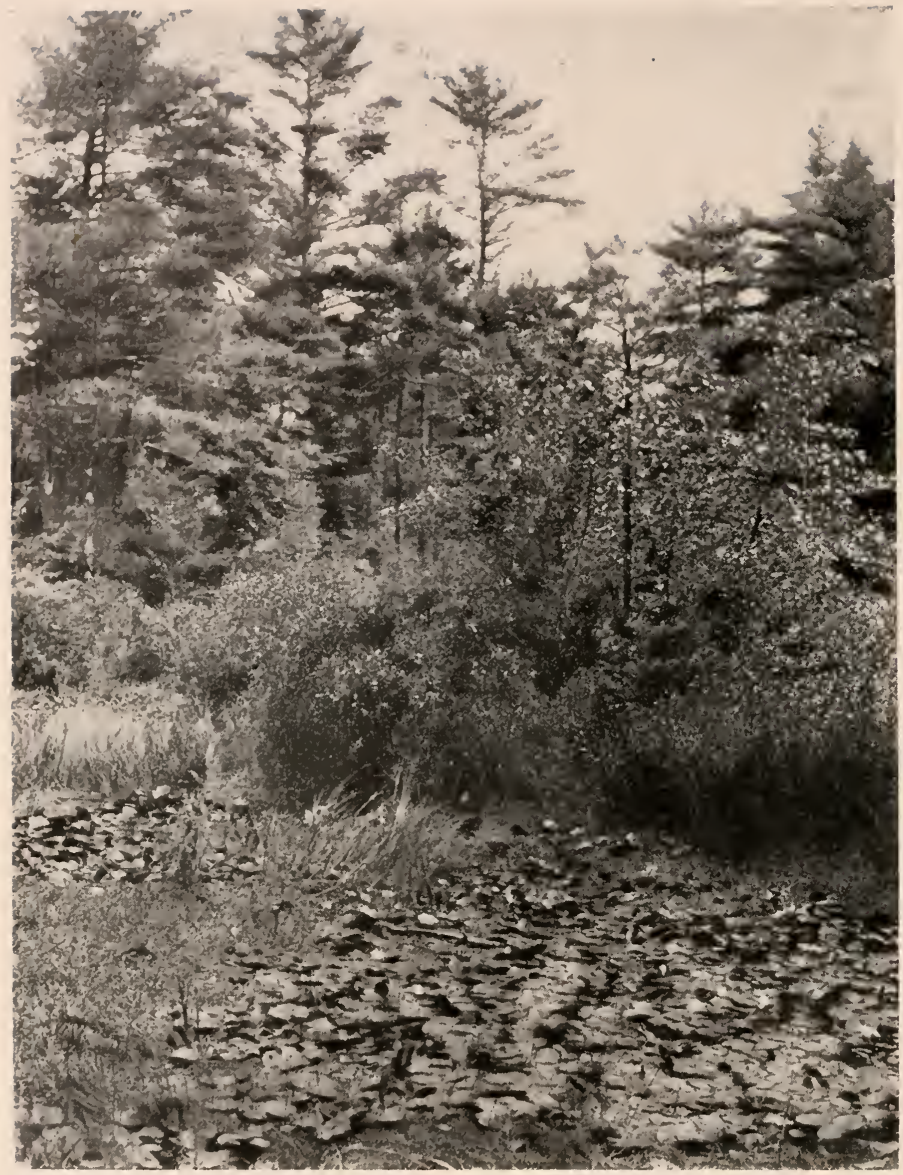

FIG. 158. A natural, but nearly overgrown lily pond. The lily pads may be seen rising more or less above the water where they are thickest. The forest growth in the background is probably a tamarack (larch) swamp. It is to be noticed that as the lily pond loses its water it is bcing invaded by the coarse sedge and grass growth of a swamp-moor. Between the lily pond and the forest is a swampthicket. At least four distinct societies are represented in this view. A fifth is probably represented in the form of plants of the reed-swamp type, which form a transition between the lily pond and the swamp-thicket. 
be noticed that the habit of anchorage demands the development of special organs of attachment, which usually take the form of root-like structures, often associated with sucker-like disks. Associated with the anchoring structures is often a development of floats, which is especially eharacteristic of seaweeds, enabling the working body to float freely in the water (see Figs. 153, 15t). It is erident that while free-swimming forms may be suitable for stagnant waters, anchored forms are better adapted for moving waters. Therefore, where there are currents of water, or wave action, the anchored forms predominate. The ability to live in moving waters, and often in those that become violently agitated, has its advantage to the plant in the more rapidly renewed food material. In such a situation free-swimming forms would soon be stranded or clisposed of in quieter waters.

In the ease of the marine seaweeds there is an interesting relation between the depth of the water and the color of the plants. While the fresh water alga are prevailingly green, it will be remembered that the prevailing colors of the alga of the seashore are brown and red. The brown often passes into some shade of yellow, and the red may merge into purple or violet, but in general the two types of color may be called brown and red. It has been noticed that the brown forms are found at less depth than the red forms, so that in a general way there are two zones of distribution in relation to depth, the red zone being the lower one and the yellow zone the upper. Just what this means in the economy of the plants is not elear, but it has been suggested that the yellow and the red eolors assist the ehlorophyll in its work. which is more or less interfered with by the diminished intensity of the light passing through sea water.

135. Loose soil societies. - This phrase is nsed merely to contrast with rock societies, referring to the fact that the anchorage is not merely for mechanieal support, but that 


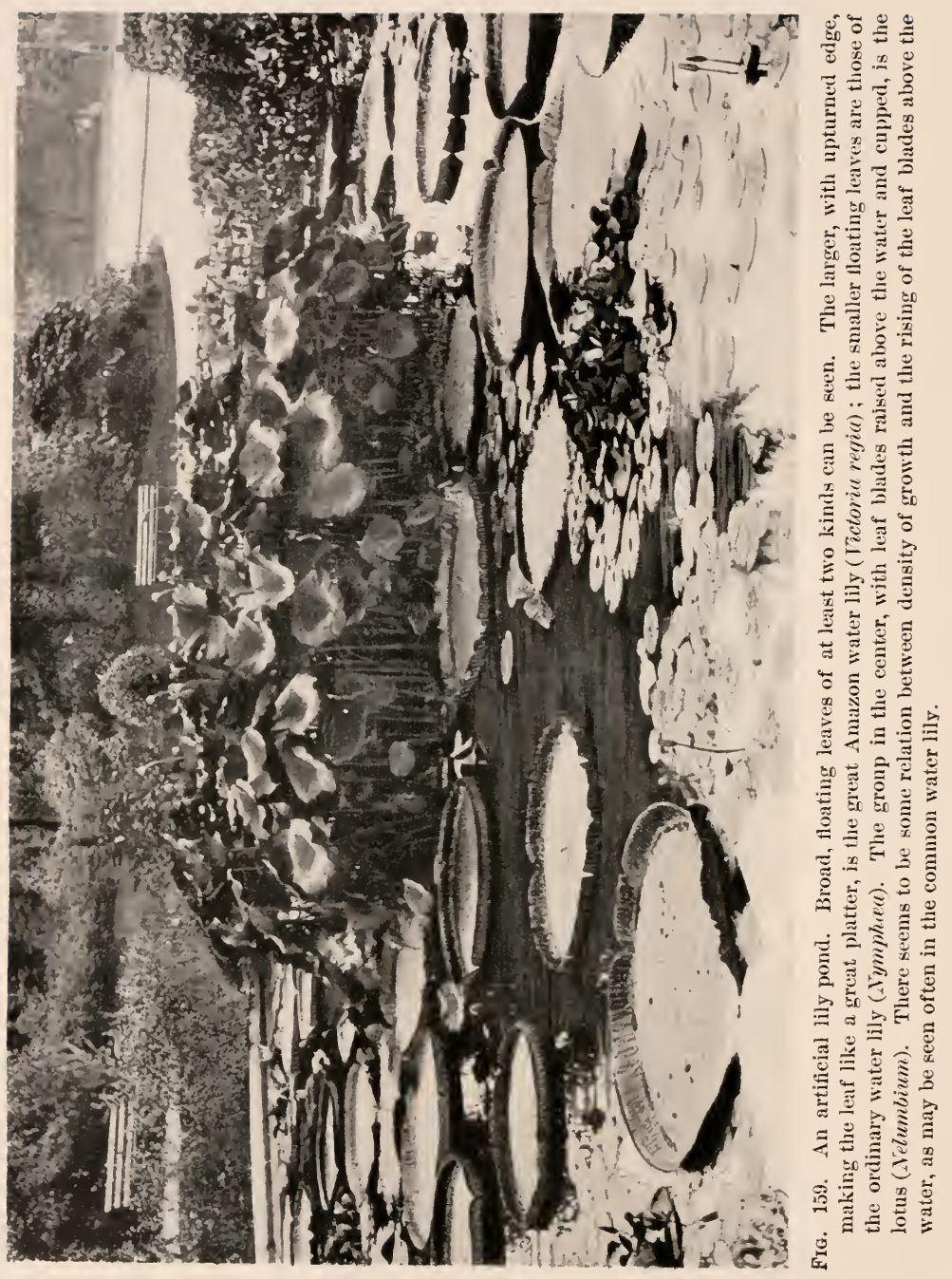


there is a definite relation to soil in which roots or root-like structures are embedded. Societies of this type contain the greatest variety of plants of all ranks. In these societies are found alga, mosses, ferm plants, pondweeds, water lilies, etc. (see Figs. 158, 159, 160, 161). Pondweeds and water lilies may be taken as eonvenient types of high grade plants which grow in such conditions.

In the first place, it will be noticed that they are inclined to social growths, great numbers of individuals growing together and forming what are known as lily ponds or pondweed beds, although in the small lakes of the interior where pondweeds abound in masses, they are more commonly known as "pickerel beds." If the petiole of a lily pad be traced down under the water, it will be found to arise from an intricate mass of thick, knotted stems. So extensirely do these stems (rootstocks) in the mucky bottom branch that they are able to give rise to elose set masses of leares.

Water lilies and pondweeds may also be compared to show the effect of the floating habit in contrast with the submerged habit. The leaves of water lilies float on the surface, and therefore are broad; and being exposed to light are a virid green, indicating the abundant development of chlorophyll. Many of the pondweeds, however, are completely submerged. As one floats orer one of these "pickerel beds," the leafy plants may be seen at considerable depths, and have a pallid, translucent look. It will be seen that in these eases the leaf forms are nalrow rather than broad. often being ribbon-like, or in some submerged plants eren ent up into thread-like forms. It is evident that such narrow leaf forms can respond more easily to water morements than broad forms. The pallid look of these submerged leares indieates that there hats not been an abundant development of chlorophyll. Some pondweeds, however, have both types of leaves, some being submerged and others floating. In these cases it is interesting to notice 


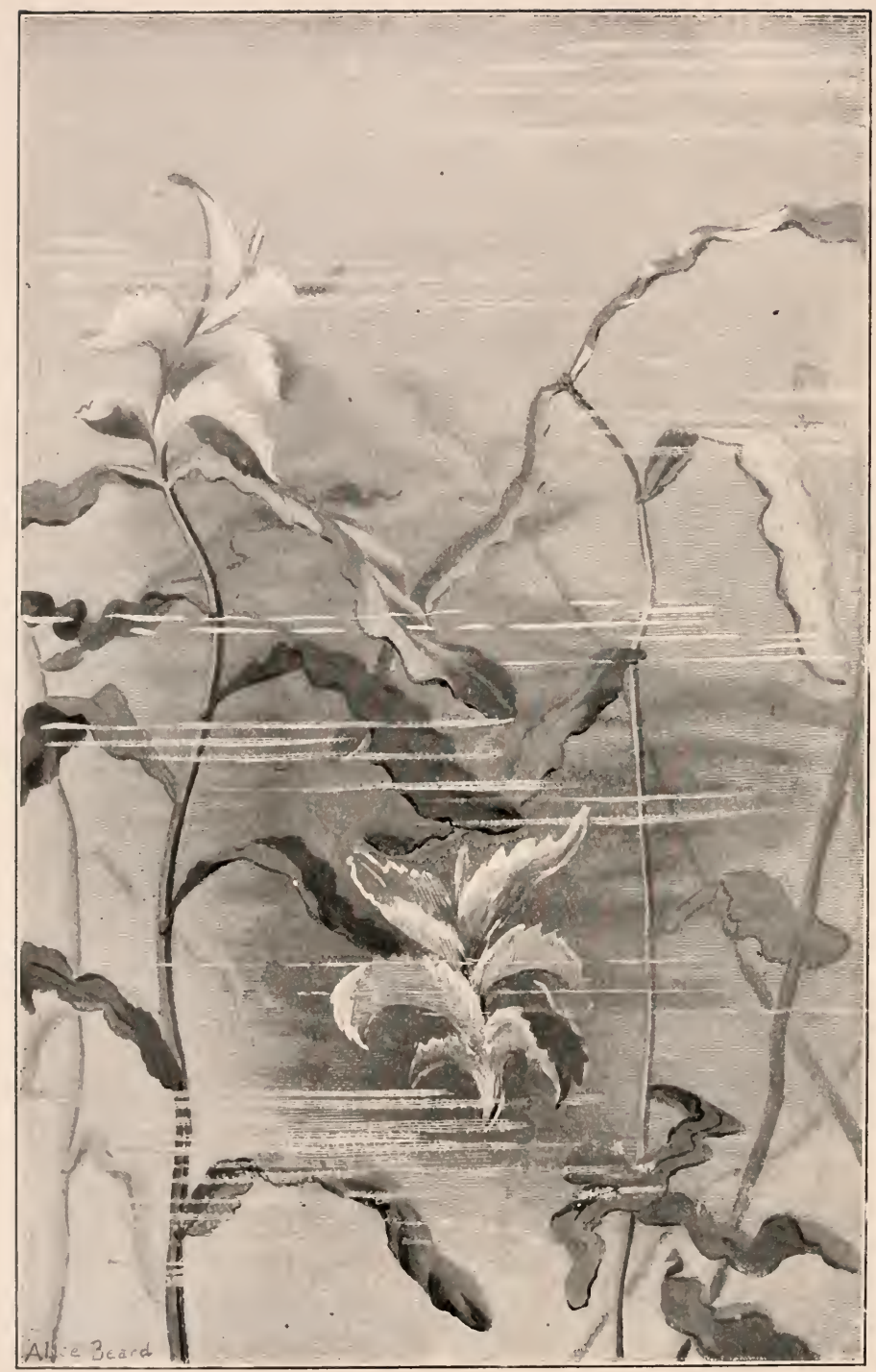

FIg. 160.-A group of pondweeds. The stems are sustained in an erect position by the water, and the narrow leaves are exposed to a light whose intensity is diminished by passing through the water.-After KerNER. 
the corresponding change of form; on the same individual the submerged leaves are very narrow, or divided into very narrow lobes, while the floating ones are broad (see Fig. 162). The relation of the plant to the water, therefore, has determined the leaf form. The advantage of the floating habit of leaves is not merely a better relation to light, but the carbon dioxide used in photosynthesis and the oxygen used in respiration may be obtained freely from the air, rather than from the water. It will also be noticed that these water plants usually send their flowers to the surface, indicating that such a position is more farorable for the work of the flower than a submerged position. Any society of this type will furnish abundant material for observation, and it is, perhaps, the most valuable type of society for study that has been mentioned so far.

\section{Swamp societies.}

136. Definition.-In swamp societies the plants are rooted in water, or in soils rich in water, but the stems bearing the leaves rise above the surface. Among the hydrophytes, swamp plants are least exposed to water, and as the stem and its leares are exposed to the air, there is no such reduction of the root system and of conducting and mechanical tissues as in the other hydrophytes. Also the epidermis is not thin, and there is no development of floats to increase the buoyaney. However, the root must be aerated, and hence air chambers and passageways are abundant. This aeration of the root system reaches a rery high development in such swamp trees as the eypress. In eypress swamps the so-called "knees" are abundant, and they are found to be special growths from the root system, which rise above the surface of the water, both for bracing and to admit air to the roots (see Fig. 91). It has been shown that if such swamps are flooded above the level of the knees, many of the trees are killed. In ordinary cases the air is admitted 


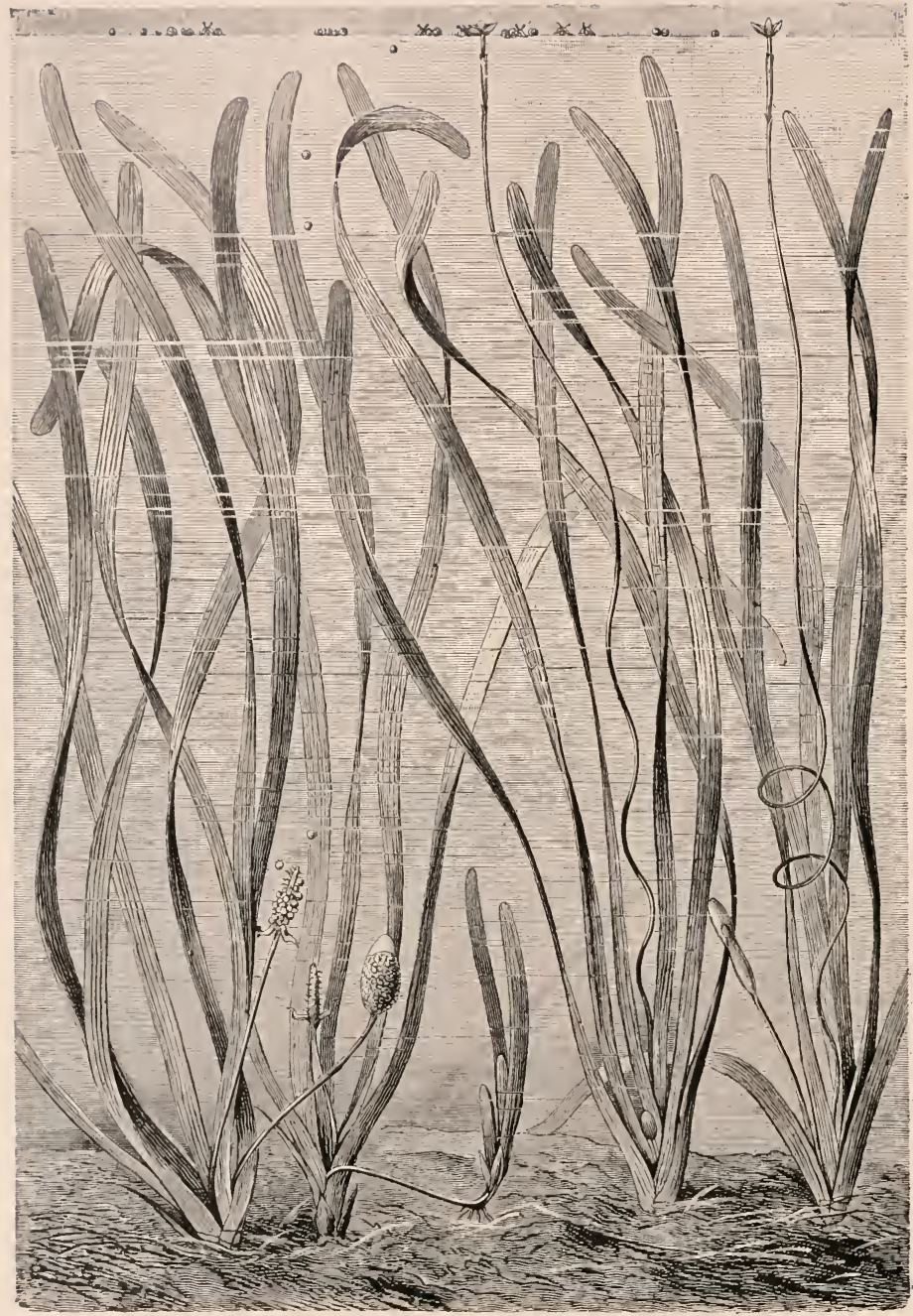

Fig. 161. Ecl grass (Vallisneria), a common pondweed plant. The plants are anchored and the foliage is submerged. The carpel-bearing flowers are carried to the surface on long stalks which allow a variable depth of water. The stamenbearing flowers remain submerged, as indicated near the lower left corner, the flowers breaking away and rising to the surface, where they float and effect pollingtion.-After KERNER. 
through openings in the epidermis of the stem and leaves, and so enters the air passageways and reaches the roots. Another habit of swamp plants is called turf-building, which means that new individuals arise from older ones, and so a dense mat of roots and rootstocks is formed. Very prominent among these turf-building swamp plants are

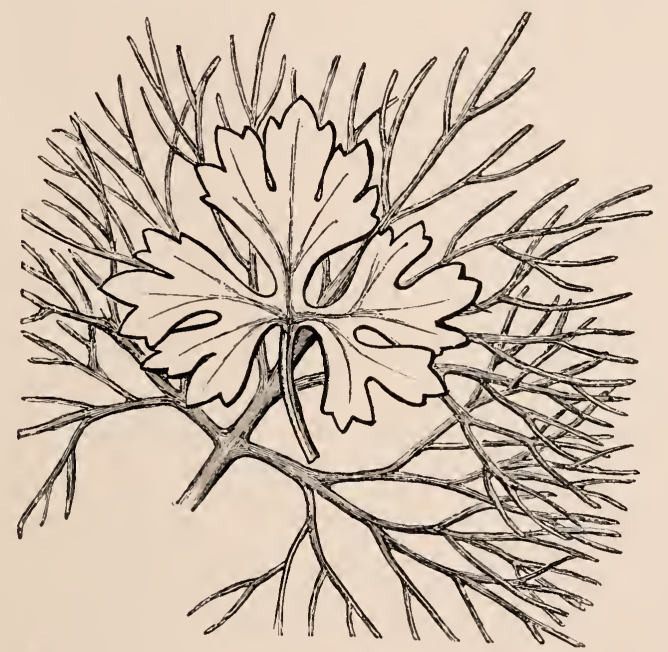

Fig. 162. Two leaves of a water buttercup, showing the difference in the forms of submerged and aerial leaves on the same plant, the former being much more finely divided.-After Strasburger.

the sedges. Some of the prominent swamp societies may be enumerated as follows:

13\%. Reed swamps.-The reed-swamp plants are tall wandlike forms, which grow in rather deep, still water (see Fig. 163). Prominent as types are the cat-tail flag, bulrushes, and reed grisses. Such an assemblage of forms usually characterizes the shallow margins of small lakes and ponds. In such places the different plants are apt to be arranged according to depth, the bulrushes standing in the deepest water, and behind them the reed grasses, and then the 
cat-tails. 'This regular arrangement in zones is so often interfered with, however, that it is not always evident.

The reed-swamp societies have been called " the pioneers of land vegetation," for the detritus collects about them,

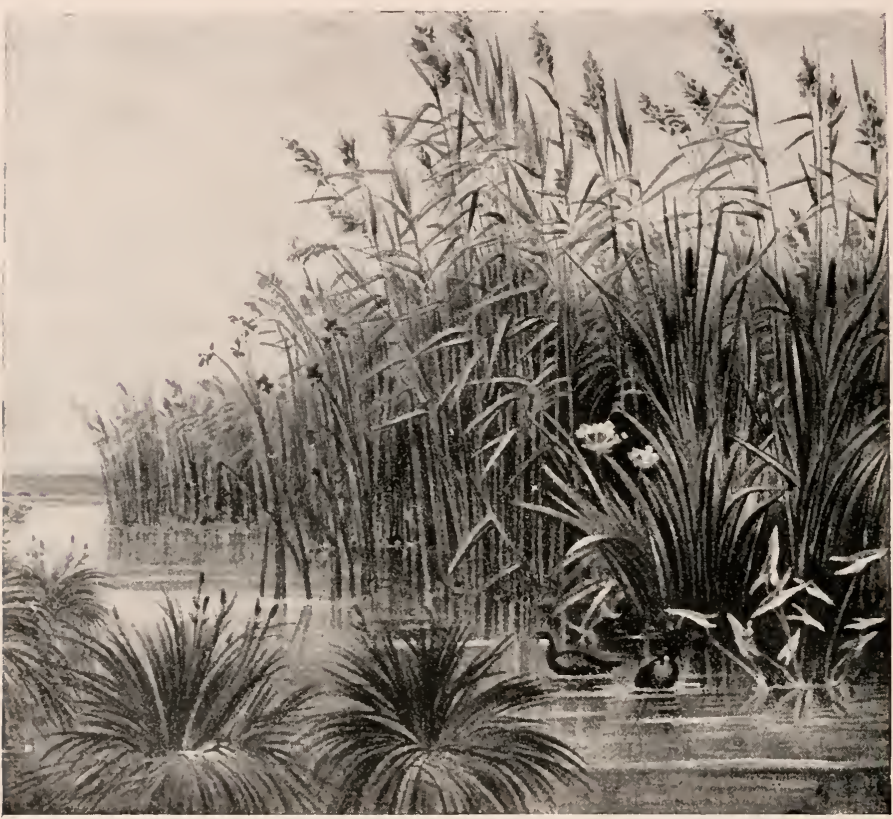

FIG. 163. A reed swamp, fringing the low shore of a lake or a sluggish stream. The plants are tall and wand-like, and all are monocotyls. Three types are prominent, the reed grasses (the tallest), the cat-tails (at the right), and the bulrushes (a group standing ont in deeper water near the middle of the fringing growth). The plant in the foreground at the extreme right is the arrow-leaf (Sagittaria), recognized by its characteristic le:tves.-After KERNER.

the water becomes more and more shallow, until finally the reed plants are compelled to migrate into deeper water (see $\$ 108)$. In this way small lakes and ponds may be completely reclaimed, and become converted first into ordinary swamps, and finally into wet meadows. Instances 


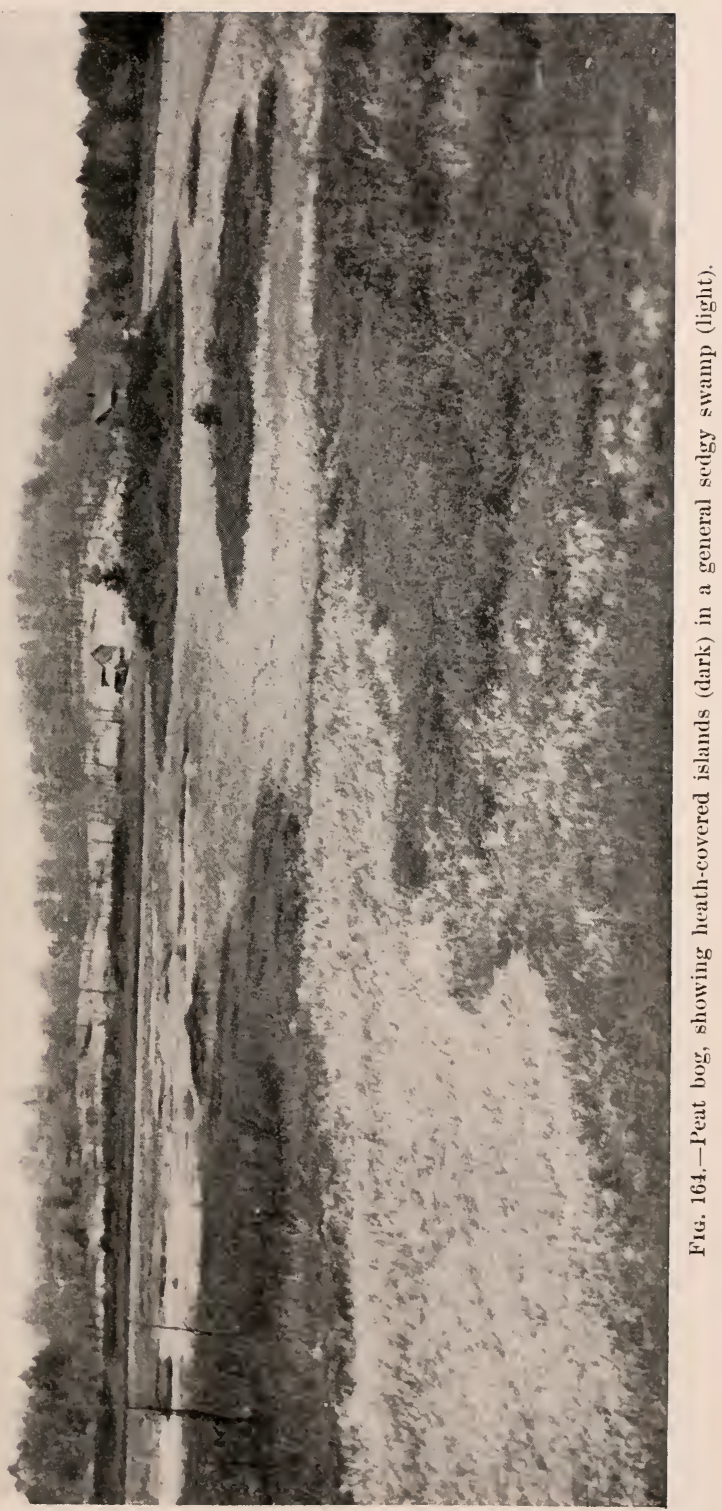



of nearly reclaimed ponds may be noticed, where bulrushes, cat-tail flags, and reed grasses still occupy certain wet spots, but are shut off from further migration. The social growth of these plants, brought about by extensive rootstock development, is especially favorable for detaining detritus and building a land surface.

Reed-swamp plants also have in general a tall and mnbranched habit of body. They may be bare and leafless, with a terminal cluster of flowers, as in the bulrushes; or the wand-like stems may bear long, linear leaves, as in the cat-tails; or the stem may be a tall stalk with two rows of narrow leaves, as in the reed grasses. No more characteristic group of forms is found in any society. Of course, associated with these forms are also free and fixed hydrophytes, which characterize the other societies.

138. Swamp-moors.-The word moor is used to designate the meadow-like expanses of swampy ground. Here belong the ordinary swamps, marshes, bogs, etc. There is less water than in the case of the reed swamps, and often very little standing water. One of the peculiarities of the swamp-moor is that the water is rich in the soil materials used in food manufacture, notably the nitrates from which nitrogen is obtained for proteid manufacture. In such conditions, therefore, the regetation is dense. and the soil is black with the humus derived from the decaying plant bodies.

'Typical swamp-moors border the reed swamps on the land side, and slowly encroach upon them as the reed plants build up land. Probably the most characteristic plant forms of the swamp-moor are the sedges. and associated with them are certain coarse grasses. These give the meadow-like aspect to the swanp), although these grasslike forms are very coarse. Along with the dominant sedges and grasses are numerous other plants adapted to such conditions, such as some of the buttereups. It would be impracticable to give a list of swamp-moor plants, as the 
forms assoeiated with sedges and grasses may vary widely in different societies (Fig. 164).

In almost all swamp-moors there is a lower stratum of regetation than that formed by the sedges. 'This lower stratum is made of certain swamp mosses, which grow in very dense masses. 'Towards the north, where the temperature conditions are not so favorable for the sedge stratum, it may be lacking almost entirely, and only the lower moss stratum left. In these cases the swamp-moor becomes little more than a great bed of moss, and it is in such conditions that peat may be formed.

139. Swamp-thickets. - Swamp-thickets are very closely associated with swamp-moors, and are doubtless derived from them. If a swamp-moor, with its sedge stratum and moss stratum, be invaded by shrubs or low trees, it becomes a swamp-thicket. It will be noticed that these shrubs and trees are of very uniform type, being mainly willows, alders, birches, etc. Such willow and alder thickets are very common in high latitudes.

\section{Xerophyte hydrophytes.}

\section{A. Fresh-water societies.}

140. Sphagnum-moors. - The sphagnum-moor is a very peculiar type of swamp society. It is so named because the common bog or peat moss, known as sphagnum, gives a peculiar stamp to the whole area. Sphagnums are large, pale mosses, whose lower parts may die, and whose upper parts continue to live and put out new branches, so that a dense turf is formed. In walking over such a bog the moss turf seems springy, and sometimes trembles so as to suggest the name "quaking bog." 'These are the great peatforming bogs. It is interesting to know what conditions keep the swamp-moor plants out of the sphagnum-moor. 'The plants of the sphagnum-moor seem to be entirely different from those of the swamp-moor, although the amount 
of water is approximately the same. Not only are the plants different in the sphagnum-moor, but they are not so numerous, and, with the exception of the moss, do not grow so densely. It is to be noticed that creeping plants are abundant, and also many forms which are known to obtain their food material already manufactured, and therefore are saprophytes. Certain kinds of sedges and grasses are found, but generally not those of the swamp-moor, while heaths and orchids are especially abundant. It is in these sphagnum-moors, also, that the curious forms of carnivorous plants are developed, among which the pitcher plants, droseras, and dionæas have been described. In considering this strange collection of forms, it is evident that there must be some peculiarity in the food supply, for the heaths and orchids are notorious for their partial saprophytic habits, and the carnivorous plants are so named because they capture insects to supplement their food supply. The fact, also, that the peculiar sphagnum mosses, rather than the mosses of the swamp-moor, are the prevalent ones, indicates the same thing.

It has been discovered that the water of the sphagnummoor is very poor in the food materials which are abundant in the water of the swamp-moor. There is a special lack of the materials which are used in the manufacture of proteids, and hence this process is seriously interfered with. It is necessary, therefore, to obtain proteids already formed in animals, or in other plants. This will account for the necessity of the saprophytic habit, and of the carnivorous habit, and for the sphagnum mosses which can endure such conditions. Of course, it also accounts for the exclusion of the characteristic plants of the swamp-moor.

Another peculiarity in comnection with the sphagnummoor, aside from its poverty in food material, is the lack of those low plant forms (bacteria) which induce decay. Bacteria are very minute plants, some of which are active agents in processes of decay, and when these are absent 
decay is ehecked. As a consequence, the sphagnum-moor waters are strongly antiseptic: that is, they prevent deeay by exeluding certain bacteria. It is a well-known fact that bodies of men and animals which have become submerged in sphagnum-bogs may not decay, but have been found preserved after a very long period. This will also indieate why such bogs are especially farorable for peat formation.

These two types of moors, therefore, may be contrasted as follows: 'The swamp-moor is rich in plant food, and is characterized chiefly by grassy plants; the sphagnum-moor is poor in food material, and is characterized chiefly by sphatgnum moss. It will be noted that peat may be formed in connection with both of these moors, but in the swampmoor the plant forms cannot be distinguished in the peat, as they have been more or less disorganized through decay, while in the peat of the sphagnum-moor the plant forms are well preserved. The peat of the swamp-moor, also, yields a great amount of ash, for the swamp-moor is rich in soil materials, while the peat of the sphagnum-moor yields very little ash.

141. Swamp forests.-It was noted that the special types of shrub or tree growth associated with the swamp-moor conditions are willows, alders, birches, ete. In the same way there is a peculiar tree type associated with the sphagnum-moor. It is very common to have a sphagnum area occupied by trees, and the area becomes a swamp forest, rather than a sphagnum-moor. The chief tree type which oecupies such conditions is the conifer type, popularly known as the evergreens. The swamp forests, therefore, with a sphagnum-moor foundation, are made up of larches, certain hemlocks and pines, junipers, etc., and towards the south the eypress comes in (see Fig. 165). The larch is a very common swamp tree of the northern regions, where such an area is commonly called a "tamarack swamp" (see Fig. 158). The lareh forests are apt to be in the form of small patches, while the larger swamp 


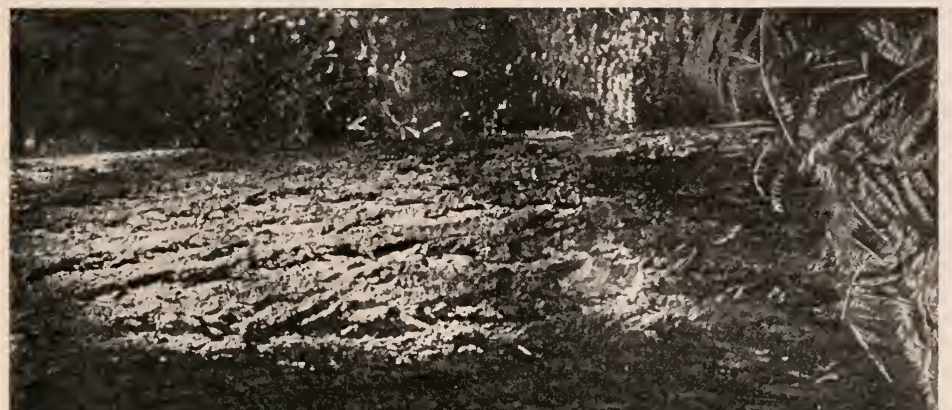

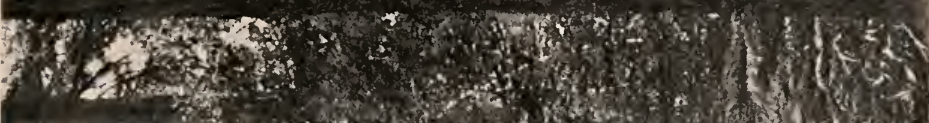

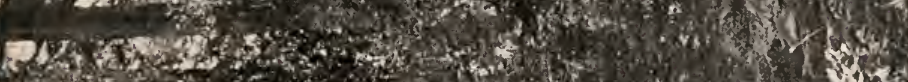
Wot 0 -

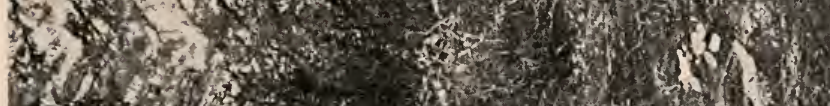

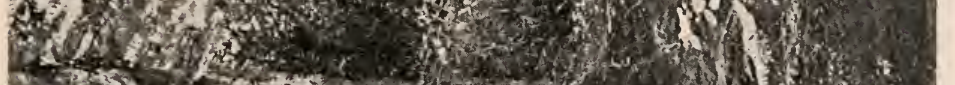
2.

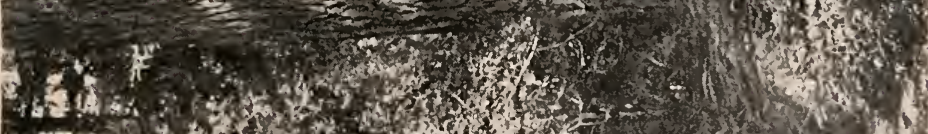
W.

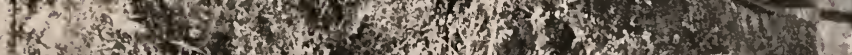

3.

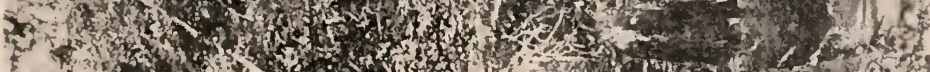

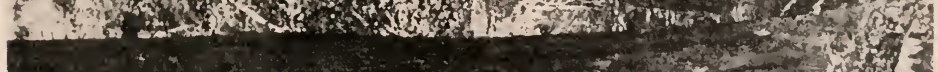

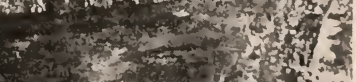


forests are made of dense growths of hemlocks, pines, etc. In the densest of these forests the shade is so complete that there may be very few associated plants oceurring in strata between the sphagnum moss and the trees. In the lareh forests, however, the undergrowth may be very dense.

\section{B. Salt-water societies.}

14\%. Mangrove swamps.-This is certainly the most vigorous of the salt-water societies. Mangrove swamps occur along flat tropical seacoasts, where the waters are quiet.

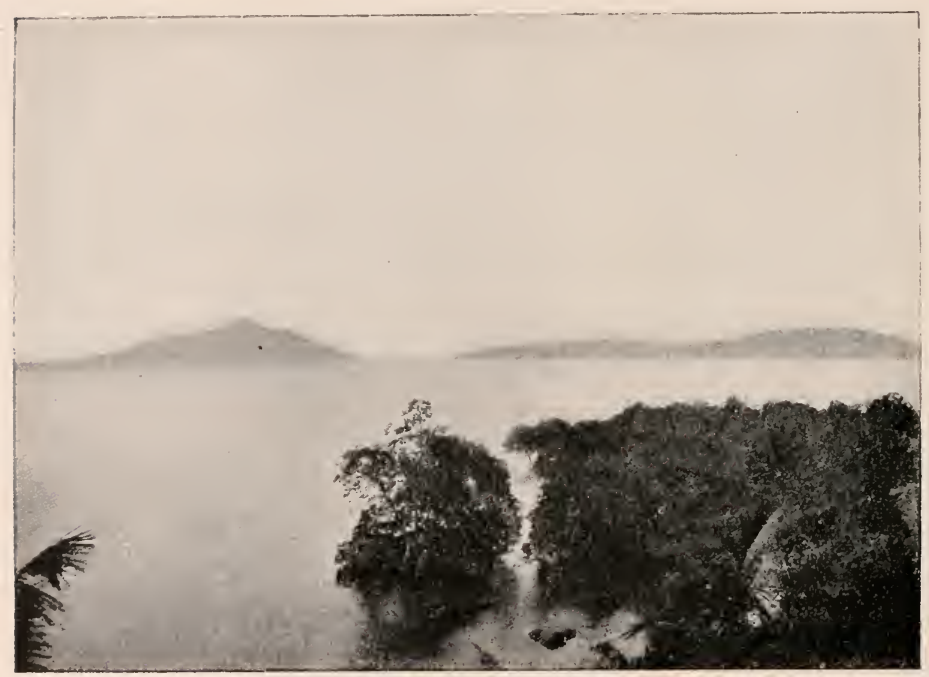

FIG. 166. A mangrove forest advancing into the water.-After ScHIMPER.

The mangrove is a tree of curious habit, which advances slowly out into the water and extends back landwards as low woods or thickets (see Figs. 166, 16\%). The whole surroundings appear forbidding, for the water is sluggish and mucky, covered with seum, rich in bacteria, and with bubbles constantly breaking upon the surface from decaying matter beneath the water. The mangrove has the pe- 


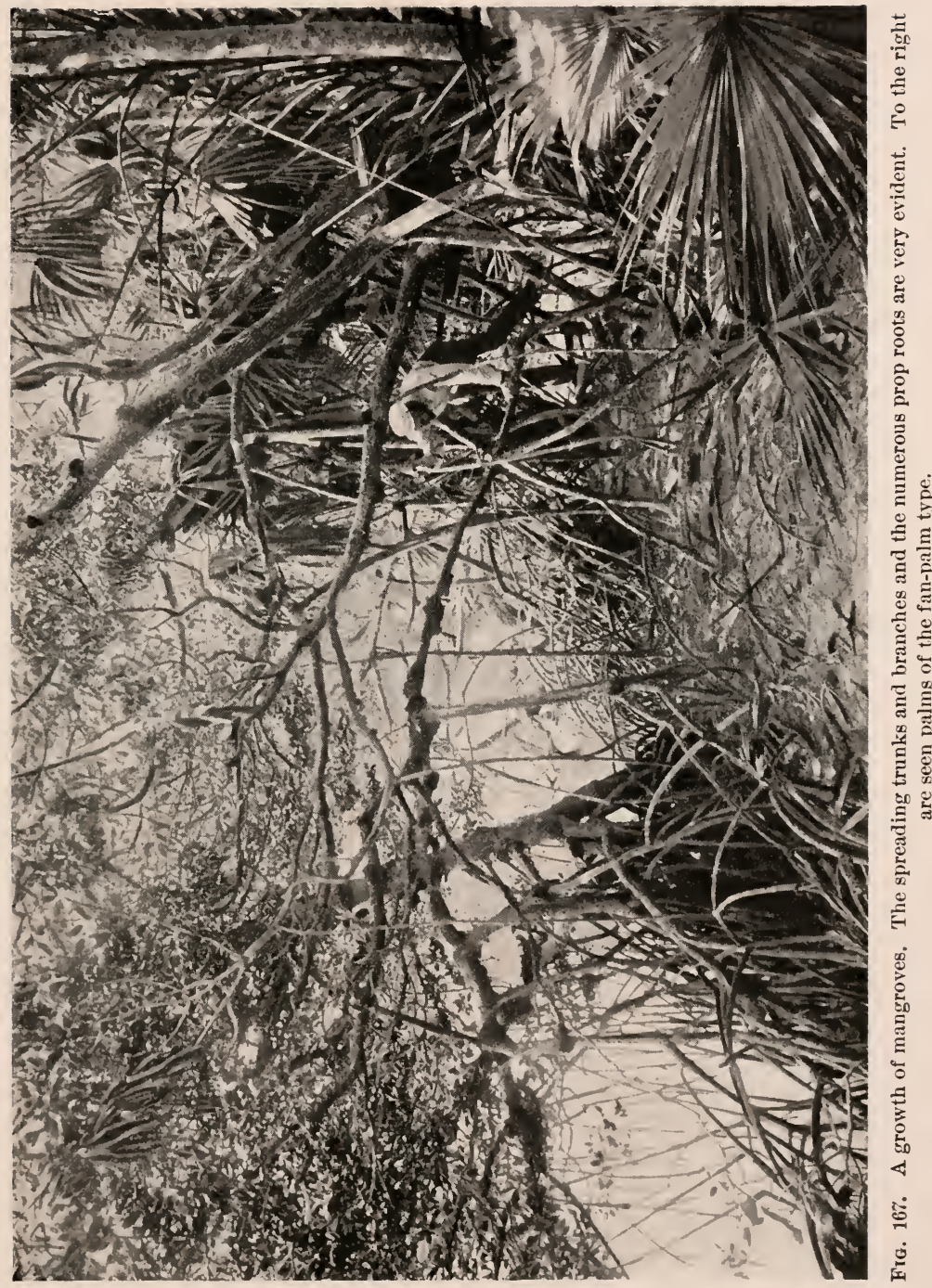


culiarity of germinating its seeds while still upon the tree, so that embryos hang from the trees, and then drop like plumb-bobs into the muck beneath, where they stick fast and are immediately in a condition to establish themselves. In these mangrove swamps the species are few, and the adaptations chiefly in the way of developing various kinds of holdfasts for anchoring in the uncertain soil, and also various devices for carrying air to the submerged parts.

143. Beach marshes and meadows. - The salt marshes and meadows near the seacoast are very well known. They lie beyond the reach of ordinary flood tide, but the waters are brackish. In these marshes and meadows occur certain characteristic salt-water grasses and sedges. Such forms being the dominant type give the general appearance of a coarse meadow. The difference between a marsh and meadow is simply a question of the amount of water. 


\section{CHAPTER XIIT.}

\section{XEROPHYTE SOCIETIES.}

144. General character.-Strongly contrasted with the hydrophytes are the xerophytes, which are adapted to dry air and soil. The xerophytic conditions may be regarded in general as drouth conditions. It is not necessary for the air and soil to be dry throughout the year to develop xerophytic conditions. These conditions may be put under three heads: (1) possible drouth, in which a season of drouth may occur at irregular intervals, or in some seasons may not occur at all; (2) periodic drouth, in which there is a drouth period as definite as the winter period in certain regions; (3) perennial drouth, in which the dry conditions are constant, and the region is distinctly an arid or desert region.

However xerophytic conditions may occur, the problem of the plant is always one of water supply, and many striking structures have been developed to answer it. Plants in such conditions must provide, therefore, for two things: (1) collection and retention of water, and (2) prevention of its loss. It is evident that in these drouth conditions the loss of water through transpiration (see $\$ 26$ ) tends to be much increased. This tendency in the presence of a very meager water supply is a menace to the life of the plant. It is impracticable to stop transpiration entirely, for it must take place in connection with a neessary life-process. The adaptations on the part of the plant, therefore, are directed towards the regulation of transpiration, that it 
mily occur sufficiently for the life-processes, but that it may not be wasteful.

The regulation of transpiration may be accomplished in two general ways. It will be remembered that the amount of transpiration holds some relation to the amount of leaf exposure or exposure of green tissue. Therefore. if the amount of leaf exposure be diminished, the total amount of transpiration will be reduced. Another general way for regulating transpiration is to protect the exposed surface in some way so that the water does not escape so easily. In a word, therefore, the general method is to reduce the extent of exposed surface or to protect it. It must be understood that plants do not differ from each other in adopting one or the other of these methods, for both are very commonly used by the same plant.

\section{Adaptations.}

145. Complete desiccation.-Some plants have a very remarkable power of completely drying up during the drouth period, and then reviving upon the return of moisture. This power is strikingly illustrated among the lichens and mosses, some of which can become so dry that they may be crumbled into powder, but revive when moisture reaches them. A group of club mosses, popularly known as “ resurrection plants," illustrates this same power. The dried up nest-like bodies of these plants are common in the markets, and when they are placed in a bowl of water they expand and may renew their activity. In such cases it can hardly be said that there is any special effort on the part of the plant to resist drouth, for it seems to yield completely to the dry conditions and loses its moisture. The power of reviving, after being completely dried out, is an offset, however, for protective structures.

146. Periodic reduction of surface- - In regions of periodic 
drouth it is very common for plants to diminish the exposed surface in a very decided way. In such cases there is what may be called a periodic surface decrease. For example, annual plants remarkably diminish their exposed surface at the period of drouth by being represented only by well-protected seeds. The whole exposed surface of the plant, root, stem, and leaves, has disappeared, and the seed preserves the plant through the drouth.

Little less remarkable is the so-called geophilous habit. In this case the whole of the plant surface exposed to the air disappears, and only underground parts, such as bulbs, tubers, etc., persist (see Figs. 45, 46, 66, 6\%, $68,69,70,75,144$, $168,169)$. At the re-

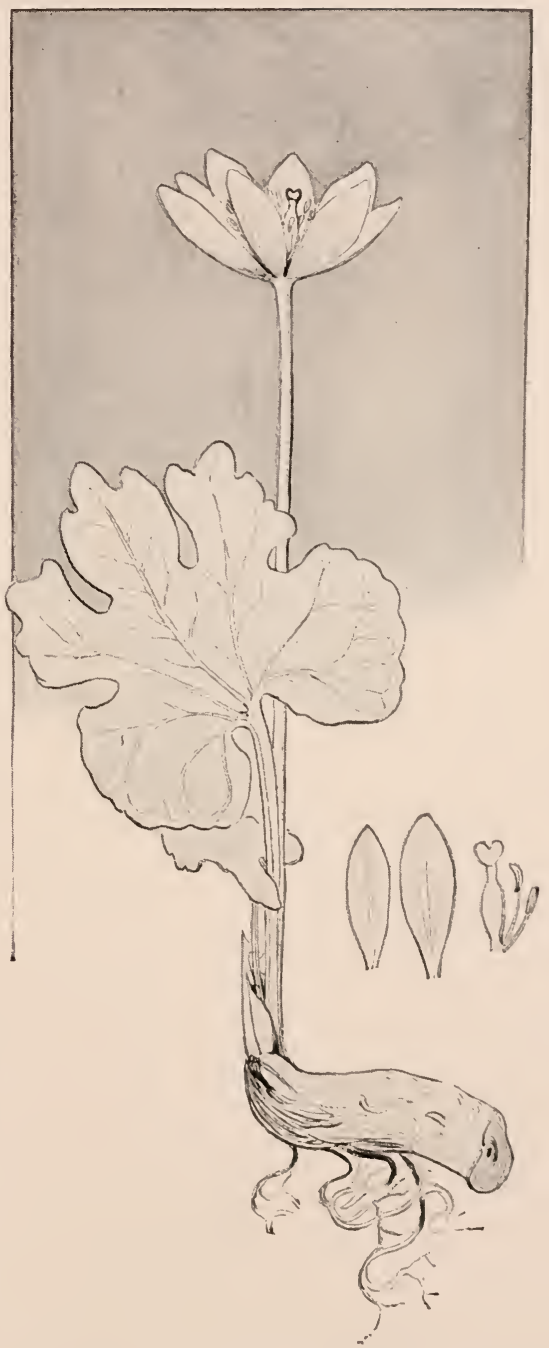

F16. 168. The bloodroot (sanguinaria), showing the subterranean rootstock sending leaves and flower above the surface.-Ifter Atkixisox. 


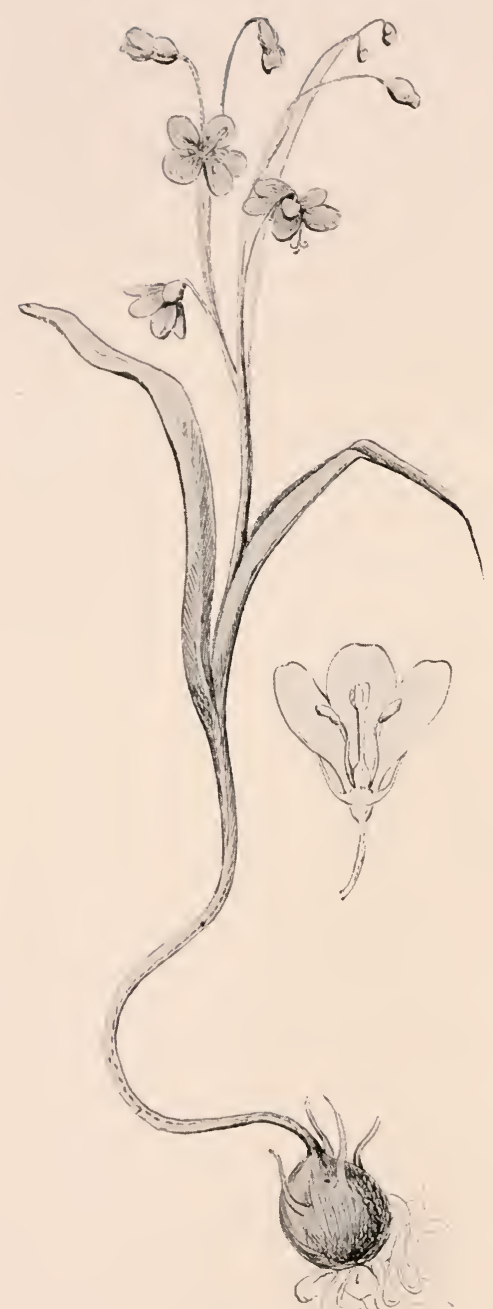

Fits. 169. The spring beauty (Claytoria), showing subterranean tuber-like stem sending leaf and flower-bearing stem above the surface.-After Atkinson. turn of the moist season these underground parts derelop new exposed surfaces. In such cases it may be said that at the coming of the drouth the plant seeks a subterranean retreat.

A little less decrease of exposed surface is shown by the deciduous habit. It is known that certain trees and shrubs, whose bodies remain exposed to the drouth, shed their leaves and thus very greatly reduce the amount of exposure : with the return of moisture, new leaves are put forth. It will be remarked, in this connection, that the same habits serve just as well to bridge over a period of cold as a period of drouth, and perhaps they are more familiar in commection with the cold period than in connection with the drouth period.

14\%. Temporary reduction of surface.-While the habits above have to do with regular drouth 
periods, there are other habits by which a temporary reduction of surface may be secured. For instance, at the approach of a period of drouth, it is very easy to observe certain leaves rolling up in various ways. As a leaf becomes rolled up, it is evident that its exposed surface is reduced. The behavior of grass leaves, under such eireumstances, is very easily noted. $\Lambda$ comparison of the grass blades upon a well-watered lawn with those upon a dried-up lawn will show that in the former ease the leaves are flat, and in the latter more or less rolled up. The same habit is also very easily observed in connection with the largerleaved mosses, which are very apt to encounter drouth periods.

148. Fixed light position.-In general, when leaves have reached maturity, they are mable to change their position in reference to light, having obtained what is known as a fixed light position. During the growth of the leaf, however, there may be changes in direction so that the fixed light position will depend upon the light direction during growth. The position finally attained is an expression of the attempt to secure sufficient, but not too much light (see \$13). The most noteworthy fixed positions of leaves are those which have been developed in intense light. A very common position in such cases is the profile position, in which the leaf apex or margin is directed upwards, and the two surfaces are more freely exposed to the morning and evening rays-that is, the rays of low intensitythan to those of midday.

Illustrations of leaves with one edge directed upwards can be obtained from the so-called compass plants. Probably most common among these are the rosin-weed of the prairie region, and the prickly lettuce, which is an introduced plant very common in waste ground (see Fig. 1\%0). Such plants received their popular name from the fact that many of the leares, when edgewise, point approximately north and south, but this direction is rery indefinite. It is 
evident that such a position aroids exposure of the leaf surface to the noon rays, but obtains for these same surfaces the morning and evening rays. If these plants are developed in the shade, the "compass" habit does not
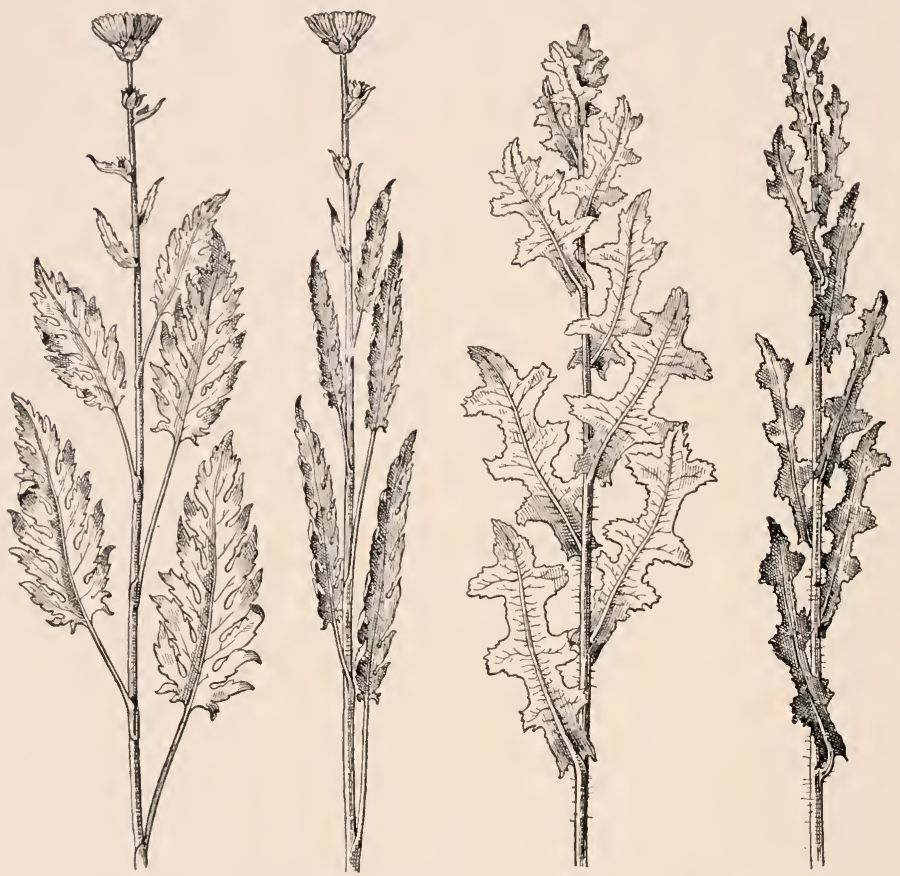

Fig. 170. Two compass plants. The two figures to the left represent the same plant (Silphium) viewed from the east and from the south. The two figures to the right represent the same relative positions of the leaves of Lactuca.-After KERNER.

appear (see $\$ 15)$. The profile position is a very common one for the leaves of Anstralian plants, a fact which gives much of the regetation a peculiar appearance. All these positions are serviceable in diminishing the loss of water, which would occur with exposure to more intense light.

149. Motile leaves.-Although in most plants the mature 
leaves are in a fixed position, there are certain ones whose leaves are able to perform movements according to the need. Mention has been made already of such forms as Oxalis (see $\$ 14$ ), whose leaves change their position readily in reference to light. Notile leaves have been developed most extensively among the Leguminose, the family to which

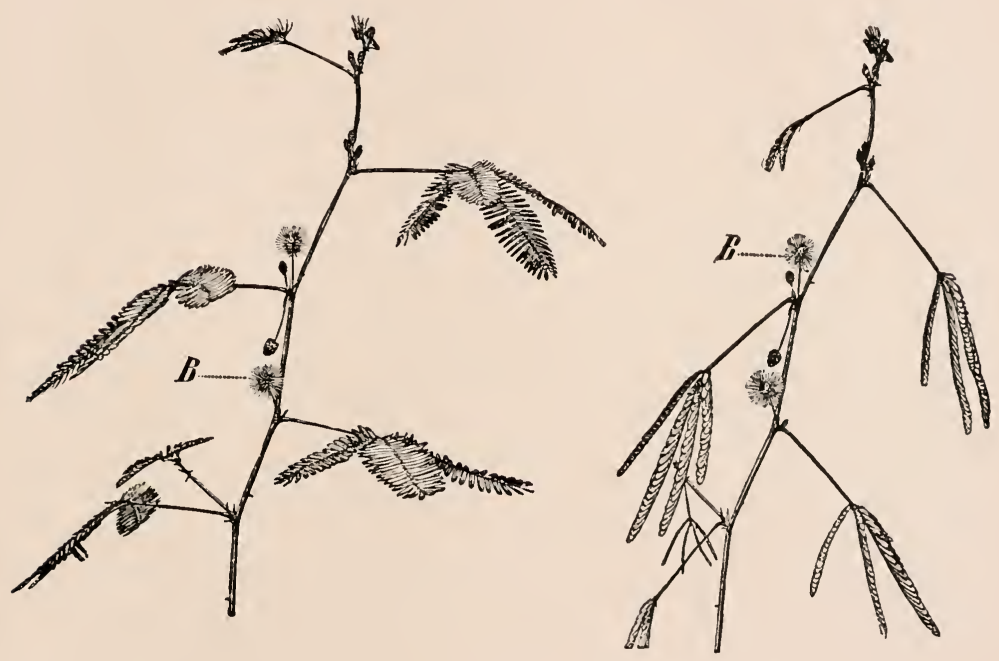

FIG. 171. Two twigs of a sensitive plant. The one to the left shows the numerous small leaflets in their expanded position; the one to the right shows the greatly reduced surface, the leaflets folded together, the main leaf branches laving approached one another, and the main leaf-stalk having bent sharply downwards. -After Strasburger.

belong peas, etc. In this family are the so-called "sensitive plants," which have received their popular name from their sensitive response to light as well as to other influences (see Fig. 1\%1). The acacia and mimosa forms are the most notable sensitive plants, and are especially developed in arid regions. The leares are usually very large, but are so much branched that each leaf is composed of very numerous small leaflets. Each leaflet has 
the power of independent motion, or the whole leaf may more. If there is danger from exposure to drouth, some of the leaflets will be observed to fold together; in case

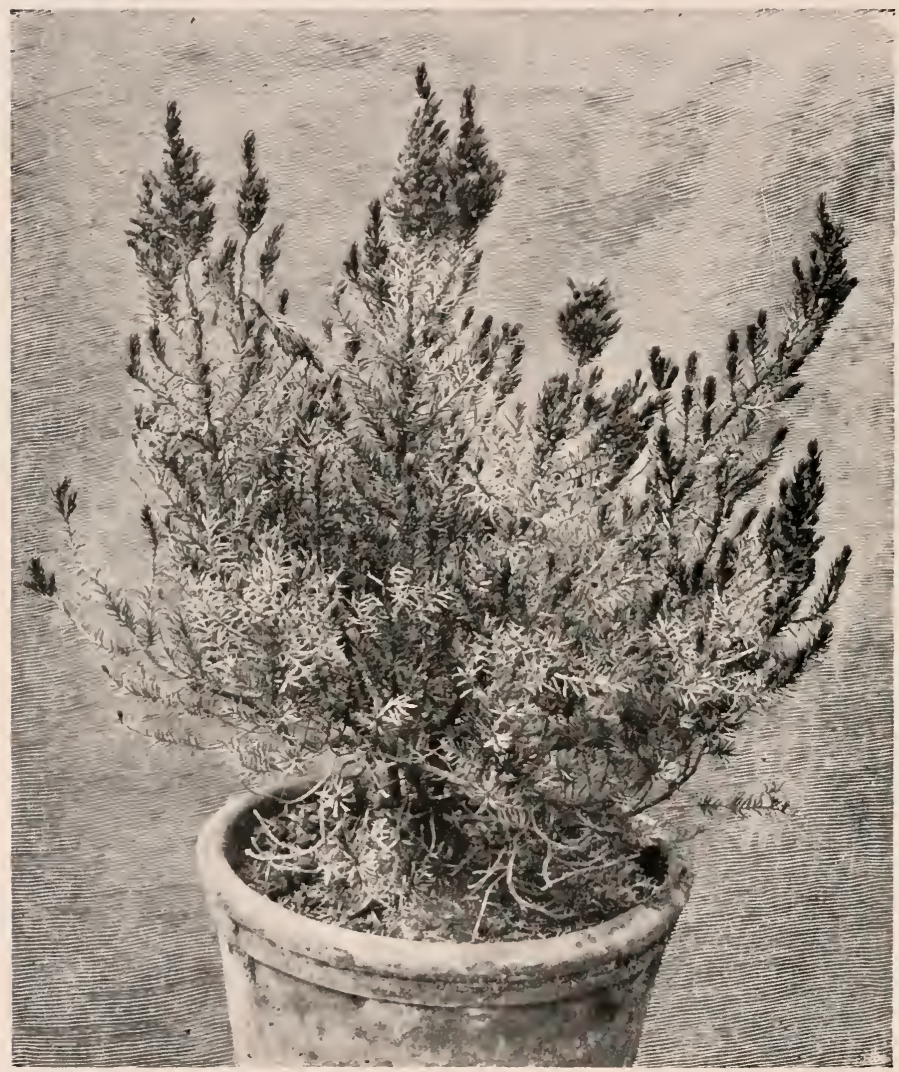

Fig. 172. A heath plant (Erica), showing low, bushy growth and small leaves.

the danger is prolonged, more leaflets will fold together; and if the danger persists, the surface of exposure will be still further reduced, until the whole plant may have its leaves completely folded up. In this way the amount of 
reduction of the exposed surface may be accurately regulated to suit the need (see $\$ 38$ ).

150. Reduced leaves.-In regions that are rather permanently dry, it is observed that the plants in general prodnce smaller leaves than in other regions (see Fig. 173). That this holds a direct relation to the dry conditions is

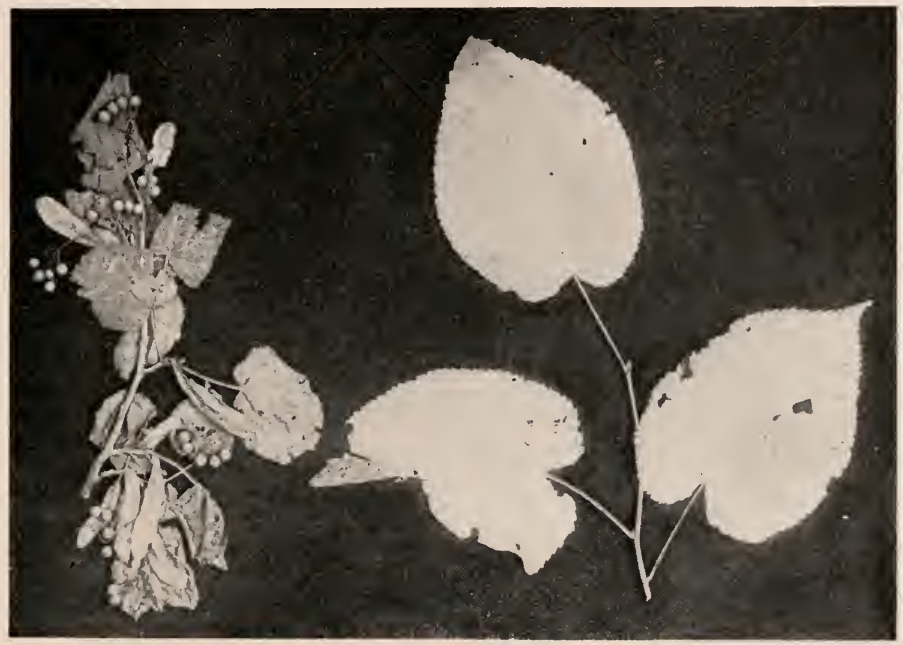

Fit. 173. Leaves from the common basswood (Tilia), showing the efiect of environment ; those at the right being from a tree growing in a river bottom (mesophyte conditions) ; those at the left being from a tree growing upon a dune, where it is exposed to intense light, heat, cold, and wind. Not only are the former larger, but they are much thinner. The leaves from the dune tree are strikingly smaller, much thicker, and more compact.-After Cowses.

evident from the fact that the same plant often prolnces smaller leaves in xerophytic conditions than in moist conditions. One of the most striking features of an arid region is the absence of large, showy leaves (see Fig. 1\%2). These reduced leares are of various forms, such as the needle leares of pines, or the thread-like leaves of certain sedges and grasses, or the narrow leares with imolled margins such as is common in many heath plants. The 

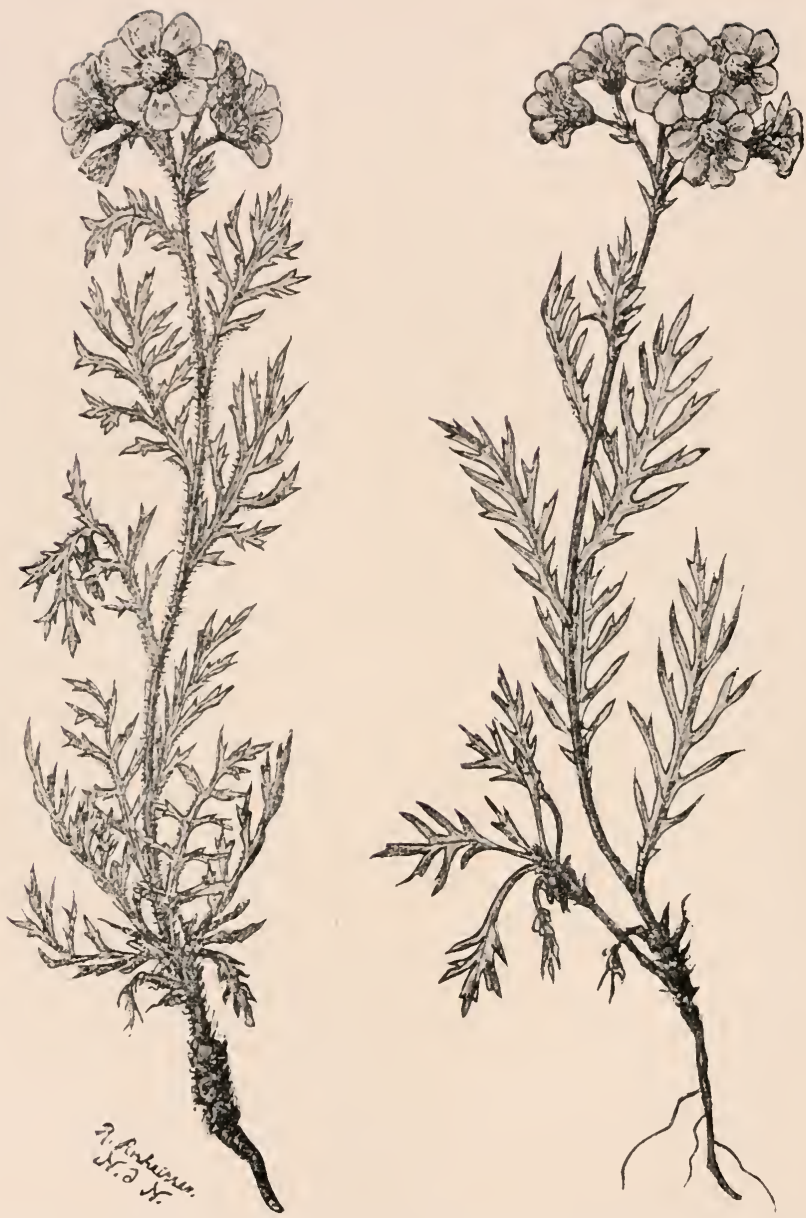

Fif. 1rt. Two species of Achillea on different soils. The one to the left was grown in drier conditions and shows an abundant development of hairs.-After SCHIMPER.

extreme of leaf reduction has been reached by the eactus plants, whose leaves, so far as foliage is concerned, have disappeared entirely, and the leaf work is done by the 
surface of the globular, cylindrical, or flattened stems (see $\S 36)$.

151. Hairy coverings. $-\mathrm{A}$ covering of hairs is an effective sun screen, and it is very common to find plants of xerophyte regions characteristically hairy (see \$35). The hairs are dead structures, and within them there is air. This causes them to reflect the light, and hence to appear white or nearly so. This reflection of light by the hairs diminishes the amount which reaches the working region of the plant (see Fig. $174)$.

152. Bodiy habit. - Besiles the various devices for diminishing exposure or leaf surface, and hence loss of water, enumerated above, the whole habit of

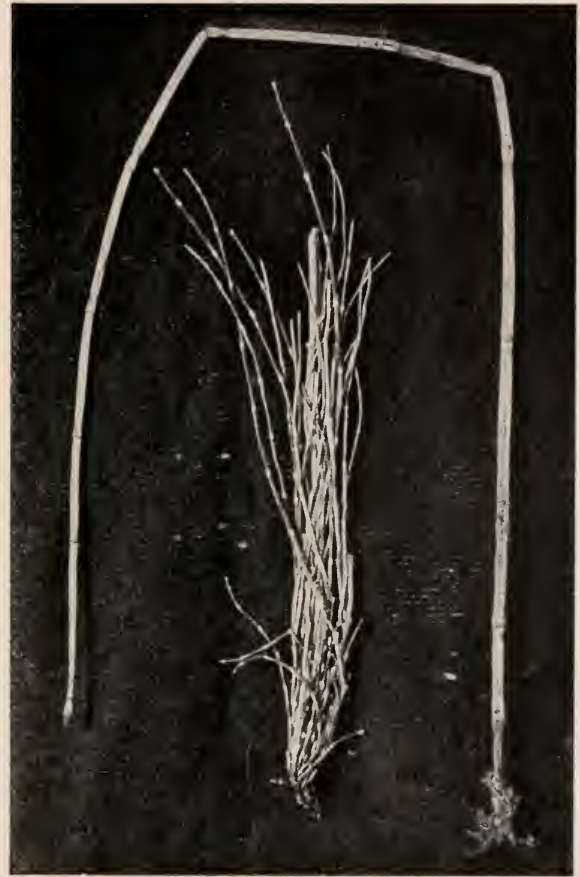

FIf. 175. Two plants of a common sconring rnsh (Equisetum), showing the effect of environment; the long, mbranched one having grown in normal mesophyte conditions; the short, bushy branching, more slender form having grown on the dunes (xerophyte conditions).-After Cowles. the plant may emphasize the same purpose. In dry regions it is to be observed that dwarf growths prevail, so that the plant as a whole does not present such an exposure to the dry air as in regions of greater moisture (see Fig. 1\%5). Also the pros- 
trate or creeping habit is a much less exposed one in such regions than the erect habit. In the same manner, the very characteristic rosette habit, with its cluster of overlapping leaves close against the ground, tends to diminish loss of water through transpiration.

One of the most common results of xerophytic conditions upon body habit is the development of thorns and spiny

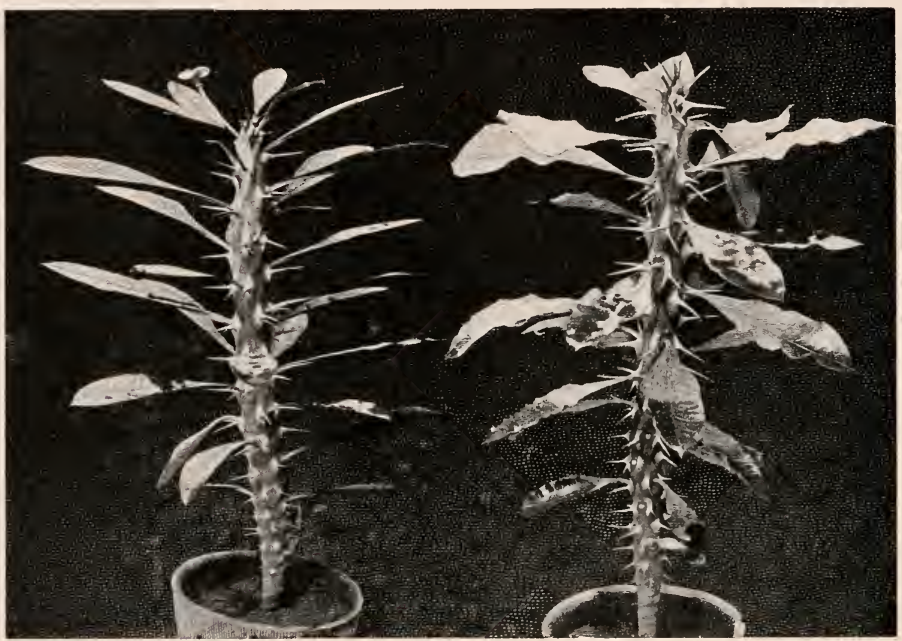

FIG. 176. Young plants of Euphorbia splendens, showing a development of thorns characteristic of the plants of dry regions.

processes. As a consequence, the regetation of dry regions is characteristically spiny. In many cases these spiny processes can be made to develop into ordinary stems or leaves in the presence of more favorable water conditions. It is probable, therefore, that such structures represent reductions in the growth of certain regions, caused by the unfarorable conditions. Incidentally these thorns and spiny processes are probably of great service as a protection to plants in regions where vegetation is peculiarly exposed to the 
ravages of animals (see \$105). Examine Figs. 176, 17\%, $178,179,180,181$.

153. Anatomical adaptations.-It is in comnection with the xerophytes that some of the most striking anatomical adaptations have been developed. In sueh conditions the epidermis is apt to be corered by layers of cuticle, which are developed by the walls of the epidermal cells, and being constantly formed beneath, the cuticle may become very thick. This forms a very efficient protective corering. and has a tendency to diminish the loss of water (see \$35). It is also to be observed that among xerophytes there is a strong development of palisade tissue. The working cells of the leaves next to the exposed surface are elongated, and are directed endwise to

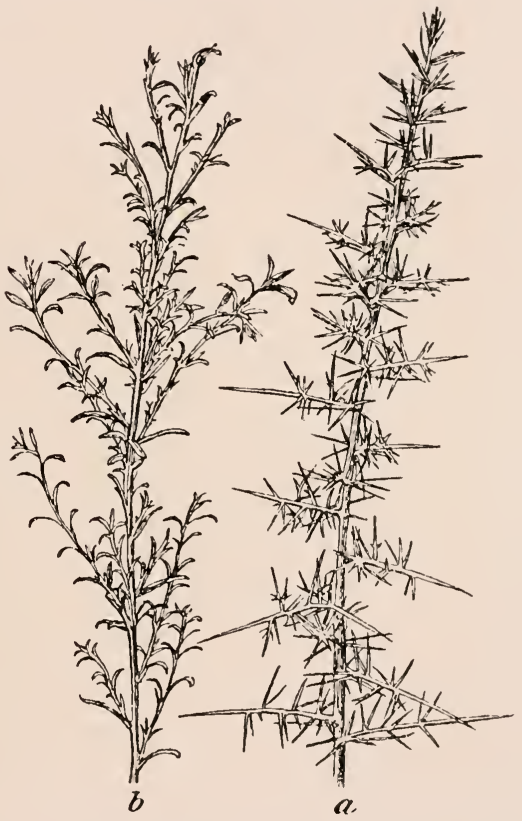

Fig. 1\%i. Two plants of common gorse or furze (Clex), showing the effect of environment: $b$ is a plant grown in moist conditions; $a$ is a plant grown in dry conditions, the leaves and branches having been almost entirely developed as thorns.-After Lotielier.

the surface. In this way only the ends of the elongated cells are exposed, and as such cells stand rery closely together, there is no drying air between them. In some cases there may be more than one of these palisade rows (see \$32). It has been observed that the chloroplasts in these palisade cells are able to assume various positions in 


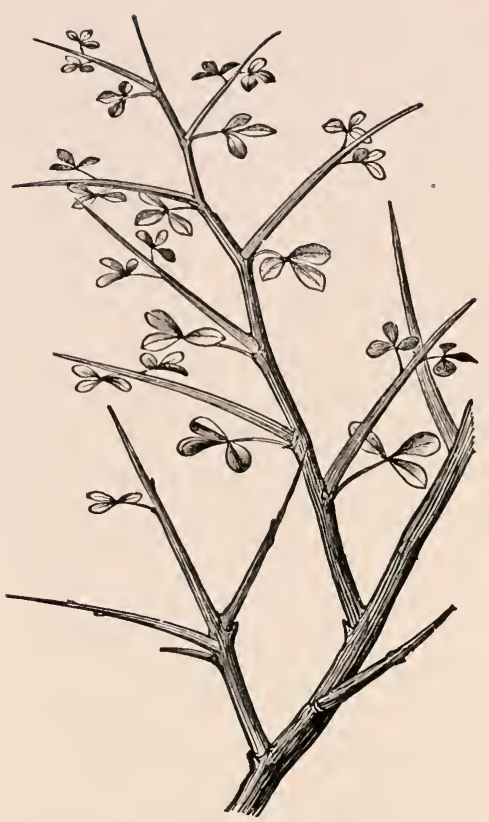

FIg. 178. A branch of Cytisus, showing the reduced leaves and thorny branches.-After KerNer.

the cell, so that when the light is very intense they move to the more shaded depths of the cell, and when it becomes less intense they move to the more external regions of the cell (see Fig. 182). The stomata, or breathing pores, which are developed in the epidermis, are also great regulators of transpiration, as has been mentioned already (see $\$ 31)$.

\section{Water reservoirs.}

-In xerophytes atte n t i o n $\mathrm{m} n \mathrm{st}$ be given not only to the regulation of transpiration, but also to the storage of water, as it is receired at rare intervals. It is very common to find a certain region of the plant body given over to this work, forming what is known as water tissue. In many leares this water tissue may be distinguished from the ordinary working cells by being a group of colorless cells (see Figs. 183, $184,185)$. In plants of the drier regions leaves may become thick and fleshy through acting as water reservoirs, as in the case of the agave, sedums, etc. Fleshy or "succulent" leaves are regarded as adaptations of prime impor-

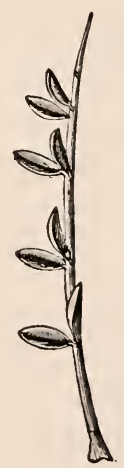

FIG. 1\%9. A leaf of tragacanth, showing the re. duced leaflets and the thorn-like tip.-After KERNER. 
tance in xerophytic conditions. In the cactus plants the peculiar stems have become great reservoirs of moisture. The globular body may be taken to represent the most complete answer to this general problem, as it is the form of body by which the least amount of surface may be exposed and the greatest amount of water storage secured. In the case of fleshy leaves and fleshy bodies it has long been noticed that they not only contain water, but also have a

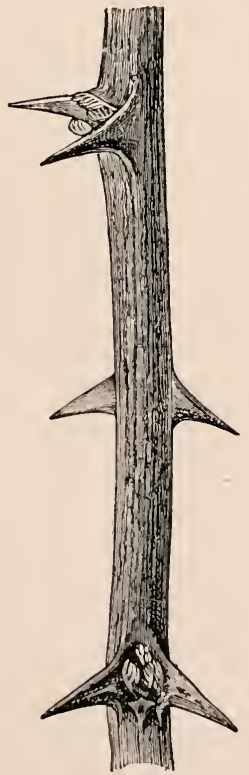

Fig. 181. Twig of common locust, showing the thorns.-After KEERNer. great power of retaining it. Plant

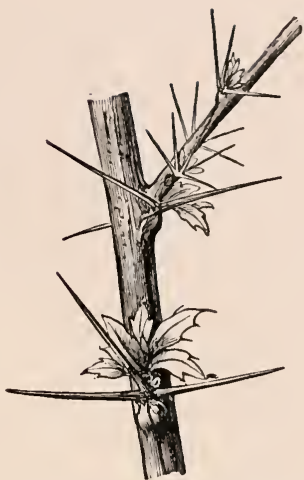

Fig. 180. A fragment of barberry, showing the thorns. -After Kerner. collectors have found great difficulty in drying these fleshy forms, some of which seem to be able to retain their moisture indefinitely, even in the driest conditions.

155. Xerophytic structure.-The adaptations given above are generally found in plants growing in drouth conditions, and they all imply an effort to diminish transpiration. It must not be supposed, however, that only plants living in drouth conditions show these adaptations. Such adaptations result in what is known as the xerophytic structure, and such a structure may appear eren in plants growing in hydrophyte conditions. For example, the bulrush grows in shallow water, and is a prominent member of ane of the hydrophyte societies (see $\$ 137$ ); and yet it has a remarkably xerophytic structure. This is probably due to the fact that although it 


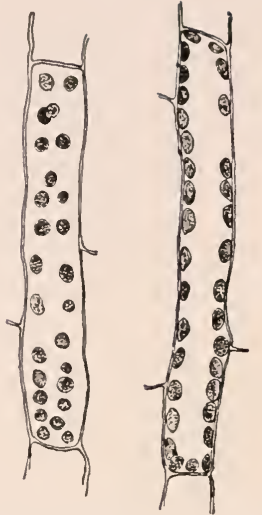

Fic. 182. Cells from the leaf of a quillwort (1soetes). The light is striking the cells from the direction of one looking at the illustration. If it be somewhat diffuse the chloroplasts distribute themselves throngh the shallow cell, as in the cell to the left. If the light be intense, the chloroplasts move to the wall and assume positions less exposed, as in the cell to the right. stands in the water its stem is exposed to a heat which is often intense.

The ordinary prairie (see $\$ 169$ ) is included among mesophyte societies on account of the rich, well-watered soil; and yet many of the plants are very xerophytic in structure, probably on account of the prevailing dry winds.

The ordinary sphagnum-bog (see $\$ 140$ ), or " peat-bog," is included among hydrophyte societies. It has an abundance of water, and is not exposed to blazing heat, as in the case of the bulrushes, or to drying wind, as in the case of prairie plants; and yet its plants show a xerophytic structure. This is found to be due, probably, to a lack of certain important soil materials.

It is evident, therefore, that xerophytic structures are not necessarily confined to xerophytic situations. It is probably true that all societies which show xerophytic structures belong to-

gether more naturally than do the societies which are grouped according to the water supply.

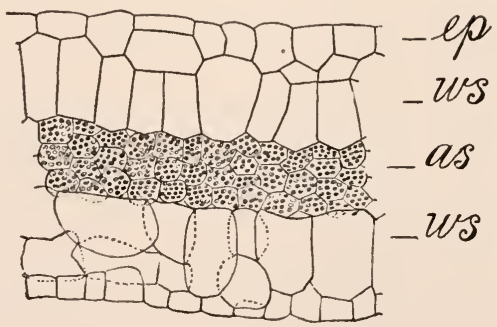

FIG. 183. A section throngh a Begoniu leaf, showing the epidermis (ep) above and below, the water-storage tissue $(w s)$ above and below, and the central chlorophyll region (as). 
inent illustrations will be given.

\section{6 . Rock societies. - Vari-} ous plants are able to live upon exposed rock surfaces, and therefore form distinet associations of xerophytes. In gen-

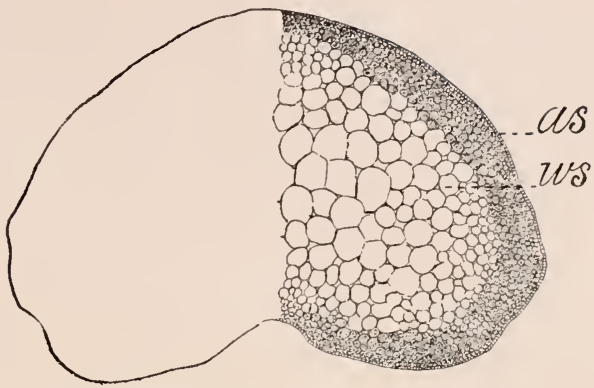

Fig. 184. A section through a fleshy leaf (Clinia), show: ing the chlorophyll region on the outside (shaded and marked $a s$ ), and the large interior water-storage region $(w s)$.

eral they are lichens, mosses, and crevice plants (see Fig.

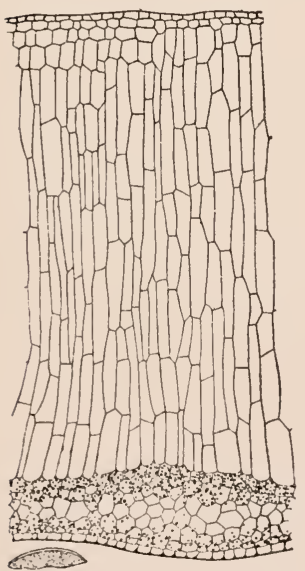

Fig. 185. A section throngh a leaf of an epiphyte, showing a very large development of water tissue between the upper epidermis and the chlorophyll region, which is restricted to near the under surface of the leaf. -After ScHimper. 186). The crevice plants are those which send their roots into the rock crevices and so gain a foothold. The crevice plants also commonly show a rosette habit, the rosette of overlapping leaves being against the rock face, and therefore in the most favorable position for checking loss of water.

15\%. Sand societies.-In general sand societies may be roughly grouped as beach societies, dune societies, and sandy field societies. These three hold a certain definite relation to one another. 'This natural relationship appears on the borders of the large lakes, and on seacoasts. The beach is nearest the water, the dumes are next, and behind them stretch the sandy fields. When the three types are thus associated, the plants of the different areas pass gradually 
into one another. It is very common to find the dunes omitted in the series, and to have the beaches pass gradually into the sandy fields.

The beach society is usually quite characteristic, and in general it is a poor flora, the beach being characteristically bare. 'The plants which grow in such conditions are apt to occur in tufts, or are creeping plants. It is evident that

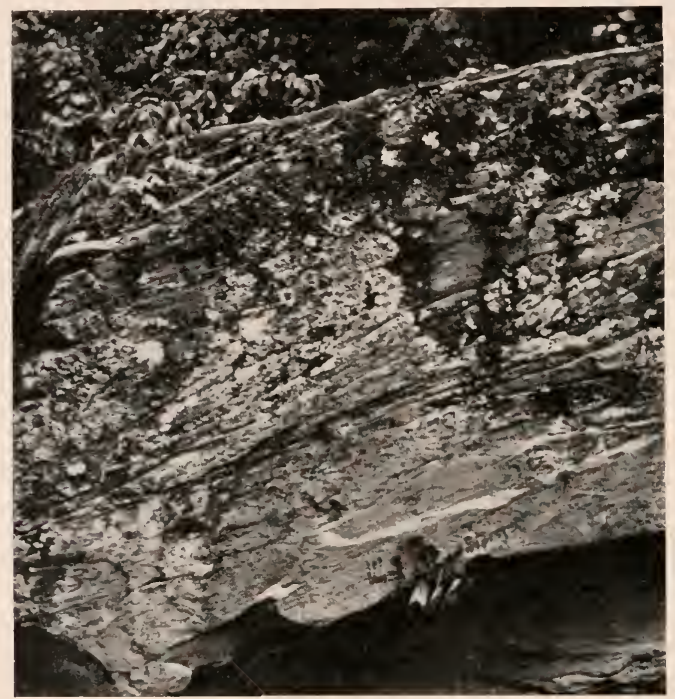

FIG. 186. A rock covered with lichens.

while the water may seem to be abundant, it disappears quickly, so that plants must adapt themselves to a dry condition of the soil, which is poor and with little or no accumulation of humus. At the same time, the exposure to intense light is extreme. 'This combination results in a poor display of individuals and of species. Here and there along beaches, where special conditions have favored the accumulation of humus, dense regetation may spring up, but it should not be confused with the ordinary beach type. 


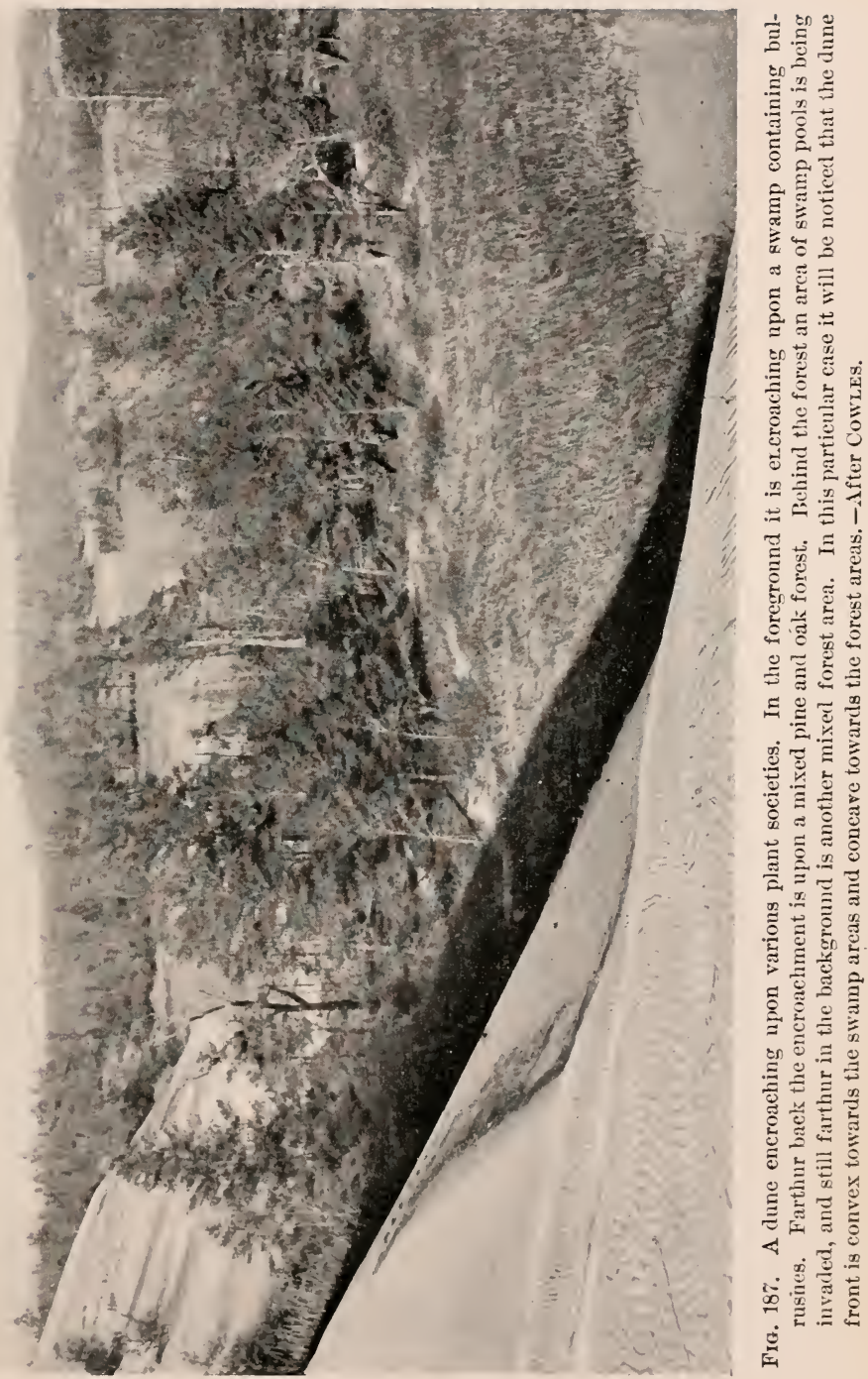


The dune societies are subjected to very peculiar conditions. Dunes are billows of sand that have been developed by prevailing winds, and in many eases they are continually changing their form and are frequently moving

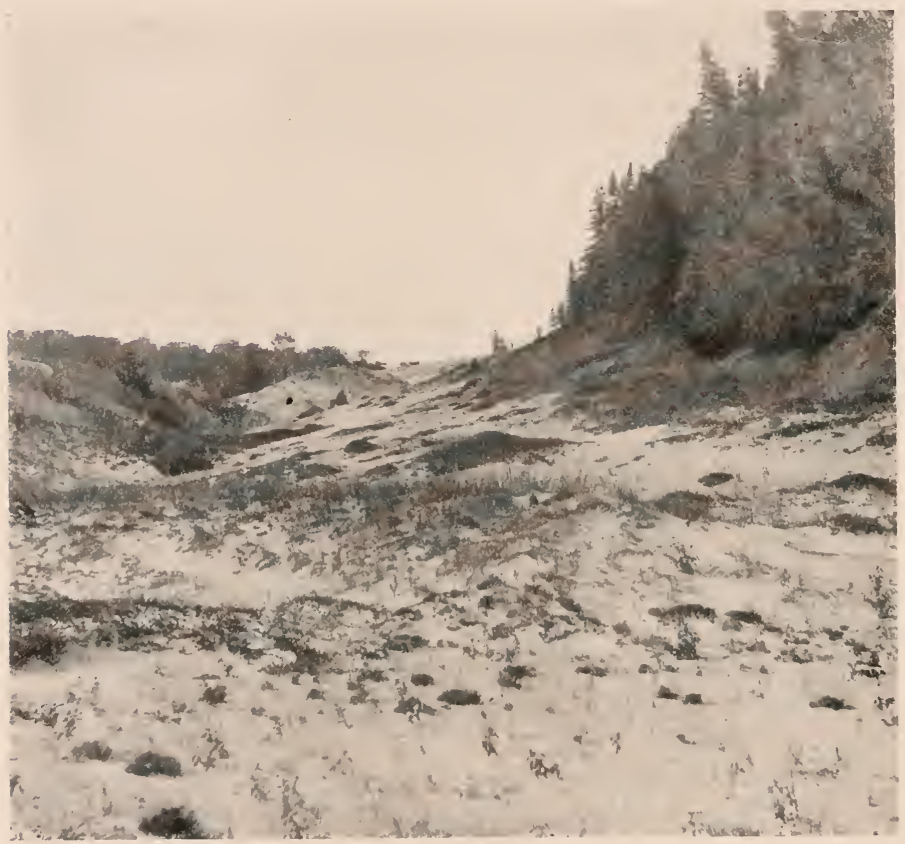

Fig. 188. A sandy field type, showing the development of vegetation upon an old beach. The vegetation is low, often tufted and heath-like, being composed chiefly of grasses, bearberry (Arctostaphylos) and Hudsonia. In the backgronnd to the right is a conifer forest, and between it and the old beach is seen a dense mass of bearberry, a very characteristic heath plant, and forming here what is called a transition zone between the beach and the forest.-After Cowles.

landward (see Fig. 18\%). The moring dunes should be distinguished from the fixed ones, where the billow form is retained, but the dunes have ceased their motion. In the case of the active dunes a peculiar type of regetation is demanded. As is to be expected, the flora is very seanty, and 


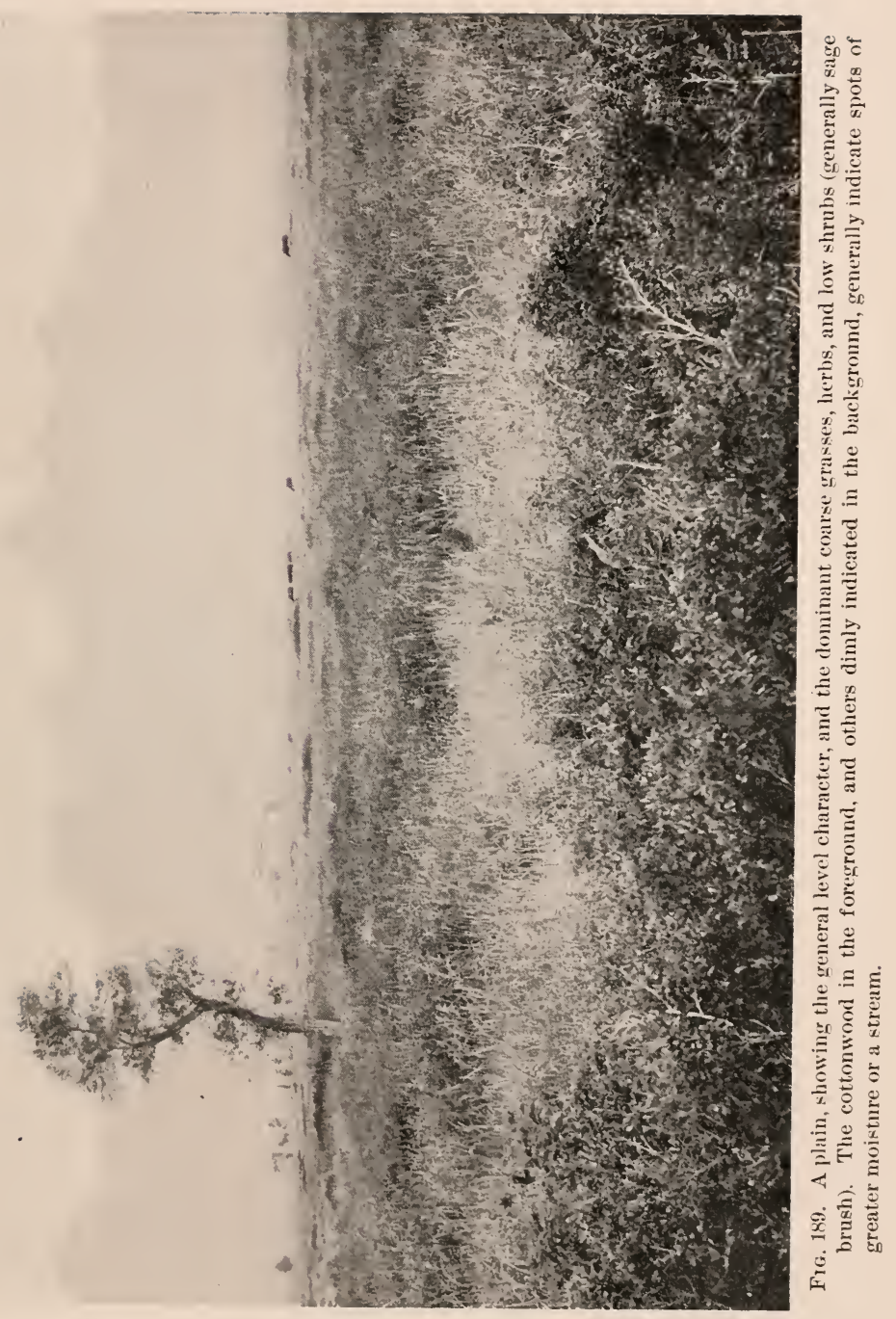


has two remarkably developed characters. The plants are what are known as "sand-binders," that is, the mnderground structures become extremely developed, reaching to great distances horizontally and vertically, so that one is always surprised at the extent of the undergromnd system. This wide searching for water results in giving the plants a deep anchorage in the shifting soil, and at the same time helps to prevent the shifting. As soon as enough of the sandbinders have established themselves, a shifting dune becomes a fixed one. Another characteristic that must be strongly developed by these plants is the ability to grow up through the sand after they have been engulfed. The plants of the shifting dunes are often buried as the dune shifts, and unless the burial has been too deep, they are able to continue their development mntil leaves may be exposed to the air. In this way plants have often developed a length of stem which is far beyond anything they attain when growing in ordinary conditions.

The sandy field societies are represented by a much more abundant fiora than the beach or the dune societies, the general character being tufted grasses and low shrubby growths (see Fig. 18s).

158. Shrubby heaths.-The shrublyy heaths are very characteristic of the more northern regions, and are closely related to the sandy field societies. The heath soil is apt to be a mixture of coarse sand, or gravel and rock, with an occasional deposit of humus, and would be regarded in general as a sterile soil. The flora of the shrubby heaths shows well-marked strata, the upper one being the low shrubby plants of the heath family, most prominent among which are hnckleberries and bearberries (see Fig. 172). The lower stratum is made up of mosses and lichens. A branching lichen, usmally spoken of as the "reindeer moss," often occurs in immense patches on such heaths. While these shrubby heaths occur most extensively towards the north, small areas showing the 


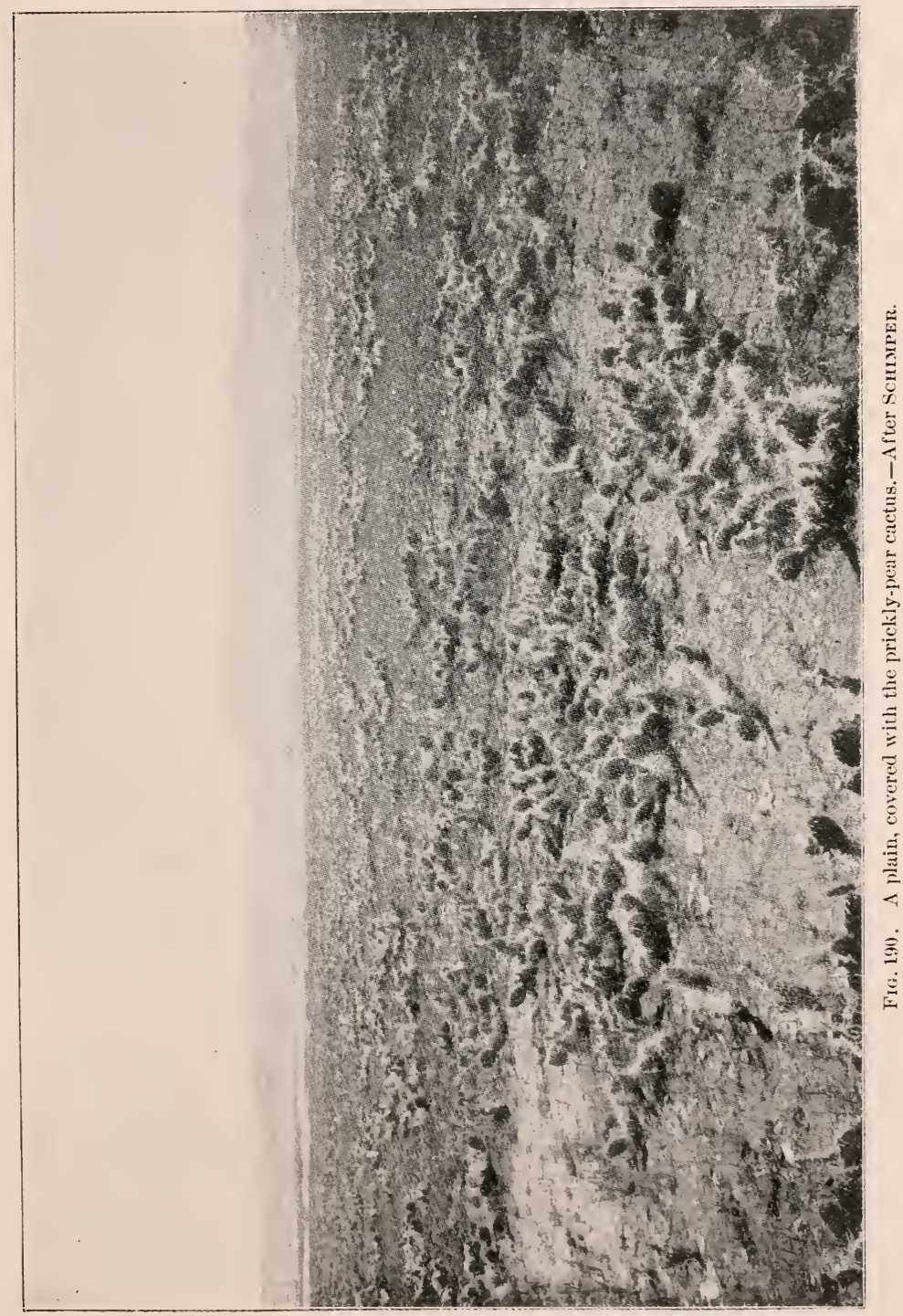


same general character are common in almost all temperate regions.

159. Plains.-Under this head are included great areas in the interior of continents, where dry air and wind prevail. The plains of the United states extend from about the one hundredth meridian westward to the foothills of the Rocky Mountains. Similar great areas are represented by the steppes of Siberia, and in the interior of all continents. These regions have been regarded as semidesert areas, but they are found for the most part to be far from the real desert conditions. They are certainly areas of eomparative dryness, on account of the dry winds which prevail.

Taking the plains of the United States as a type, a very characteristic plant physiognomy is presented (see Fig. 189). In general, there is a meadow-like expanse, but the vegetation is much more sparse than in meadows, and is much more dense than in deserts. The two characteristic plant forms are the bunch grasses, that is, grasses which grow in great tufts; and low grayish shrubs, predominantly "sage brush." Under the shelter of the sage brush or other bush forms, many low herbs sueceed in growing. In such areas the growing season is very short, during which time the regetation looks vigorous and fresh; but during the rest of the year it is very dull. In some parts the plain is dry enough to permit the growth of the pricklypear cactus (Opuntia), which may take possession of extensive areas (see Fig. 190).

Usually there are two rest periods during the year, developed by the summer drouth and the winter cold. As a consequence, the plants of the area are partly spring plants, which are apt to be very brilliant in flower; and partly the later, deep-rooted forms. Orer such areas the transportation of seeds by the wind is very prominent, as the force of the wind and the freedom of its sweep make possible very wide distribution. It is in such areas that 


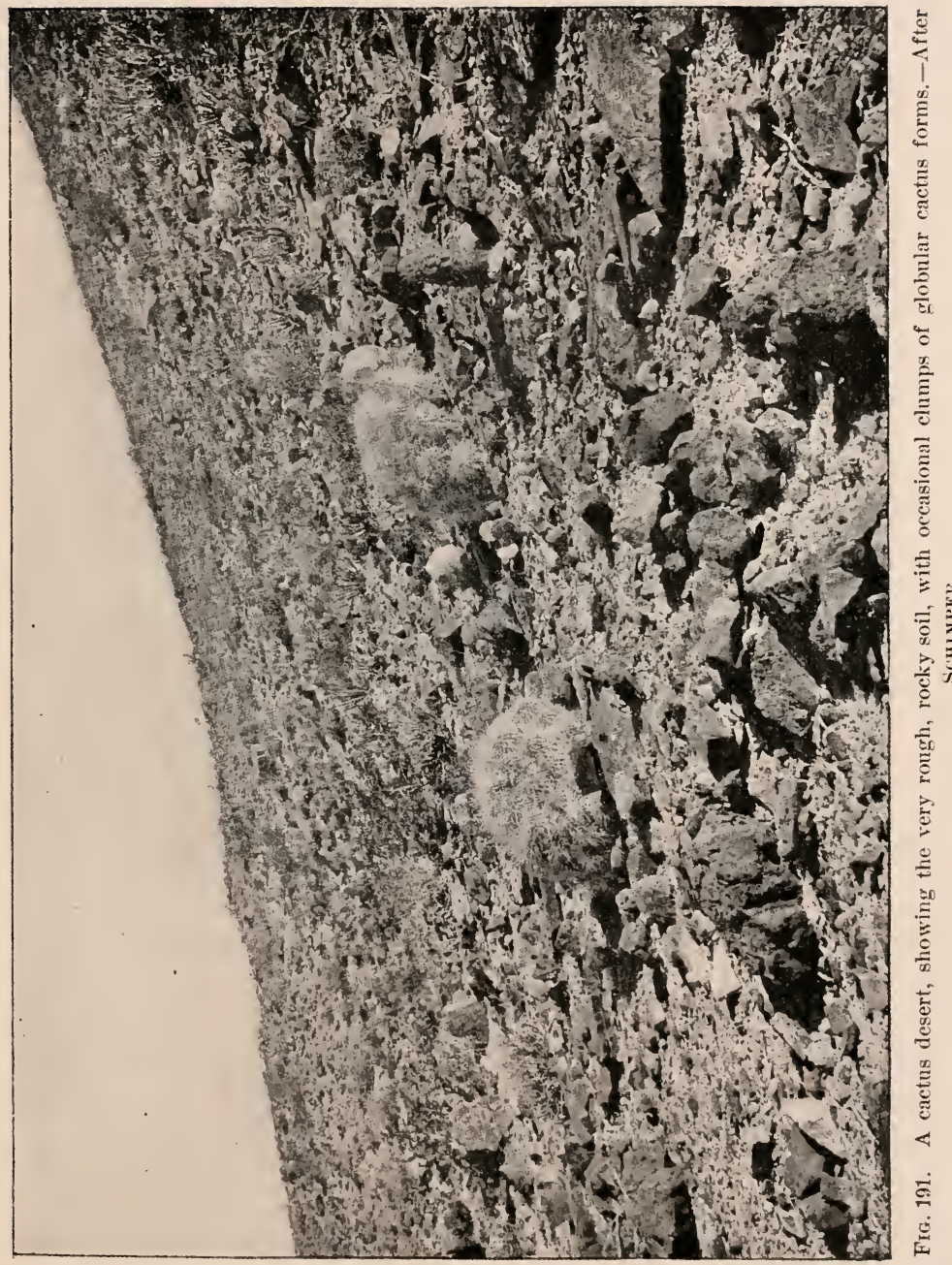




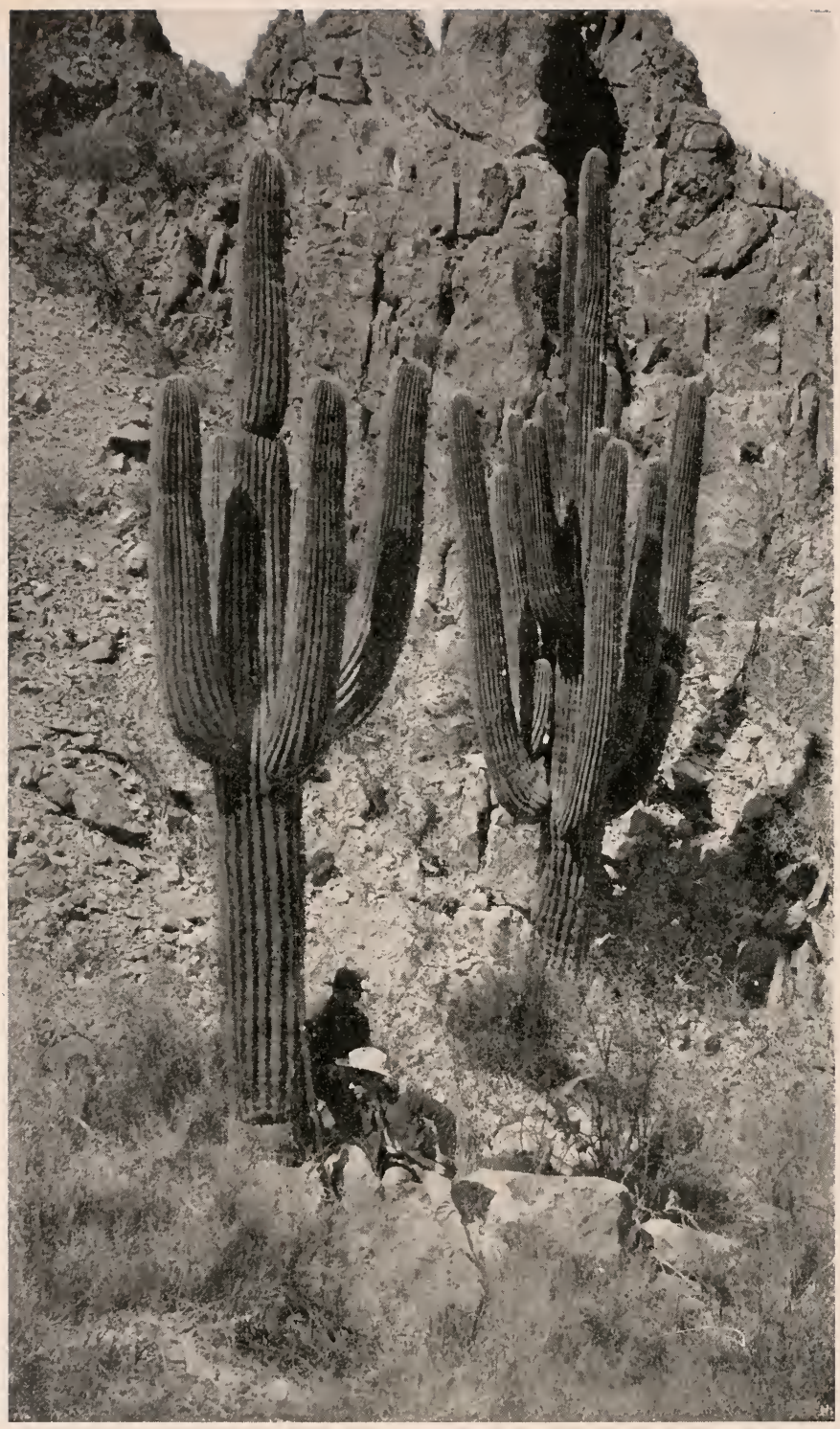

F1(i, 192. Two plants of the giant cactus. Note the fluted, clumsy branching, leafless bodies growing from the rocky, sterile soil characteristic of cactus deserts. Certain dry-ground grasses and low, shrubby plants with small leaves may be seen in the foreground. 


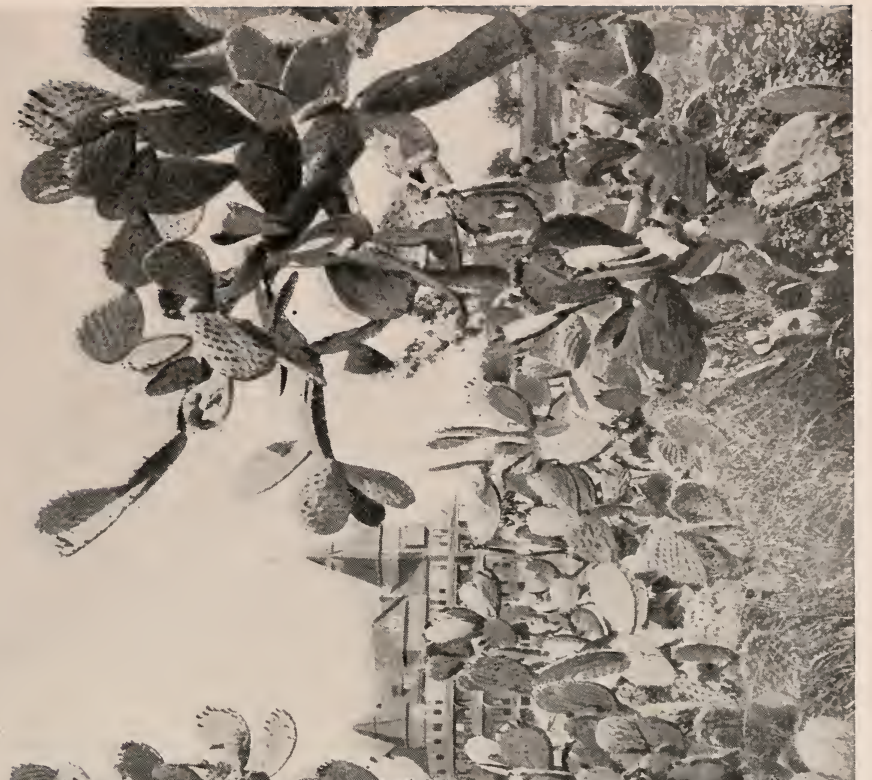

$\frac{\cdots}{\vdots}$

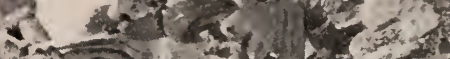

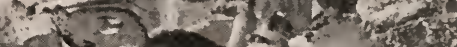
$\stackrel{\Xi}{\cong}$

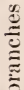

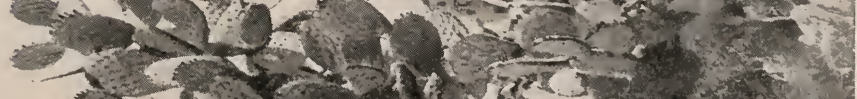

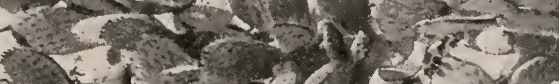

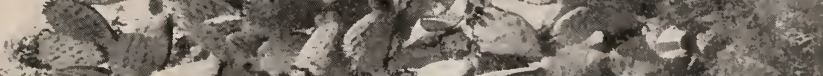

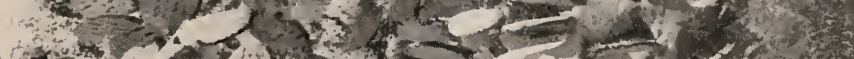
Ty

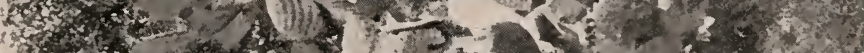
tritos

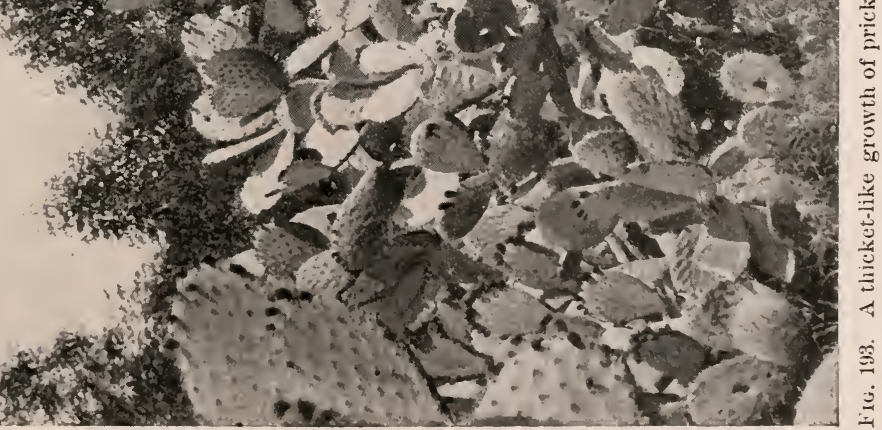


the tumbleweed habit is prominently developed. Certain low and densely branching plants are lightly rooted in the soil, so that at the close of their growing period they are easily uprooted by the wind, and are rolled to great

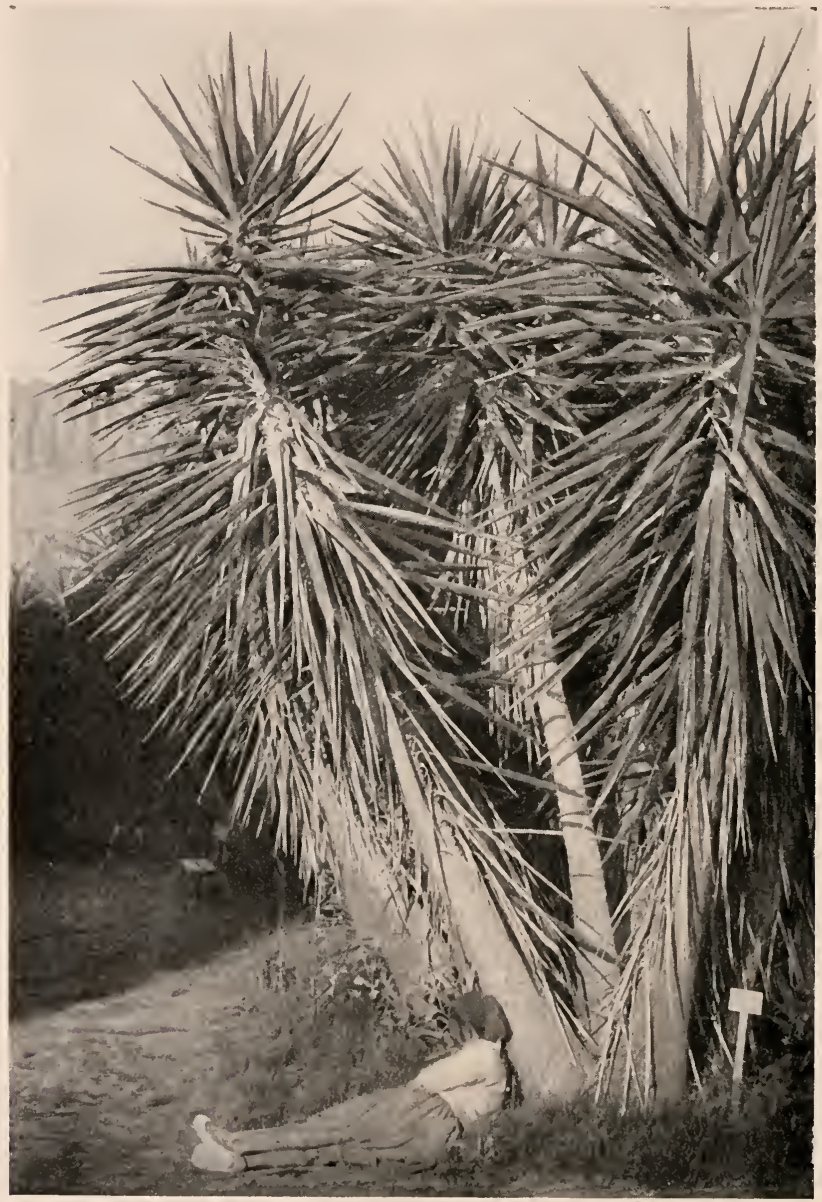

Fig. 194. 'Tree-like yuccas from the arid regions of Africa, showing the very numer ous thick and pointed, sword-like leaves. 


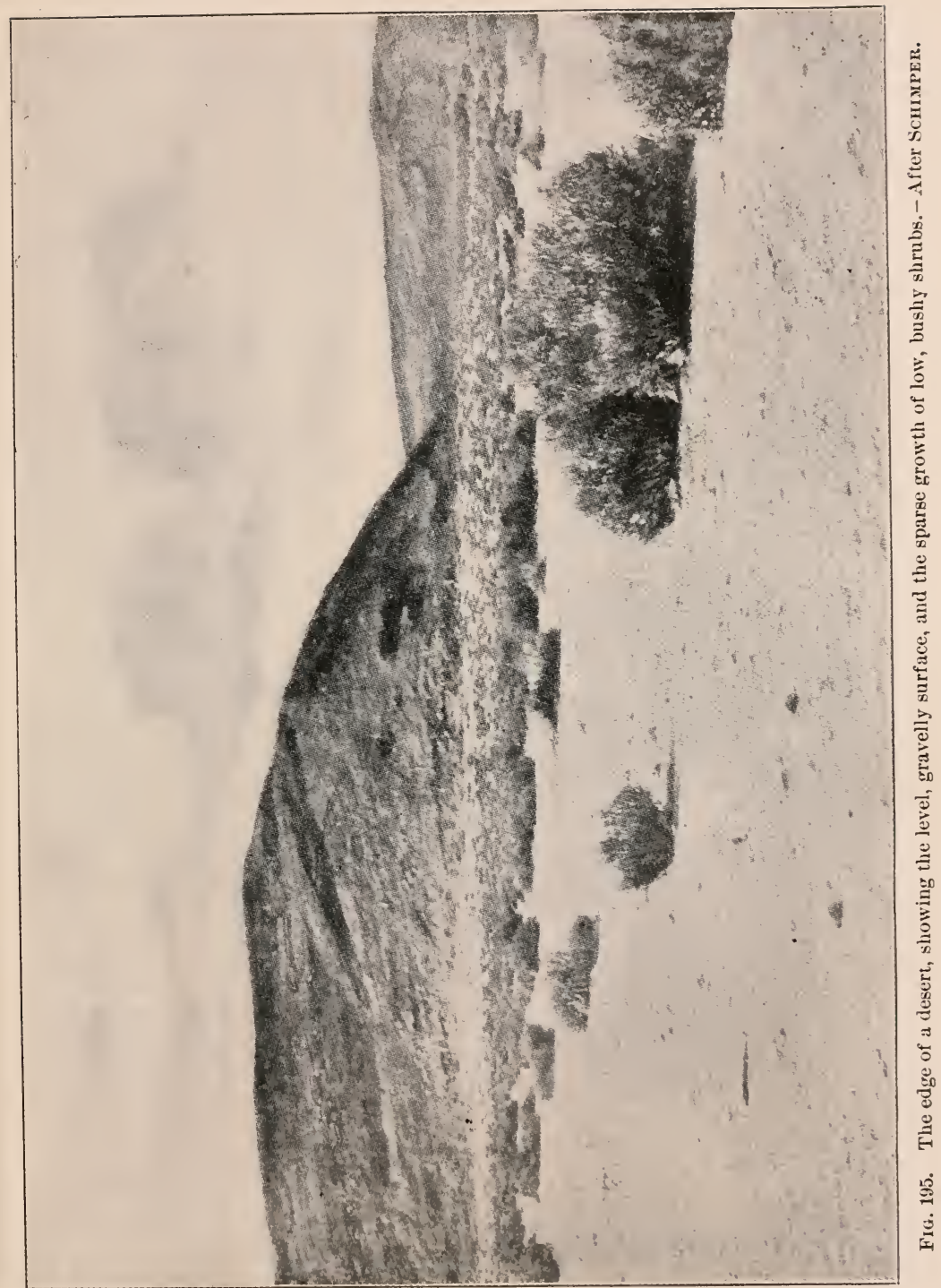


distarces. Where some barrier, such as a fence, lies across the track of the wind, these tumbleweeds may accumulate in great masses. 'This tumbling over the surface results in an extensive scattering of seeds (see Fig. 120).

The prairies, so characteristic of the United States, are regarded by some as belonging to the plains. 'They certainly are elosely related to them in origin. but can hardly be regarded as being included in xerophyte conditions, as the conditions of water supply and soil are characteristically mesophyte, under which head they will be considered.

160. Cactus deserts.-In passing southward on the plains of the United States, it is to be noted that the conditions become more and more rerophytic, and that the bunch grasses and sage brush, peculiar to the true plains, gradually merge into the cactus desert, which represents a region whose conditions are intermediate between true plains and true deserts (see Fig. 191). In the United States this characteristic desert region begins to appear in IVestern 'Texas, New Mexico, Arizona, and Sonthern California, and stretches far down into the Mexican possessions. This vast arid region has dereloped a peculiar flora, which contains most highly specialized rerophytic forms. The varions cactus forms may be taken as most characteristic, and associated with them are the agaves and the yuccas. Not only are the adaptations for ehecking transpiration and for retaining water of the most extreme kind, but there is also dereloped a remarkable armature. It is evident that such suceulent bodies as these plants present might speedily disappear through the attacks of animals, were it not for the armor of spines and bristles and rigid walls. Study Figs. 38, 39, 40, 192, 193, 194.

161. Tropical deserts. - In such areas xerophyte conditions reach the greatest extreme in the combination of maximum heat and minimum water supply. It is evident that such a combination is almost too difficult for plants to endure. 'That the very scanty vegetation is due to lack 


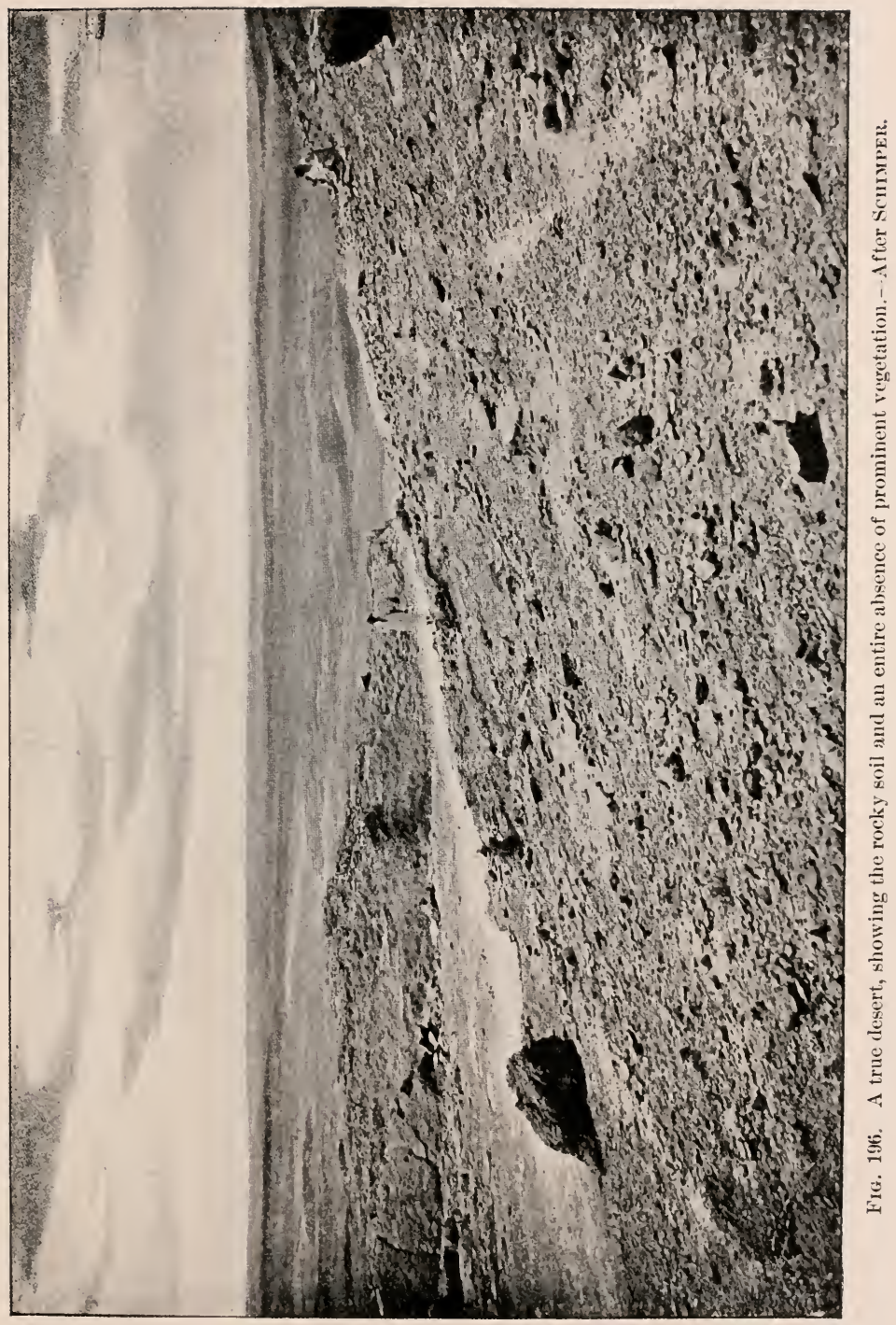


of water, and not to lack of proper materials in the soil, is shown by the fact that where water does occur oases are developed, in which luxuriant vegetation is found.

The desert which extends from Egypt across Arabia may be regarded as a typical one. It is to be noted that the regetation is so scanty that the soil is the conspicuous feature, and really gives the characteristic physiognomy (see Fig. 196). Accordingly the appearance of the deserts will depend upon whether the desert soil is rocky, or of small stones, or gravel (as in the Desert of Sahara), or of red elay, or of the dune type. As is to be expected, such vegetation as does oceur is of the tuft and bunch type, as developed by certain grasses, or of the low irregular bush type (see Fig. 195).

In the Sonth African deserts certain remarkable plants have been noted which have attained a certain amount of protection through mimicry, rather than by means of armor, as in the case of the eactus forms. Some of these plants resemble the ordinary stones lying abont npon the desert. With the tropical deserts should not be confused such areas as those about the Dead Sea, or in the Death's Valley in Southern California, as the barremness of these areas is due to the strongly alkaline soils, and therefore they belong to the halophyte areas.

162. Thickets. - The xerophyte thicket is the most strongly developed of all thicket growths. Mention has been made of willow and alder thickets in hydrophyte conditions, but these are not to be compared in real thicket characters with the rerophyte thickets. These thickets are especially developed in the tropies and subtropies, and may be described as growths which are scraggy, thorny, and impenetrable. Warming speaks of these thickets as "the unsuceessful attempt of Nature to form a forest." Evidently the conditions are not quite favorable for forest development, and an extensive thicket is the result. Such thickets are well developed in Texas, where they are 


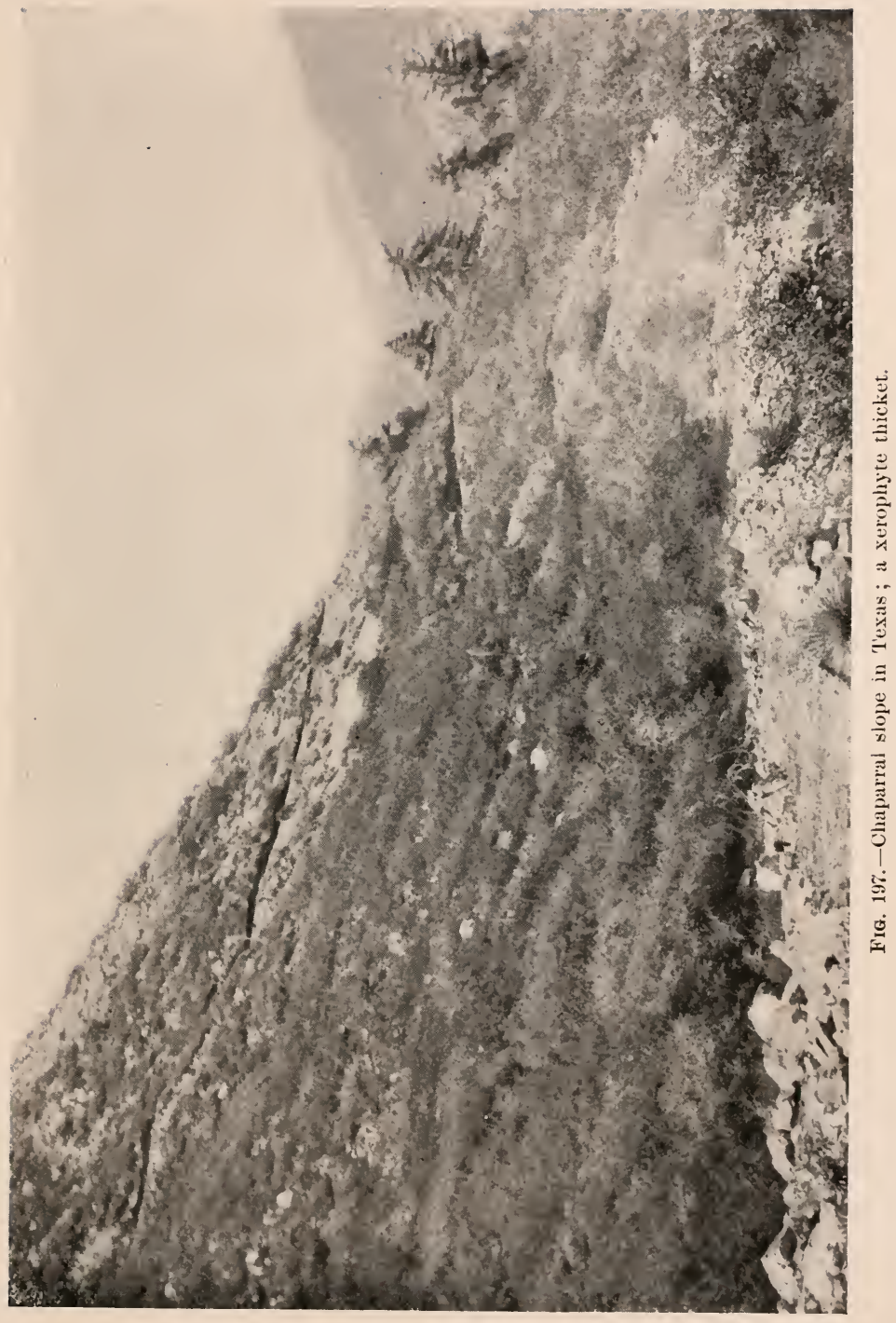




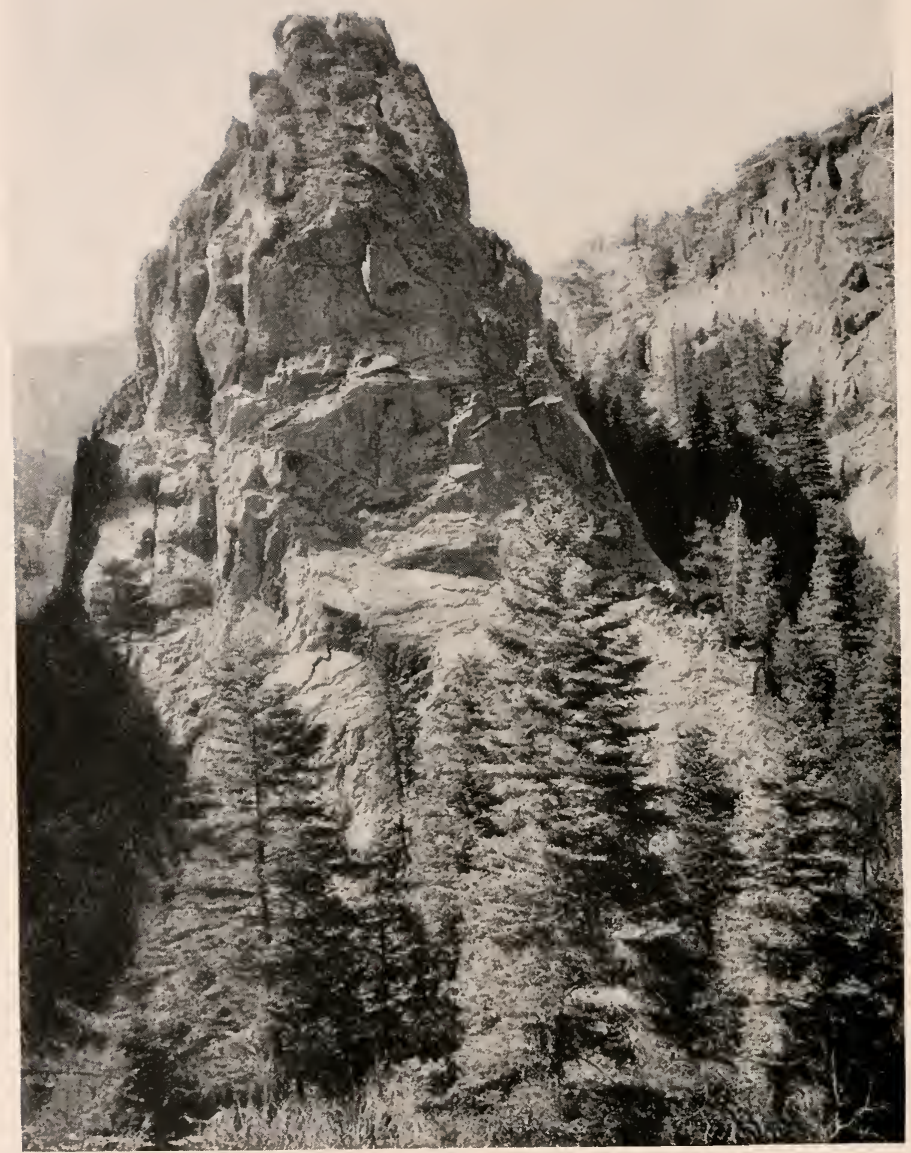

Fig. 198. A xerophyte conifer forest in the mountains. The peculiar conifer habit of body is recognized, the trees finding foothold in the crevices of rocks or in areas of rock débris. 
spoken of as "chaparral." These chaparrals are notably composed of mesquit bushes, acacias and mimosas of various sorts, and other plants. Similar thickets in Africa and Australia are frequently spoken of as "bush" or "scrub." In all of these cases the thicket has the same general type, and probably represents one of the most forbidding areas for travel.

163. Forests. - The xerophyte forest societies may be roughly characterized under three general heads:

(1) Coniferous forests.-These forests are very common in xerophyte conditions to the north, and also in the more sterile regions towards the south (see Figs. 198 to 201). 'They are generally spoken of as evergreen forests, although the name is not distinctive. These forests are of several types, such as true pine forests, in which pines are the prevailing trees and the shade is not dense; the fir and hemlock forests, which are relatively dark; and the mixed forests, in which there is a mingling of rarious conifers. In such forests the soil is often very bare, and such undergrowth as does occur is largely composed of peremnial plants. Many characteristic shrubs with fleshy fruits occur, such as huckleberries, bearberries, junipers, etc. It will be noted that in these forests a characteristic adaptation to xerophyte conditions is the development of needle leares, which are not only narrow, thus presenting a small exposure of surface, but also have heary walls, which further prevents excessive transpiration.

(:) Foliage forests. - These are more characteristic of tropical and subtropical xerophyte regions. Illustrations may be obtained from the encalyptus, a characteristic Australian forest tree, the live oaks, oleanders, etc. It will be noticed that in these cases the leares are not so narrow as the needles of conifers, but are generally lanceshaped, and stiff and leathery, indicating heary walls to reduce transpiration.

(3) Leafless forests. - In Java and other oriental regions 16 


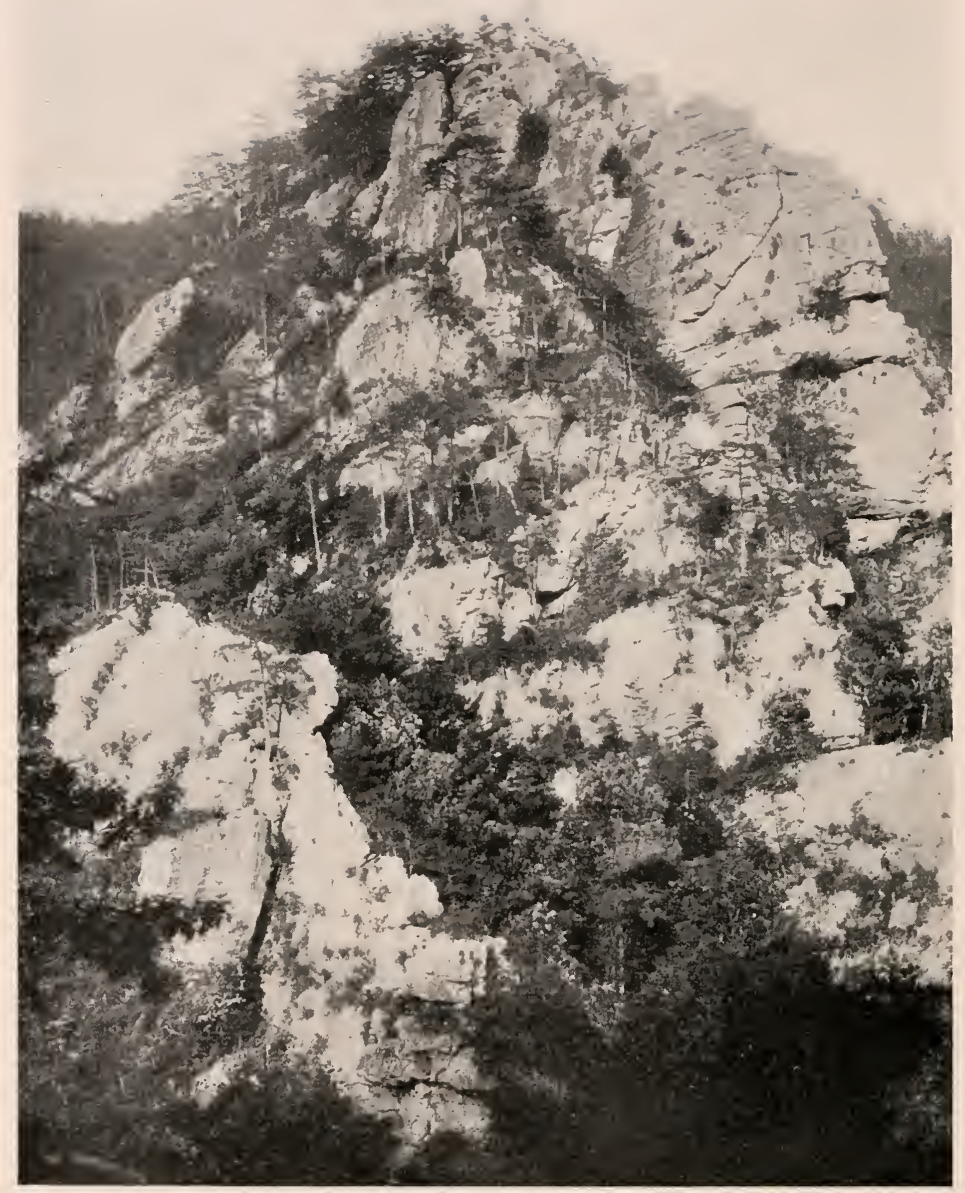

FI(i. 199. - A xerophyte conifer forest in the Cumberland Mountains of Tennessee. The table mountain pines find footholds in erevices of the rocks. 


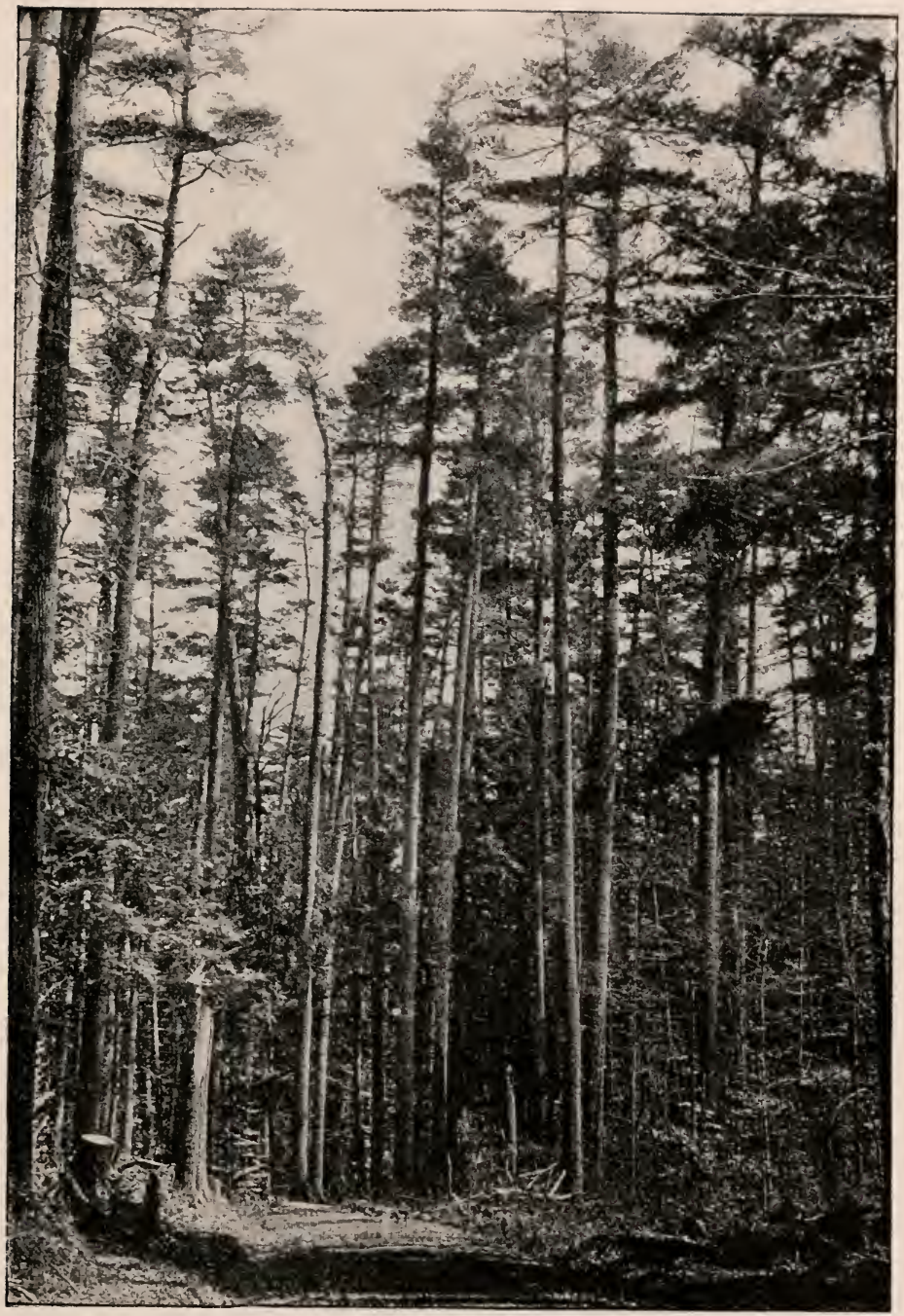

Fig. 200. A pine forest, showing the slender, tall, continuous trunks and comparatively little undergrowth.-After Sспи PER. 


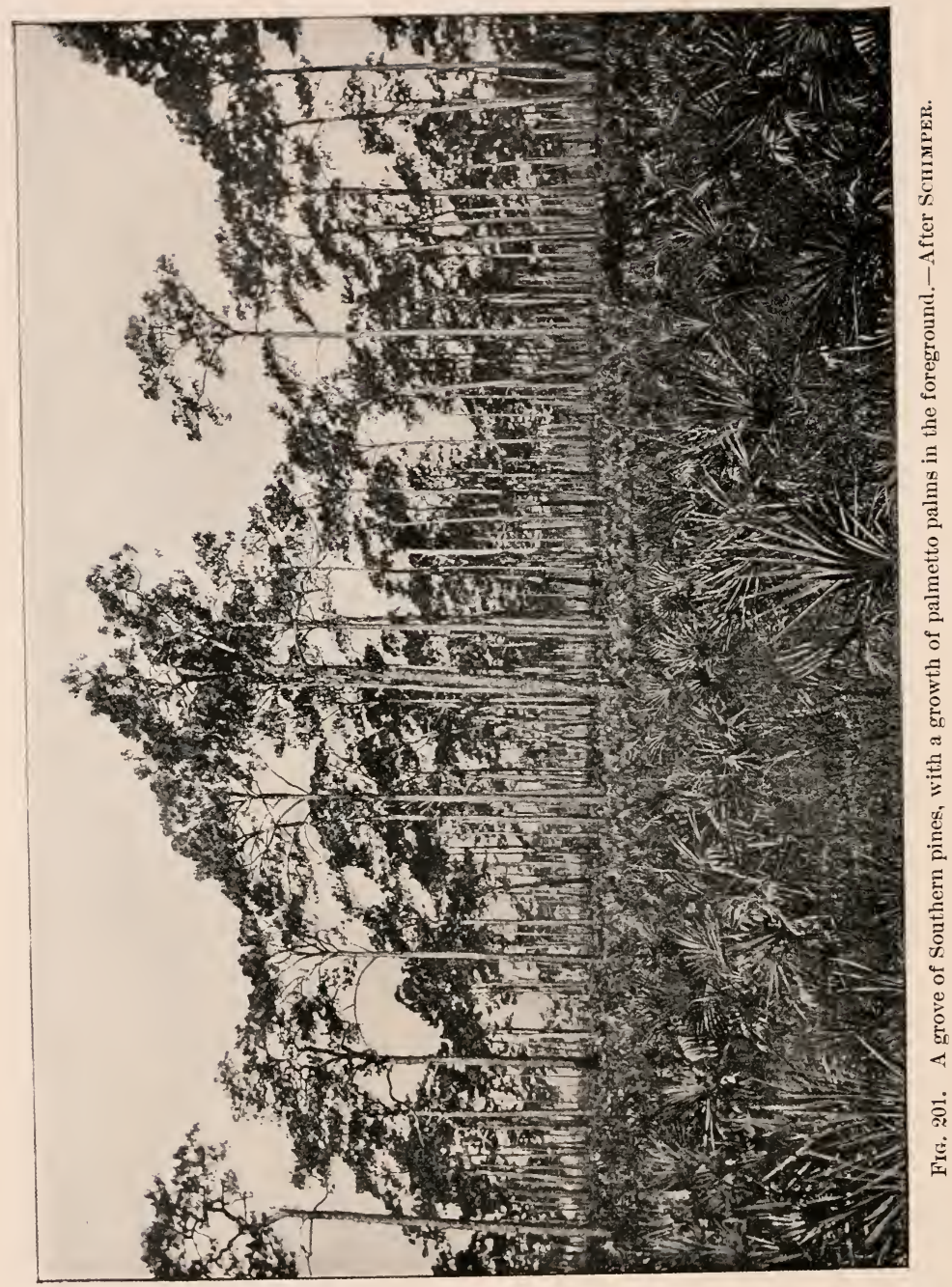


areas of dry naked soil are sometimes oceupied by forest growths which show no development of leaves, the tree-like forms appearing continually bare. The oriental leafless tree form is mostly a Casuurina. Bordering the Gulf of California, both in Mexico proper and in Lower California, there are leafless forests composerl of various kinds of giant cactus (see Fig. 192), known as the "cardon forests." These leafless forests represent the most extreme xerophyte conditions occupied by plant forms which may be regarded as trees.

164. Salt steppes.-In addition to the xerophyte societies enumerated above, in which the water though scanty is fresh, the two following may be considered. The soil and air are relatively dry, as in ordinary xerophytic conditions, but the water is more or less saturated with common salt or alkaline salts. The salt steppes are interior arid wastes, which probably mark the position of old sea basins. In the United States one of the most extensive of the salt steppes is in the Great Salt Lake basin (see Fig. 202). It is here that members of the chenopod family are especially at home, such as greasewoods, seablights, samphires, ete., for more than any other plants have they learned to endure such extremely unfavorable conditions. An extensive alkaline waste in the United States is that known as the Bal Lands, which stretches over certain portions of Nebraska and Dakota, and in which the waters are strongly alkaline.

165. Salt and alkaline deserts. - In these areas the water supply reaches its minimum, and therefore the water becomes saturated with the characteristic salts of the soil. Fo worse combination for plant activity can be imagined than the combination of minimum water and maximum salts. In consequence, such areas are almost, if not absolutely, devoid of vegetation. As illustrations, the extensire desert of the Dead Sea region and the Death's Valley in Southern California may be cited. 


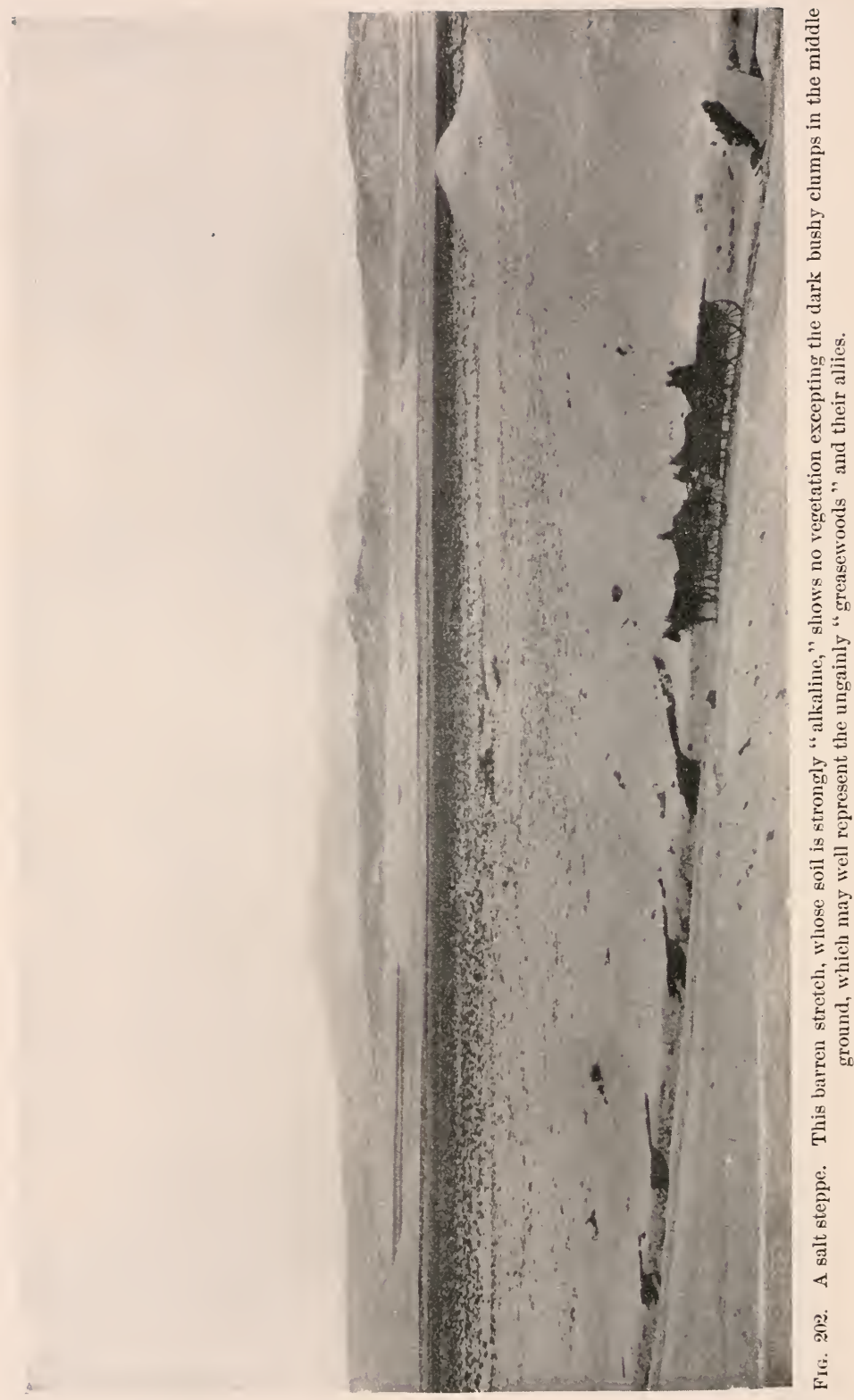




\section{CHAPTER XIV.}

\section{MESOPHYTE SOCIETIES.}

166. General characters.-Mesophytes make up the com. mon regetation of temperate regions, the regetation most commonly met and studied. The conditions of moisture are medium, precipitation is in general evenly distributed, and the soil is rich in humus. The conditions are not extreme, and therefore special adaptations, such as are necessary for xerophyte or hydrophyte conditions, do not appear. This may be regarded as the normal plant condition. It is certainly the arable condition, and most adapted to the plants which men seek to eultivate. When for purposes of cultivation xerophyte areas are irrigated, or hydrophyte areas are drained, it is simply to bring them into mesophyte conditions.

In looking over a mesophyte area and contrasting it with a xerophyte area, one of the first things erident is that the former is far richer in leaf forms. It is in the mesophyte conditions that foliage leaves show their remarkable diversity. In hydrophyte and xerophyte areas they are apt to be more or less monotonous in form. Another contrast is found in the dense growth over mesophyte areas, much more so than in xerophyte regions, and eren more dense than in hydrophyte areas.

Among the mesophyte societies must be included not merely the natural ones, but those new societies which have been formed under the influence of man, and which do not appear among xerophyte and hydrophyte societies. 


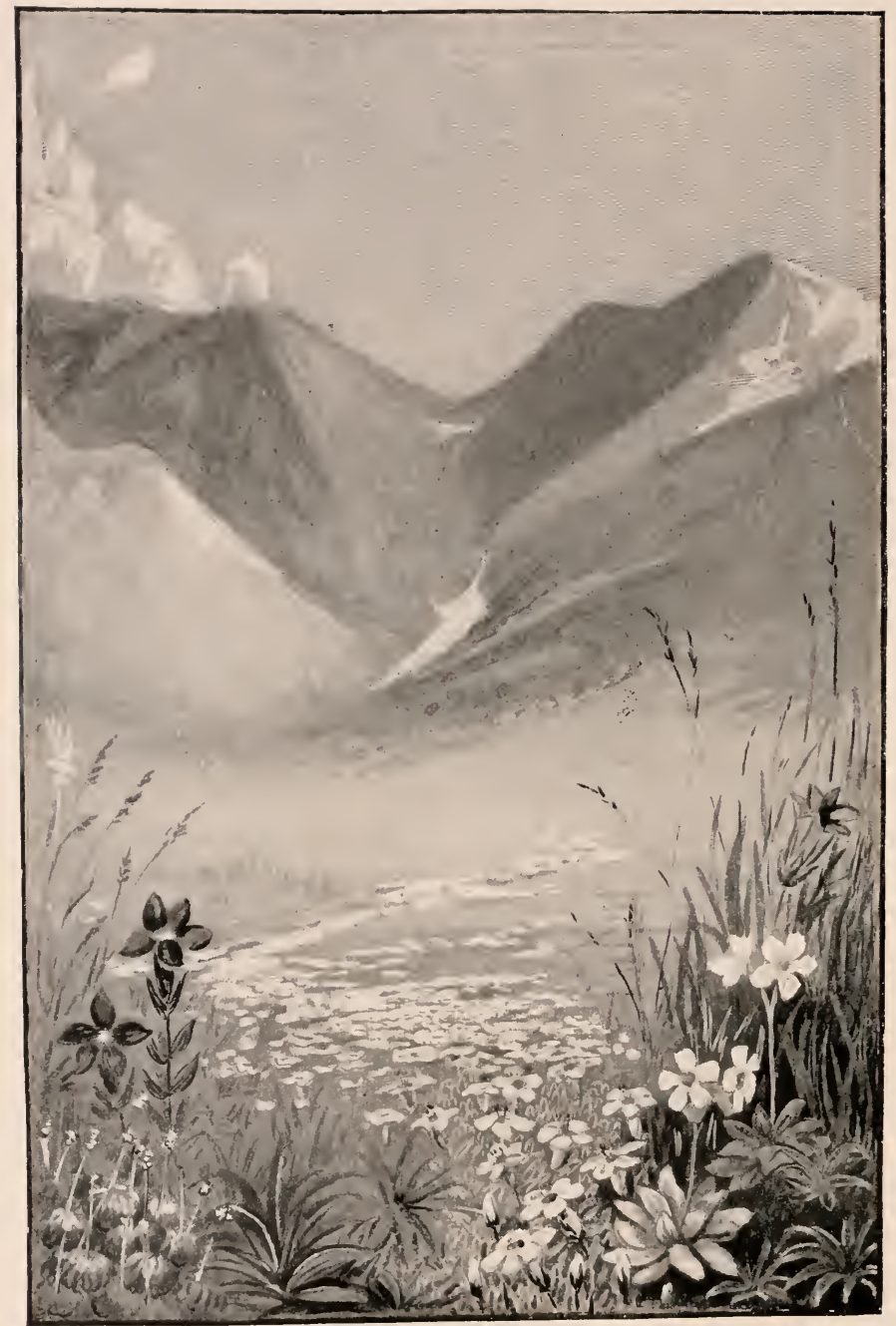

Fig. 203. Alpine vegetation, showing the low stature, dense growth, and conspicuous flowers.--After ǨERNER. 
These new societies have been formed by the introduction of weeds and culture plants.

16\%. The two groups of societies.-Two very prominent types of societies are included here under the mesophytes, althongh they are probably as distinct from one another as are the mesophyte and xerophyte societies. One group is composed of low vegetation, notably the common grasses and herbs; the other is a higher woody vegetation, composed of shrubs and trees. The most characteristic types under each one of these divisions are noted as follows.

\section{A. Grass and herb societies.}

It should not be inferred from this title that most grasses are not herbs, but it is convenient to consider grasses and ordinary herb forms separately.

168. Arctic and alpine carpets.-These are dense mats of low vegetation occurring beyond forest growth in aretic regions, and above the tree limit in high mountains. These carpet-like growths are a notable feature of such regions. In such positions the growing season is very short, and the temperature is quite low at times, especially at night. It is evident, therefore, that there must be provision for rapid growth, and also for preventing dangerons radiation of heat, which might chill the active plant helow the point of safety. It is further evident that the short season and the low temperature form a combination which prevents the growth of trees or shruls, or even tall herbs, hecanse the season is too short for them to reach a protected condition, and their more exposed young structures are not in a position to withstand the daily fall of temperature.

'These carpets of vegetation are notably fresh-looking, indicating rapid growth ; green, indicating an abundance of chlorophyll and great activity: thick, as they are mostly peremnials, developed from abundint underground structures; low, on account of the short season and low 


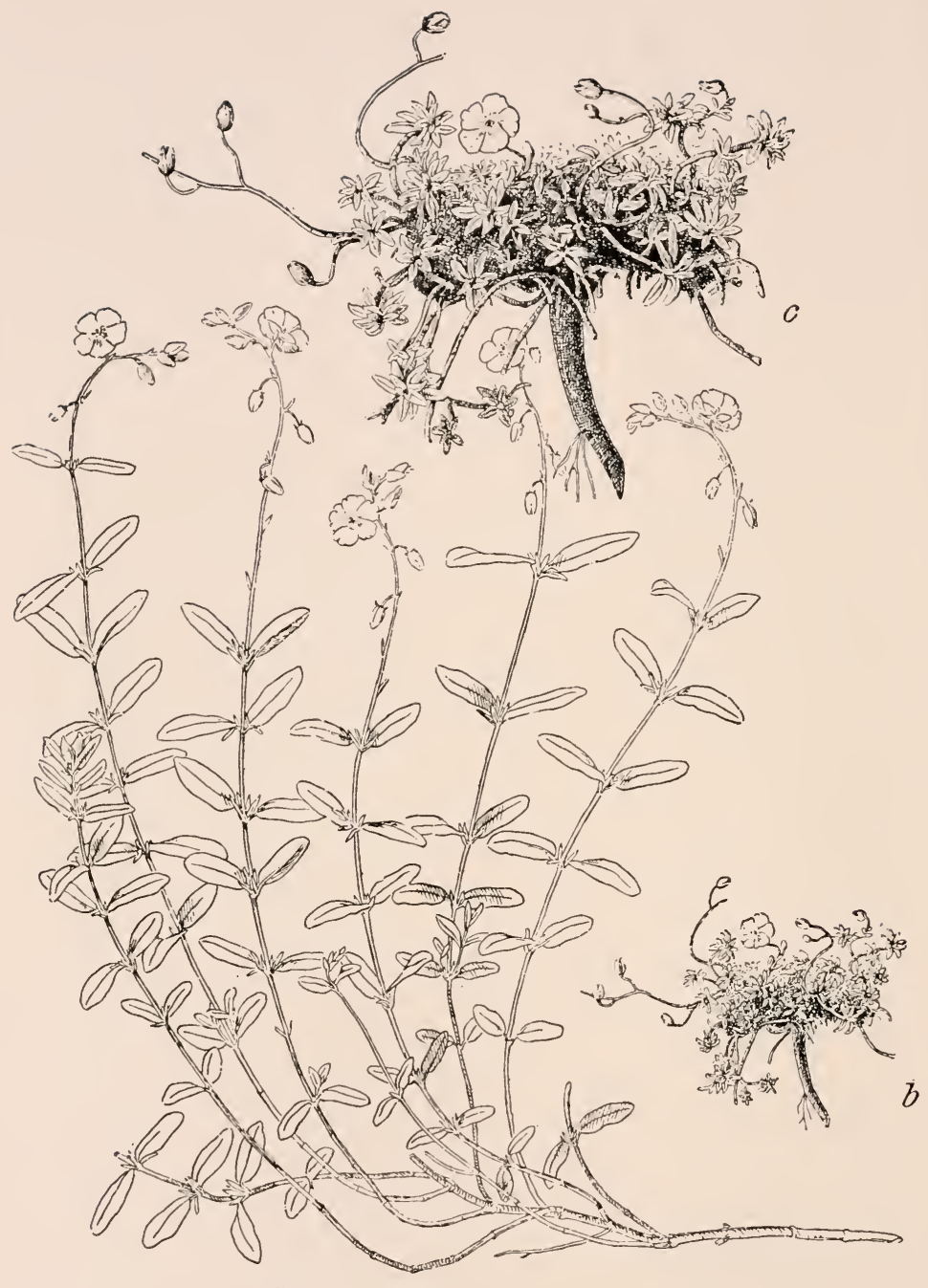

$a$

Fig. 204. Two plants of a rock-rose (Helianthemum), showing the effect of low ground and alpine conditions. The low-ground plant $(a)$ shows an open habit, and elongated stems with comparatively large and well-separated leaves. The same plant in alpine conditions is drawn to the same scale in $b$, and magnitied in $c$, the very short and compact habit being in striking contrast with that of the lowground form.-After Bowiser. 
temperature; and soft, the low stature and short life not involving the development of specially rigid structures for support or resistance. In such conditions, as would be expected, annuals are in the minority, the plants being mostly perennial and geophilous. Geophilous plants are those which have the habit of disappearing underground when protection is needed. This is probably the best adaptation for total disappearance from the surface and for rapid reappearance (see \$146). In such conditions, also, rosette forms are very common, the overlapping leaves of the rosette closely pressed to the ground diminishing the loss of heat by radiation. It has also been noticed that these arctic and alpine carpets show intense color in their flowers, and often a remarkable size of flower in proportion to the rest of the plant. Wherever the area is relatively moist, the carpet is prevailingly a grass mat; in the drier and sandier spots the herbs predominate (see Fig. 203).

In the case of plants which can grow both in the low ground and in the alpine region, a remarkable adaptation of the plant body to the different conditions may be noted. The difference in appearance is sometimes so great that it is hard to realize that the two plants belong to the same species (see Fig. 204).

169. Meadows. - This term must be restricted to natural meadow areas, and should not be confused with those artificial areas under the control of man, which are commonly mowed. The appearance of such an area hardly needs definition, as it is a well-known mixture of grasses and flowering herbs, the former usually being the predominant type. Such meadow-like expanses are common in connection with forest areas (see Fig. 205), but they are most characteristically developed on flood-plains along streams. In most cases the local meadow is probably an ephemeral society, to be replaced by forest growth.

The greatest meadows of the United States are the wellknown prairies, which extend from the Missouri eastward 


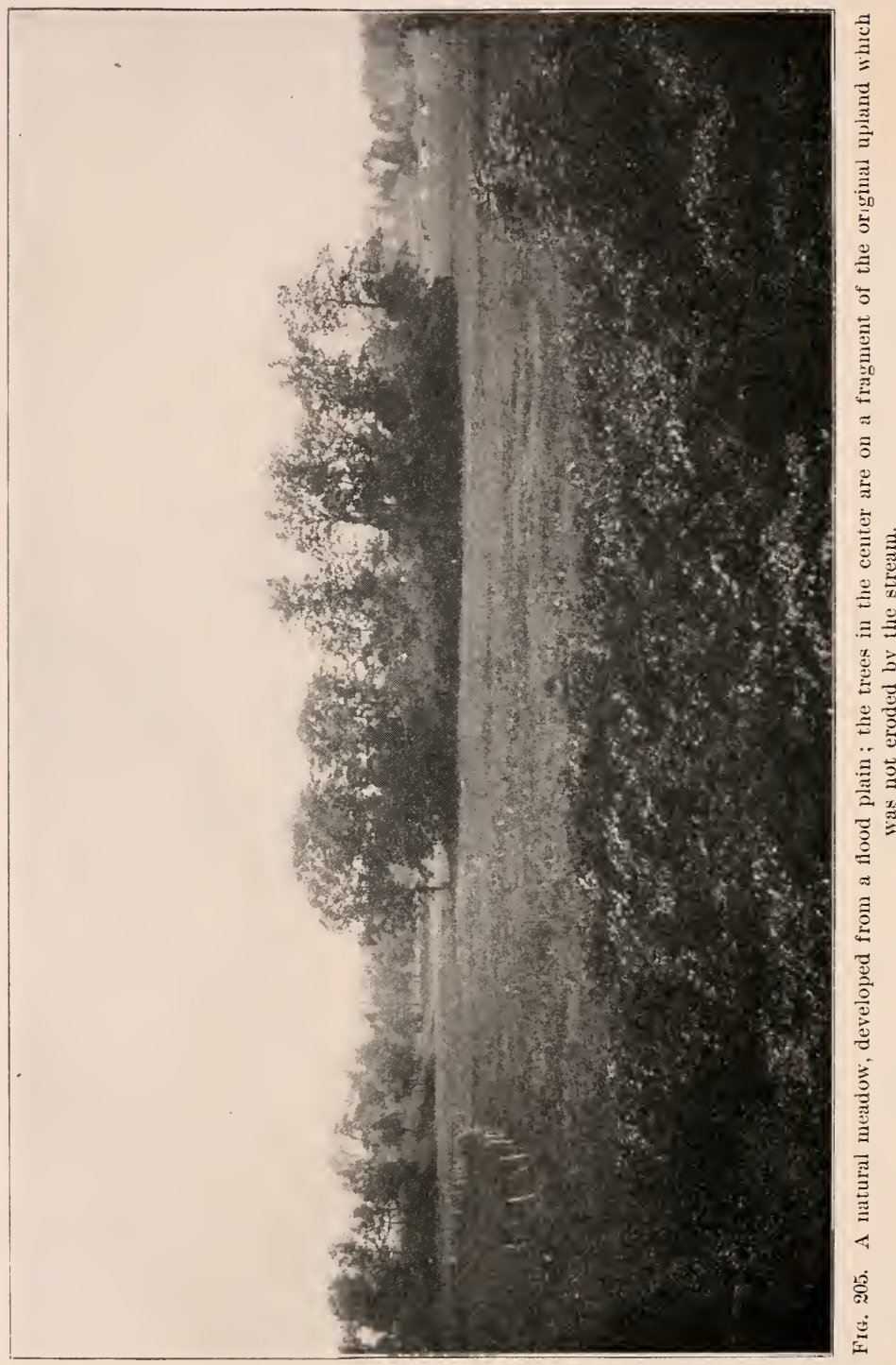


to the forest regions of Illinois and Indiana (see Fig. 206). The prairie is regarded by some as a xerophyte areat, and this is a natural eonchusion when one examines only the structures of the plants which ocenpy it. It is certainly a transition area between the plains of the West and the true mesophytic areas of the East, and there is a general transition from the more xerophytic western prairies to the more mesophytic eastern prairies. Moreover, in the eastern part of the prairie region there is locally every gradation between the strongly mesophytic type of the low ground to the more xerophytic type of the high ground.

The regetation of the prairies in general is composed of tufted grasses and peremnial flowering herbs. Cufortunately, most of the natural prairie has disappeared, to be replaced by farms, and the eharacteristic prairie forms are not easily seen. 'The flowering herbs are often very tall and eoarse, but with brilliant flowers, such as species of aster, goldenrod, rosin-weed, indigo plant, lupine, bush clover, ete. The most characteristic of these forms show their xerophytic adaptations by their rigidity and roughness.

The origin of the prairie has long been a vexed question, which has usually taken the form of an inquiry into the conditions which forbid the growth of forests. Prairies are at least of two kinds. Some are edaphic-that is, they are due to local soil eonditions. Sneh prairies are eharacteristic of the eastern prairie region, and even appear in scattered patches thronghout the forest region as far east as Ohio, Kentucky, ete. They are probably best explained as representing old swamp areas, which at a still more ancient time were ponds or lakes. All the prairies of the Chicago area are eridently edaphic, being associated with former extensions of Lake Michigan. Other prairies are climaticthat is, they are dne to general elimatic conditions. Such prairies are characteristic of the western prairie region, merging into the plains, and are more puzzling tham the edaphic prairies. Among the several explanations sug- 


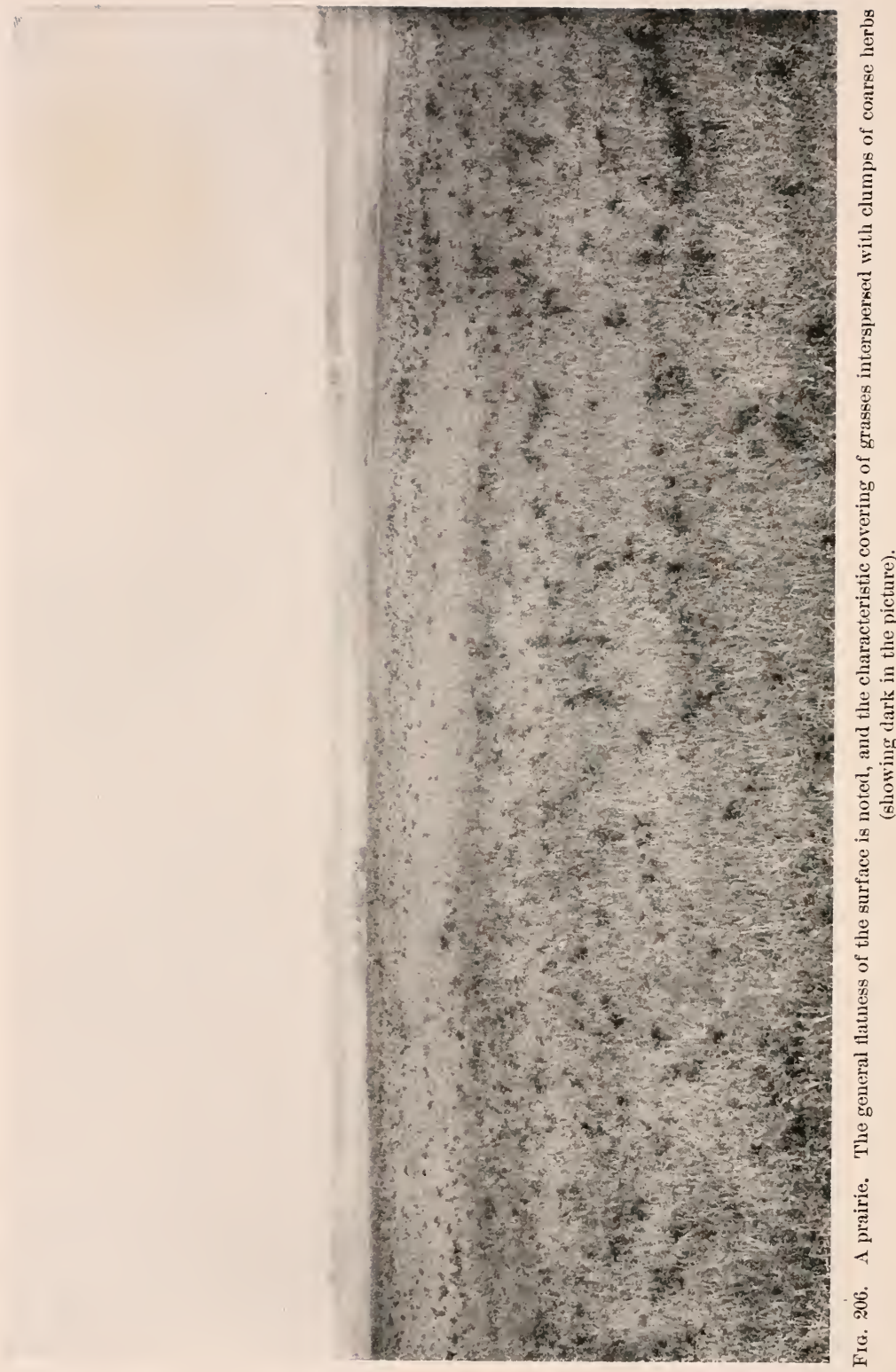


gested perhaps that which refers the western prairies to the prevailing dry winds is the most prominent.

The extensive plains of the West develop the strong and dry winds which prevail over this prairie region, and this brings about extremes of heat and drouth, in spite of the character of the soil. In such conditions a tree in a germinating condition could not establish itself. If it is protected through this tender period it can maintain itself afterward, but the drying winds forbid any plant with a prolonged and sensitive juvenile period. These prairies, therefore, would represent a sort of broad beach between the western plains and the eastern prairies and forests.

What seems to be a confirmation of this view may be observed in eertain north and south valleys in the Missouri region which lies on the border between plains and prairies. The eastern slopes of such valleys, exposed to the wind from the plains, are without trees; while on the western slopes, protected from this wind, trees occur.

Probably the oldest explanation of sueh prairies is the occurrence of prairie fires, but this would appear to be too local a cause for what seems to be a continental feature. Recently, however, the fire theory has been revived, and evidence has been brought forward to show that in some places, at least, a forest growth would appear if fire and stock were kept ont. In fact, the elaim is made that $\mathrm{Ne}$ braska is becoming gradually forest-clad.

1\%0. Pastures.-This term is applied to areas drier than natural meadows, and includes the meadows formed or controlled by man (see Fig. 20\%). They may be natural, or derived from natural meadow areas, or from forest clearings; therefore they are often maintained in conditions which, if not interfered with, would not prodnce a meadow. In general, the pasture differs from the natural meadow in being drier, a fact often due to drainage, and in developing lower and more open vegetation. Naturally the plant forms are prevailingly grasses, and their eultivation is the 
purpose of the artificial pasture, but the meadow tendency is shown by the coming in of perennial weeds. The invasion of pastures by weeds suggests many interesting questions. Are the weeds natives or foreigners? Are they

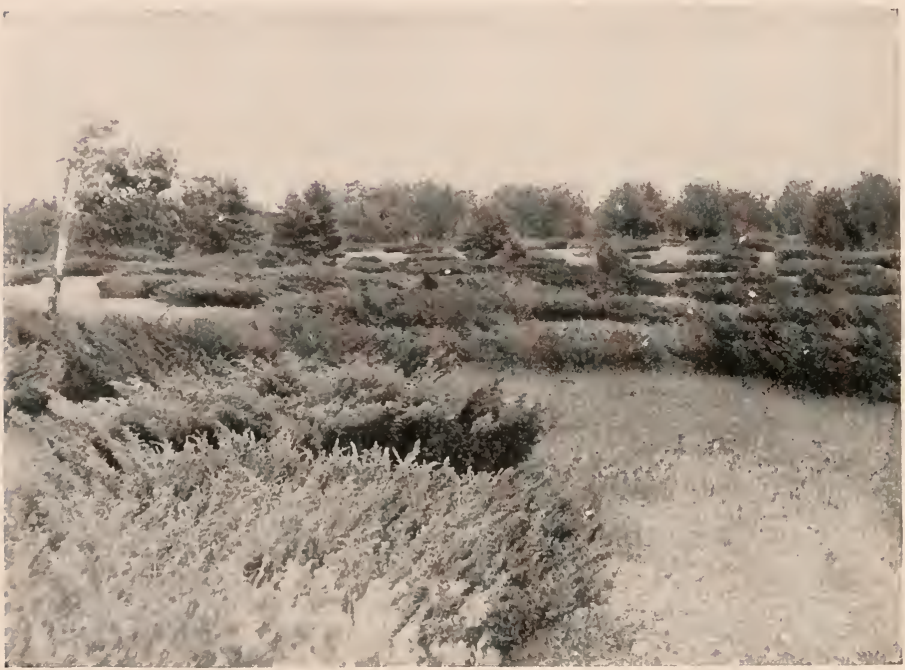

Fig, $20 \%$. A juniper heath interspersed with pastures. The growths of juniper are very dense, excluding all other vegetation, and the grass or pasture areas are too dry to form real meadows._-After Cow Les.

annuals or perennials? What is the relative success of the different invaders, and why are some more successful than others? A study of pastures will also reveal the fact that there is great difference in the vegetation of mowed and grazed pastures. The same effects are noted when natural meadows are used for grazing.

\section{B. Woody societies.}

These societies include the various shrub and tree associations of mesophyte areas, associations entirely distinct from the grass and herb societies. 
171. Thickets. -The mesophyte thickets are not so abundant or impenetrable as the xerophyte thickets. 'They seem to be developed usually as forerunners of forest vegetation. An illustration of this fact may be obtained by noting the succession of plants which appear on a cleared area. After such an area has been cleared of its trees, by cutting or by fire, it is overrun by herbs which develop rapidly from the seed. Sometimes these herbs are tall and with showy flowers, as the so-called fire-weed or great willow herb. Following the herb societies there is a gradual invasion of coarser herbs and shrubby plants, forming thickets, and finally a forest growth nay appear again.

In arctic and alpine mesophyte regions the willow is the great thicket plant, often covering large areas, but in temperate regions willow thickets are confined to stream banks and boggy places, being the characteristic hydrophyte thicket form.

The upland and flood-plain mesophyte thickets of temperate regions are different in character. For example, the upland thicket of the Northern States very commonly contains hazel, birch, and aspen as dominant plants; while the flood-plain thicket is apt to contain, in addition to these, prominent growths of haws and wild crab-apples. In this same region pure thickets frequently occur-that is, thickets in which a single form is the prevailing type, as pure hazel thickets on uplands, or pure haw thickets on flood-plains.

In the Southern States the plants enumerated above may not be the characteristic mesophyte thicket plants. For example, in Kentucky and Temmessee the dominant thicket plants are persimmon, locust, redbud, and sassafras.

$1 \%$. Forests of temperate regions.-Decidnous forests are especially characteristic of temperate regions. The deciduous habit, that is, the habit of shedding leares at a 
certain period, is an adaptation to climate. In the temperate regions the adaptation is in response to the winter cold, when a vast reduction of delicate exposed surface is necessary. Instead of protecting delicate leaf structures from the severe cold of winter, these plants have formed the habit of dropping them and putting out new leaves when the favorable season returns.

It is instructive to notice how differently the conifers (pines, etc.) and the deciduous trees (oaks, maples, etc.) have

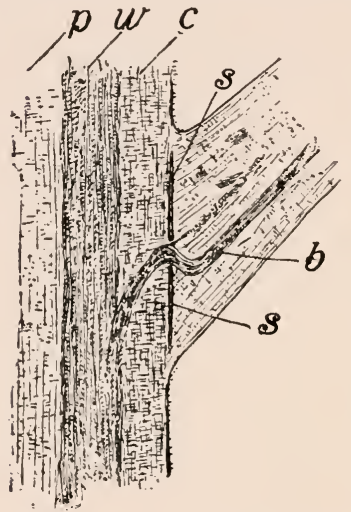

Fig. 208. A section through the base of a leaf of horse-ehestnut preparing to fall off at the end of the growing season. A cleavage plate $(s)$ has developed between the woody bundle $(b)$ and the surface. Presently this reaches the surface, and only the woody strand fastens the leaf to the stem. answered the problem of adaptation to the cold of winter. The conifers have protected their leaves, giving them a small surface and heavy walls. In this way protection has been secured at the expense of working power during the season of work. Reduced surface and thick walls are both obstacles to leaf work. On the other hand, the deciduous trees have developed the working power of their leaves to the greatest extent, giving them large surface exposure and comparatively delicate walls. It is out of the question to protect such an amount of surface during the winter, and hence the deciduous habit. 'The conifers are saved the annual renewal of leaves, but lose in working power; the decidnous trees must renew their leaves annually, but gain greatly in working power.

It should be remarked that leaves do not fall because they are broken off, but that in a certain sense it is a process of growing off. Often at the base of the leaves, where the separation is to occur, a cleavage region is 
gradually developed until the leaf is entirely separated from the stem except by a woody strand or two, which is easily broken (see Fig. 208). In this way the scar which remains has really been formed before the leaf falls.

In this process of sloughing off leaves, the plant cannot afford to lose the living substance present in the working leaves. This substance, during the preparation for the fall, has been gradually withdrawn into the permanent parts of the plant.

It will be noticed that in general deciduous leaves are thin, exceedingly variable in form, and in a general horizontal position, nor do they have the firm, leathery texture of the xerophyte leaves. All this indicates great leaf activity, for, the necessity of protection being removed, the leaf is not impeded in its work by the development of protective structures.

One of the most prominent features associated with the deciduous habit is the antumnal coloration. The vivid colors which appear in the leaves of many trees, just before the time of falling, is a phenomenon which has attracted a great deal of attention, but although it is so prominent, the causes for it are very obscure. It will be noticed that this autumnal coloration consists in the development of various shades of two typical colors, yellow and red. These colors are often associated together in the same leaf, and sometimes a leaf may show a pure color.

The two colors hold a very different relation in the leaf cell. It is known that the yellow is due to the breaking down of chlorophyll, so that the chloroplasts, which are green when active, become yellow when disorganizing, and finally bleach out entirely. That yellow may indicate a post mortem change of chlorophyll may be noticed in connection with the blanching of celery, in which the leares and upper part of the stem may be green, the green may shade gradually into yellow, and finally into the pure white of complete blanching. 
The red shades, however, do not seem to hold any such relation to the disorganization of ehlorophyll. The red coloring matter appears as a stain in the cell sap, so that what might be called the atmosphere of the active cell is suffused with red. Certain experiments upon plant colors have indieated that the presence of the red eolor slightly increases the temperature by absorbing more heat. 'This has suggested that the red color may be a slight protection to the living substance, which has ceased working and which is in danger of exposure to cold. If this be true, it may be that the same explanation will cover the case of the red flush so conspicuous in buds and young leaves in the early spring. It must not be supposed that the need of protection has developed the color, but that since it is developed it may be of some such service to the plant. The whole subject, however, is too indefinite and obseure to be presented in any other form than as a bare suggestion.

Even the conditions which determine autumnal coloration have not been made out certainly. To many the autumnal coloration is associated with the coming of frost, which simply means a reduction of temperature; others associate it with diminishing water supply; still others associate it with the ehange in the direction of the rays of light, which are mors oblique in autumn than during the aetive growing season. It is certainly true that the colors are far more brilliant in certain years than in others, and that the coloration must be eonnected in some way with the food relations of the plants. Recent experiments have shown that the red coloration is largely dependent upon low temperature, which affects certain of the food-stuffs, and the red stain is one of the products.

The autumnal eolors are notably striking in American forests on account of the fact that in these forests there is the greatest displany of species, and hence not only are more colors produced, but they are usually strikingly associated. 
Not only is protection during the cold period secured by deciduous forests through the falling of leaves, but the development of scaly buds is an adaptation to the same end. By means of these overlapping, often hairy, and even varnished structures, delicate growing tips are protected during the cold season. The development of cork, also, on the older parts, is a measure of protection.

Although the trees are the dominant plants of a forest society, it must not be forgotten that numerous other forms are associated with them. At a lower level stand the shrubs, below these the tall herbs, then the low herbs and grasses, and finally close to the soil mosses and lichens occur. These different strata, as they are called, represent different habits in reference to light, the lower strata being made up of shade plants as compared with the upper strata. In fact, the shade habit has become so established in many plants of the lower strata that they depend upon the presence of the overshadowing strata, and could not live without them.

The vernal habit is also an interesting feature of deciduous forests. It is a matter of common observation that the rich display of "spring flowers" occur's in forests and wooded glens before the trees come into full foliage. The working season of these vernal plants is before the dense foliage of the forest shuts off the light. Accordingly, they are mostly geophilous in habit (see \$1+6), sending up their shoots or leaves with great rapidity from underground tubers, rootstocks, etc., and completing their regetative work in the short period during which the light is available. After the forest leaves are fully developed the spring flowers disappear, waiting in their subterranean retreats for the next short period of activity. Two prominent forms of the rernal habit may be observed. The leaves may appear before the flowers, as in Erythronium and IIydrophyllum; or they may appear after the flowers, is in Hopatica and Sangninuria. One of the wild leeks (Allium tricoccum) has developed a 
very interesting modification. It sends up its rosette of large and very active leaves during the vernal season, and when these have disappeared the flowers are developed in the forest shade. 'The significance of this is that while the leaves must have the light for their work, the flowers can develop just as well in the shade.

As in the case of thickets, deciduous forests may be pure or mixed. A very common type of pure forest is the beech forest, which is a characteristic dark forest. The wide-spreading branches of neighboring beeches overlap each other, so as to form dense shade. As a consequence, in a pure beech forest there is little or no undergrowth; in fact, no lower strata of vegetation until the lowest ones are reached, made up of grasses and mosses. Another type of pure forest, which belongs to the drier regions, is the oak forest, which forms a sharp contrast to the beech, in that it is a light forest, permitting access of light for lower strata of plants. Hence in such a forest there is usually more or less undergrowth, consisting of shrubs, etc., which may develop regular thickets. The typical American deciduous forest, however, is the great mixed forest, made up of many varieties of trees, such as beech, oak, elm, walnut, hickory, gum, maple, etc.

The deciduous forests may be roughly grouped as upland and flood-plain forests, the former being less luxuriant and containing fewer types, the latter being the highest expression of forest development in its region. A few general illustrations may be given as follows :

In northern Illinois the upland forest is mostly made up of three forms, white and red oaks and shellbark hickory; while the flood-plain forest contains twenty to twentyfive tree forms, prominent among which are the elms (white and slippery), linden (basswood), cottonwood, ash, silver maple, box elder, walnut, and willows (see Fig. 211).

Farther south, from central Illinois, Indiana, and Ohio southward, as well as in the Alleghanies, the flood-plain for- 


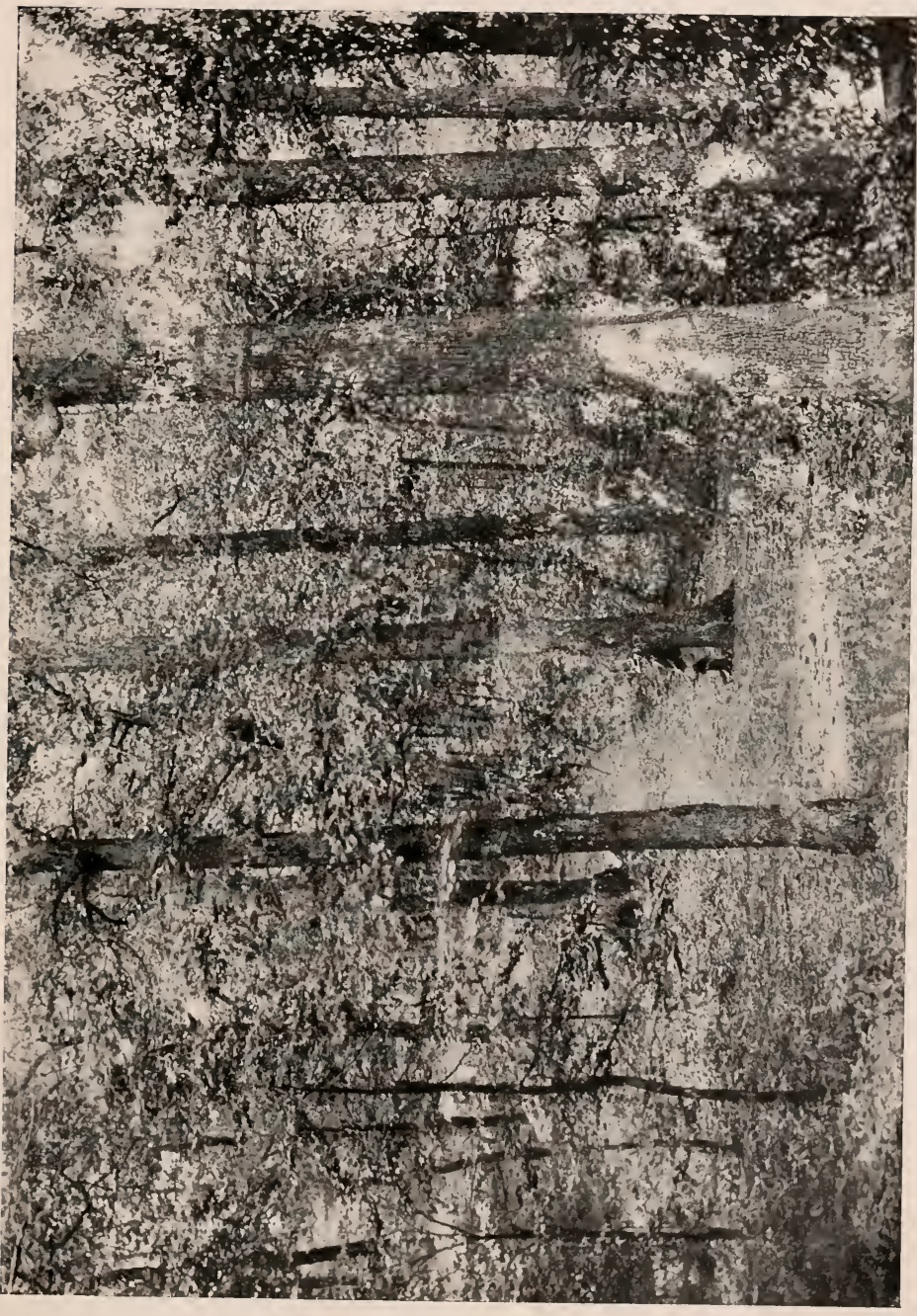


ests are the richest known, containing, in addition to the forms enumerated above, such prominent trees as the sycamore, beech, hackberry, honey locust, coffee tree, sugar maple, tulip tree, buckeye, etc.

In Michigan and II isconsin the upland forests consist prominently of beech, sugar maple, and hemlock, a characteristic mixture of decidnous and evergreen trees; while the flood-plain forests are scarcely at all developed.

In the Alleghany region and New England the upland forests are very extensive and complicated, grading from the rich flood-plain forests of the lower levels on the one hand, to the strictly xerophytic forests (pines and black oaks) of the higher levels on the other hand, and dominated by various oaks (especially white, red, and chestnut oaks), chestnuts, and hickories (see Figs. 209, 210).

The flood-plain forests of New England are not so rich as those of the Alleghany region and Central West, the dominant forms being elms, linden, ash, maples, sycamore, tulip tree, etc.

173. Tropical forests. - The tropical forests may be grouped under two general heads: (1) the evergreen forests, and $(:)$ the deciduous or monsoon forests. 'The former are characterizer by continuous moisture, and are most largely developed in the East Indies and along the Amazon and its tributaries in South America. 'The deciduous tropical forests are characterized by having a period of relative dryness, luring which the leaves are shed, and usually border the evergreen forests.

A. Evergreen furests.-These rainy forests of the tropies maly be regarded, as Warming salys, "as the climax of the world's regetation," for the conditions in which they are developed favor constant plant activity at the highest possible pressure. Such great forest growths are found within the region of the trade winds, where there is heavy rainfall, great heat, and rich black soil. So abundant is the precipitation that the air is often saturated and the plants drip 


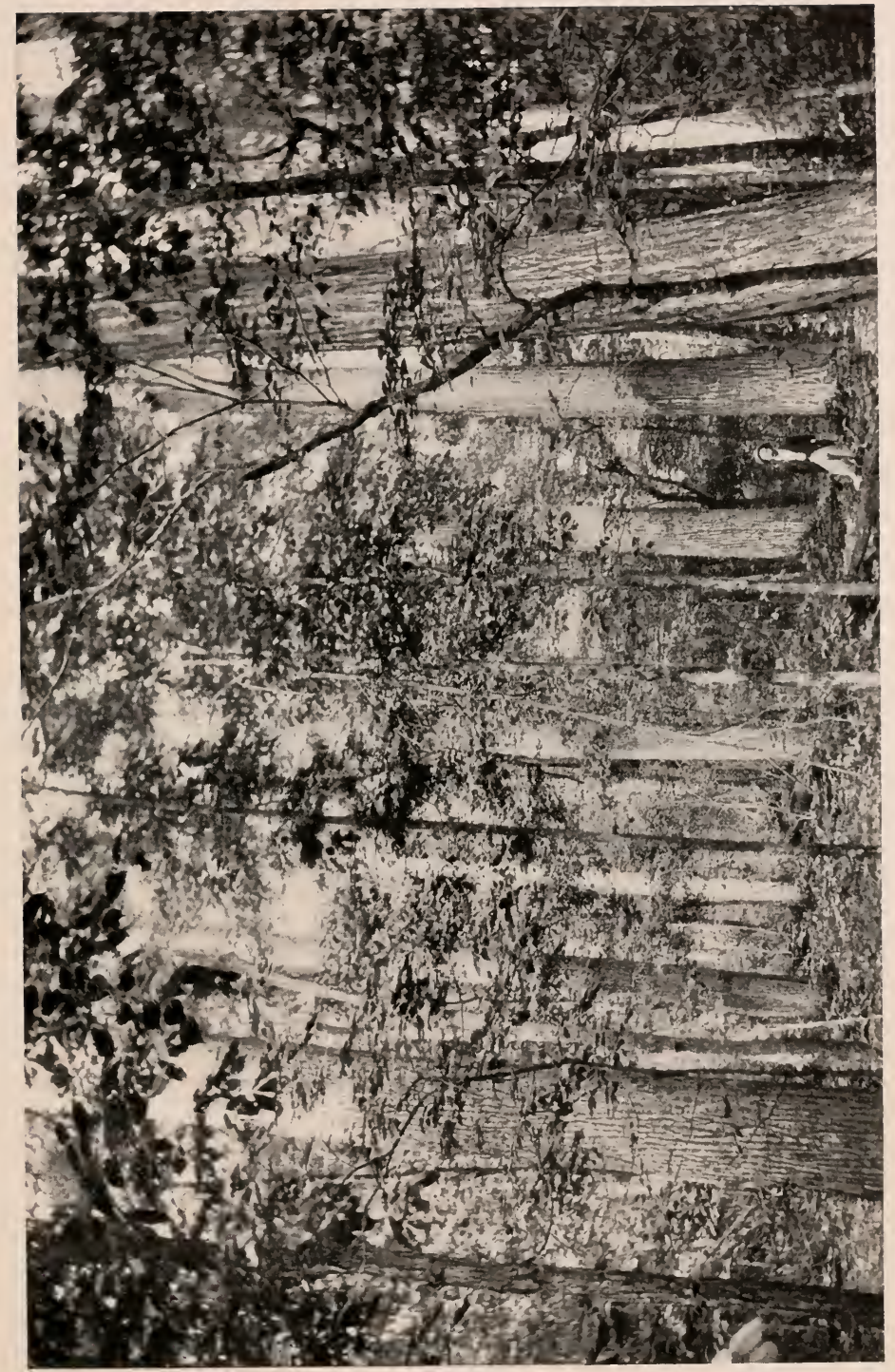


with moisture. In such conditions pure forests may occur, characterized by such tree forms as the tree ferns, palms, or bamboos. Only the great mixed tropical forest will be considered. The main characteristics are as follows :

(1) Absence of simultaneous periodicity-Perhaps the most striking feature, in contrast with the deciduous forests, is that there is no regular period for the development or fall of leaves. Leaf activity is possible throughout the year, and there is no time of bare forest, or of forests just putting out leaves. This does not mean that the leaves persist indefinitely, but that there is no regular time for their fall and formation. Leaves are continually being shed and formed, but the trees always appear in full foliage.

(:) Density of growth.-Such an area is remarkably filled with vegetation stratum, after stratum occurring, resulting in gigantic jungles. The higher strata may be made up of trees of different heights, below them are shrubs of varying heights, then tall and low herbs, and finally mosses and liverworts. Among these close-set standing forms, great vines or lianas climb and bind the standing vegetation into an inextricable tangle (sce Figs. 55, 212). In addition to these, hosts of aerial plants find lodging places upon the tree-trunks and vines (see Fig. 213). These rainy forests of the tropics furnish the very best conditions for the development of the numerous epiphytic orchids, bromelias, etc. In such conditions also numerous saprophytes occur. Such an assemblage of vegetation is to be found nowhere else.

(3) Number of species. - Not only is there an immense number of individuals, but an extraordinary number of species occur. A list of plants growing in these forests would show a remarkable representation of the plant kingdom.

(4) Forms of trees.-The dense vegetation results in 


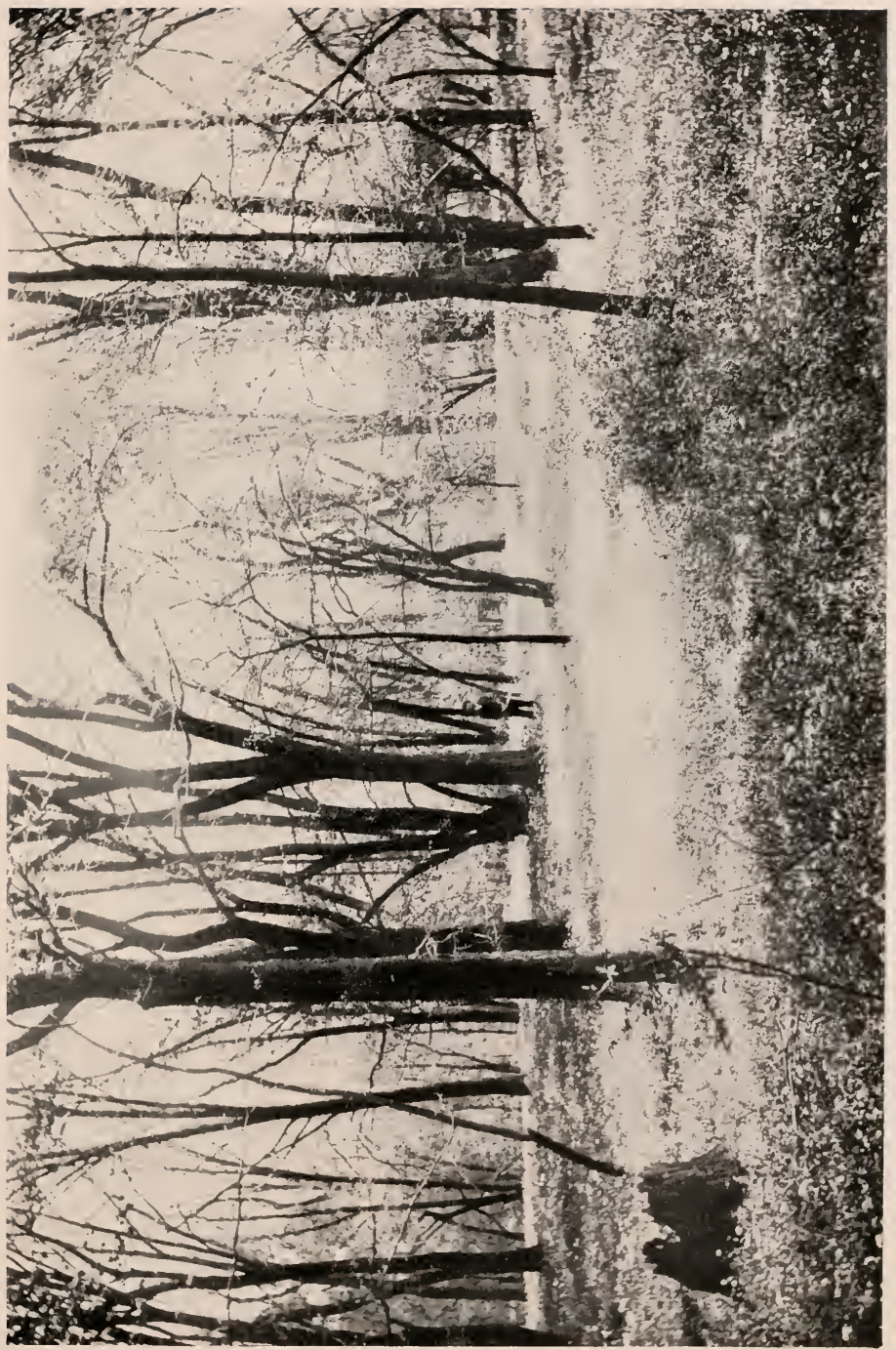




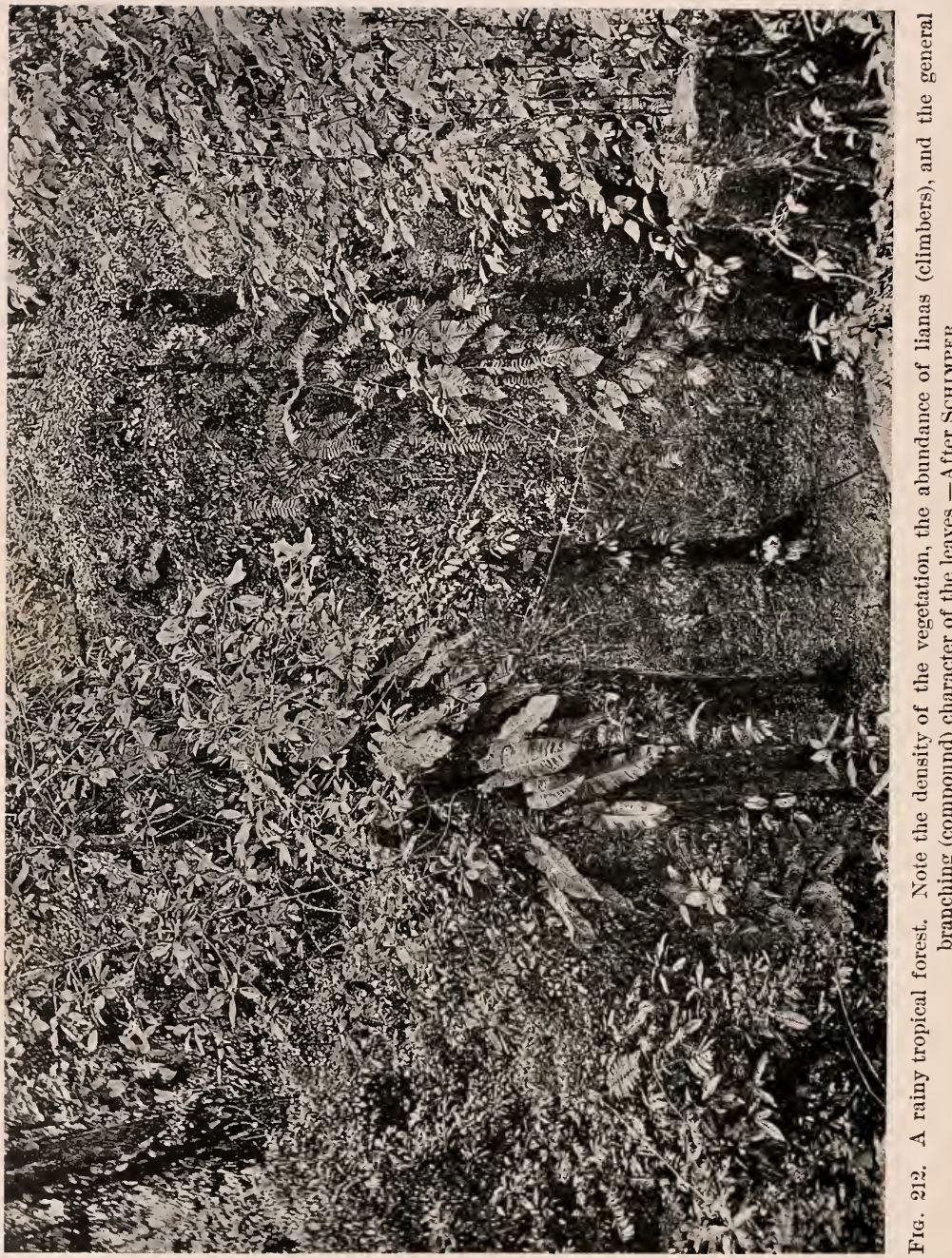


straight leafless tree-trunks, so that the leaves of trees are mainly clustered at the tops of high branches. The shade is so dense and the interference is so great that the development of low branches is impossible. It is common, also,

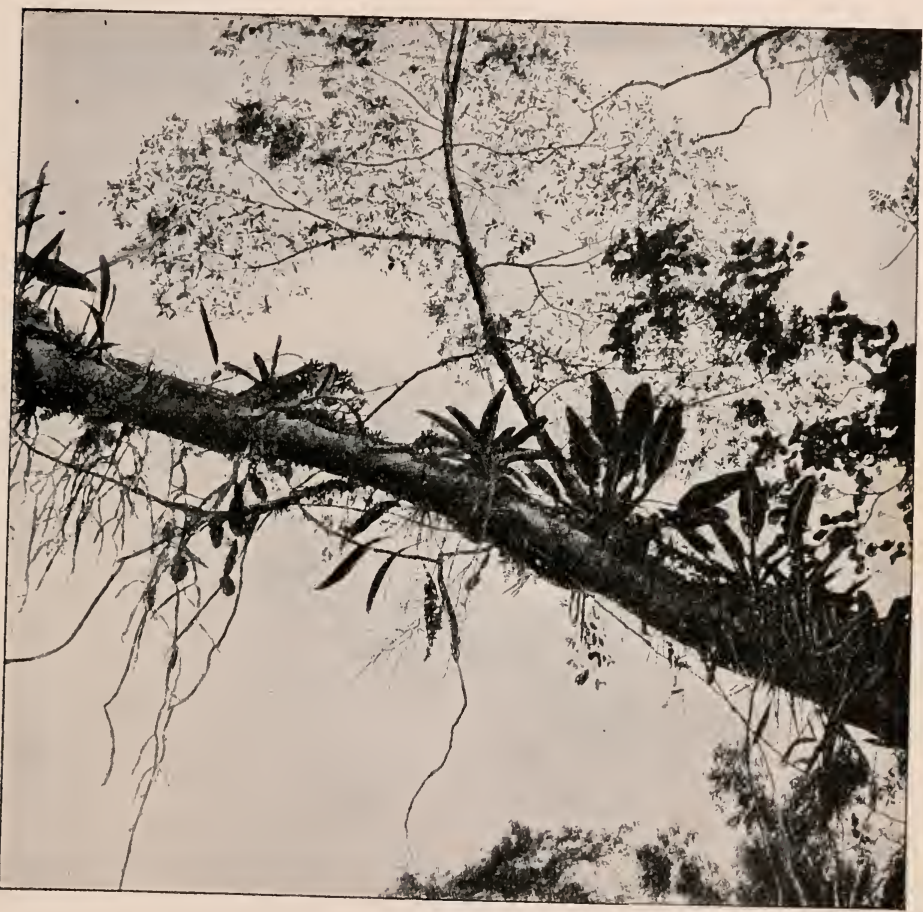

Fig. 213. A group of aerial plants (epiphytes) from a tropical forest. Note the varions habits of the epiphytes attaehed to the tree-trunks, and the dangling roots.After ScIIIMPER.

for the larger trees to develop a system of buttresses near the base, and also frequently to send out prop roots (see Figs. 100, 101).

(5) Absence of but scules.-In the deciduous forest bud scales are necessary to protect the tender growing tips during the period of cold. The same derice would be suffi- 
cient to protect against a period of drouth. In the tropical forest there is danger neither from eold nor drouth, and in such conditions bud seales are not developed, and the buds remain naked and mprotected.

(6) Derices against too abundant rain.-The abundance of rain is in danger of checking transpiration, and as this

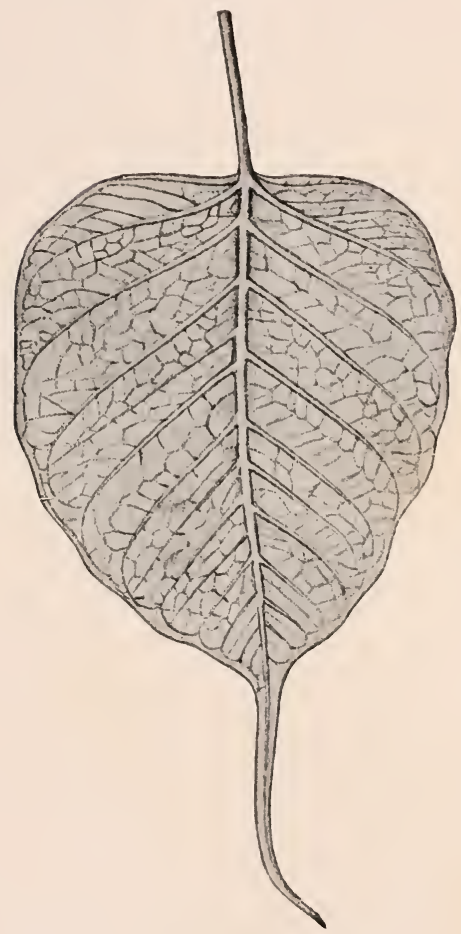

FIG. 214. A gutter-pointed leaf from a tropical plant.-After Scmmper. process is essential to plant activity, there are often found devices to prevent the leaves from becoming saturated. Many leaves have cuticles so smooth and glazed that the water glances off without soaking in ; in other cases a velvety eovering of hairs answers the same purpose; in still other cases leaves are gutter-pointed, that is, the tip is prolonged as a sort of gutter, and the veins are depressed, the whole surface of the leaf resembling a drainage system, so that the rain is conducted rapidly from the surface (see Fig. 214). These are only a few illustrations of many devices against dangerous wetting.

B. Deciduous or monsoon forests.-In these forests the same general habits prevail as in the rainy evergreen forests, but to a less degree. For example, the epiphytes and lianas are present, but they are not so numerous or conspicuous. The striking difference, however, is the 
deciduous habit, developed apparently by the regular recurrence of a relatively dry period, although it may be very short. Such forests are usually adjacent to the evergreen forests, much as upland forests are adjacent to floodplain forests. 



\section{N D E X.}

[The italicized numbers indicate that the subject is illustrated on the page cited. In such case the subject may be referred to only in the illustration, or it may be referred to also in the text.]

\section{A}

Acacia, 199.

Achillea, 20?.

Adaptation, $14 \%$.

Adiantum, 27.

Aeration, 92, 93, 95, 183.

Agave, 45, 47.

Agrimony, 121.

Ailanthus, 116 .

Air, 95, 98, 114, 122, 138.

Air cavities, 1\%1, 1\%?, 1\%3, 1\%5.

Air passages, 92, 93, 94, 95.

Air plants, 97, 98.99, 100, 101, 246.

Air roots, 9\%, 98, 99, 100.

Alchemilla, $\% 9$.

Algie, 1, 2, 87, 99, 107, 109, 110, $111,113,150,1 \% 1,1 \% 2,1 \%$.

Alkaline deserts, 255.

Alpine plants, 148, 234, 236.

Amicia, 9.

Ampelopsis, 63 .

Anemophilous, 1:2.

Animals, 119, 121, 12:, 123, 14i, 205.

Annual habit, 195.

Annual rings, 84 .

Anthurium, 9\%.

Apple, $\% 9$.

Araucaria. \%4.
Arbor vitæ, 139.

Arctic plants, 148, 235.

Arrow-leaf, 186.

Artillery plant, 120 .

Ash, 116.

Aspidium, 55.

Assimilation, 154, 156.

Autumn coloration, 245.

\section{B}

Bacteria, 189.

Banana, 88 .

Banyan, 105, 106.

Barberry, 20\%.

Bark, 84.

Basswood, 116, :01.

Beach, 209, 210 .

Beach marshes, 19, 26.

Beach pea, 118.

Beach societies, 209.

Bean, 140.

Bearberry, 212.

Beech drops, $15 \%$.

Beech forest, 14i).

Beggar ticks, 119, 121.

Begonia, .85, .208.

Bellflower, 19, 80 .

Bidens, 119.

Bignonia, 115. 
Bilbergia, 136.

Birches, $\approx 1$.

Black moss, $96,101$.

Bladderwort, $1 \% 3$.

Blade, 3i).

Bluodroot, 195.

Bogs, 14:3.

Box elder, $8 \%$.

Bramble, 94.

Branched leaves, 19, $20,21,23$.

Buds, $70,73,75,141,24 \%$.

Bulbs, $73,75, s 1$.

Bulrush, 14:, 148, 185, 186, 20\%.

Burdock, 121, 122.

Bush, 227.

Bush clover, 43.

Buttercup, 185.

Buttresses, 103, 104.

\section{C}

Cactus deserts, 21\%, 222.

Cactus forms, 45, 4t, 4r, 146, 202, $207,215,216,21 \%, 218,219,222$.

Calyx, $\% s, \% 9,80,125$.

Campanula, 19,80 .

Caoutchoue, 136.

Carbohydrates, 153, 156.

Carbon, 153.

Carbon clioxide, 30, 151, 153.

Cardon forests, 231.

Carnation, $4 \cdots$

Carnivorous plants, $155,156,15 \%$, $173,189$.

Carpel, $78, \% \%, 80,125$.

('arrot, 120.

C'astor-oil bean, $\% 3$.

Casuarina, 231.

Cutalpa, 11\%.

Catchfly, 136.

Cat-tail flag, 142, 148, 185, 186.

Cercis, 10 .
Change in temperature, 145.

Chaparral, $22 \%$.

Chlorophyll, 6, 8, 149, 152.

Chloroplasts, 39, 10\%, 15:, 205, 20S, 209, 245.

Chrysanthemum, 23.

Cilia, 109, 111.

C'laytonia, 196.

Cleistogamous, 130.

Clematis, 113.

Climbing stems, 60, 61, 62, 68, 64, 10?.

Clinging roots, $99,10 \%$.

Clinia, 809.

Cocklebur, $120,121$.

Compass plants, 10, 1?, 197, 198 .

Compound leaves, $19,20,21,23$.

Conducting tissue, 171.

Conifer forests, $226,227,228,229$, 230.

Conifers, 83, 190, 191, .225, 226.

Cork, 247.

Corn, 85, 90.

Corolla, $\% 8, \pi ?, s o$.

Cortex, 83, s4, 23, 94, 10\%, 108 .

Cottonwood, ro.

Cotyledons, 50, 51, 73, 139, 140.

Crevice plants, 94, 209.

Cuticle, $4 ?, 205$.

Cycad, 22.

Cycloloma, $11 \%$.

Cypress knees, 95, 26, 183.

Cypripedium, 132, 133, 134, 135, 136.

Cytisus, 206.

\section{D}

Dandelion, 82, 114, 117.

Darlingtonia, $15 \%$.

Date palm, $\delta 6$.

Dead-nettle, 80 . 
Decidnous forests, 243 .

Deciduous habit, 14:3, 196, 243, 44.

Deserts, 221, 222, 223 .

Desiccation, 194.

Desmodium gyrans, 49 .

Destruction of plants, 148 .

Diatoms, 174.

Dicotyledons, 35, 83, 116.

Differentiation, 3.

Digestion, 154, 156.

Dionea, 160, 161.

Dodder, 106, 10\%, $15 \%$.

Dog-tooth violet, 14.

Dragon tree, 15.

Drainage, $143,145$.

Drosera, 158, 159.

Drouth, 193.

Duckweed, 97, 175 .

Dunes, 145, 201, 209, 211, 212.

Dwarf growths, 203 .

\section{E}

Easter lily, 14.

Echeveria, $1 \%$.

Ecological factors, 163 .

Ecology, 4, 149.

Eel grass, 184 .

Egg, 110, 111.

Elaters, 118.

Elatine, 93.

Elm, 63, 6\%, 68, 75 .

Embryo, 111, 139.

Entomophilous, 122, 123.

Epitermis, 37, 40, 41, 4, 83, 84, $107,1 \% 0,205, .208 .209$.

Epilobium, 113, 113, 12S, 135.

Epiphyte, 209.

Equisetum, 111, 203.

Erect stems, $62,65,66,6 \%, 68,69$, ro, 71 .

Erica, 200.
Erythronium, 14.

Euphorbia, 204.

\section{F}

Ferns, 55, 56, 85, $8 S, 100,111,113$, 119.

Fertilizing, 145.

Ficus, $\delta$.

Figwort, 128, 135.

Fireweed, 112, 113, 12S, 135, 243.

Fittonia, 3\%, 15?.

Fixed light position, $19 \%$.

Flag, 126, 133.

Floating stems, 59.

Floats, 1\%1, 1\%2, 1\%3.

Flower's, $\tau 6, \tau s, 140$.

Foliage forests, $22 \%$.

Foliage leares, 6, 28, 139 .

Forest clearing, 143, 145.

Forests, 190, 226, 227, 22S, 229.

Fruit, 113, 11\%, 115, 116, 11\%, 118, $119,120,121,12 ?$.

Fucus, 171 .

Functions, 3.

Fungi, 8\%, 107, 109, 110.

Furze, 205.

G

Galium, 121.

Gamete, 110, 111, 112, 113.

Geophilous habit, $55,56,73,74,75$, $\% 6, \tau \%, \tau 8,81,19 \overline{5}, 196,23 \%$.

Geotropism, 69, 91, 138.

Germination, 111, 138, 139, 140 .

Gorse, 205 .

Grape vine, 61.

Griss, $18 \%, 19 \tau, 216,236$.

Gravity, 91.

Guard cells, 38 .

Gymnosperms, 115. 


\section{HI}

IIabenaria, 12\%.

Ilairs, 43, 92, 136, 146, 202, 203.

IIalophytes, 169, 249.

Harebell, 19, so.

Hawthorn, 36.

IIeart-wood, 151.

Heat, 112, 138, 145, 164.

Heath plants, $189,200,214$.

II elianthemum, $23 \%$.

Heliotropism, 12, 13， 68, 72, \%3, 139.

Hemlock, 190.

Horse-chestnut, 244 .

Hlosts, 106.

IIouse leek, 19.

Houstonia, 129, 135.

IIuckleberry, 214.

II udsonia, 212.

Hura crepitans, 120.

IIydrogen, 153 .

Hydrophytes, 168, 170, 174.

Hydrotropism, 91, 138.

\section{I}

Insects and flowers, 123.

Iris, $126,133$.

Isoetes, 9.4, 95, 208.

Iry, 99.

\section{J}

Juncus, $7 \%$.

Juniper, 51, 24 ?.

L

Lactuca, $12,197,198$.

Lady-slipper, 1.32, 13.3, 1.34, 135, 136.
Lakes, $143,148$.

Laminaria, $17 \%$.

Larch, $1 \% S, 190$.

Latex, 136 .

Leafless forests, 227.

Leaflet, 19.

Leaf-relation, 53.

Lemna, 97 .

Lesperleza, 43.

Lianas, 60, 61, 62, 63, 64, 102, 245, 246.

Lichens, 194, 209, 214 .

Life-relations, $4,7,8,53,77$.

Light, 143, 16\%, $19 \%$.

Light-relation, $\tau, 8$.

Lily, 38, 40.

Live-for-ever, $1 S$.

Live oak, 101.

Liverworts. 118.

Locomotion, 113.

Locust, $20 \%$.

Long moss, 96, 101.

Loosestrife, 130, 135.

Lotus, 180.

\section{M}

Mangroves, 192, 192a.

Maple, 26, 115, 116.

Maranta, 38 .

Marchantia. 10\%.

Neadows, 23\%, 238 .

Mechanical tissne, 172.

Mesophyll, 38, 39, 40 41, 4?, 15\%

Mesophytes, 168, 2:3:3.

Migration, 58, 75, $14 \%$.

Mildew, 109, $15 \%$.

Milkweed, 117.

Mimosa, 199.

Mistletoe, $10 \%$.

Mold, 109.

Monocotyledons, 35, 85, 88, 116, 186. 
Noors, $18 \pi, 188$.

Mosaic arrangement, 25, $27,3 \%$. Mosses. 8\%, 10\%, 110, 113, 118, 188, 194, $209,214$.

Motile leaves, 9. 10, 11, 49, 198, 199.

Mould, 109.

Mullein, 43, 44.

Mushrooms, $15 \%$.

\section{$\mathrm{N}$}

Nectar, 123, 158.

Nelumbium, 180.

Nicotiana, 80 .

Nightshade, 26.

Nitrogen, 153.

Nodes, 54.

Nuphar, 9?.

Nutrition, 3, 149.

Nymphra, 1\%s, 180.

\section{O}

Oak, 69, 101.

Oak forest, $145,248$.

(Edogonium, 111.

Orchids, 98, 99, 126, 12\%, 139, 133, 134, 185, 136, 189.

Organs, 3.

Ornithogalum, 81 .

Ovary, 29, so, 125.

Ovules, r8, r9, so.

Oxalis, 10, 50, 199.

Oxygen, 29, 138, 153 .

\section{P}

Palisade tissue, 39, 40, 4?, 205 .

Palms, S6, 87,230 .

Pandanus, 103.
Parasites, 106, 150.

Passion rine, $6 ?$.

Pastures, 241, 242.

Pellionia, 24.

Pentstemon, 137.

Peony, $r s$.

Petals, $\% \mathcal{S}, 79, \mathcal{S O}$.

Petioles, 15, $26,35,55$.

Phlox, so.

Photosynthesis, 28, 29, 150, 152, $153,156$.

Physiology, 149.

Pickerel weed, 181, 18?.

Pines, 63, 65, 66, 112, 115, 117, 190, 227, 229, 230 .

Pirus, $\% 9$.

Pistil, 77. 79,80 .

Pitcher plant, 155, 156, 15\%, 158.

Pith, 83, S4, 107.

Plains, 213, 215, 216.

Plankton, 174.

Plant body, 2.

Plant societies, 1, 146, 162, 168, 174.

Plastid, 152.

Platycerium, 100.

Plumes, 11?, 113, 114, 116, 11\%.

Plumule, 51, 140.

Pollen, $\%$, 111, 112, 11j, 121, 123.

Pollination, 7\%. 115, 122, 123.

Polygonatum, 85.

Ponds, 142, 175, 1\% $, 180,184$.

Pondweed, 176, 181, 18?.

Potato, $74, \pi 6$.

Potentilla, 43, $\pi 9$.

Prairies, 208, 222, 23i, 240.

Prickles, 146.

Prickly lettuce, 12, 19\%, $19 \mathcal{S}$.

Primrose, 13\%.

Procumbent stem, $5 \%$.

Profile position, 19\%, 198.

Pronuba, 130, 131. 
Prop roots, 99, 103, 104, 105, 106, 255.

Protandry, 128, 135.

Protection of leaves, $9,10,11,12$,

41. $42,43,48.49$

Proteids, 153, 156, 189.

Protogyny, 128, 135.

Protoplasm, 154, 156.

Ptelea, 115.

Putf-balls, $15 \%$.

\section{Q}

Quillwort, 94, 95, 20S.

R

Rain, 51, 256.

Ranunculus, 185.

Raspberry, 91.

Receptacle, $79,81,114$.

Redbud, 10.

Reed grass, 142, 185, 186.

Reed swamps, 185.

Reproduction, 3, 109.

Respiration, 32, 154, 156.

Rhizoids, $10 \%$.

Rivalry, 146.

Robinia, 125, 126, 133, 20\%.

Rock-rose, 236 .

Rock societies, 209,210 .

Roots, 89, 90, 95, 98, 99, 138, 139, 171.

lioot-eap, $10 S$.

Root-hairs, 90 .

Rootstalk, 55, 56, \%5, $\% 6, \% \%, \% S$, 195.

Rose acacia, 125, 126, 13:3.

Rosette habit, $16,1 \%, 18,19,4 \%, 94$, $158,160,209,23 \%$.

Rosinweed, 10, 19\%, 198 .

Rubber tree, 10.4.

Runners, $5 \%, 93$.

Rusts, 157.
S

Sage brush, 216 .

Sagittaria, 186.

Saintpaulia, 16.

Salt deserts, 231 .

Salt steppes, 231 .

Sand societies, 209.

Sandy fields, 209, 212.

Sanguinaria, 195.

Saprophytes, 150, 189.

Sap-wood, 151.

Sargassum, 1\%2.

Sarracenia, $155,156,158$.

Saxifrage, $5 s$.

Scale leaves, $70, \pi 5$.

Scales, 141.

Scouring rush, 203.

Screw pine, 103.

Scrub, $22 \%$.

Seaweeds, 1, 2, 87, 99.

Sedges, $18 \%$.

Seed-dispersal, 112, 113, 114, 116, $11 \%, 118,119,120$.

Seed-plants, 111, 119, 121.

Seeds, 111, 112, 113, 115, 138, 139, 140.

Selaginella, 26, 100, 194 .

Sempervivum, 19.

Senecio, 114 .

Sensitive plants, $11,4 S, 50,199$.

Sepals, $\% \mathcal{S}, \% 9, \delta O$.

Shepherdia, 44.

Shoots, 53.

Silphium, 10, 19\%, $19 S$.

Smilax, 61 .

Snapdragon, $80,137$.

Soil. $90,94,145,151,166,214$, 224.

Solomon's seal, 35,76 .

Spanish needle, 119, 121.

Sphagnum, 188. 
Sphagnum-bogs, 208.

Sphagnum-moors, 188.

Spines, 146, 204 .

Spirogyra, 110.

Spongy tissue, 39, 40.

Spore case, 55, 118, 119.

Spore-dispersal, 109, 111, 112, 113, $114,118$.

Spores, 109, 110, 111, 11?.

Spring beauty, 196 .

Spring plants, 143, 144.

Squash seedlings, 50 .

squirting cucumber, 120.

Staghorn fern, 100.

Stamens. $78,79,80,125$.

Stareh, 153.

Star cucumber, 61.

Star-of-Bethlehem, 81 .

Stem, 54, 83, 139.

Steppes, 216.

Stigma, so, 125.

Stipules, 35.

Stomata, 38, 40, 206.

Strawberry plant, 57, 58, 93.

Struggle for existence, 142.

Style, $80,125$.

Subterranean stems, $\tilde{5} 4,55,56, \approx 6$, $\tau \%, \tau$.

Succulent plants, 222.

Sugar, 153.

Sundew, 158, 159.

Sunflower, r.

Swamp-forest, 190, 191.

Swamp-moors, $18 \%$.

Swamp-thickets, 188.

Swamps, 183.

\section{$\mathrm{T}$}

Tamarack, 1is, 190.

Tap root, 93.

Taxus, 4?.
Teasel, 136.

Telegraph plant, 49.

'Temperature, 145 .

Tendrils, 61, 62, 63.

Thallus, $10 \%$.

Thickets, 188, 224, 243.

Thistle, $11 \%$

Thorns, 146, 204, 205, 206, 20\%, 224.

Thuja, 139.

Tilia, 116, 801 .

Tillandsia, 96, 101.

Toad-flax, so.

Toadstools, 149 .

Tobacco, so.

Touch-me-not, 119.

Tragacanth, 206 .

Transpiration, 31, 33, 154, 193, 256.

Tropical forest, 254.

Trumpet creeper, 99.

Tubers. $74,76,196$.

Tumbleweeds, 11\%, 220.

Turf-building, 185.

\section{U}

Ulex, 205.

Ulothrix, 109. 111.

Utricularia, 1;3, 174.

\section{V}

Vallisneria. 184.

Vascular bundles, 83, 84, 92, 93, 94, 10\%, 108, 151, $1 \% 1$.

Vegetative multiplication, 109.

Veins, 35, 36, 3\%, 40, 151.

Velamen, 99.

Venation. $35,36,3 \%$.

Victoria, 180.

Violet, 117, 119. 


W
Walnut, 8 ?.
Water, 90, 92, 94, 95, 113, 138,
14:, 151, 163, 19:, 206, 250.
Water lily, 1\% $180,181$.
Water reservoirs, 206, 20S, 209.
Weeds, 14\%.
Willow, 35, 243.
Wind, 9.5, 98, 114, 122, 16\%.
Wings, 112, 115, 116.

Witch hazel, 118, 119.

Woodbine, 61, 63.

$\mathrm{X}$

Nerophytes, 168, 193, 208.

Xerophyte structure, 207.

\section{Y}

Yew, 4?.

Yucea, 45, 47, 130, 131, 220. 


\section{TWENTIETH CENTURY TEXT-BOOKS.}

The closing years of the nineteenth century witnessed a remarkable awakening of interest in American educational problems. There has been elaborate discussion in every part of our land on the co-ordination of studies, the balancing of contending elements in school programmes, the professional training of teachers, the proper age of pupils at different stages of study, the elimination of pedantic and lifeless methods of teaching, the improvement of textbooks, uniformity of college-entrance requirements, and other questions of like character.

In order to meet the new demands of the country along these higher planes of educational work, the Twentieth Century Text-Books have been prepared.

At every step in the planning of the series care has been taken to secure the best educational advice, in order that the books may really meet the increasing demand from academies, high schools, and colleges for text-books that shall be pedagogically suitable for teachers and pupils, sound in modern scholarship, and adequate for college preparation.

The editors and the respective authors have been chosen with reference to their qualifications for the special work assigned to them. These qualifications are: First, that the author should have a thorough knowledge of his subject in its latest developments, especially in the light of recent educational discussions ; second, that he should be able to determine the relative importance of the subjects to be treated in a text-book; third, that he should know how to present properly his topics to the ordinary student.

The general editorial supervision of the series is in the hands of Dr. A. F. Nightingale, Superintendent of High Schools, Chicago, with whom is associated an advisory committee composed of an expert in each department of study.

The offer of a complete series of text-books for these higher grades of schools, issued under auspices so favorable, is an event worthy of the twentieth century, and a good omen for the educational welfare of the future.

One hundred volumes are comprised in the series. A list of those now ready, and of others in preparation, will be sent upon request.

\section{APPLETON AND COMPANY, NEW YORK.}




\title{
TWENTIETH CENTURY TEXT-BOOKS.
}

\author{
Uniform, $12 \mathrm{mo}$.
}

\section{NOW READY.}

Botanical Text-Books by John Merle Coulter, A. M., Ph. I., Head of Department of Botany, University of Chicago

Plant Relations. A First Book of Botany. Cloth, \$I.IO.

Plant Structures. A Second Book of Botany. Cloth, \$1.20.

Plant Studies. An Elementary Botany. Cloth, \$1.25.

Plants. Piant Relations and Plant Structures in one volume. Cloth, \$I.So.

Key to Some of the Common Flora. Limp cloth, 45 cents.

A History of the American Nation. By Andrew C. McLaughlin, A. M., LL. B. Cloth, \$I.40.

English Texts. For College Entrance Requirements. Carefully edited. Per volume, cloth, 50 cents ; boards, 40 cents.

Animal Life. A First Book of Zoölogy. By David S. Jordan, M. S., M. D., Ph. D., LL. D, and Vernon L. KellogG, M. S. Cloth, \$I.2O.

The Elements of Physics. By C. Hanford HenDerson, Ph. D., and John F. Woodhull, A. M., Ph. D. Cloth, \$1.IO. With Experiments, \$1.25.

Physical Experiments. A Laboratory Manual. By John F. Woodhull, Ph. D., and M. B. Van Arsiale. Cloth, with blank pages, 60 cents. Without blank pages, limp cloth, 45 cents.

The Elementary Principles of Chemistry. By Abrair Van Eps Young, Ph. B. Cloth, 95 cents. With Experiments, \$I.IO. Laboratory Manual separately, 45 cents.

A Text-Book of Geology. By Albert Perry Brighau, A. M. Cloth, \$i.to.

A Text-Book of Astronomy. By George C. Comsтоск, Ph. B., LL. B. Cloth, \$1.30. \$1.00.

A German Reader. By H. P. Jones, Ph. D. Cloth, OTHERS IN PREPARATION.

Send for complete Prospectus of the Twentieth Century Text-Books for Iligh Schools.

D. A P PLETON A N D COMPA NY, NEW YORK. 


\section{BOOKS BY JOHN M. COULTER, A. M., Ph. D.,}

Head of Department of Botany, University of Chicago.

\section{Plant Relations. A First Book of Botany. I 2 mo. Cloth, \$I. Io.}

"Plant Relations" is the first part of the botanical section of Biology, and, as its title indicates, treats what might be termed the human interests of plant life, the conditions under which plants grow, their means of adaptation to environments, how they protect themselves from enemies of various kinds in their struggle for existence, their habits individually and in family groups, and their relations to other forms of life-all of which constitute the economic and socioiogical phases of plant study.

\section{Plant Structures. A Second Book of Botany. I 2 mo. Cloth, \$1.20.}

This volume treats of the structural ard morphological features of plant life and plant growth. It is intended to follow "Plant Relations," by the same author, but may precede this book, and either may be used independently for a half-year's work in botanical study. "Plant Structures" is not intended for a laboratory guide, but a book for study in connection with laboratory work.

\section{Plant Studies. An Elementary Botany. I 2mo. Cloth, $\$ 125$.}

This book is designed for those schools in which there is not a sufficient allotment of time to permit the development of plant Ecology and Morphology as outlined in "Plant Relations " and "Plant Structures," and yet which are desirous of imparting instruction from both points of view.

\section{Plants. A Text-Book of Botany. I 2 mo. Cloth, \$1.80.}

Many of the high schools as well as the smaller colleges and seminaries that devote one year to botanical work prefer a single volume covering the complete course of study. For their convenience, therefore, "Plant Relations" and "Plant Structures" have been bound together in one book, under the title of "Plants."

\section{An Analytical Key to some of the Common Wild and Cultivated Species of Flowering Plants. I 2 mo. Limp cloth, 6o cents.}

An analytical key and guide to the common flora of the Northern and Eastern States, as its title indicates. May be used with any text-book of botany.

D. APPLETON A N D COMPA NY, NE W YORK. 


\section{TWENTIETH CENTURY TEXT BOOKS.}

\section{A History of the American Nation.}

By Andrew C. McLaughlin, Professor of American History in the University of Michigan. With many Maps and Illustrations. I 2 mo. Cloth, \$I.40 net.

"One of the most attraetive and complete one-volume his. tories of America that has yet appeared."-Boston Beacon.

"Complete enough to find a place in the library as well as in the school."-Denver Republican.

"This excellent work, although intended for school use, is equally good for general use at home." - Boston Transcript.

"It should find a place in all historic libraries." - Toledo Blade.

"Clearness is not sacrificed to brevity, and an adequate knowledge of political causes and effects may be gained from this concise history." -New York Cbristian Advocate.

"A remarkably good beginning for the new Twentieth Century Series of text-books. . . The illustrative feature, and especially the maps, have received the most careful attention, and a minute examination shows them to be accurate, truthful, and illustrative." -Pbiladelpbia Press.

"The work is up to date, and in accord with the best modern methods. It lays a foundation upon which a s:Lperstructure of historical study of any extent may be safely built." - Pittsburg Times.

"A book of rare excellence and practical usefulness."-_Salt Lake Tribune.

"The volume is eminently worthy of a place in a series destined for the readers of the coming century. It is highly creditable to the author."-Cbicago Evening Post.

D. APPLETON AND COMPANY, NEW YORK. 


\title{
MCMASTER'S FIFTH VOLUME.
}

\section{History of the People of the United States.}

\author{
By Prof. Јohn Bach McMaster. Vols. I, II, III, \\ $\mathrm{IV}$, and $\mathrm{V}$ now ready. 8vo. Cloth, with Maps, \\ $\$ 2.50$ per volume.
}

The fifth volume covers the time of the administrations of John Quincy Adams and Andrew Jackson, and describes the development of the democratic spirit, the manifestations of new interest in social problems, and the various conditions and plans presented between I 821 and I 830 . Many of the subjects included have necessitated years of first-hand investigations, and are now treated adequately for the first time.

"John Bach Mcllaster needs no introduction, but only a greeting. . . . The appearance of this fifth volume is an event in American literature second to none in importance this season."-New York Times.

"This volume contains 576 pages, and every page is worth reading The author has ransacked a thousand new sources of information, and has found a wealth of new details throwing light upon all the private and public activities of the American people of three quarters of a century ago."Chicago Tribune.

"In the fifth volume Professor McMaster has kept up to the high standard he set for himself in the previous numbers. It is hard to realize thoroughly the amount of detailed work necessary to produce these books, which contain the best history of our country that has yet been published."-Fhiladelphia Telegraph.

"The first installment of the history came as a pleasant surprise, and the later volumes have maintained a high standard in regard to research and style of treatment." - New York Critic.

"A monumental work. . . Professor McMlaster gives on every page ample evidence of exhaustive research for his facts."-Rochester Herald.

"The reader can not fail to be impressed by the wealth of materiai out of which the author has weighed and condensed and arranged his matter." - Detroit Free Press.

"Professor Mc.Master is our most popular historian. ... He never wearies, even when dealing with subjects that would be most wearisome under clumsier handling. This fifth volume is the most triumphant evidence of his art."-New York Herald.

D. APPLETON A D COMPANY, NEW YORK. 


\section{APPLETONS' WORLD SERIES.}

\section{A New Geographical Library.}

Edited by H. J. Mackinder, M. A., Student of Christ Church, Reader in Geography in the University of Oxford, Principal of Reading College. I 2mo. Cloth, \$ I.50 each.

\section{A COMPLETE ACCOUNT OF THE WORLD.}

The series will consist of twelve volumes, each being an essay descriptive of a great natural region, its marked physical features, and the life of its people. Together, the volumes will give a complete account of the world, more especially as the field of human activity.

\section{LIST OF THE SUBJECTS AND AUTHORS.}

I. BRITAIN AND THE NORTH ATLANTIC. By the EDITOR.

2. SCANDINAVIA AND THE ARCTIC OCEAN. By Sir Clements R. Markham, K. C. B., F. R. S., President of the Royal Geographical Society.

3. THE ROMANCE LANDS AND BARBARY. By ElisÉE REclus, author of the "Nouvelle Géographie Universelie."

4. Central EUROPE. By Dr. Joseph Partsch, Professor of Geography in the University of Breslau.

5. AFRICA. By Dr. J ScotT Keltie, Secretary of the Royal Geographical Society ; Editor of "The Statesman's Year-Book."

6. THE NEAR EAST. By D. G. Hogarth, M. A., Fellow of Magdalen College, Oxford; Director of the British School at Athens; Author of "A Wandering Scholar in the Levant."

7. THE RUSSIAN EMPIRE. By Prince KRAPOTKIN, author of the articles "Russia" and "Siberia" in the Encyclopadia Britannica.

8. THE FAR EAST. By ARCHIBALD LitTLE.

9. INDiA. By Sir T. Hungerford Holdich, K. C. I. E., C. B., R. E., Superintendent of Indian Frontier Surveys.

io. AUSTRAlasia AND ANTARCTICA. By Dr. H. O. Forbes, Curator of the Liverpool Museum; late Curator of the Christ Church Museum, N. Z. ; Author of "A Naturalist's Wanderings in the Eastern Archipelago."

II. NORTH AMERICA. By Prof. I. C. RUssell, University of Michigan.

12. SOUTH AMERICA. By Prof. John C. Branner, Vice-President of Leland Stanford Junior University.

MAPS by J. G. Bartholonew.

D. APPLETON AND COMPANY, NEW YORK. 


\section{A WORK OF GREAT VALUE.}

\section{The International Geography.}

By Seventy Authors, including Right Hon. JAMES Bryce, Sir W. M. Conway, Prof. W. M. Davis, Prof. Angelo Heilprin, Prof. Fridtjof Nansen, Dr. J. Scott Keltie, and F. C. Selous. With 488 Illustrations. Edited by Hugh Robert Mill, D. Sc. 8vo. 1088 pages. Cloth, $\$ 3.50$.

"Can unhesitatingly be given the first place among publications of its kind in the English language. . . . An inspection of the list of associate authors leads readily to the conclusion that no single volume in recent scientific literature embodies, in original contributions, the labor of so many eminent specialists as this one. . . . The book should find a place in every library, public or private, that contains an atlas or gazetteer."-The Nation.

"The attempt to present in one volume an authoritative modern summary of the whole of geography as fully as space would permit has been admirably successful."-New York Sun.

"In brief, it may be said to be both a reference book and a connected geographical history of the modern world, something that any one can read with profit in addition to finding it of constant value in his library."-Chicago Evening Post.

"In his entirely studious moments the geographer cherishes above all things facts and accuracy. He must, therefore, value very highly a work like the 'International Creography.' It should be precious alike to the specialist and to the beginner. . . Small but adequate maps are constantly introduced, and there is, finally, a splendid index." -New York Tribune.

"Simply invaluable to students, teachers, and others in need of such a book of reference."-Washington Times.

"Not only as complete as the limits would allow, but is strictly up to date."-San Francisco Argonaut.

D. APPLETON A N COMPANY, NEW YORK. 


\section{By DAVID STARR JORDAN, Ph. D.}

\section{Animal Life.}

A First Book of 'loölogy. By David Starr Jordan, M. S., M. D., Ph. D., LL. D., President of Leland Stanford Junior University, and Vernon L. Kellogg, M. S., Professor of Entomology in Leland Stanford Junior University. $12 \mathrm{mo}$. Cloth, $\$ 1.20$.

This book gives an account in an elementary form of animal ecology - that is, of the relations of animals to their surroundings. It treats of animals from the standpoint of the observer, and attempts to show the student why the present conditions and habits of animal life are as we find them. It explains how the infinite variety of animal form and mode of life is the inevitable outcome of the struggle for existence under changing conditions and environments. Beginning with the amœba, the simplest form of cell life, it traces the evolution of animal variations and adaptations through successive stages of development, until the highest specialization and the most complex organization are reached in man.

The book is designed from the outset to make the student an independent observer and thinker. It treats of the phase of zoölogy that appeals most strongly to the interest of the young learner, and in a way to make the study a most pleasant and profitable one. It is intended to provide work for one half year in the ordinary high-school course, and is to be followed by a second volume, "Animal Forms," treating of structure, to complete a year's study when this period is assigned to the subject. The topics as treated are elastic, however, and either book can be made to cover a somewhat longer or shorter time, if desireà.

The illustrations, which have been prepared expressly for the work, are of an especially attractive and instructive character, and add conspicuously to its distinctive features. Like the other vol. umes of the Twentieth Century Text-Books, it is accompanied by a brief manual containing hints to teachers, references, etc.

D. APPLETON AND COMPANY, NEW YORK. 

Aprie 2 1902

Braies

Indekiscunt

Bury

Pome appla

Druge cherry

ablumen, on sous mint

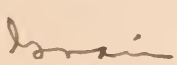

nut

Sommen masentmit

may 171902.
Dehiscent

Tods

(a) Simple prit baingur. tat oplile cing, sich mit for pe aret. the as in pung woct bidno

(b)

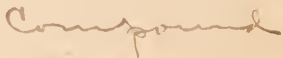
Capaule truit fa mony celled

Jumas of Soil

1. Rockes - Lichums caurse diray of nock

2. Sand

3. Clay

H. stumuse

$\checkmark$ Salt 

